Supporting Information for

\title{
Controlling Polymer Composition in Organocatalyzed Photoredox Radical Ring- Opening Polymerization of Vinylcyclopropanes
}

Dian-Feng Chen, Bret M. Boyle, Blaine G. McCarthy, Chern-Hooi Lim, and Garret M. Miyake*

Department of Chemistry, Colorado State University, Fort Collins, CO 80523, United States

\section{Table of Contents}

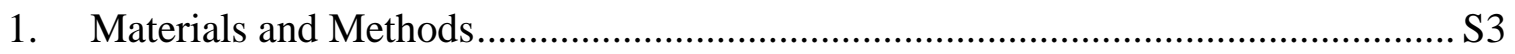

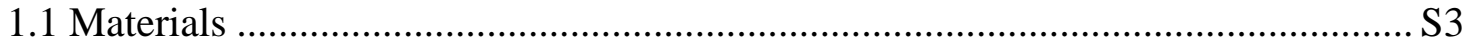

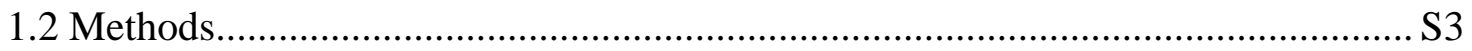

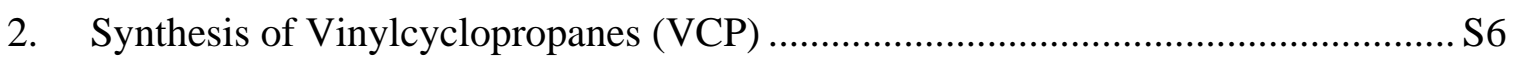

3. Synthesis of Poly(EtVCP) with High Linear $(l)$ Content...................................... S11

3.1 General Experimental Procedures............................................................. S11

3.2 Optimization of Polymerization Conditions .............................................. S13

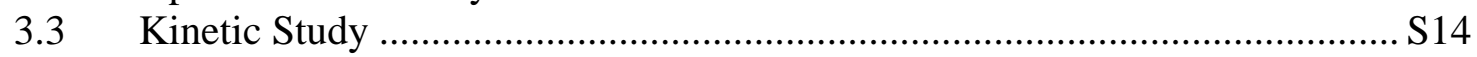

3.4 Pulsed-Irradiation Experiment ............................................................... S15

3.5 Investigation of Chain-End Fidelity...................................................... S16

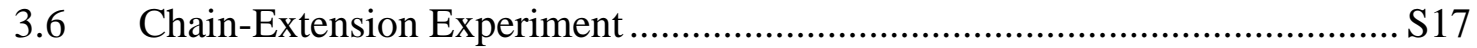

3.7 Mechanistic Studies of the Photoredox Mechanism ..................................... S19

4. Synthesis of Poly(EtVCP) with High Cyclic $(c)$ Content ..................................... S27

4.1 General Experimental Procedures.......................................................... S27

4.2 Optimization of Polymerization Condition............................................... S29

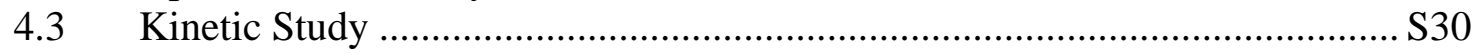

4.4 Pulsed-Irradiation Experiment .................................................................. S31

4.5 Investigation of Chain-end Fidelity ......................................................... S32

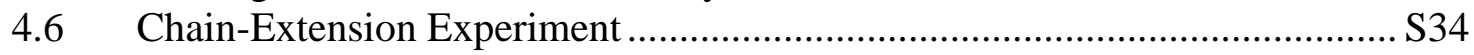

4.7 Investigation of Cyclobutyl Bromide Chain-end ......................................... S36

5. Post-Polymerization Modification of High Linear ( $l$ ) Polymer Chain ................... S39

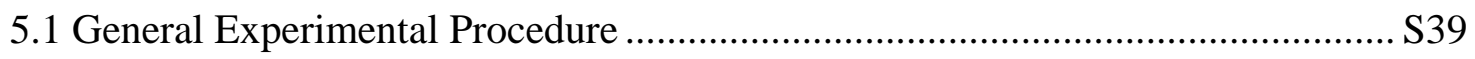

5.2 Comparison of Poly(EtVCP) from Free Radical Polymerization, Photoredox

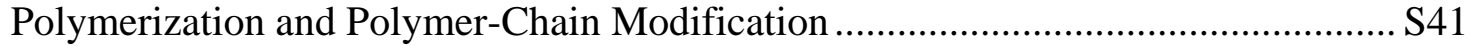

5.3 Model Reaction Mimicking Polymer-Chain Modification .................................. S44

5.4 Density Functional Theory Calculations ....................................................... S50

5.5 Possible Pathways and Cyclic Structures in Polymer-Chain Modification .......... S62

6. Synthesis of Poly(EtVCP) with Variable Linear Content....................................S63 
7. Characterizations of Poly(Vinylcyclopropanes) ………………………………....... 64

7.1 GPC Traces, DSC/TGA Curves of Poly(EtVCP) .......................................... S64

7.2 ${ }^{1} \mathrm{H}-\mathrm{NMR}$ spectra, GPC Traces and DSC/TGA Cures of Poly(PrVCP) .......... S66

7.3 ${ }^{1}$ H-NMR Spectra, GPC, DSC, TGA Traces of Poly (BuVCP) ......................... S69

$7.4{ }^{1} \mathrm{H}-\mathrm{NMR}$ Spectra, GPC traces, and DSC/TGA Curves of Poly $\left({ }^{t} \mathrm{BuVCP}\right)$...... S72

7.5 ${ }^{1} \mathrm{H}-\mathrm{NMR}$ Spectra, GPC Traces, and DSC/TGA Curves of Poly(BnVCP) ..... S75

7.6 ${ }^{1} \mathrm{H}-\mathrm{NMR}$ Spectra, GPC Traces, and DSC/TGA Curves of Poly(PhVCP) ...... S78

7.7 ${ }^{1}$ H-NMR Spectra, GPC Traces, and DSC/TGA Curves of Poly(EEVCP) ..... S81

$7.8 \quad{ }^{1}$ H-NMR Spectra, GPC Traces, and DSC/TGA Curves of Poly(CEVCP) ..... S84

$7.9{ }^{1} \mathrm{H}-\mathrm{NMR}$ spectra, GPC Traces, and DSC/TGA Curves of Poly(LMVCP) ..... S87

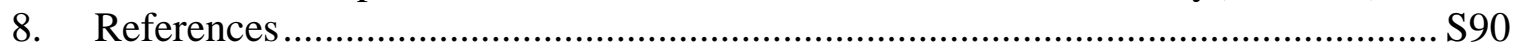




\section{Materials and Methods}

\subsection{Materials}

Phenoxazine was purchased from Beantown Chemical. Trans-1,4-dibromo-2-butene, diethyl malonate, dipropyl malonate, dibutyl malonate, di-tert-butyl malonate and dibenzyl malonate were purchased from TCI America. Deuterated chloroform was purchased from Cambridge Isotope Laboratories. All other chemicals and anhydrous solvents were purchased from Sigma-Aldrich.

Ethyl $\alpha$-bromophenylacetate (EBP), methyl 2-bromopropionate (M2BP) and diethyl 2-bromo-2-methylmalonate (DBMM) were purified by vacuum distillation, degassed by three freeze-pump-thaw cycles and stored at $-34{ }^{\circ} \mathrm{C}$ in the freezer of a nitrogen-filled glovebox. All alkyl halides were allowed to warm to room temperature before use.

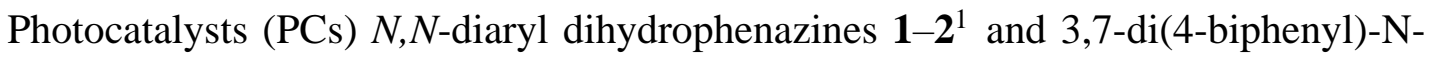
naphthylphenoxazine $3^{2}$ were synthesized according to our previous reports.

For cyclic voltammetry and spectroelectrochemistry, tetrabutylammonium hexafluorophosphate (>99\% purity), $\mathrm{AgNO}_{3}$ (>99\% purity), and $\mathrm{MeCN}$ (HPLC, gradient grade, $>99.9 \%$ purity) were purchased from Sigma Aldrich.

\subsection{Methods}

Thin layer chromatography was performed on EMD Milipore silica gel 60 F254 glass plates. Column chromatography was performed on SiliCycle®SilicaFlash ${ }^{\circledR}$ P60, 40-63 $\mu \mathrm{m}$, 60A. Visualization was accomplished with a solution of $\mathrm{KMnO}_{4}$.

The visible light source was a $45 \mathrm{~cm}$ of double density white LEDs (Creative Lighting Solutions, item no. CL-FRS1210-5M-12V-WH) wrapped around the inside of a $400 \mathrm{~mL}$ beaker, and powered by a 12VDC power Supply (2.1A Commercial, 25W Power Supply by Creative Lighting Solutions LLC). The blue LED (HP150, 1.5 A, 34W) was purchased from Kessil.

${ }^{1} \mathrm{H}$ and ${ }^{13} \mathrm{C}$ spectra were recorded on a Bruker $400 \mathrm{~Hz}\left(100 \mathrm{~Hz}\right.$ for $\left.{ }^{13} \mathrm{C}\right)$ spectrometer at ambient temperature. All NMR spectra are referenced to the residual solvent $\left(\mathrm{CHCl}_{3}\right)$ signal.

Analysis of polymer molecular weight and dispersity was performed using gel permeation chromatography (GPC) coupled with multi-angle light scattering (MALS), 
using an Agilent HPLC fitted with one guard column and three PLgel $5 \mu \mathrm{m}$ MIXED-C gel permeation columns in series. The detectors were a Wyatt Technology TrEX differential refractometer and a Wyatt Technology mini DAWN TREOS light scatter detector. The solvent used was THF with a flow rate of $1.0 \mathrm{~mL} /$ minute.

Glass transition temperatures $\left(T_{\mathrm{g}}\right)$ and melting point $\left(T_{\mathrm{m}}\right)$ of the polymers were measured by differential scanning calorimetry (DSC) on a DSC 2500 (TA Instrument) at a rate of $10{ }^{\circ} \mathrm{C} / \mathrm{min} . T_{\mathrm{g}}$ values reported were from the second heating scan after the thermal history (the first scan) being removed. Decomposition temperatures $\left(T_{\mathrm{d}}\right)$ at $10 \%$ of weight loss and maximum rate decomposition temperatures $\left(T_{\max }\right)$ of the polymers were measured by thermal gravimetric analysis (TGA) on a Q50 TGA Analyzer (TA Instrument), by heating the polymer samples from 25 to $700{ }^{\circ} \mathrm{C}$ at the rate of $10{ }^{\circ} \mathrm{C} / \mathrm{min}$.

Analysis of low molecular weight polymer was performed on a Ultraflex matrixassissted laser desorption/ionization time-of-flight (MALDI-TOF) spectrometer (Bruker Daltonics); the experiment was performed on a MALDI-TOF mass operated in positive ion, reflector mode using a Nd:YAG laser at $355 \mathrm{~nm}$ and $25 \mathrm{kV}$ accelerating voltage. 2,5dihydroxylbenzoic acid (DHB) was used as the matrix and sodium iodide was used as the cationic reagent. A peptide calibration mixture (4-6 peptides) was done before the sample analysis. For the preparation of the sample thin layer, a $1 \% \mathrm{NaI}$ solution was first deposited on the target plate, followed by $0.5 \mu \mathrm{L}$ of premixed sample and DHB $(10 \mathrm{mg} / \mathrm{mL}$ in THF).

Cyclic voltammetry (CV) was performed on an Interface 1010B Potentiostat (Gamry Instruments) with a scan rate of $0.10 \mathrm{~V} / \mathrm{s}$. A solution of $\mathrm{Ag} / \mathrm{AgNO}_{3}(0.01 \mathrm{M})$ and $0.1 \mathrm{M}$ $\mathrm{Bu}_{4} \mathrm{NPF}_{6}$ in MeCN was used as the reference electrode (Gamry Instruments, part no. 93000059). A $0.1 \mathrm{M} \mathrm{Bu}_{4} \mathrm{NPF}_{6}$ in $\mathrm{MeCN}$ was used as the electrolyte for the analyte solution. A platinum disk was used for the working electrode (Gamry Instruments, part no. 932-00024) and a platinum wire was used as the counter electrode (Gamry Instruments, part no. 99000193).

Emission spectra were acquired using a spectrofluorometer FS5 (Edinburgh Instruments). Luminescence quenching experiments were carried out using a spectrofluorometer FS5 (Edinburgh Instruments) with sample solutions being irradiated at $380 \mathrm{~nm}$ for $0.1 \mathrm{~s}$ and emission intensities recorded at $540 \mathrm{~nm}$. 
Transient absorption (TA) spectroscopy measurements were acquired using a LP980KS Laser Flash Photolysis Spectrometer from Edinburgh Instruments equipped with a Continuum Minilite II Q-switched Nd:YAG laser with a $1 \mathrm{~Hz}$ repetition rate, $\sim 5 \mathrm{~ns}$ pulse width, and set to $355 \mathrm{~nm}$ output. The Minilite laser was used as the excitation source ("pump") and a $150 \mathrm{~W}$ continuous wave xenon lamp was used as the broadband probe. At the center of the sample holder, the pump lasing beam and the probe beam were positioned $90^{\circ}$ relative to each other. To acquire transient absorption spectra (with a spectral range spanning 180-850 nm), an image intensified charge-coupled device (ICCD) camera (Andor) was used as the detector. To analyze individual kinetic traces at particular wavelengths, a TMS302-A monochromator with a spectral resolution of $0.05 \mathrm{~nm}$ was used to select a single wavelength $(430 \mathrm{~nm})$ before detection by a photomultiplier tube (Hamamatsu R928, 5 ns minimum response width). The power of the laser was altered using a manual attenuator and measured using a Coherent PM10 Fieldmate and power meter. The lasing power was measured within the sample chamber and modulated between 4-6.5 $\mathrm{mW}$ for all transient absorption measurements. The singlewavelength kinetic absorption measurements were corrected for probe lamp fluctuations by collecting two traces for each scan, one with the laser and probe light (to collect the transient decay spectrum) and a second with only the probe background.

The absorbance of all samples analyzed using TA spectroscopy was kept at or below 0.1 at $355 \mathrm{~nm}\left(\lambda_{\text {ex }}\right)$. The integrity of all samples was ensured by comparison of the steadystate UV-visible absorption spectrum of each sample before and after analysis with the transient absorption spectrometer. The UV-visible absorption spectra were acquired using a Cary 5000 UV-visible absorption spectrometer. All single-wavelength kinetic absorption measurements were analyzed using a tail-fitting approach and fit to a single exponential decay model using the LP-980 software. Analysis of the goodness of fit was determined by how well the exponential decay fit followed the center of the trace of each transient decay and by how evenly distributed the residuals were for each fit.

The rheological characterization of these polymers were carried out using a DHR2 rheometer from Thermal Analysis Instruments with $8 \mathrm{~mm}$ electrically heated parallel plates keeping the axial force $0.00 \pm 0.2 \mathrm{~N}$ under constant nitrogen flow. 


\section{Synthesis of Vinylcyclopropanes (VCP)}

General Procedure A. To a mixture of $\mathrm{NaH}(60 \%, 2.4$ equiv.) in anhydrous THF (3.0 mL per mmol of malonate) at $0{ }^{\circ} \mathrm{C}$, under $\mathrm{N}_{2}$ atmosphere, trans-1,4-dibromo-2-butene (1.0 equiv.) was added in one portion, followed by dropwise of the malonate (1.0 equiv.). The mixture was then vigorously stirred at room temperature. After $12 \mathrm{~h}$, the reaction was carefully quenched by slow addition of sat. $\mathrm{NH}_{4} \mathrm{Cl}$, extracted with ether three times. The combined organic layer was washed with $\mathrm{H}_{2} \mathrm{O}$ and brine, dried over anhydrous $\mathrm{Na}_{2} \mathrm{SO}_{4}$ and concentrated under vacuum. The residue was purified by silica gel flash column chromatography using hexane/EtOAc (20:1 to 10:1) as the eluent. EtVCP, PrVCP, BuVCP, ${ }^{t} \mathrm{BuVCP}, \mathrm{BnVCP}$ and $\mathrm{PhVCP}$ are known compounds and spectroscopic data matched literatures. are known compounds and spectroscopic data matched the literature. ${ }^{3}$

Bis(2-chloroethyl) 2-vinylcyclopropane-1,1-dicarboxylate (CEVCP)

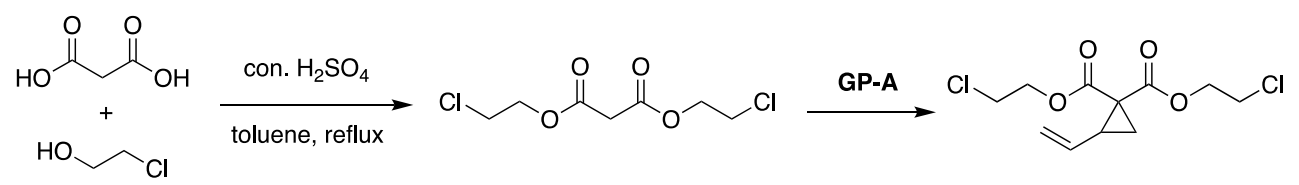

A solution of malonic acid (4.0 g, $38.5 \mathrm{mmol})$, 2-chloroethanol (13.0 mL, $206 \mathrm{mmol})$ and concentrated $\mathrm{H}_{2} \mathrm{SO}_{4}(0.5 \mathrm{~mL})$ in anhydrous toluene $(20.0 \mathrm{~mL})$ was heated to reflux for $3 \mathrm{~h}$. After cooling to room temperature, the reaction was carefully quenched by slow addition of $10 \% \mathrm{Na}_{2} \mathrm{CO}_{3}$. The organic and aqueous phases were separated, and the aqueous phase was extracted with ether $(50 \mathrm{~mL} \times 3)$. The combined organic layer was washed with $5 \% \mathrm{NaHCO}_{3}(100 \mathrm{~mL}), \mathrm{H}_{2} \mathrm{O}(100 \mathrm{~mL} \times 2)$ and brine $(100 \mathrm{~mL})$, dried over anhydrous $\mathrm{Na}_{2} \mathrm{SO}_{4}$, concentrated in vacuum to give crude bis(2-chloroethyl) malonate as a colorless oil (5.2 g), which was used without further purification. Bis(2-chloroethyl) 2vinylcyclopropane-1,1-dicarboxylate (CEVCP) was then synthesized according to General Procedure A. Colorless oil, 4.34 g, $40 \%$ yield for two steps. ${ }^{1} \mathbf{H}$ NMR $(400 \mathrm{MHz}$, $\left.\mathrm{CDCl}_{3}\right) \delta 5.48(\mathrm{ddd}, J=17.0,10.2,8.1 \mathrm{~Hz}, 1 \mathrm{H}), 5.32(\mathrm{dd}, J=17.0,1.5 \mathrm{~Hz}, 1 \mathrm{H}), 5.17$ (dd, $J=10.2,1.5 \mathrm{~Hz}, 1 \mathrm{H}), 4.50-4.28(\mathrm{~m}, 4 \mathrm{H}), 3.90-3.40(\mathrm{~m}, 4 \mathrm{H}), 2.65(\mathrm{dd}, J=9.0,7.7 \mathrm{~Hz}$, $1 \mathrm{H}), 1.79(\mathrm{dd}, J=7.7,5.0 \mathrm{~Hz}, 1 \mathrm{H}), 1.64(\mathrm{dd}, J=9.0,5.0 \mathrm{~Hz}, 1 \mathrm{H}) .{ }^{13} \mathbf{C}$ NMR $(100 \mathrm{MHz}$, $\left.\mathrm{CDCl}_{3}\right) \delta 169.0,166.7,132.4,119.2,65.1,65.0,41.3,41.2,35.6,31.8,20.8$. 


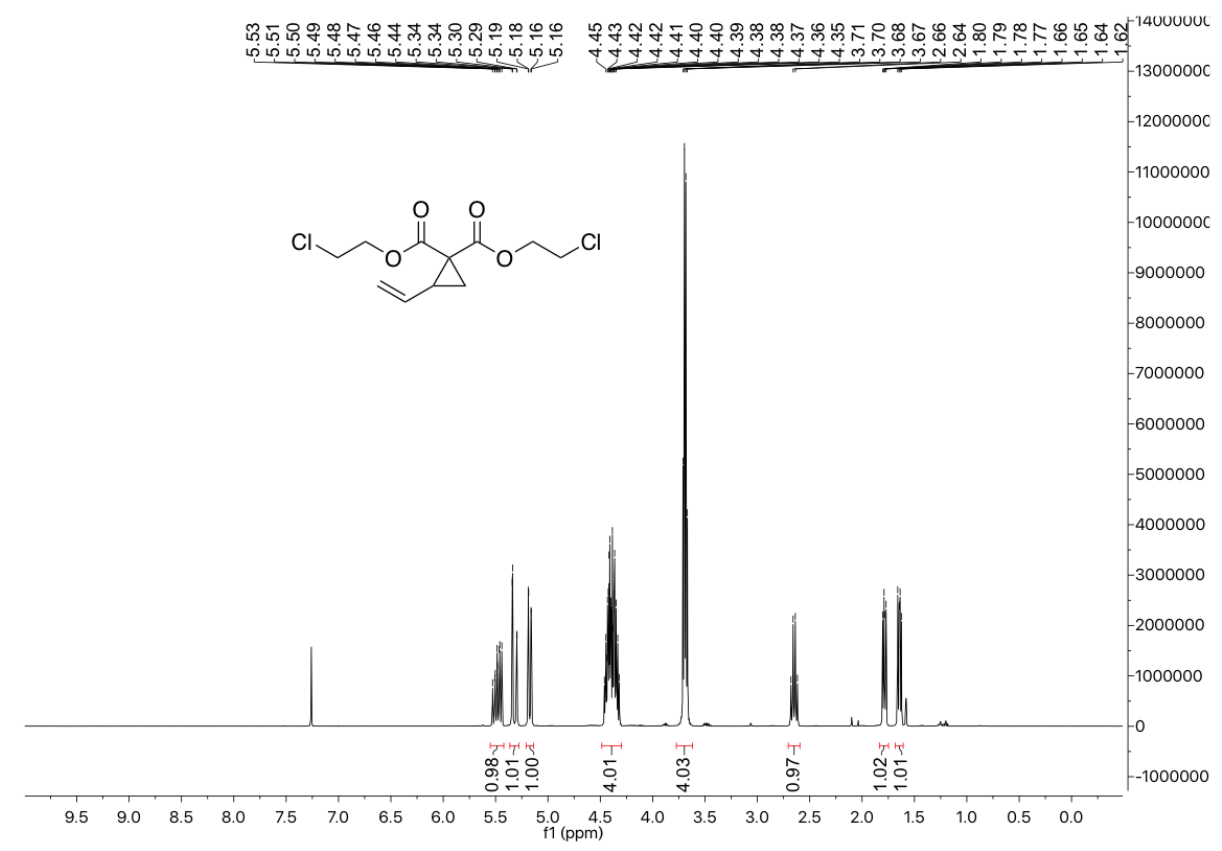

Figure S1. ${ }^{1} \mathrm{H}-\mathrm{NMR}$ spectrum of $\mathrm{CEVCP}$ in $\mathrm{CDCl}_{3}$.

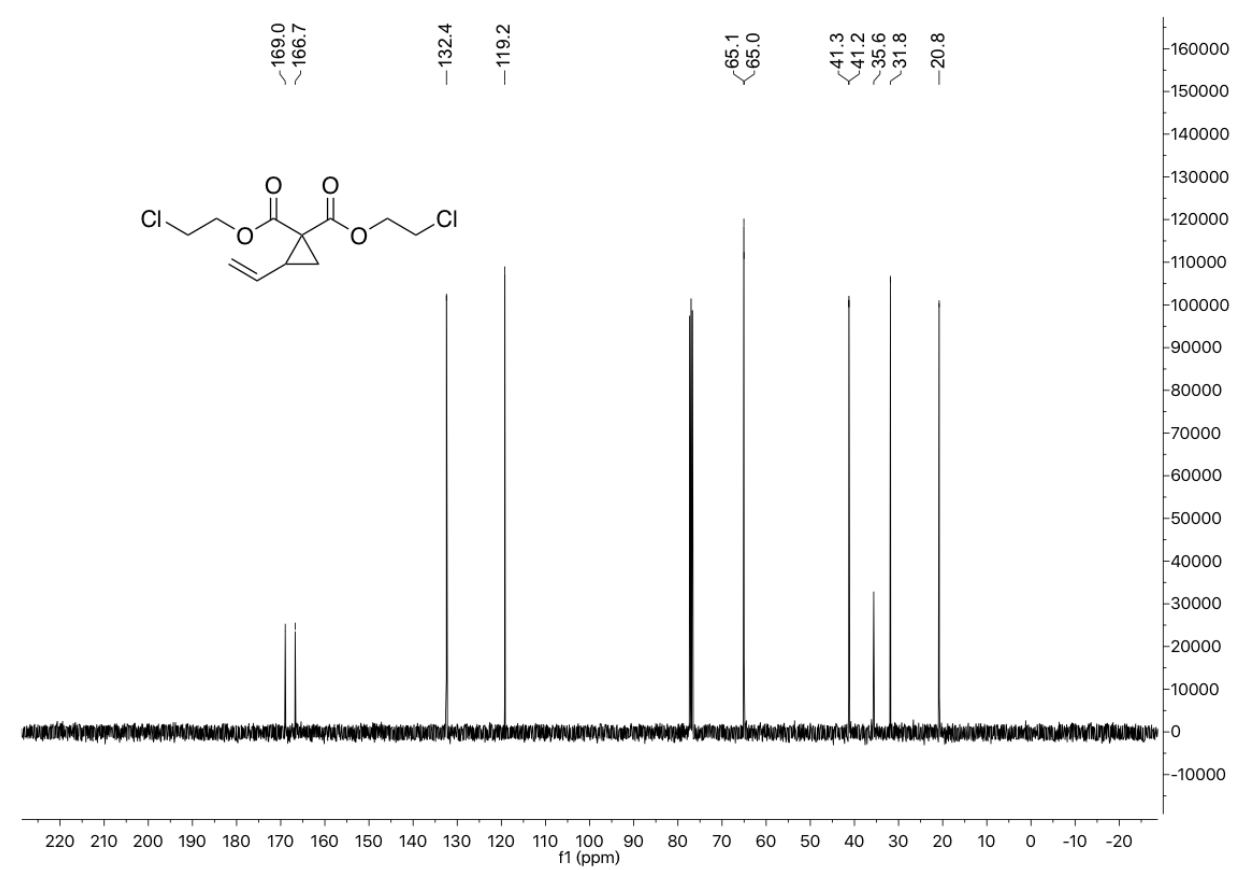

Figure S2. ${ }^{13} \mathrm{C}-\mathrm{NMR}$ spectrum of $\mathrm{CEVCP}$ in $\mathrm{CDCl}_{3}$. 


\section{Bis(2-ethoxyethyl) 2-vinylcyclopropane-1,1-dicarboxylate (EEVCP)}

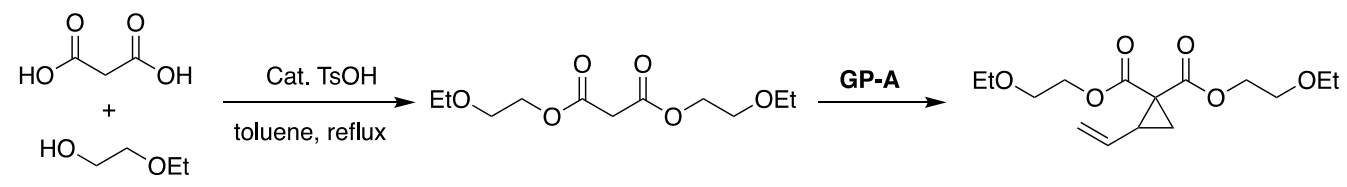

A solution of malonic acid (4.0 g, $38.5 \mathrm{mmol})$, 2-ethoxyethanol (7.5 mL, $77.0 \mathrm{mmol})$ and $p$-toluenesulfonic acid mono hydrate $(66 \mathrm{mg}, 0.385 \mathrm{mmol})$ in anhydrous toluene $(20.0$ $\mathrm{mL}$ ) was heated to reflux for $12 \mathrm{~h}$. After cooling to room temperature, the reaction was diluted with $100 \mathrm{~mL}$ of ether, washed with $10 \% \mathrm{NaHCO}_{3}(100 \mathrm{~mL}), \mathrm{H}_{2} \mathrm{O}(100 \mathrm{~mL} \times 2)$ and brine $(100 \mathrm{~mL})$, dried over anhydrous $\mathrm{Na}_{2} \mathrm{SO}_{4}$, concentrated in vacuum to give crude bis(2-ethoxyethyl) malonate as a colorless oil (4.07 g), which was used without further purification. Bis(2-ethoxyethyl) 2-vinylcyclopropane-1,1-dicarboxylate (EEVCP) was then synthesized according to General Procedure A. Colorless oil, $2.37 \mathrm{~g}, 21 \%$ yield for two steps. ${ }^{1} \mathbf{H}$ NMR (400 MHz, $\left.\mathrm{CDCl}_{3}\right) \delta 5.48$ (ddd, $\left.J=16.9,10.1,8.3 \mathrm{~Hz}, 1 \mathrm{H}\right), 5.29$ (ddd, $J=17.0,1.5,0.7 \mathrm{~Hz}, 1 \mathrm{H}), 5.20-5.08(\mathrm{~m}, 1 \mathrm{H}), 4.35-4.20(\mathrm{~m}, 4 \mathrm{H}), 3.66-3.59(\mathrm{~m}, 4 \mathrm{H})$, $3.55-3.45(\mathrm{~m}, 4 \mathrm{H}), 2.61(\mathrm{dd}, J=9.0,7.7 \mathrm{~Hz} 1 \mathrm{H}), 1.74(\mathrm{dd}, J=7.6,4.9 \mathrm{~Hz}, 1 \mathrm{H}), 1.59$ (dd, $J=9.0,4.9 \mathrm{~Hz}, 1 \mathrm{H}), 1.19(\mathrm{t}, J=7.0 \mathrm{~Hz}, 6 \mathrm{H}) .{ }^{13} \mathbf{C ~ N M R}\left(100 \mathrm{MHz}, \mathrm{CDCl}_{3}\right) \delta 169.5,167.2$, 133.0, 118.6, 68.1, 68.0, 66.6, 66.5, 64.7, 64.5, 35.8, 31.6, 20.7, 15.1.

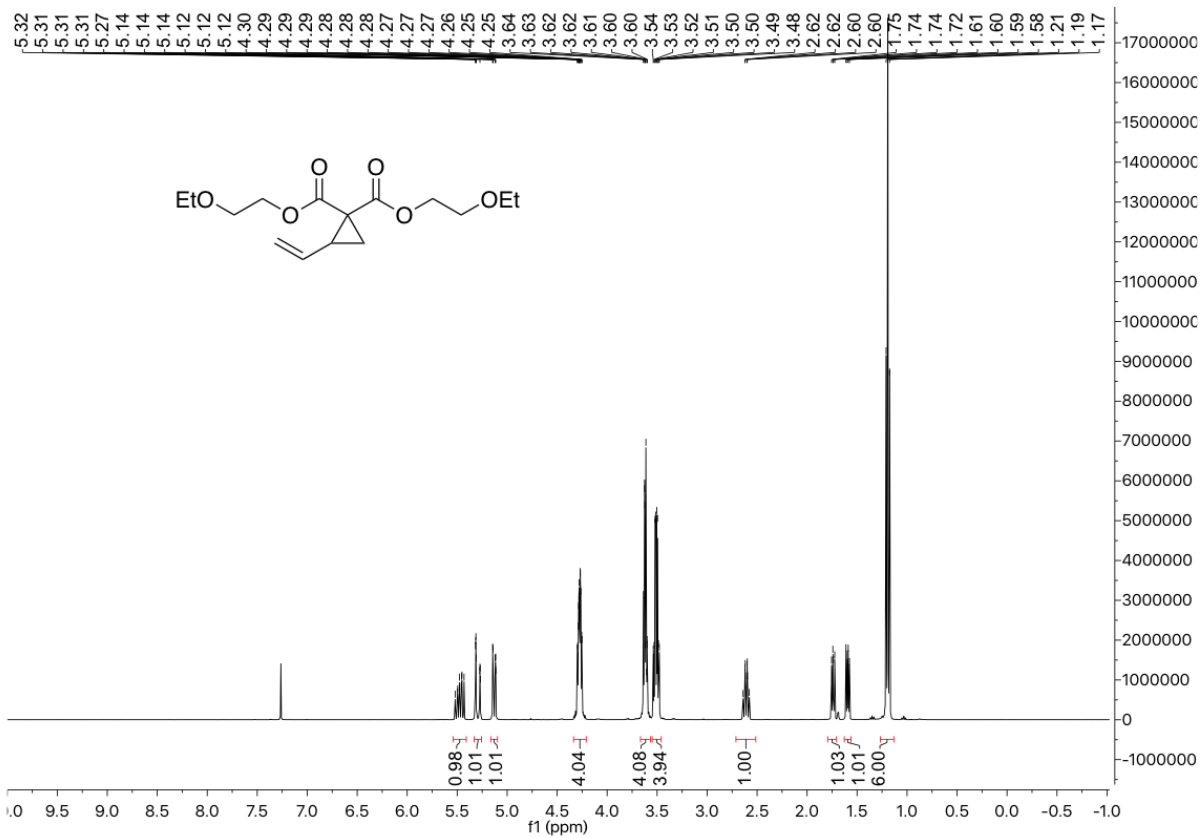

Figure S3. ${ }^{1} \mathrm{H}-\mathrm{NMR}$ spectrum of $\mathrm{EEVCP}$ in $\mathrm{CDCl}_{3}$. 


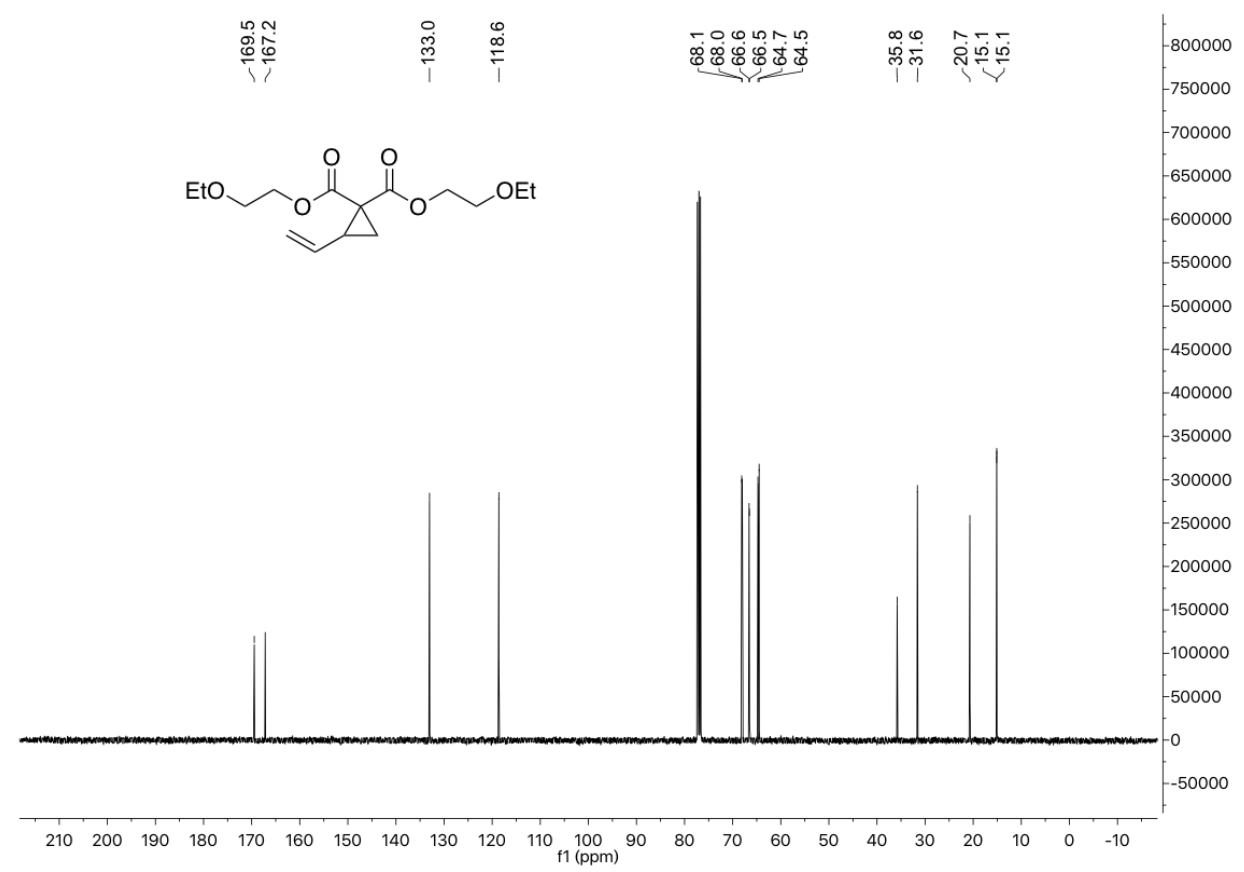

Figure S4. ${ }^{13} \mathrm{C}-\mathrm{NMR}$ spectrum of EEVCP in $\mathrm{CDCl}_{3}$.

\section{Bis(L-menthyl) 2-vinylcyclopropane-1,1-dicarboxylate (LMVCP)}

LMVCP was then synthesized from di-L-menthyl malonate ${ }^{4}$ according to General Procedure A (20.0 mmol scale). Colorless oil as a 7:3 mixtures of inseparable diastereomers. 7.9 g, 91\% yield for two steps. ${ }^{1} \mathbf{H}$ NMR $\left(400 \mathrm{MHz}, \mathrm{CDCl}_{3}\right) \delta 5.55-5.35$ (m, 1H), $5.32-5.24(\mathrm{~m}, 1 \mathrm{H}), 5.16-5.04(\mathrm{~m}, 1 \mathrm{H}), 4.82-4.62(\mathrm{~m}, 2 \mathrm{H}), 2.60-2.45(\mathrm{~m}$, 1H), $2.14-1.78(\mathrm{~m}, 4 \mathrm{H}), 1.76-1.60(\mathrm{~m}, 5 \mathrm{H}), 1.58-1.30(\mathrm{~m}, 5 \mathrm{H}), 1.12-0.95(\mathrm{~m}, 4 \mathrm{H})$, $0.94-0.80(\mathrm{~m}, 14 \mathrm{H}), 0.79-0.66(\mathrm{~m}, 6 \mathrm{H}) .{ }^{13} \mathbf{C ~ N M R}\left(100 \mathrm{MHz}, \mathrm{CDCl}_{3}\right) \delta 169.5,169.3$, 167.1, 167.0, 133.6, 133.5, 118.2, 117.9, 75.7, 75.6, 75.5, 75.4, 47.2, 47.0, 46.8, 41.0, 40.9, $40.8,36.4,36.2$, 34.3, 34.2, 34.1, 31.5, 31.4, 31.3, 30.6, 26.2, 25.8, 25.5, 25.4, 23.5, 23.0, $22.7,22.1,22.0,21.2,21.0,20.7,20.6,20.2,16.4,16.0,5.9,15.7$. 


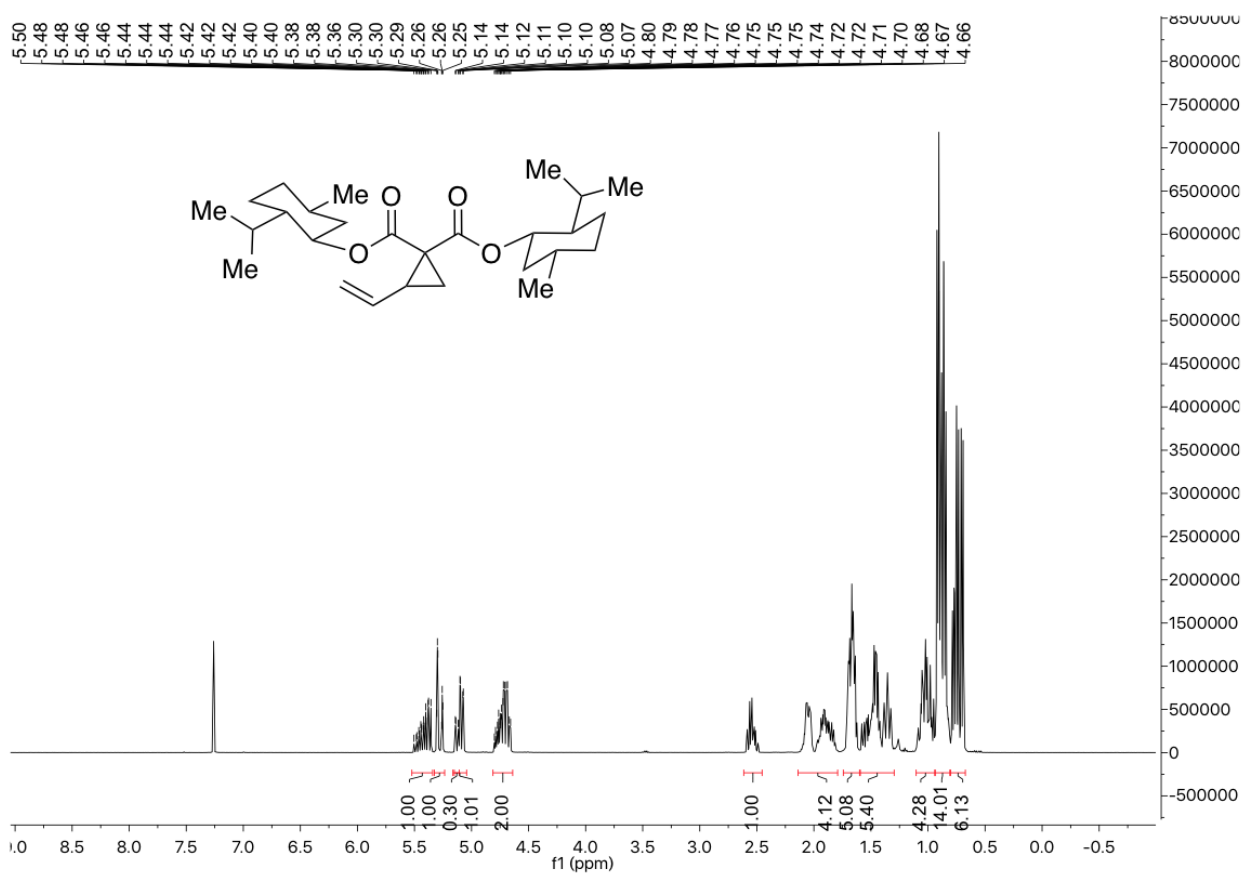

Figure S5. ${ }^{1} \mathrm{H}-\mathrm{NMR}$ spectrum of $\mathrm{LMVCP}$ in $\mathrm{CDCl}_{3}$.

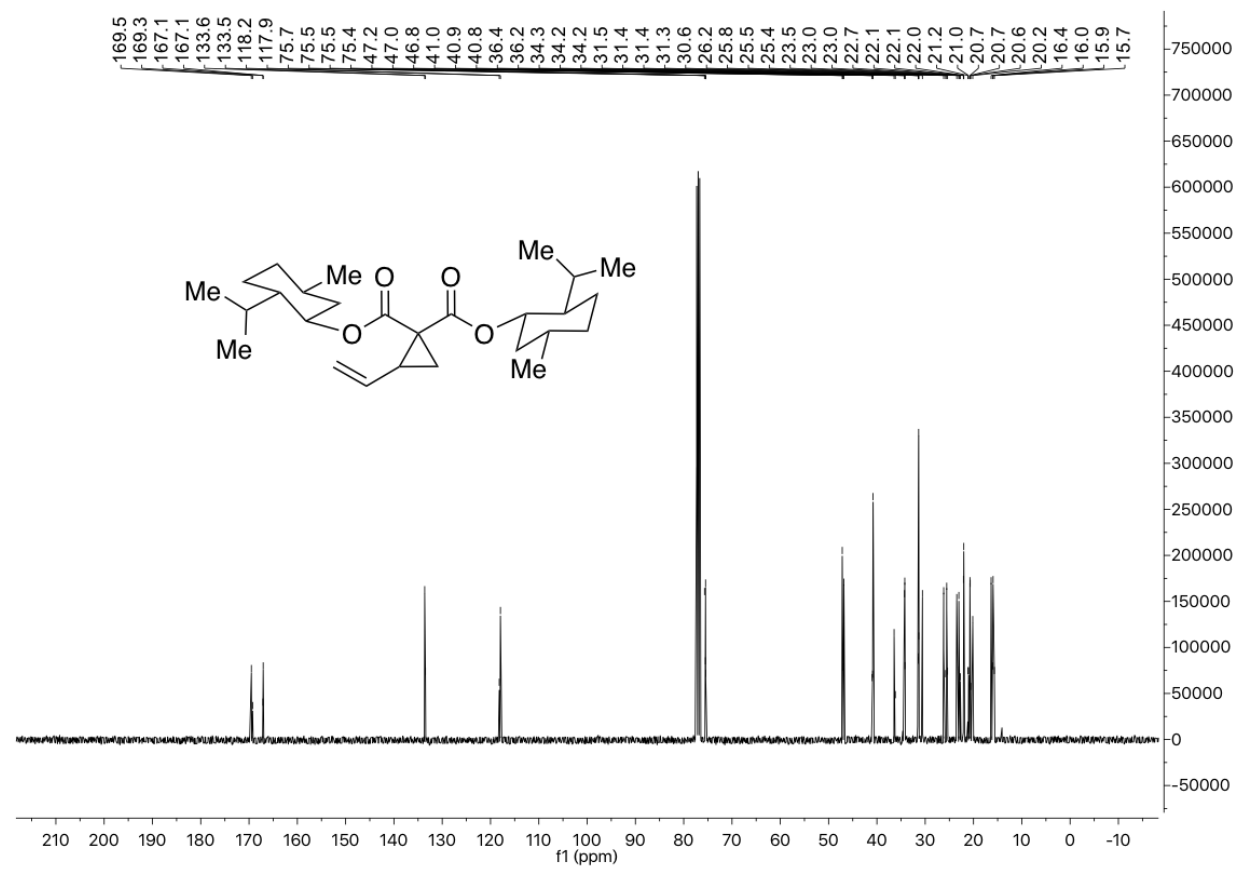

Figure S6. ${ }^{13} \mathrm{C}-\mathrm{NMR}$ spectrum of $\mathrm{LMVCP}$ in $\mathrm{CDCl}_{3}$. 


\section{Synthesis of Poly(EtVCP) with High Linear (l) Content}

\subsection{General Experimental Procedures}

General Procedure B: $1.0 \mathrm{~mL}$ of freshly made solution $(1.0 \mathrm{mM})$ of photoredox catalyst (PC) in anhydrous dichloromethane (DCM) was added to a $20 \mathrm{~mL}$ scintillation vial. DCM was then removed and the vial was dried under vacuum for $12 \mathrm{~h}$. The abovementioned scintillation vial equipped with PC and a small magnetic stir bar was transferred into a $\mathrm{N}_{2}$ filled glove box. To this vial, solvent, EtVCP $(212.2 \mathrm{mg}, 1.0 \mathrm{mmol})$ and the initiator stock solution $(0.10 \mathrm{M})$ were sequentially added. The vial was then tightly capped and placed under white LED irradiation while stirring in the glove box (Figure S7). The temperature was about $28{ }^{\circ} \mathrm{C}$ with a cooling fan. For the progress analysis of the polymerization at a given time point, a $0.10 \mathrm{~mL}$ aliquot of the reaction mixture was taken via syringe and immediately quenched by injecting into a $1.5 \mathrm{~mL}$ vial containing $\sim 0.70 \mathrm{~mL} \mathrm{CDCl}_{3}$ with $250 \mathrm{ppm}$ butylated hydroxytoluene (BHT). This aliquot was then analyzed via ${ }^{1} \mathrm{H}$ NMR for monomer conversion. The aliquot was then dried under vacuum to remove all volatiles, re-dissolved in THF and passed through a syringe filter for direct analysis by gel permeation chromatography (GPC) equipped with multi-angle light scattering. For further purification, the reaction mixture was slowly added into $30.0 \mathrm{~mL}$ of hexane while stirring at $-78^{\circ} \mathrm{C}$. The precipitated polymer was collected by vacuum filtration, washed with cold hexane $(5.0 \mathrm{~mL} \times 2)$ and dried overnight under vacuum at $50{ }^{\circ} \mathrm{C}$ to a constant weight.
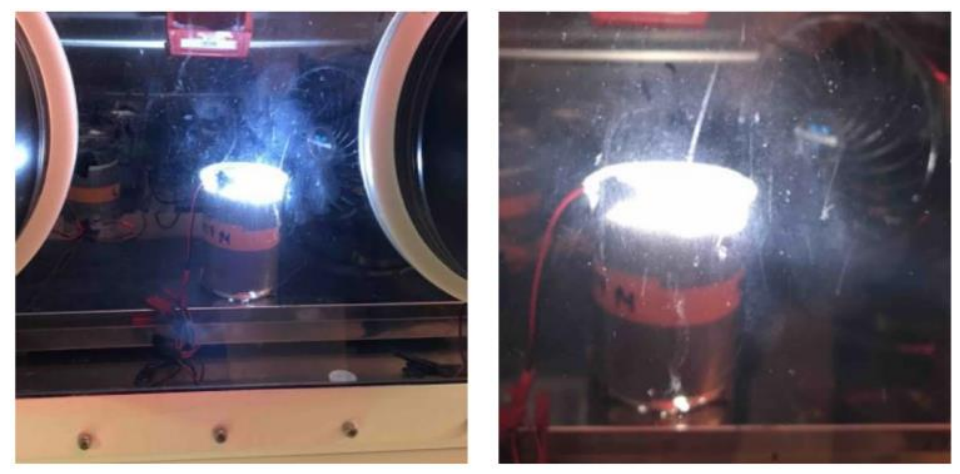

Figure S7. Reaction setup for the synthesis of poly(vinylcyclopropanes) with high $l$ content 


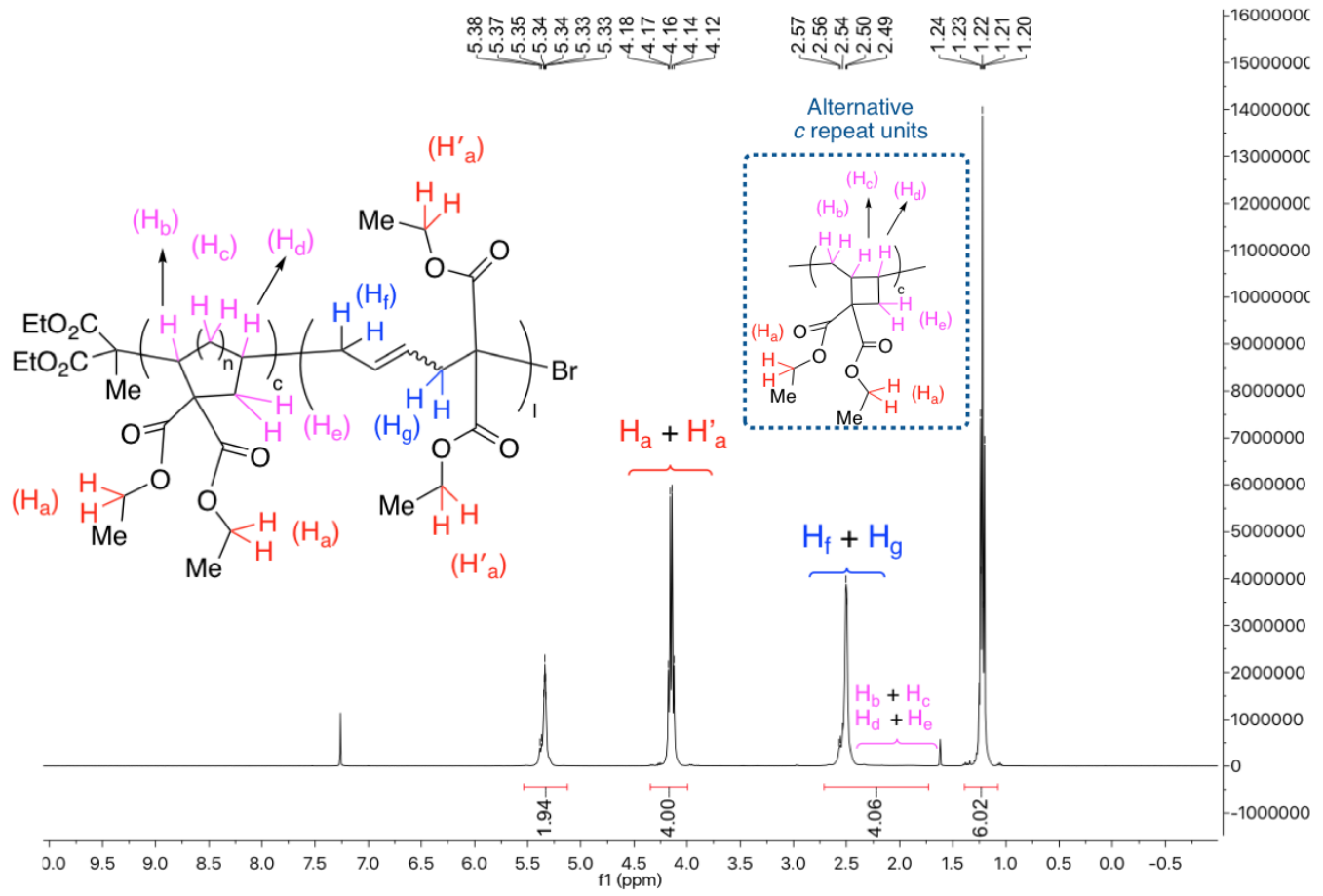

Figure S8. ${ }^{1} \mathrm{H}-\mathrm{NMR}$ of poly(EtVCP) in Table 1 , entry $5 .{ }^{1} \mathbf{H} \mathbf{~ N M R}\left(400 \mathrm{MHz}, \mathrm{CDCl}_{3}\right) \delta$ $5.46-5.22$ (br, 1.94H), 4.15 (q, $J=7.1 \mathrm{~Hz}, 4.00 \mathrm{H}), 2.70-1.70$ (br, $4.06 \mathrm{H}), 1.32-1.10$ $(\mathrm{m}, 6.00 \mathrm{H})$.

The calculation of the linear factor $S_{\mathrm{L}}$ of the polymers was based on ${ }^{1} \mathrm{H}-\mathrm{NMR}$ as described here:

(1) $m=$ percentage of the cyclobutane repeat units, $n=$ percentage of the linear repeat units;

(2) Number of the methylene protons (red, $\delta 4.3-3.8 \mathrm{ppm}$ ) is 4 in both the cyclobutane and linear repeat units;

(3) Number of the signature protons (pink $\mathrm{H}_{b}, \mathrm{H}_{\mathrm{c}}, \mathrm{H}_{\mathrm{d}}, \mathrm{H}_{\mathrm{e}}, \delta 2.3-1.7 \mathrm{ppm}$ ) of the cyclobutane ring is 6; number of the signature protons (blue $\mathrm{H}_{\mathrm{f}}, \mathrm{H}_{\mathrm{g}} \delta 2.7-2.3 \mathrm{ppm}$ ) in the linear alkene units is 4; integration of $\mathrm{H}_{\mathrm{b}}, \mathrm{H}_{\mathrm{c}}, \mathrm{H}_{\mathrm{d}}, \mathrm{He}_{\mathrm{e}}, \mathrm{H}_{\mathrm{f}}$ and $\mathrm{H}_{\mathrm{g}}$ is 4.06;

(4) $\left\{\begin{array}{l}m+n=100 \% \\ 6 m+4 n=4.06\end{array}\right.$

(5) Thus, $\mathrm{m}=(4.06-4.00 \times 100 \%) / 2=3 \% ; S_{\mathrm{L}}=\mathrm{n} /(\mathrm{m}+\mathrm{n})=97 \%$.

The $S_{\mathrm{L}}$ of other polymers were calculated in identical fashion. 


\subsection{Optimization of Polymerization Conditions}

All reactions to optimize the polymerization of EtVCP were carried out according to General Procedure B. Crude ${ }^{1} \mathrm{H}-\mathrm{NMR}$ was taken for the analysis of monomer conversion and the linear factor $S_{\mathrm{L}}$.

Table S1. Initiator screening for polymerization of $\mathrm{EtVCP}^{a}$

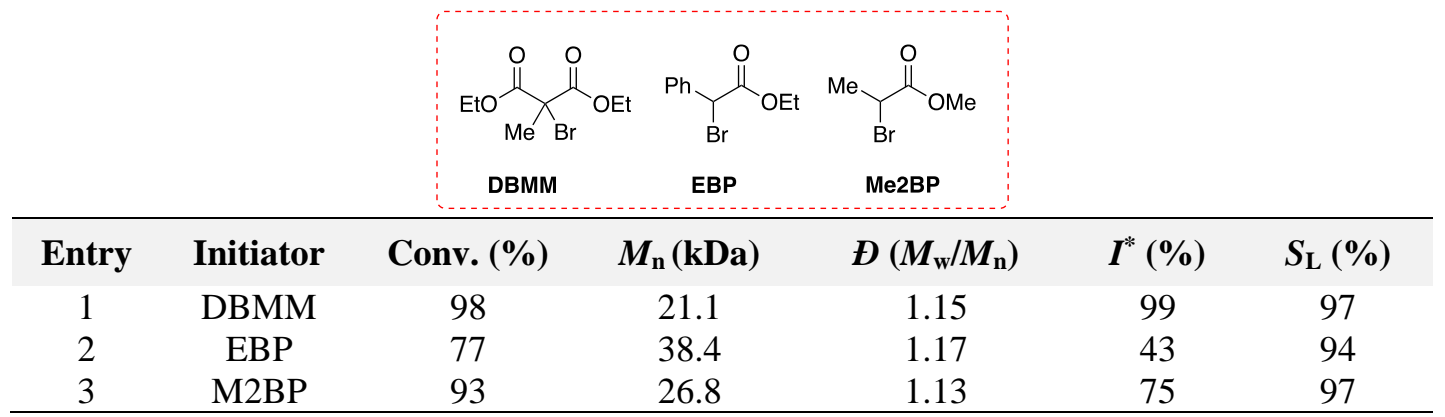

${ }^{a}$ Polymerizations of [EtVCP]/[initiator]/[1] (1000/10/1) were performed in $1.0 \mathrm{~mL}$ of anhydrous EtOAc for $8 \mathrm{~h}$, with white LEDs irradiation at $28^{\circ} \mathrm{C}$.

Table S2. Control experiments ${ }^{a}$

\begin{tabular}{ccccccccc}
\hline Entry & Light & PC 1 & DBMM & $\begin{array}{c}\text { Conv. } \\
(\%)\end{array}$ & $\begin{array}{c}M_{\mathrm{n}(\mathrm{GPC})} \\
(\mathrm{kDa})\end{array}$ & $\begin{array}{c}Ð \\
\left(M_{\mathrm{w}} / M_{\mathrm{n}}\right)\end{array}$ & $I^{*}(\%)$ & $S_{\mathrm{L}}(\%)$ \\
1 & - & - & - & 0 & - & - & - & - \\
2 & - & $\sqrt{ }$ & - & 0 & - & - & - & - \\
3 & - & - & $\sqrt{ }$ & 0 & - & - & - & - \\
4 & - & $\sqrt{ }$ & $\sqrt{ }$ & 0 & - & - & - & - \\
5 & $\sqrt{ }$ & - & - & 0 & - & - & - & - \\
6 & $\sqrt{ }$ & $\sqrt{ }$ & - & 0 & - & - & - & - \\
7 & $\sqrt{ }$ & - & $\sqrt{ }$ & 0 & - & - & - & - \\
\hline
\end{tabular}

${ }^{a}$ Polymerizations of $[\mathrm{EtVCP}] /[\mathrm{DBMM}] /[1] \mathrm{(1000/10/1)}$ were performed in $1.0 \mathrm{~mL}$ of anhydrous EtOAc for $12 \mathrm{~h}$, with white LEDs irradiation at $28^{\circ} \mathrm{C}$. 


\subsection{Kinetic Study}

Table S3. Results of progress analysis for polymerization of EtVCP at $28{ }^{\circ} \mathrm{C}^{a}$

\begin{tabular}{ccccccc}
\hline Entry & Time (h) & Conv. $(\boldsymbol{\%})$ & $\boldsymbol{M}_{\mathbf{n}}(\mathbf{k D a})$ & $\boldsymbol{D}\left(\boldsymbol{M}_{\mathbf{w}} / \boldsymbol{M}_{\mathbf{n}}\right)$ & $\boldsymbol{I}^{*}(\boldsymbol{\%})$ & $\boldsymbol{S}_{\mathbf{L}}(\boldsymbol{\%})$ \\
1 & 1 & 29 & 6.9 & 1.19 & 94 & 97 \\
2 & 2 & 53 & 11.8 & 1.15 & 97 & 97 \\
3 & 3 & 69 & 14.7 & 1.15 & 100 & 97 \\
4 & 4 & 79 & 17.1 & 1.12 & 99 & 97 \\
\hline
\end{tabular}

${ }^{a}$ The polymerization of $\left.[\mathrm{EtVCP}] /[\mathrm{DBMM}] /[1]\right](1000 / 10 / 1)$ was performed in $1.0 \mathrm{~mL}$ of EtOAc, with white LED irradiation at $28^{\circ} \mathrm{C}$.

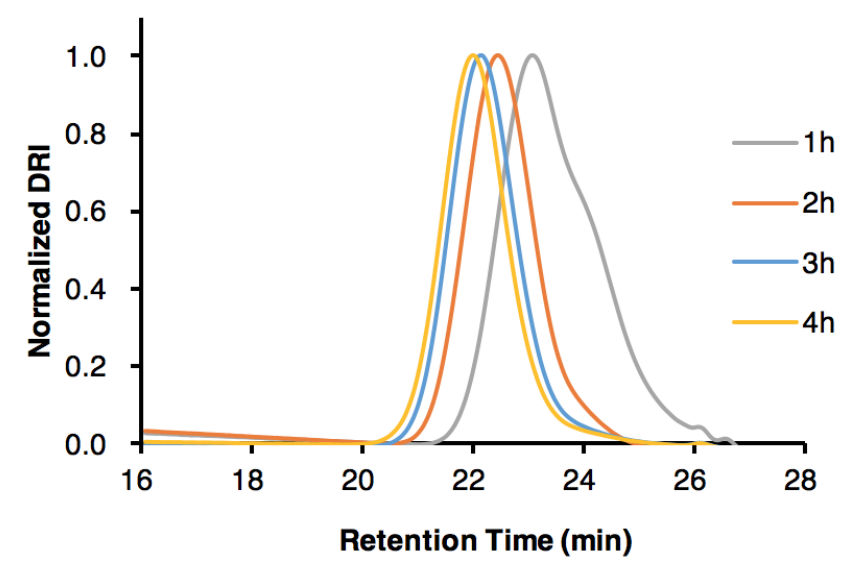

Figure S9. Overlay of GPC traces for poly(EtVCP) in Table S3. 


\subsection{Pulsed-Irradiation Experiment}

Table S4. Pulsed-irradiation experiment for polymerization of EtVCP at $28^{\circ} \mathrm{C}^{a}$

\begin{tabular}{ccccccc}
\hline Entry & Time $(\mathbf{h})$ & Conv. $(\boldsymbol{\%})$ & $\boldsymbol{M}_{\mathbf{n}}(\mathbf{k D a})$ & $\boldsymbol{D}\left(\boldsymbol{M}_{\mathbf{w}} / \boldsymbol{M}_{\mathbf{n}}\right)$ & $\boldsymbol{I}^{*}(\boldsymbol{\%})$ & $\boldsymbol{S}_{\mathbf{L}}(\boldsymbol{\%})$ \\
1 & 1 & 28 & 6.33 & 1.08 & 98 & 97 \\
2 & 2 & 28 & 6.39 & 1.08 & 97 & 97 \\
3 & 3 & 52 & 11.62 & 1.11 & 97 & 97 \\
4 & 4 & 52 & 11.67 & 1.12 & 97 & 97 \\
5 & 5 & 68 & 15.68 & 1.12 & 94 & 97 \\
6 & 17 & 68 & 15.54 & 1.15 & 95 & 97 \\
7 & 18 & 80 & 17.66 & 1.15 & 98 & 97 \\
8 & 19 & 80 & 17.79 & 1.15 & 97 & 97 \\
\hline
\end{tabular}

${ }^{a}$ The polymerization of $[\mathrm{EtVCP}] /[\mathrm{DBMM}] /[1]$ (1000/10/1) was performed in $1.0 \mathrm{~mL}$ of EtOAc, with white LED irradiation at $28{ }^{\circ} \mathrm{C}$.

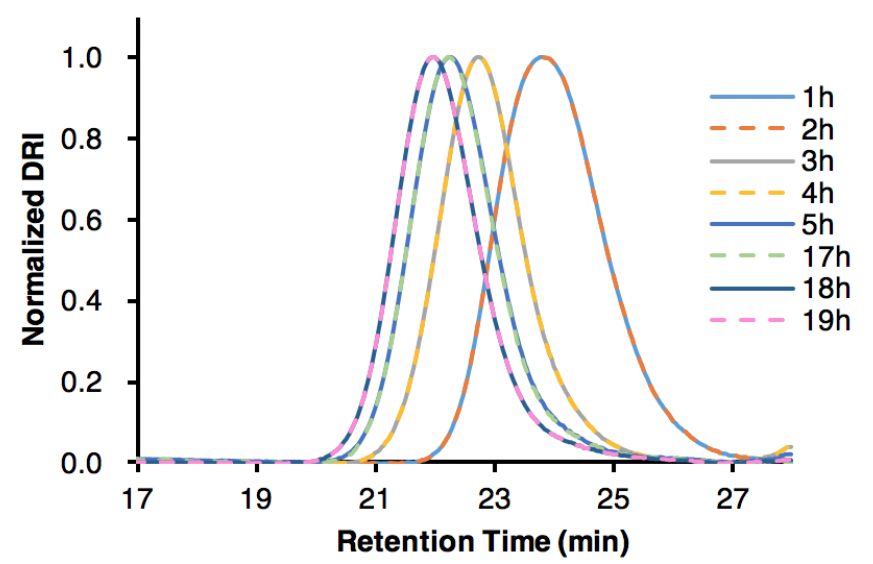

Figure S10. Overlay of GPC traces for poly(EtVCP) in Table S4. 


\subsection{Investigation of Chain-End Fidelity}

(a)

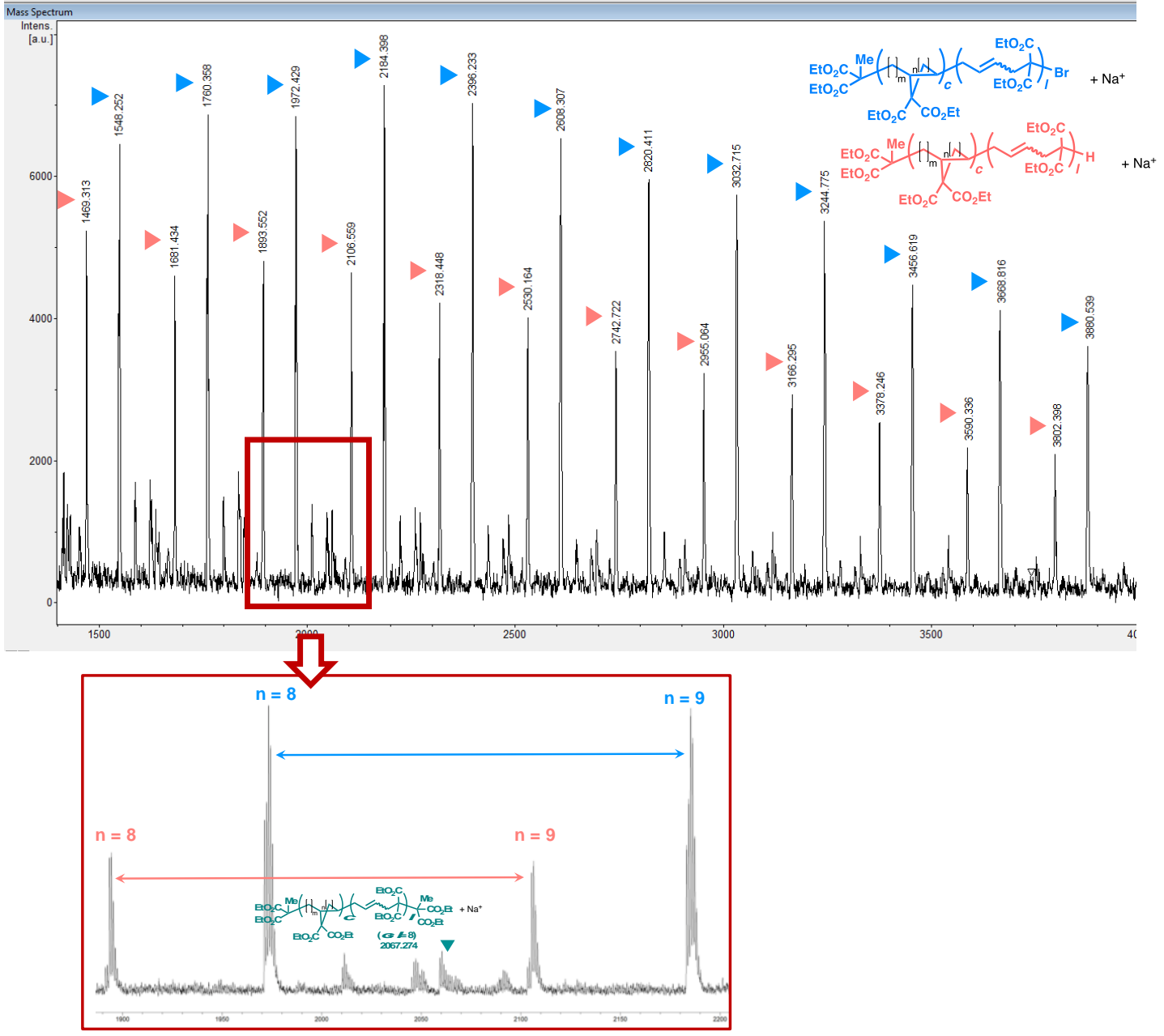

(b)

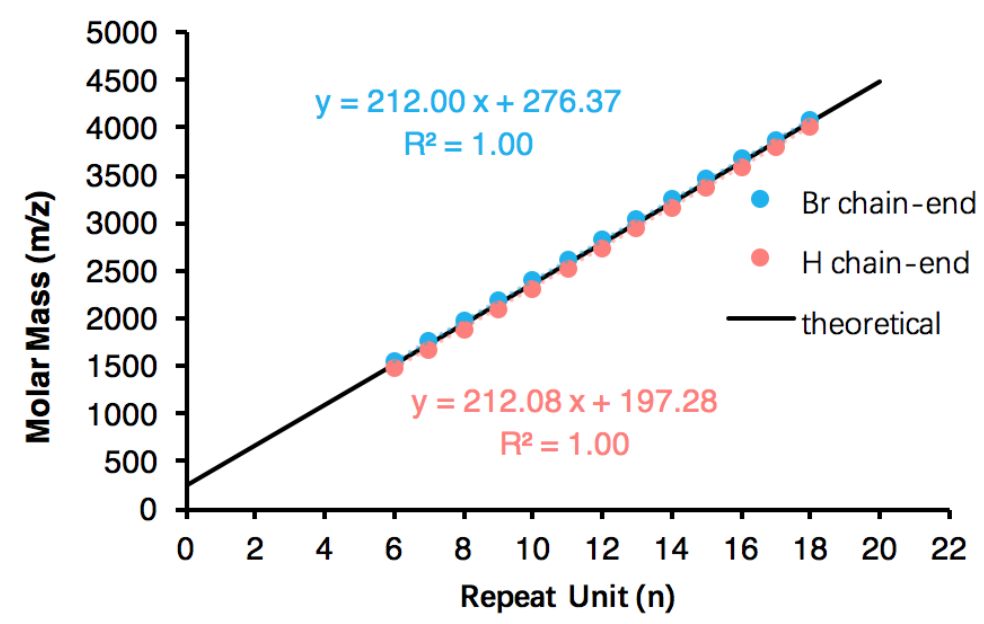

Figure S11. MALDI-TOF spectra of poly(EtVCP) $\left(6.9 \mathrm{kDa}, \oslash=1.19, S_{\mathrm{L}}=98 \%\right.$, Table S3, entry 1). (A) Structural assignment. (B) Plots of $\mathrm{m} / \mathrm{z}$ vs number of EtVCP repeat units 
from the MALDI-TOF analysis. The slope of the linear fit represents the $\mathrm{m} / \mathrm{z}$ of the monomer unit (calcd. 212.11); the y-intercept indicates $\mathrm{Br}$ (blue, plus $\mathrm{Na}^{+}$, calcd. 274.99, observed 275.05) and $\mathrm{H}$ (red, plus $\mathrm{Na}^{+}$, calcd. 196.08, observed. 195.74) chain-end groups. Black dashed line represents the theoretical $M_{\mathrm{n}}$ values for a polymer with terminal groups derived from the DBMM initiator.

\subsection{Chain-Extension Experiment}

\subsubsection{Synthesis of poly(EtVCP) macroinitiator}

Polymerization of [EtVCP]/[DBMM]/[1] (1000/20/1) was set up on $2.0 \mathrm{mmol}$ scale in $2.0 \mathrm{~mL}$ of EtOAc by following General Procedure B. After 8 hours, the reaction mixture was slowly added into $50.0 \mathrm{~mL}$ of hexane at $-78{ }^{\circ} \mathrm{C}$ and stirred for 1 hour. The white precipitate was collected by vacuum filtration, washed with cold hexane $(10.0 \mathrm{~mL} \times 2)$ and dried overnight under vacuum at $50{ }^{\circ} \mathrm{C}$ to a constant weight ( $350 \mathrm{mg}, 82 \%$ yield, GPC $M_{\mathrm{n}}$ $\left.=11.6 \mathrm{kDa}, Ð=1.10, I^{*}=94 \%, S_{\mathrm{L}}=95 \%\right)$.

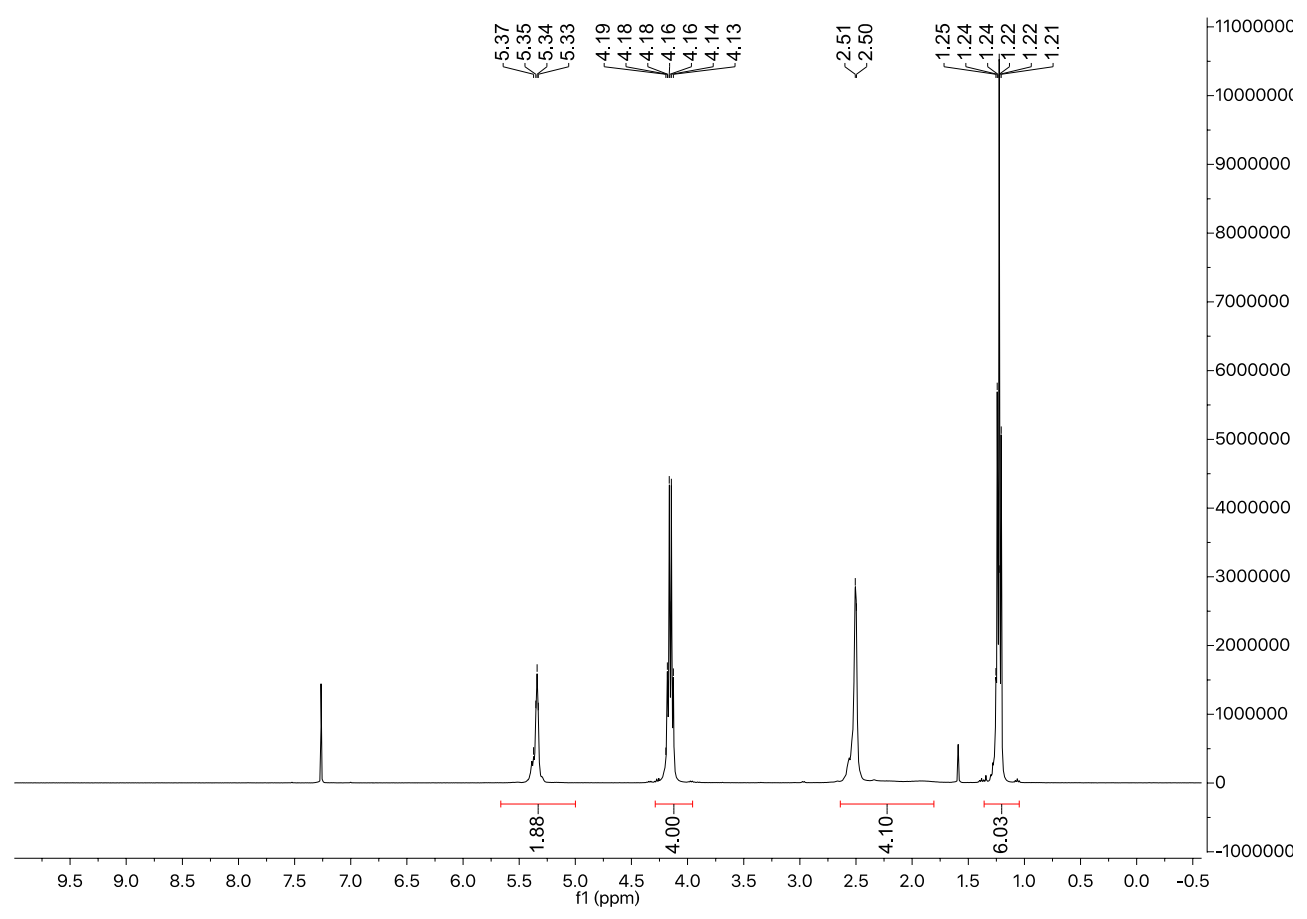

Figure S12. ${ }^{1} \mathrm{H}-\mathrm{NMR}$ spectrum of the poly(EtVCP) macroinitiator. 


\subsubsection{Synthesis of poly(EtVCP)-b-poly(PhVCP)}

An oven-dried $20 \mathrm{~mL}$ scintillation vial was charged with a magnetic stir bar, poly(EtVCP) macroinitiator $(116 \mathrm{mg}, 0.010 \mathrm{mmol})$ and PC $1(0.44 \mathrm{mg}, 0.0010 \mathrm{mmol})$. The vial was transferred into a $\mathrm{N}_{2}$-filled glovebox where $1.0 \mathrm{~mL}$ of anhydrous EtOAc and PhVCP (154.2 mg, $0.5 \mathrm{mmol}$ ) were quickly added. The vial was then tightly capped and irradiated in the beaker equipped with $45 \mathrm{~cm}$ white LED strips while stirring in the glove box. A cooling fan was used to keep the temperature at $28{ }^{\circ} \mathrm{C}$ around. After 12 hours, a $0.10 \mathrm{~mL}$ aliquot was taken for ${ }^{1} \mathrm{H}$ NMR analysis (> 99\% conv. was achieved in this reaction). The aliquot was then dried under vacuum for direct analysis by gel permeation chromatography (GPC) equipped with multi-angle light scattering $\left(M_{\mathrm{n}}=27.8 \mathrm{kDa}, D=1.23\right.$, $\left.I^{*}=97 \%, S_{\mathrm{L}}=90 \%\right)$. Block copolymer was purified by adding the reaction mixture into $30.0 \mathrm{~mL}$ of hexane at $-78{ }^{\circ} \mathrm{C}$. The precipitated polymer was then collected, washed with cold hexane $(5.0 \mathrm{~mL} \times 2)$ and dried overnight under vacuum at $50{ }^{\circ} \mathrm{C}$ to a constant weight. ${ }^{1} \mathbf{H}$ NMR (400 MHz, CDCl $) \delta 7.35$ - 6.50 (m, 5 H), 5.80 - 5.10 (m, $\left.1.8 \mathrm{H}\right), 4.25$ - 4.15 $(\mathrm{m}, 2.0 \mathrm{H}), 3.35-1.70(\mathrm{br}, 4.2 \mathrm{H}), 1.35-1.15(\mathrm{~m}, 3.0 \mathrm{H})$. The total $S_{\mathrm{L}}$ in this block copolymer $90 \%$.

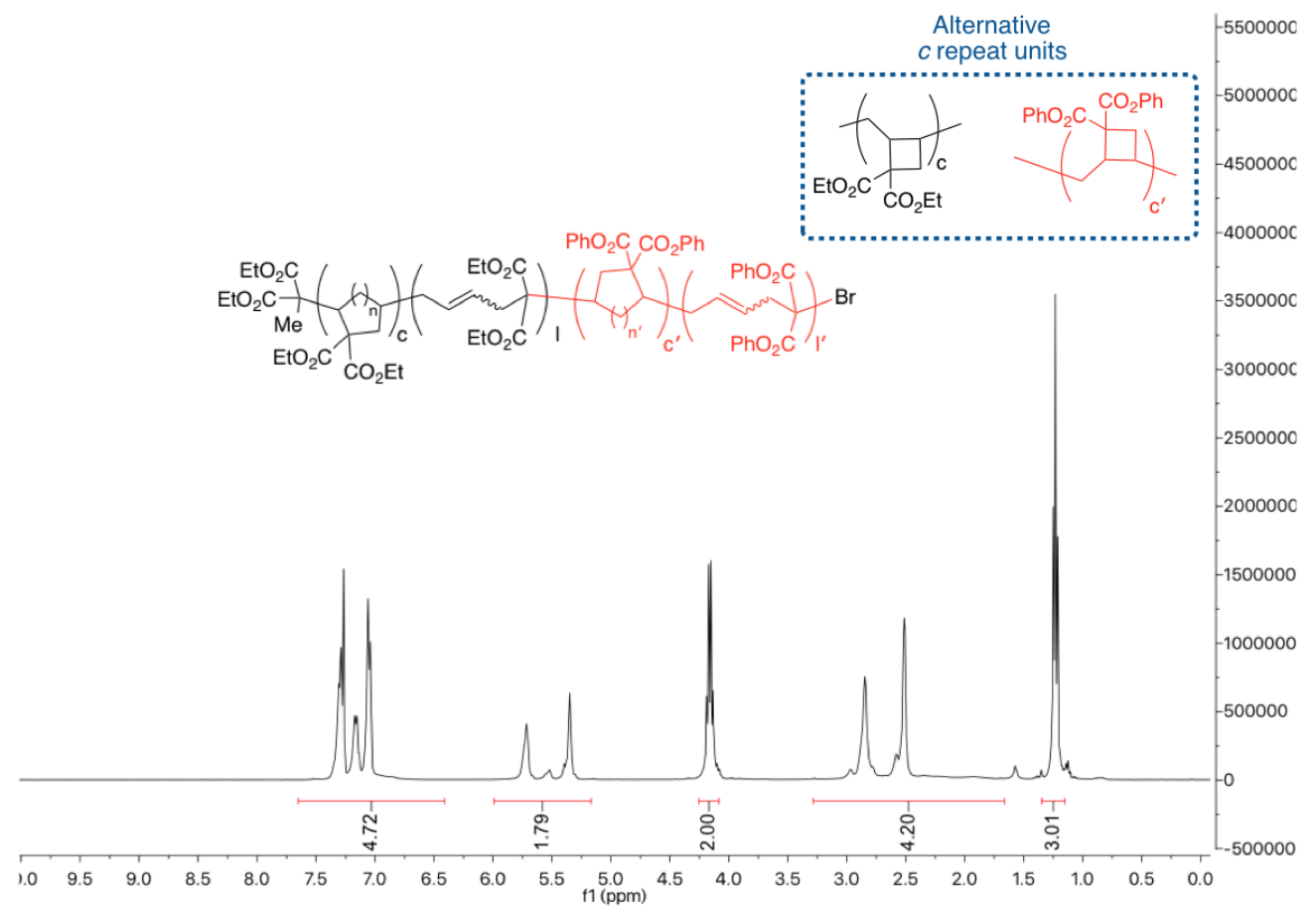

Figure S13. ${ }^{1} \mathrm{H}-\mathrm{NMR}$ spectrum of poly(EtVCP)- $b$-poly(BnVCP). 


\subsection{Mechanistic Studies of the Photoredox Mechanism}

\subsubsection{Emission of PC 1 in the presence of DBMM}

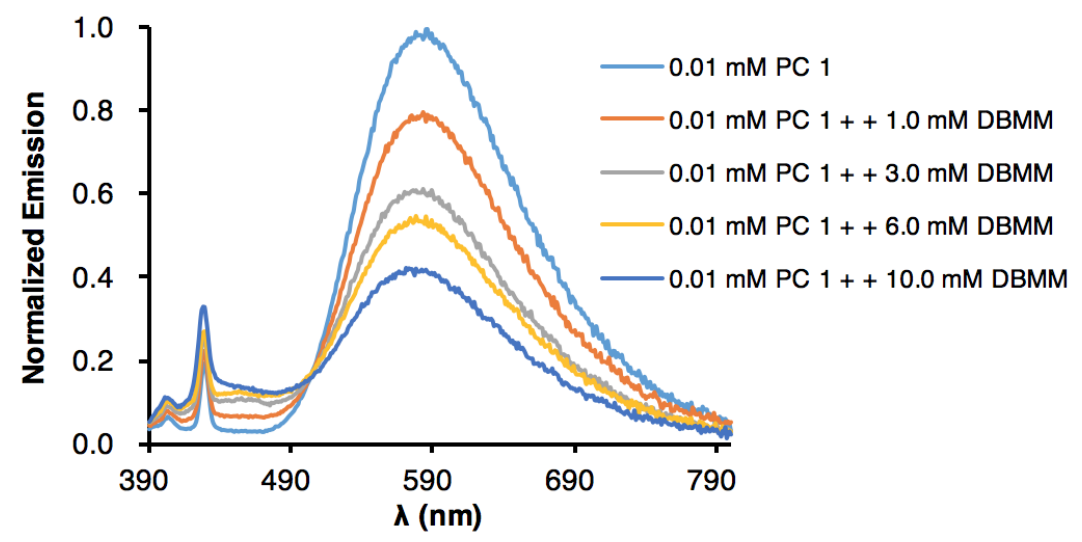

Figure S14. Emission spectra of PC 1 in EtOAc, in the presence of varying concentrations of $\operatorname{DBMM}\left(\lambda_{\mathrm{ex}}=380 \mathrm{~nm}\right)$.

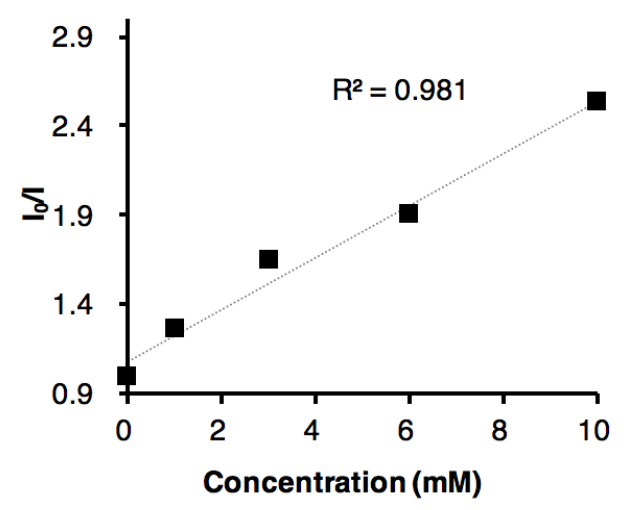

Figure S15. Stern-Volmer quenching experiment PC 1 by DBMM in EtOAc $\left(\mathrm{I}_{0}=\right.$ intensity of emission at $585 \mathrm{~nm}$ and $\mathrm{I}=$ intensity of emission at $585 \mathrm{~nm}$ in the presence of quencher). 


\subsubsection{Transient Absorption (TA) Spectroscopy}

PC 1 in EtOAc. Inside a nitrogen-filled glovebox, a $0.50 \mathrm{mM}$ solution was prepared by mixing $2.0 \mathrm{mg}\left(4.6 \times 10^{-6} \mathrm{~mol}\right)$ of $\mathbf{P C} \mathbf{1}$ in $9.2 \mathrm{~mL}$ of anhydrous EtOAc in a vial. Then, $50 \mu \mathrm{L}$ of this $0.50 \mathrm{mM}$ solution $\left(2.5 \times 10^{-8} \mathrm{~mol}\right)$ was dissolved in $3.0 \mathrm{~mL}$ of EtOAc inside a $1.0 \mathrm{~cm}$ x $1.0 \mathrm{~cm}$ quartz cuvette (Starna, 1-Q-10/GS modified with an air-tight PTFE screw cap seal) to make a $8.2 \mu \mathrm{M}$ solution. The solution inside the cuvette was sparged with argon for 15 minutes using Teflon tubing inserted into a septum stopper which was fitted onto the side-arm of the cuvette (Figure S16).

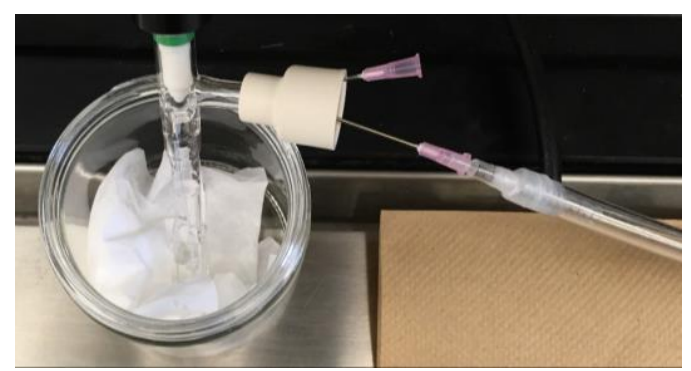

Figure S16. Apparatus for sparging samples with argon prior to TA spectroscopy.

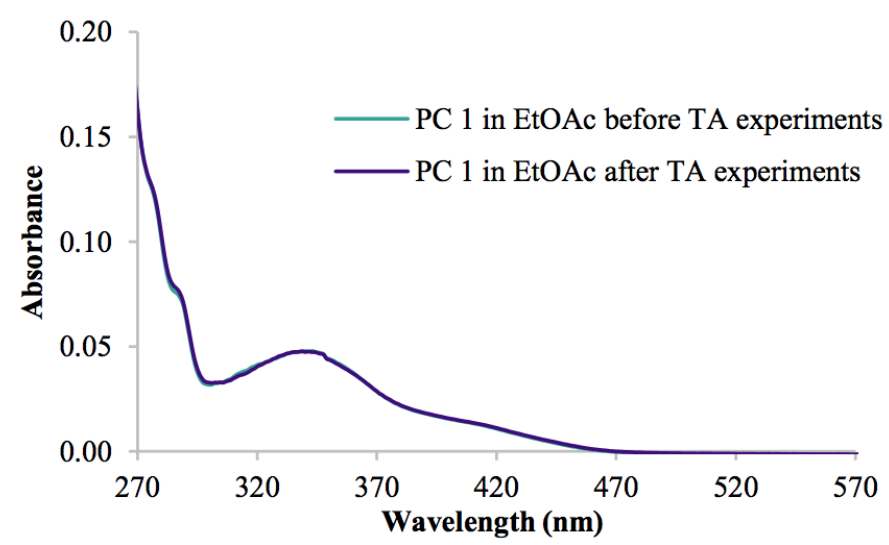

Figure S17. UV-visible absorption spectra of PC 1 in EtOAc before and after TA experiments $\left(\lambda_{\mathrm{ex}}=355 \mathrm{~nm}\right)$ to ensure that no degradation of PC $\mathbf{1}$ occurred. 


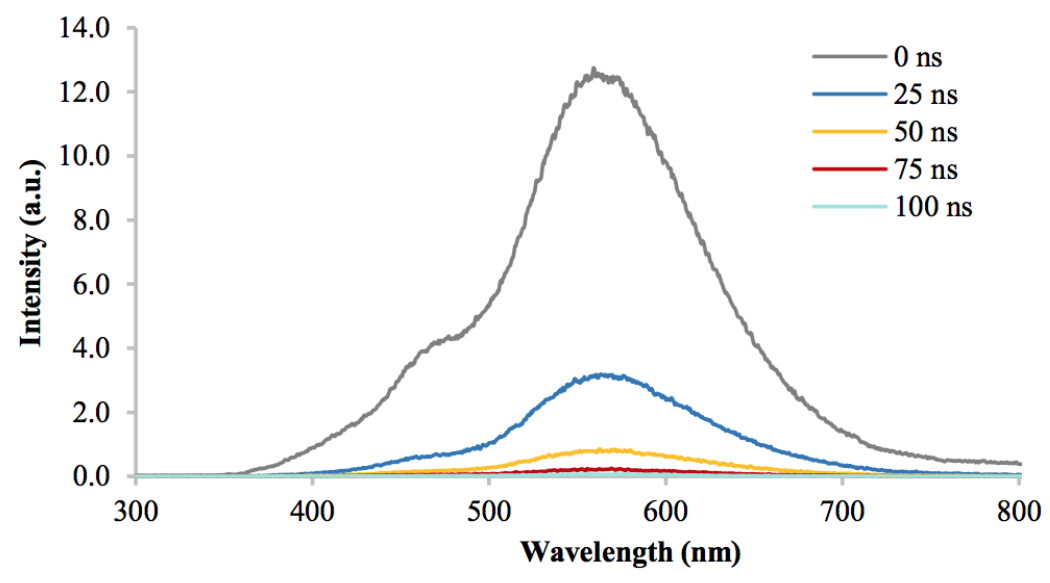

Figure S18. Emission spectra of PC 1 in EtOAc acquired at various time delays (0-100 $\mathrm{ns})$. The spectrum at each time delay is the average of 25 scans $\left(\lambda_{\mathrm{ex}}=355 \mathrm{~nm}\right)$.

To determine the lifetime of ${ }^{3}(\mathrm{PC} \mathbf{1})^{*}$ in EtOAc in the absence of quenchers, three samples were prepared as described above and analyzed using transient absorption spectroscopy. First a transient absorption spectrum was acquired to determine a suitable wavelength to monitor the transient decay at (Figure S19). An excited state absorption feature was observed spanning from $~ 400-475 \mathrm{~nm}$. As such, subsequent single-wavelength decay experiments tracking ${ }^{3}(\mathrm{PC} \mathbf{1}) *$ were monitored at $430 \mathrm{~nm}$.

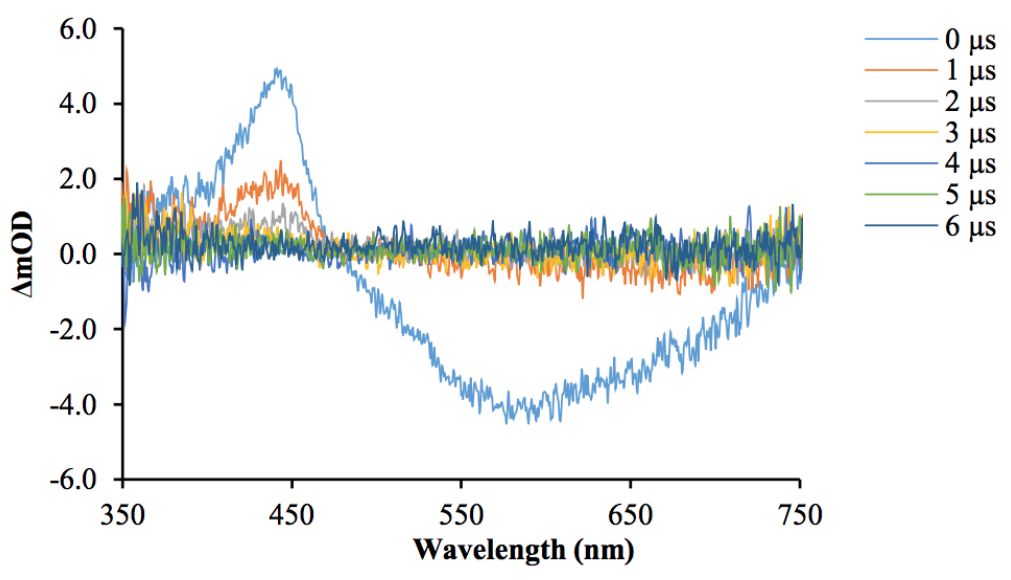

Figure S19. Transient absorption spectra of $\mathbf{1}$ in EtOAc acquired at various time delays $(0-6 \mu \mathrm{s})$. Each spectrum is an average of 100 scans $\left(\lambda_{\mathrm{ex}}=355 \mathrm{~nm}\right)$. 
Three independent samples were analyzed by tracking the decay of the excited state absorption signal at $430 \mathrm{~nm}$. A tail-fitting, single exponential decay model was used to determine the excited state lifetime. Based on analysis of two samples (Figure S20), the excited state lifetime was determined to be $26.0 \pm 0.1 \mu$ s in EtOAc.
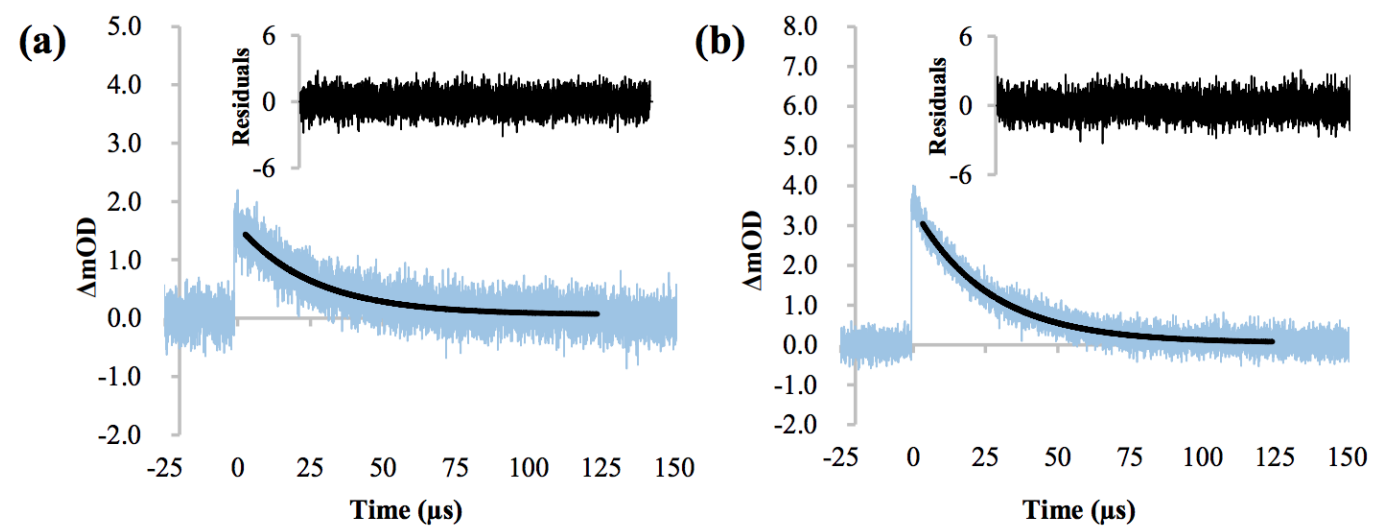

Figure S20. Kinetic transient decay spectrum for ${ }^{3}(\mathrm{PC} \mathrm{1}) *$ in EtOAc monitoring at 430 nm. (a) Trial one, $\tau=26.1 \mu \mathrm{s}$. (b) Trial two, $\tau=26.0 \mu \mathrm{s}$. Each spectrum was averaged over 500 scans $\left(\lambda_{\mathrm{ex}}=355 \mathrm{~nm}\right)$.

PC 1 in the presence of DBMM in EtOAc. One of the samples of PC 1 in EtOAc described above $(8.2 \mu \mathrm{M})$ was checked for degradation using steady-state UV-visible absorption spectroscopy and brought into a nitrogen-filled glovebox. Inside the nitrogenfilled glovebox, a separate vial was used to prepare a $20 \mathrm{mM}$ stock solution of DBMM in EtOAc by dissolving $5.0 \mu \mathrm{L}\left(2.6 \times 10^{-5} \mathrm{~mol}\right)$ of DBMM in $1.3 \mathrm{~mL}$ of EtOAc to make a 20.0 $\mathrm{mM}$ stock solution. Then $12.5 \mu \mathrm{L}$ of the $20 \mathrm{mM}$ stock solution of DBMM in EtOAc was added to the cuvette $\left(2.5 \times 10^{-7} \mathrm{~mol}, 82.0 \mu \mathrm{M}, 10\right.$ equivalents of DBMM relative to catalyst). The sample was prepared in this way to ensure that any differences in the singlewavelength decay spectrum of the catalyst were due to the presence of the added DBMM. The cuvette was kept in the dark while it was transported to the transient absorption spectrometer for analysis.

Two independent samples prepared using the abovementioned procedure were analyzed by transient absorption spectroscopy. The first trial is shown in Figure $3 \mathrm{G}$ of the main text and the second trial is shown in Figure S21. A tail-fitting, single exponential decay model was used to determine the excited state lifetime of each sample. 

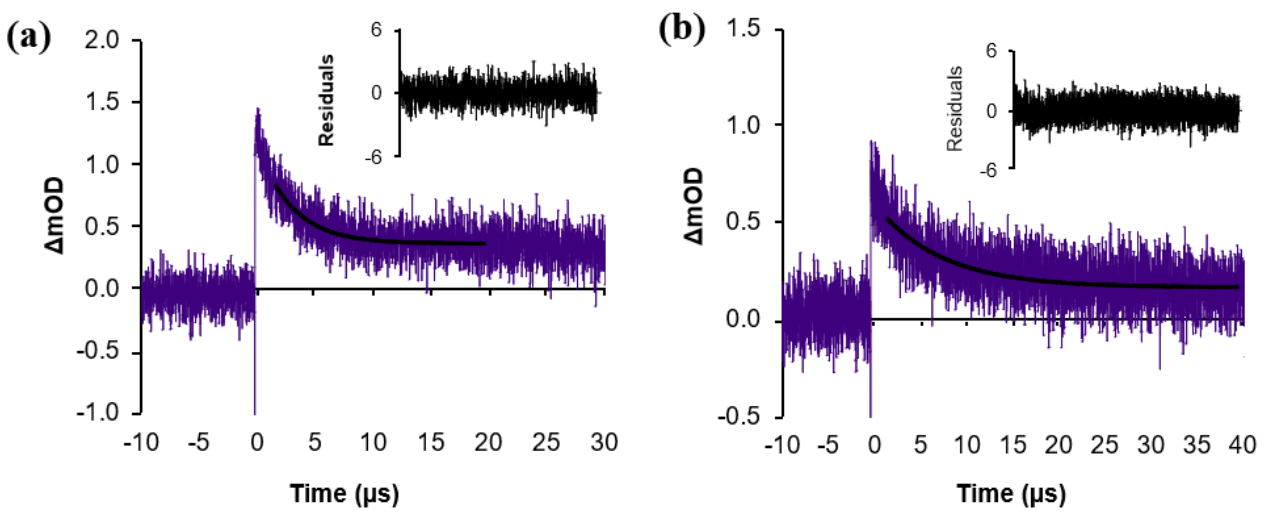

Figure S21. Kinetic transient decay spectrum for ${ }^{3}(\mathrm{PC} 1) *$ in EtOAc in the presence of 10 equivalents of DBMM monitoring at $430 \mathrm{~nm}$. (a) $\tau=3.2 \mu \mathrm{s}$; (b) $\tau=7.1 \mu \mathrm{s}$. The spectra were averaged over 250 scans $\left(\lambda_{\mathrm{ex}}=355 \mathrm{~nm}\right)$.

\subsubsection{Identification of Species Present after TA Analysis}

After analysis with transient absorption spectroscopy, samples were analyzed using UV-visible absorption spectroscopy to identify changes in the species present due to the presence of DBMM (Figure S22). Analysis of the absorption spectra of PC 1 in the presence of DBMM (purple trace) after lasing revealed the presence of $\mathbf{1}$ and another species with features predominantly arising between $\sim 400-500 \mathrm{~nm}$. Comparison with the spectrum of electrochemically generated ${ }^{2}(\mathrm{PC} \mathbf{1})^{\circ+}$ in EtOAc (red trace) indicates that these features arise from overlap of $\mathbf{1}$ and ${ }^{2}(\mathrm{PC} \mathbf{1})^{++}$(for details see Figure S26). Due to the rapid generation of ${ }^{2}(\mathrm{PC} \mathrm{1})^{\circ+}$ using the laser, analogous experiments were also performed to identify the formation of ${ }^{2}(\mathrm{PC} \mathbf{1})^{\cdot+}$ from reaction of $\mathbf{1}$ and DBMM under more catalytically relevant conditions (see Figure S23).

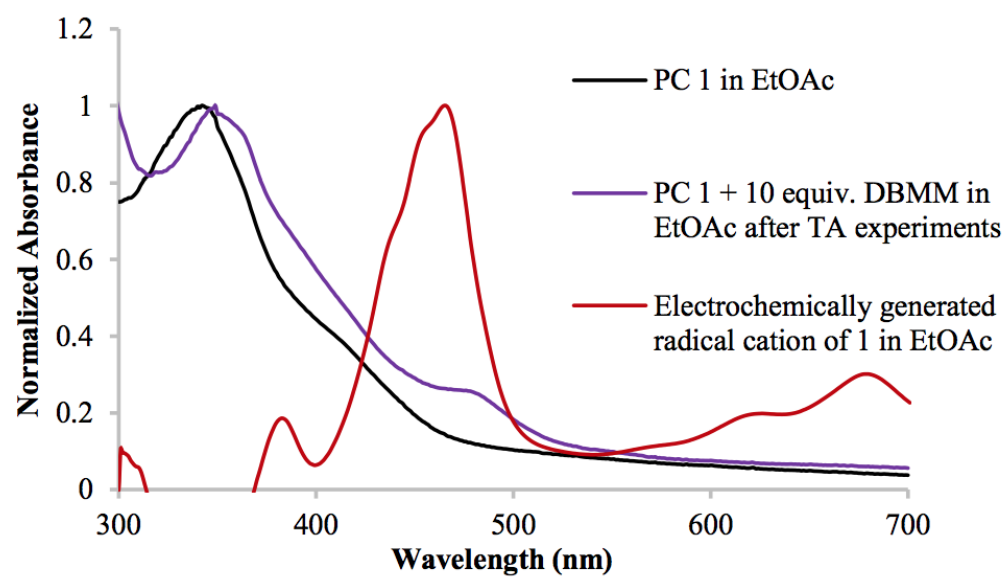


Figure S22. UV-visible absorption spectra of PC 1 alone (black), PC 1 in the presence of DBMM (purple) after TA analysis. The spectrum for ${ }^{2}(\mathrm{PC} \mathbf{1})^{\cdot+}$ (red) was acquired by generating it electrochemically.

Reaction of 1 and DBMM using Polymerization Light Source. Inside a nitrogen-filled glovebox, $3.4 \mathrm{mg}\left(7.8 \times 10^{-6} \mathrm{~mol}, 1.0\right.$ equiv.) of PC 1 was dissolved in $1.00 \mathrm{~mL}$ of anhydrous DMAc (7.8 mM with respect to PC 1) inside a $20.0 \mathrm{~mL}$ scintillation vial. Then, $15.0 \mu \mathrm{L}$ of DBMM was added to the vial $\left(7.8 \times 10^{-5} \mathrm{~mol}, 10.0\right.$ equiv. $)$ and the vial was placed in a white-light LED beaker $(\mathrm{t}=0)$. Aliquots were removed from the reaction vial at predetermined time intervals ( $\mathrm{t}=5$ minutes, 8 minutes, 30 minutes, and 50 minutes), diluted with $3.00 \mathrm{~mL}$ of anhydrous DMAc inside a quartz cuvette, and analyzed using UV-visible absorption spectroscopy (Figure S23). Overtime, features grow in at $400 \mathrm{~nm}$ and between $450-550 \mathrm{~nm}$ which are attributed to formation of ${ }^{2}(\mathrm{PC} \mathbf{1})^{\bullet+}$ based on the alignment of these spectral features with those of the electrochemically generated ${ }^{2}(\mathrm{PC} \mathbf{1})^{\bullet+}$ (see Figure S25).

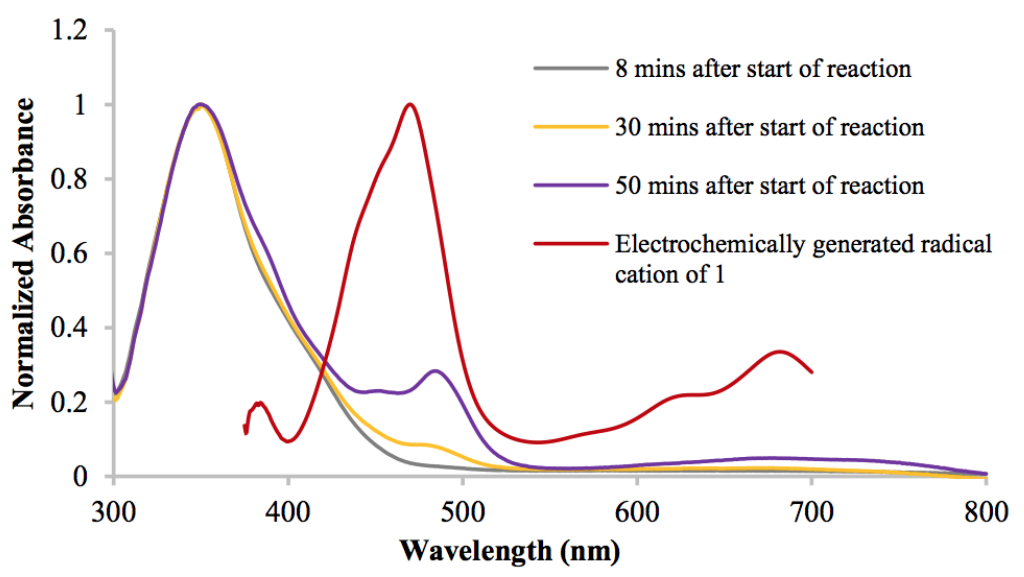

Figure S23. UV-visible absorption spectra of aliquots taken from the reaction of PC 1 with 10 equivalents of DBMM in the presence of white-light LEDs (gray, yellow and purple, traces). The spectrum for ${ }^{2}(\mathrm{PC} \mathbf{1})^{\bullet+}$ (red) was acquired by generating it electrochemically.

\subsubsection{Generation and Characterization of the Photocatalyst Radical Cation via} Spectroelectrochemistry

Spectroelectrochemistry was performed using an in-house setup. A 14/20 septum stopper was modified with openings to hold the counter, working, and reference electrodes (Figure S24a). A stock solution was prepared such that $\left[\mathrm{NBu}_{4} \mathrm{PF}_{6}\right]=0.10 \mathrm{M}$ and $[\mathrm{PC} 1]=$ $1.0 \mathrm{mM}$ in anhydrous DMAc or $\left[\mathrm{NBu}_{4} \mathrm{PF}_{6}\right]=0.050 \mathrm{M}$ and $[\mathrm{PC} 1]=0.050 \mathrm{mM}$ in anhydrous 
EtOAc. A portion of this solution was used to fill a $1 \mathrm{~cm} \times 1 \mathrm{~cm}$ quartz cuvette which was then capped with the septum stopper cap containing the electrodes. The cap was then secured using two pieces of parafilm and the solution was sparged with nitrogen for ten minutes. The cuvette was placed in a Cary 5000 UV-visible absorption spectrometer and alligator clips were used to connect the electrodes to the potentiostat (Figure S24b). Tape was used to secure all components and ensure that the electrodes did not touch during the experiment.

(a)

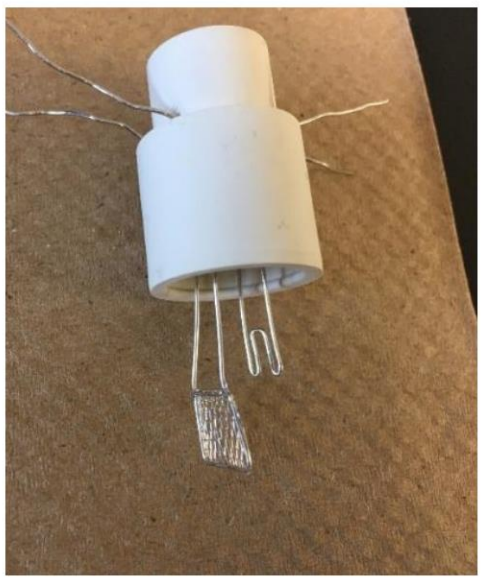

(b)

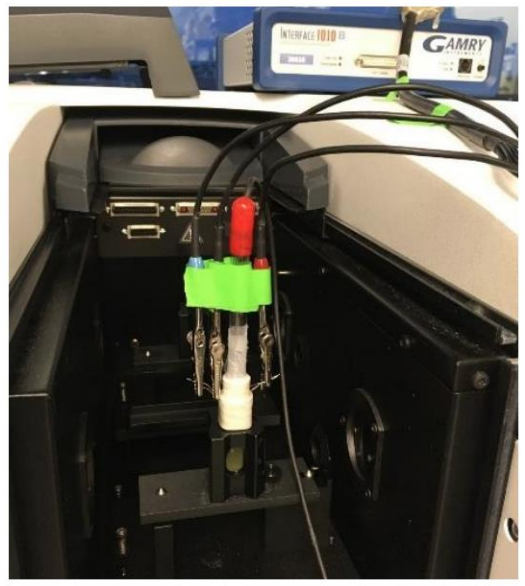

Figure S24. Setup for spectroelectrochemistry. (a) A septum stopper was fitted with the counter and working electrodes to which the reference electrode was later inserted. (b) This septum stopper cap was fitted onto a cuvette with the analyte solution (right) and connected to the potentiostat.

Before a potential was applied, the UV-visible absorption spectrum of the solution was acquired to use the spectrum of the ground state PC $\mathbf{1}$ as the blank. As such, the generation of new species due to application of a potential were evident by the growth of new spectral features coupled with depletion of spectral features corresponding to the ground state PC 1 (negative absorbance values). To generate ${ }^{2}(\mathrm{PC} \mathbf{1})^{\bullet+}$, chronoamperometry was performed using an over-potential compared to the oxidation potential of the catalyst $\left[E_{1 / 2}\left({ }^{2} \mathrm{PC}{ }^{*} /{ }^{1} \mathrm{PC}\right)=0.21 \mathrm{~V}\right.$ vs $\mathrm{SCE}$ in $\left.\mathrm{MeCN}\right]$. The potential was held at $+0.25 \mathrm{~V}$ vs $\mathrm{Ag} / \mathrm{AgNO}_{3}(+0.50 \mathrm{~V}$ vs SCE$)$ for the duration of the experiment. Once the desired potential was reached on the potentiostat, the UV-visible absorption spectrometer was set to scan from $700 \mathrm{~nm}$ to $300 \mathrm{~nm}$ every minute. The spectra acquired from electrochemical generation of ${ }^{2}(\mathrm{PC} 1)^{\cdot+}$ in DMAc are shown in Figure S25-S26. Overtime 1 is oxidized to 
${ }^{2}(\mathrm{PC} \mathrm{1})^{\bullet+}$ giving rise to a ground state bleach observed at $344 \mathrm{~nm}$ coupled with growth of features at $382 \mathrm{~nm}$ and $464 \mathrm{~nm}$ arising from ${ }^{2}(\mathrm{PC} \mathrm{1})^{\bullet+}$.

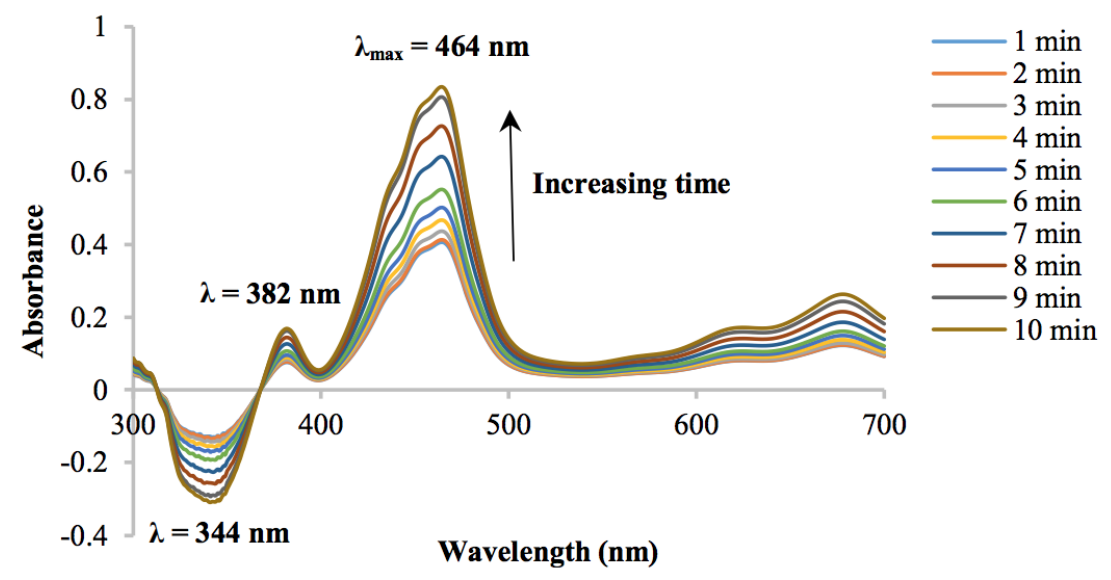

Figure S25. UV-visible absorption spectra of ${ }^{2}(\mathrm{PC} \mathrm{1})^{\cdot+}$ generated electrochemically in DMAc by applying a constant $+0.50 \mathrm{~V}$ vs SCE potential.

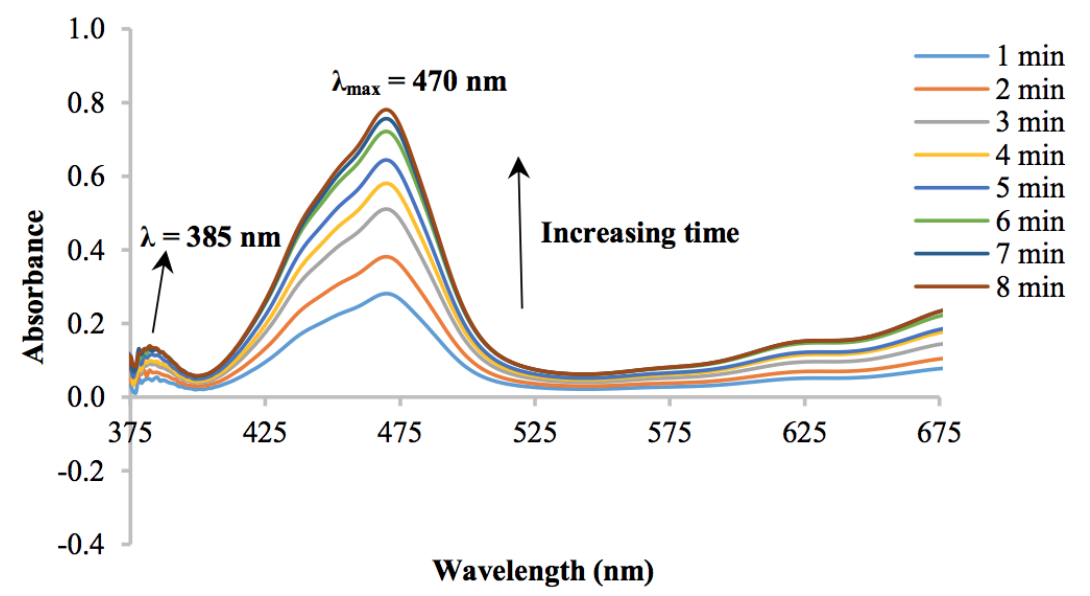

Figure S26. UV-visible absorption spectra of ${ }^{2}(\mathrm{PC} \mathrm{1})^{\cdot+}$ generated electrochemically in EtOAc by applying a constant $+0.55 \mathrm{~V}$ vs SCE potential. 


\section{Synthesis of Poly(EtVCP) with High Cyclic (c) Content}

\subsection{General Experimental Procedures}

General Procedure C: PC 1 or $2(0.0010 \mathrm{mmol})$ was weighed according to General Procedure B. In a N2-filled glovebox, anhydrous EtOAc, EtVCP (212.2 mg, $1.0 \mathrm{mmol})$ were sequentially added into the scintillation vial equipped with PC $\mathbf{1}$ or $\mathbf{2}$ and a small magnetic stir bar. The vial was then tightly capped and placed under white LED irradiation while stirring with $\left(\sim 28{ }^{\circ} \mathrm{C}\right)$ or without $\left(\sim 60{ }^{\circ} \mathrm{C}\right)$ a cooling fan in the glove box for indicated time. To determine the conversion of polymerization, a $0.10 \mathrm{~mL}$ aliquot was taken and quenched by injecting into a vial containing $\sim 0.70 \mathrm{~mL} \mathrm{CDCl}_{3}$ with 250 ppm butylated hydroxytoluene (BHT). This aliquot was analyzed via ${ }^{1} \mathrm{H}$ NMR for conversion, then dried under vacuum for direct analysis by GPC equipped with multi-angle light scattering for $M_{\mathrm{n}}$ and $Ð$. For purification of the obtained polymers, the reaction mixture was slowly added into $30.0 \mathrm{~mL}$ of hexane while stirring at $-78{ }^{\circ} \mathrm{C}$. The precipitated polymer was collected, washed with cold hexane $(5.0 \mathrm{~mL} \times 2)$ and dried overnight under vacuum at $50{ }^{\circ} \mathrm{C}$ to a constant weight.

(a)

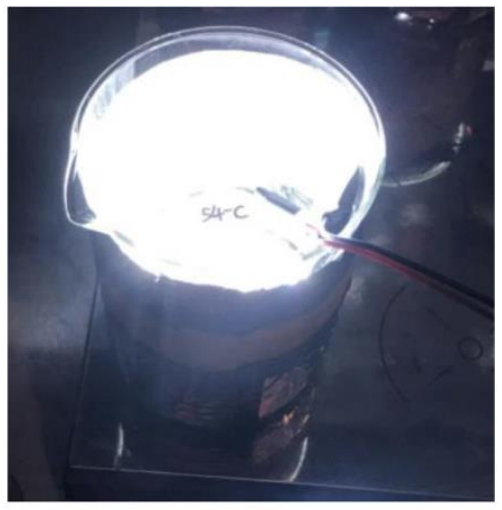

(b)

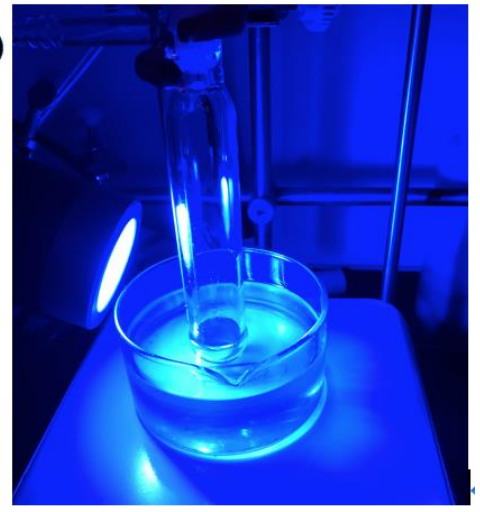

Figure S27. Setup for synthesis of poly(vinylcyclpropanes) with high $c$ content using (a) white LEDs or (b) $34 \mathrm{~W}$ Kessil blue LED (distance between the LED and the sealed tube is about $5 \mathrm{~cm}$ ). 


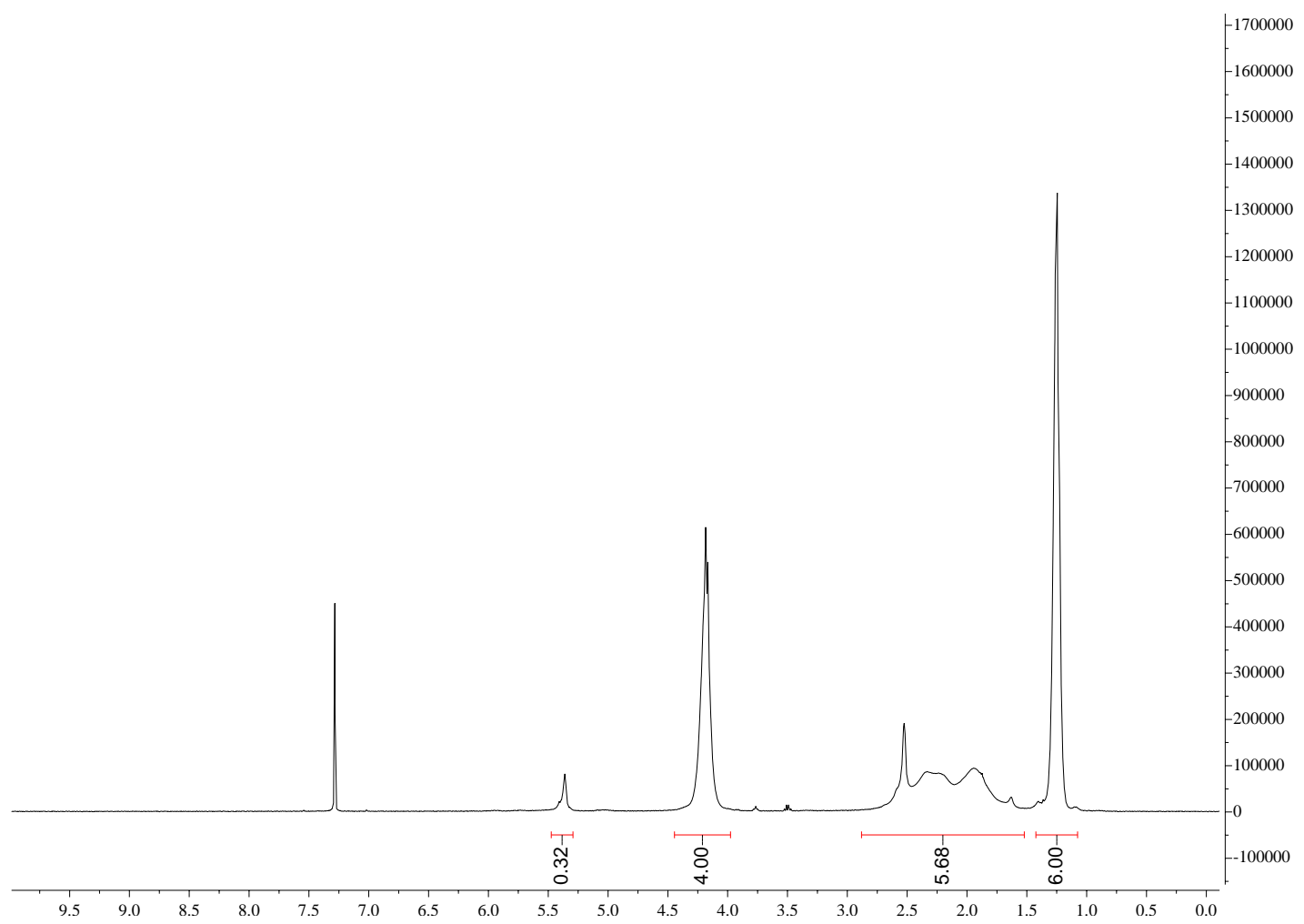

Figure S28. ${ }^{1} \mathrm{H}-\mathrm{NMR}$ spectrum of poly(EtVCP) in Table 2 , entry $9\left(M_{\mathrm{n}}=21.1 \mathrm{kDa}, Ð=\right.$ 1.09, $\left.S_{\mathrm{L}}=16 \%\right) .{ }^{1} \mathbf{H} \mathbf{N M R}\left(400 \mathrm{MHz}, \mathrm{CDCl}_{3}\right) \delta 5.46-5.25(\mathrm{br}, 0.32 \mathrm{H}), 4.45$ - 3.95 (br, $4.00 \mathrm{H}), 2.85-1.65(\mathrm{br}, 5.68 \mathrm{H}), 1.32-1.10(\mathrm{~m}, 6.00 \mathrm{H})$. 


\subsection{Optimization of Polymerization Condition}

Table S5. Volume of EtOAc used for polymerizations of various concentration ${ }^{a}$

\begin{tabular}{ccc}
\hline Volume of EtVCP $(\mathbf{m L})$ & Volume of solvent $(\mathbf{m L})$ & Concentration $^{b}(\mathbf{m o l} / \mathbf{m L})$ \\
& 0.5 & 1.429 \\
& 1.0 & 0.833 \\
$0.2 \mathrm{~mL}$ for $1.0 \mathrm{mmol}$ & 2.0 & 0.455 \\
& 5.0 & 0.192 \\
& 8.0 & 0.122 \\
& 10.0 & 0.098 \\
\hline
\end{tabular}

${ }^{a}$ Volume of polymerization roughly equals the total volume of monomer and EtOAc. bThe density of EtVCP is $1.002 \mathrm{~g} / \mathrm{mL}$. The volume (V) change when mixing EtVCP and EtOAc is considered to be negligible, therefore the total volume $\mathrm{V}=\mathrm{V}(\mathrm{EtVCP})+\mathrm{V}(\mathrm{EtOAc})$.

Table S6. Control experiments ${ }^{a}$

\begin{tabular}{ccccccccc}
\hline Entry & Light & PC 1 & DBMM & $\begin{array}{c}\text { Conv. } \\
(\%)\end{array}$ & $\begin{array}{c}M_{\mathrm{n}(\mathrm{GPC})} \\
(\mathrm{kDa})\end{array}$ & $\begin{array}{c}Ð \\
\left(M_{\mathrm{w}} / M_{\mathrm{n}}\right)\end{array}$ & $I^{*}(\%)$ & $S_{\mathrm{L}}(\%)$ \\
1 & - & - & - & 0 & - & - & - & - \\
2 & - & $\sqrt{ }$ & - & 0 & - & - & - & - \\
3 & - & - & $\sqrt{ }$ & 0 & - & - & - & - \\
4 & - & $\sqrt{ }$ & $\sqrt{ }$ & 0 & - & - & - & - \\
5 & $\sqrt{ }$ & - & - & 0 & - & - & - & - \\
6 & $\sqrt{ }$ & $\sqrt{ }$ & - & 0 & - & - & - & - \\
7 & $\sqrt{ }$ & - & $\sqrt{ }$ & 0 & - & - & - & - \\
\hline
\end{tabular}

${ }^{a}$ Polymerizations of [EtVCP]/[DBMM]/[1] (1000/10/1) were performed in $1.0 \mathrm{~mL}$ of anhydrous EtOAc at $60{ }^{\circ} \mathrm{C}$ for $12 \mathrm{~h}$, with $34 \mathrm{~W}$ Kessil blue LED. 


\subsection{Kinetic Study}

Table S7. Progress analysis for polymerization of EtVCP at $60{ }^{\circ} \mathrm{C}$ with blue $\mathrm{LED}^{a}$

\begin{tabular}{ccccccc}
\hline Entry & Time (h) & Conv. $(\boldsymbol{\%})$ & $\boldsymbol{M}_{\mathbf{n}}(\mathbf{k D a})$ & $\boldsymbol{D}\left(\boldsymbol{M}_{\mathbf{w}} / \boldsymbol{M}_{\mathbf{n}}\right)$ & $\boldsymbol{I}^{*}(\boldsymbol{\%})$ & $\boldsymbol{S}_{\mathbf{L}}(\boldsymbol{\%})$ \\
1 & 0.5 & 26 & 6.7 & 1.20 & 87 & 80 \\
2 & 1 & 49 & 10.9 & 1.31 & 98 & 68 \\
3 & 2 & 69 & 13.8 & 1.24 & 108 & 54 \\
4 & 3 & 86 & 19.8 & 1.21 & 94 & 45 \\
\hline
\end{tabular}

${ }^{a}$ The polymerization of $[\mathrm{EtVCP}] /[\mathrm{DBMM}] /[2](1000 / 10 / 1)$ was performed in $5.0 \mathrm{~mL}$ of EtOAc, with 34 w blue LED irradiation at $60^{\circ} \mathrm{C}$.

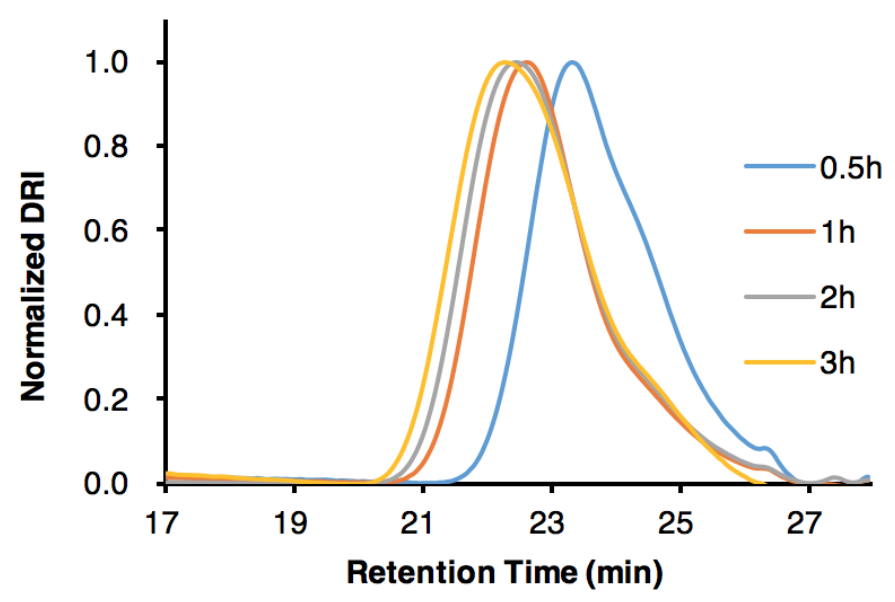

Figure S29. Overlay of GPC traces for poly(EtOAc) in Table S7. 


\subsection{Pulsed-Irradiation Experiment}

Table S8. Pulsed-irradiation experiment for polymerization of EtVCP at $60{ }^{\circ} \mathrm{C}$ with $34 \mathrm{~W}$ Kessil blue $\operatorname{LED}^{a}$

\begin{tabular}{ccccccc}
\hline Entry & Time $(\mathbf{h})$ & Conv. $(\boldsymbol{\%})$ & $\boldsymbol{M}_{\mathbf{n}}(\mathbf{k D a})$ & $\boldsymbol{D}\left(\boldsymbol{M}_{\mathbf{w}} / \boldsymbol{M}_{\mathbf{n}}\right)$ & $\boldsymbol{I}^{*}(\boldsymbol{\%})$ & $\boldsymbol{S}_{\mathbf{L}}(\boldsymbol{\%})$ \\
1 & 0.5 & 30 & 9.2 & 1.19 & 72 & 78 \\
2 & 1 & 29 & 9.1 & 1.20 & 71 & 78 \\
3 & 2 & 54 & 11.3 & 1.29 & 103 & 68 \\
4 & 3 & 55 & 11.2 & 1.31 & 106 & 68 \\
5 & 4 & 75 & 17.3 & 1.33 & 94 & 53 \\
7 & 8 & 78 & 17.1 & 1.41 & 98 & 52 \\
\hline
\end{tabular}

${ }^{a}$ The polymerization of $[\mathrm{EtVCP}] /[\mathrm{DBMM}] /[2](1000 / 10 / 1)$ was performed in $5.0 \mathrm{~mL}$ of EtOAc, with 34 W Kessil blue LED irradiation at $60{ }^{\circ} \mathrm{C}$.

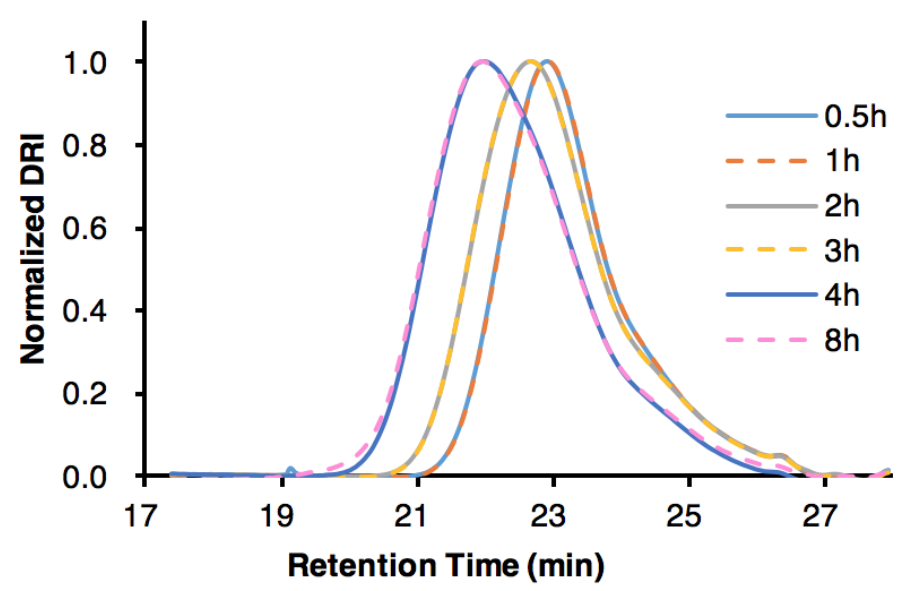

Figure S30. Overlay of GPC traces for poly(EtVCP) in Table S8. 


\subsection{Investigation of Chain-end Fidelity}

(a)
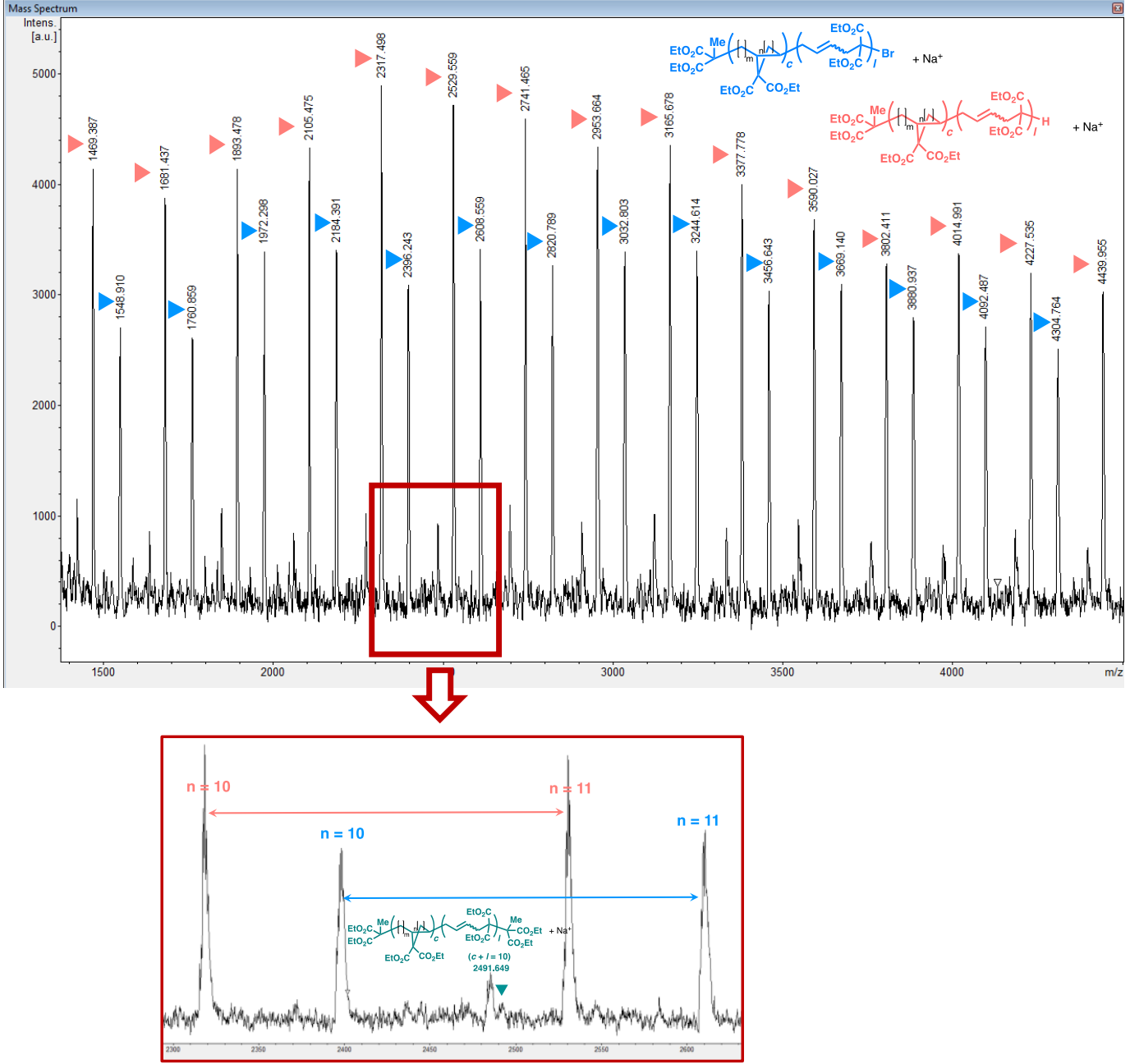

(b)

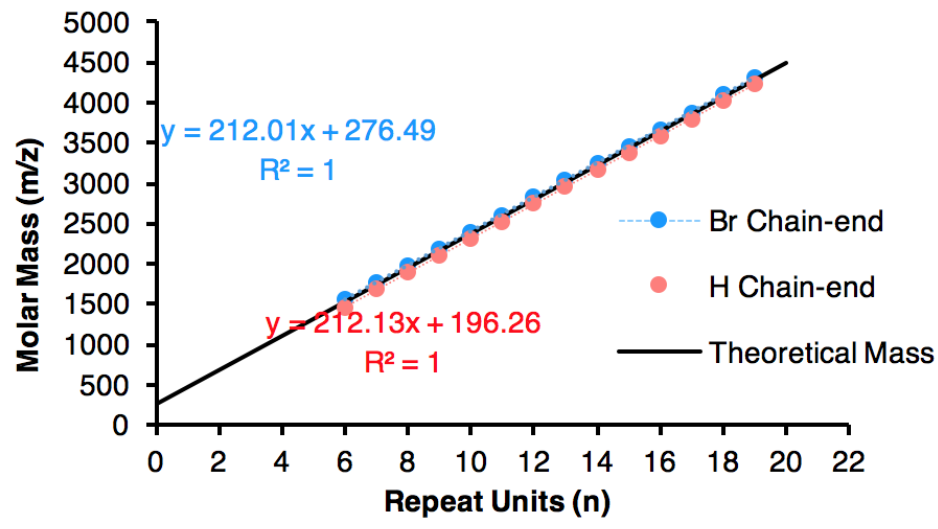

Figure S31. MALDI-TOF spectra of poly(EtVCP) $\left(13.8 \mathrm{kDa}, Ð=1.24, S_{\mathrm{L}}=54 \%\right.$, Table S7, entry 3). (a) Structural assignment. (b) Plots of $m / z$ vs number of EtVCP repeat units from the MALDI-TOF analysis. The slope of the linear fit represents the $\mathrm{m} / \mathrm{z}$ of the monomer unit (calcd. 212.11); the y-intercept indicates $\mathrm{Br}$ (blue, plus $\mathrm{Na}^{+}$, calcd. 274.99, 
observed 275.49) and $\mathrm{H}$ (red, plus $\mathrm{Na}^{+}$, calcd. 196.08, observed. 196.26) chain-end groups. Black line represents the theoretical $M_{\mathrm{n}}$ values for a polymer with terminal groups derived from the DBMM initiator. 


\subsection{Chain-Extension Experiment}

\subsubsection{Synthesis of $c$-poly $(\mathrm{EtVCP})$ macroinitiator}

$C$-poly(EtVCP) macroinitiator was synthesized according to General Procedure $\mathbf{C}$. $[\mathrm{EtVCP}] /[\mathrm{DBMM}] /[2]=1000: 10: 1,1.0 \mathrm{mmol}$ scale, in $5.0 \mathrm{~mL}$ of anhydrous EtOAc and with irradiation of Kessil $34 \mathrm{w}$ blue LED at $60{ }^{\circ} \mathrm{C}$. Combined 8 runs of such polymerization, after precipitating in hexane at $-78^{\circ} \mathrm{C}$, gave $1.38 \mathrm{~g}$ polymer $\left(81 \%\right.$ yield, $M_{\mathrm{n}}=22.9 \mathrm{kDa}, Ð$ $\left.=1.16, S_{\mathrm{L}}=15 \%\right) .{ }^{1} \mathbf{H}$ NMR $\left(400 \mathrm{MHz}, \mathrm{CDCl}_{3}\right) \delta 5.46$ - $5.25(\mathrm{br}, 0.33 \mathrm{H}), 4.45$ - 3.95 (br, $4.00 \mathrm{H}), 2.85-1.65(\mathrm{br}, 5.71 \mathrm{H}), 1.32-1.10(\mathrm{~m}, 6.00 \mathrm{H})$.

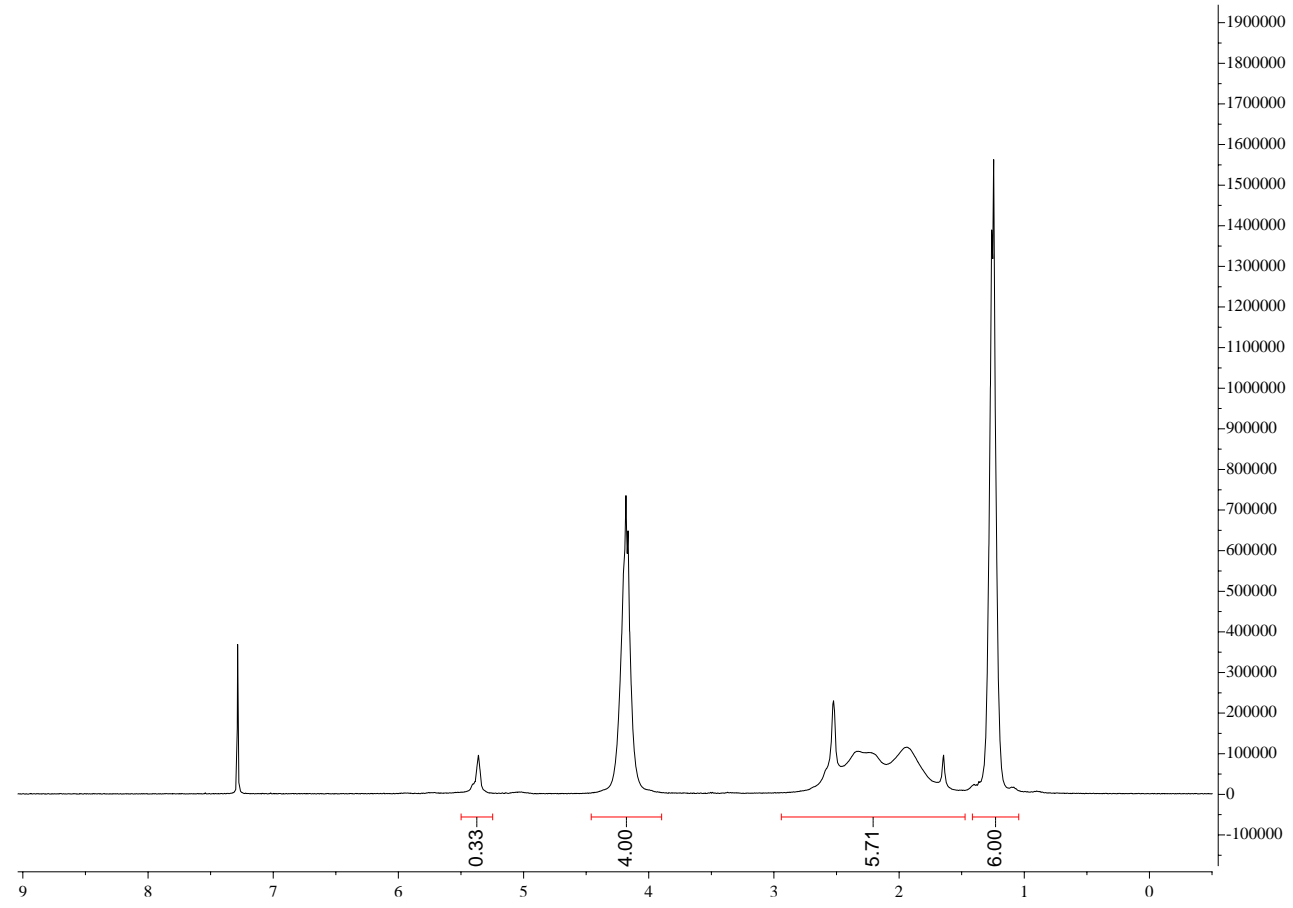

Figure S32. ${ }^{1} \mathrm{H}-\mathrm{NMR}$ spectrum of the c-poly $(\mathrm{EtVCP})$ macroinitiator $\left(M_{\mathrm{n}}=22.9 \mathrm{kDa}, Ð=\right.$ $\left.1.16, S_{\mathrm{L}}=15 \%\right)$. 


\subsubsection{Synthesis of chain-extended poly(EtVCP)}

An oven-dried $20 \mathrm{~mL}$ scintillation vial was charged with a magnetic stir bar, the isolated poly(EtVCP) macroinitiator $(229.0 \mathrm{mg}, 0.010 \mathrm{mmol})$ and PC $1(0.44 \mathrm{mg}, 0.0010$ mmol). The scintillation vial was transferred into a $\mathrm{N}_{2}$-filled glovebox where $1.0 \mathrm{~mL}$ of anhydrous EtOAc and EtVCP (212.2 mg, $1.0 \mathrm{mmol})$ were quickly added. The vial was then tightly capped and irradiated white LED while stirring in the glove box. After $12 \mathrm{~h}$, a 0.10 $\mathrm{mL}$ aliquot was taken and quenched by injecting into a vial containing $\sim 0.70 \mathrm{~mL} \mathrm{CDCl}_{3}$ with $250 \mathrm{ppm}$ butylated hydroxytoluene (BHT). This aliquot was then analyzed via ${ }^{1} \mathrm{H}$ NMR for conversion of monomer to polymer ( $46 \%$ conv. was achieved in this reaction). The aliquot was then dried under vacuum for direct analysis by GPC equipped with multiangle light scattering $\left(M_{\mathrm{n}}=29.3 \mathrm{kDa}, \nexists=1.17, I^{*}=112 \%, S_{\mathrm{L}}=75 \%\right) .{ }^{1} \mathrm{H} \mathbf{N M R}(400 \mathrm{MHz}$, $\left.\mathrm{CDCl}_{3}\right) \delta 5.45-5.20(\mathrm{br}, 0.50 \mathrm{H}), 4.45-3.95(\mathrm{br}, 4.00 \mathrm{H}), 2.85-1.65(\mathrm{br}, 5.51 \mathrm{H}), 1.32-$ $1.10(\mathrm{~m}, 6.00 \mathrm{H})$.

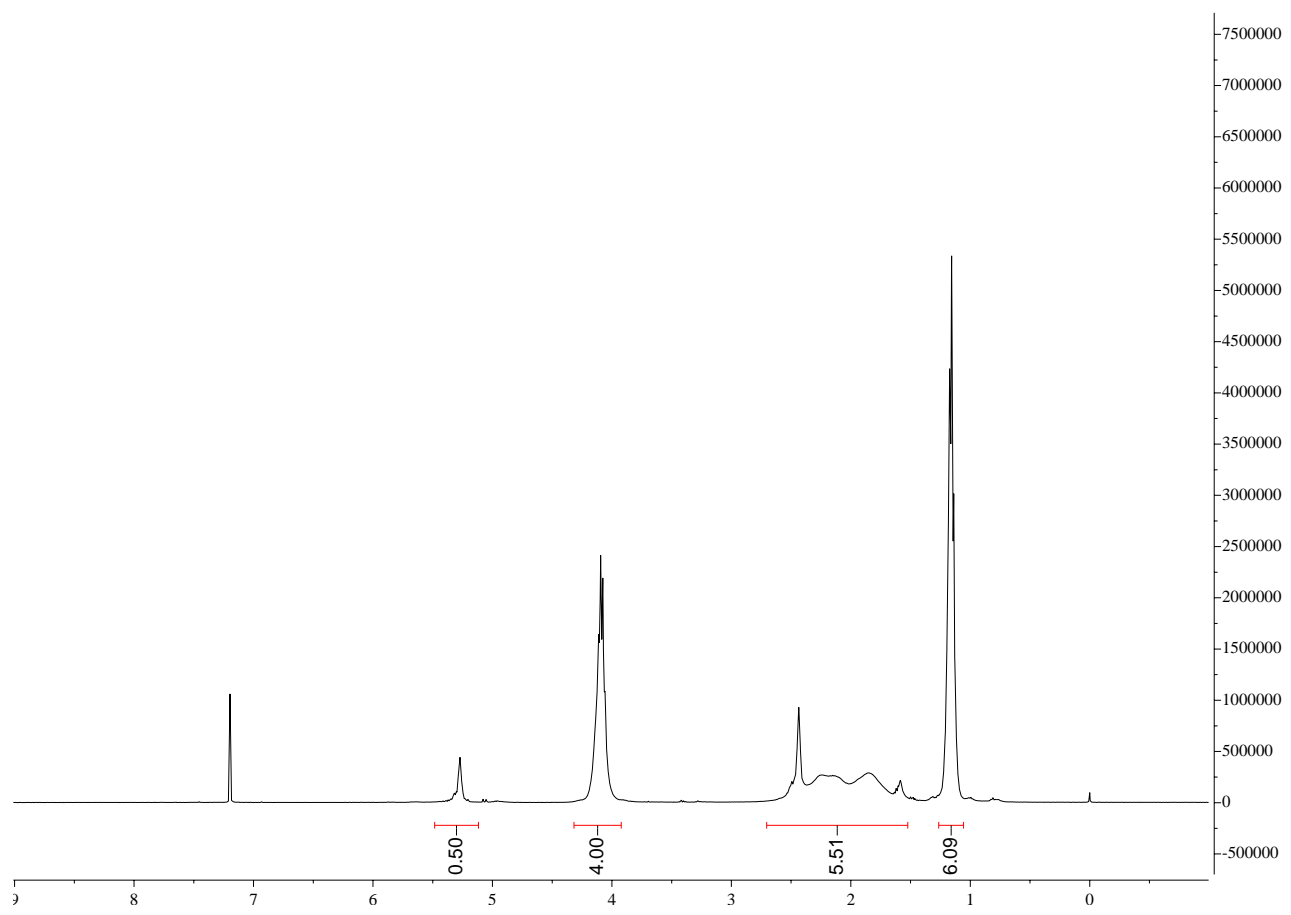

Figure S33. ${ }^{1} \mathrm{H}-\mathrm{NMR}$ of chain-extended $c$-poly $(\mathrm{EtVCP})\left(M_{\mathrm{n}}=29.3 \mathrm{kDa}, \nexists=1.17, S_{\mathrm{L}}=\right.$ $75 \%)$. 


\subsection{Investigation of Cyclobutyl Bromide Chain-end}

\subsubsection{Synthesis of diethyl 3-bromocyclobutane-1,1-dicarboxylate (DBCC)}

Under $\mathrm{N}_{2}$ atmosphere, a solution of diethyl 3-hydroxycyclobutane-1,1-dicarboxylate ${ }^{5}$ (649 mg, $3.0 \mathrm{mmol}$ ) and $\mathrm{PPh}_{3}(3.54 \mathrm{~g}, 13.5 \mathrm{mmol})$ in $20 \mathrm{~mL}$ of anhydrous $\mathrm{CH}_{2} \mathrm{Cl}_{2}$ was added to an oven-dried $100 \mathrm{~mL}$ Schlenk flask. The flask was then cooled down to $0{ }^{\circ} \mathrm{C}$ and a solution of $\mathrm{CBr}_{4}(3.98 \mathrm{~g}, 12.0 \mathrm{mmol})$ was added dropwise over $10 \mathrm{~min}$. The reaction was then allowed to warm to room temperature and stir for $24 \mathrm{~h}$. The reaction was quenched by the addition of $\mathrm{H}_{2} \mathrm{O}(2.0 \mathrm{~mL})$, diluted with $\mathrm{Et}_{2} \mathrm{O}(100 \mathrm{~mL})$ and filtered. The filtrate was concentrated in vacuum and the crude product was purified by silica gel chromatography using hexane to hexane/EtOAc (1:20) as the eluents. Colorless oil, $317 \mathrm{mg}$, 38\% yield. ${ }^{1} \mathbf{H}$ NMR $\left(400 \mathrm{MHz}, \mathrm{CDCl}_{3}\right) \delta 4.58-4.47(\mathrm{~m}, 1 \mathrm{H}), 4.22$ (qd, J = 7.1, 2.6 Hz, 4H), $3.20-3.12$ $(\mathrm{m}, 2 \mathrm{H}), 3.03-2.93(\mathrm{~m}, 2 \mathrm{H}), 1.26(\mathrm{td}, J=7.1,2.6 \mathrm{~Hz}, 6 \mathrm{H}) .{ }^{13} \mathbf{C ~ N M R}\left(100 \mathrm{MHz}, \mathrm{CDCl}_{3}\right)$ $\delta 170.8,169.8,62.0,61.8,50.8,41.3,35.6,14.0,14.0$. Data matches the literature.

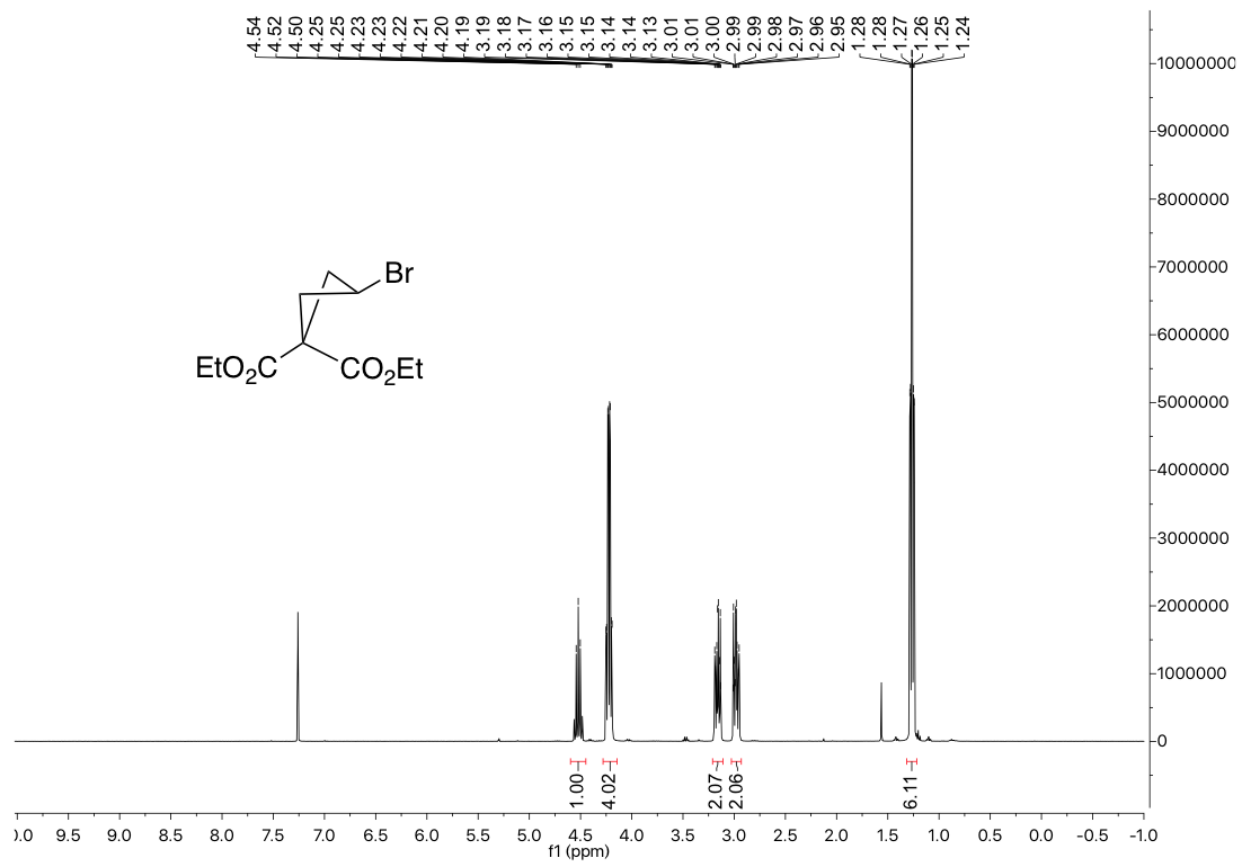

Figure S34. ${ }^{1} \mathrm{H}-\mathrm{NMR}$ spectrum of $\mathrm{DBCC}$ in $\mathrm{CDCl}_{3}$. 


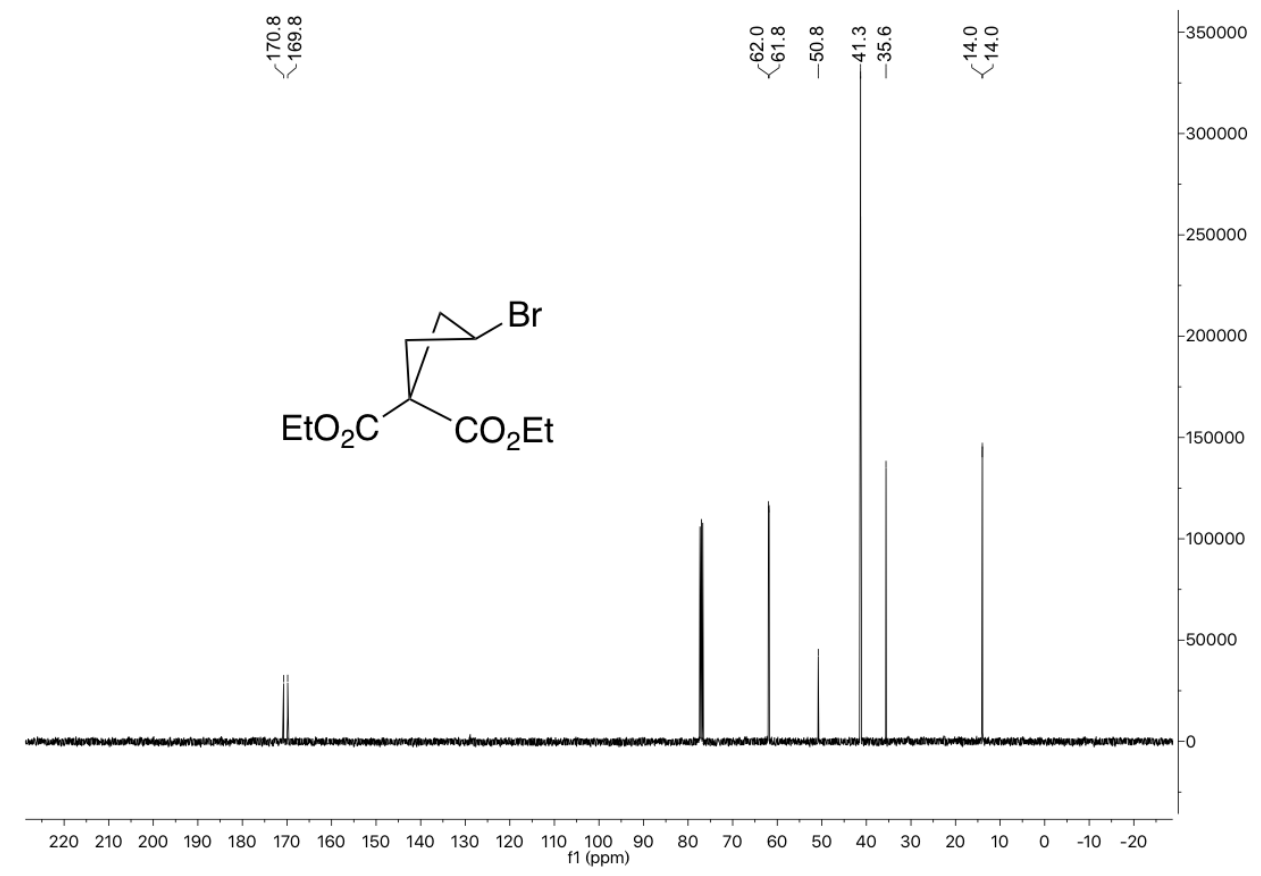

Figure S35. ${ }^{13} \mathrm{C}-\mathrm{NMR}$ spectrum of $\mathrm{DBCC}$ in $\mathrm{CDCl}_{3}$.

\subsubsection{Cyclic Voltammetry}

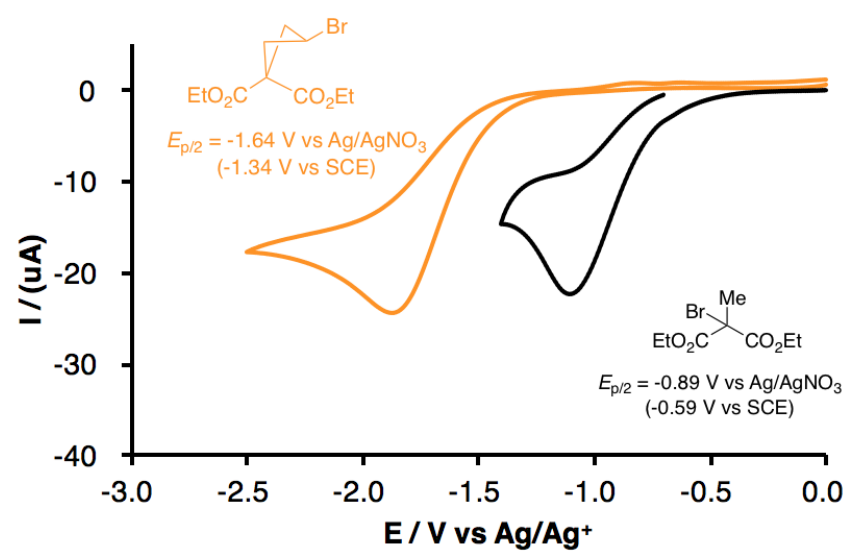

Figure S36. Cyclic Voltammetry of DBMM (black, $-0.59 \mathrm{~V}$ vs SCE) and DBCC (oragne, $-1.34 \mathrm{~V}$ vs SCE). The concentrations of each analyte were $0.05 \mathrm{M}$ in $\mathrm{MeCN}$ (see Methods section for more details) 


\subsubsection{Emission Quenching Experiment}

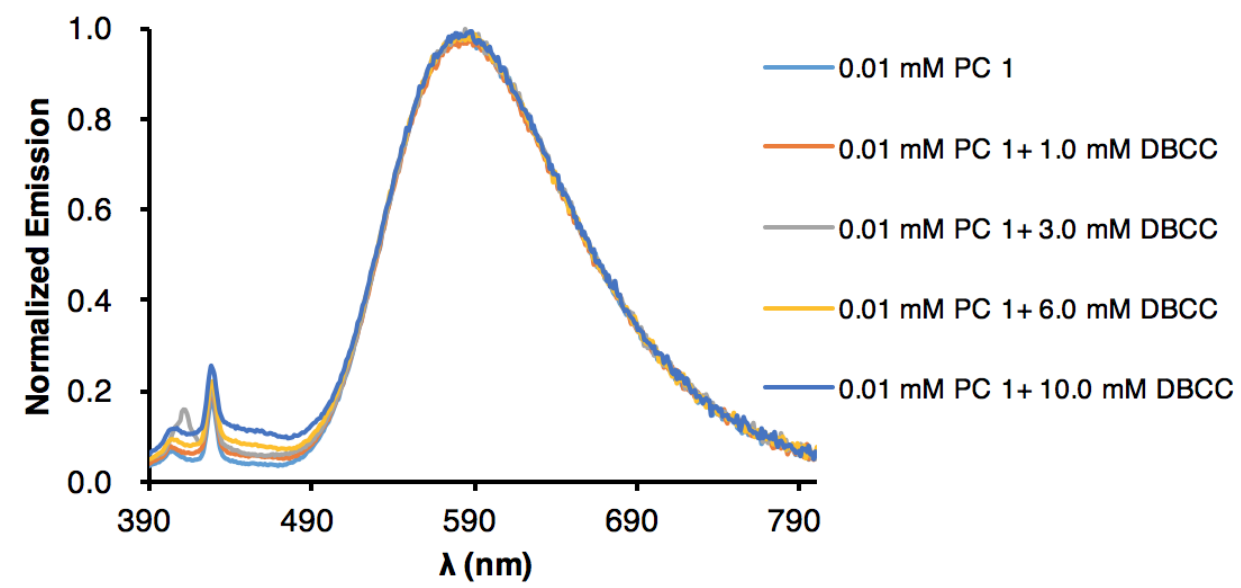

Figure S37. Emission quenching of PC 1 by DBCC in EtOAc $\left(\lambda_{\mathrm{ex}}=380 \mathrm{~nm}\right)$.

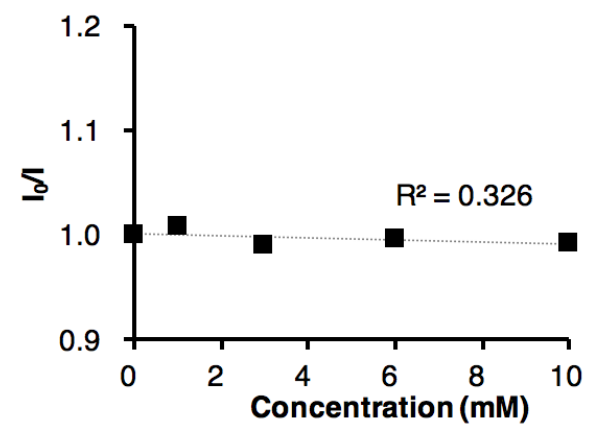

Figure S38. Stern-Volmer plots for the emission quenching experiments of PC 1 by DBCC in EtOAc.

\subsubsection{Polymerization using DBCC as the initiator}

Table S9. Results of polymerizations using DBCC as the initiator ${ }^{a}$

\begin{tabular}{cccccccccc}
\hline Entry & $\begin{array}{c}\text { Conc. } \\
(\mathbf{m o l} / \mathbf{L})\end{array}$ & $\begin{array}{c}\mathbf{T} \\
\left({ }^{\mathbf{C}} \mathbf{C}\right)\end{array}$ & $\mathbf{L E D}$ & $\begin{array}{c}\text { Time } \\
(\mathbf{h})\end{array}$ & $\begin{array}{c}\text { Conv. } \\
(\boldsymbol{\%})\end{array}$ & $\begin{array}{c}\boldsymbol{M}_{\mathbf{n}} \\
(\mathbf{k D a})\end{array}$ & $\begin{array}{c}\boldsymbol{D} \\
\left(\boldsymbol{M}_{\mathbf{w}} / \boldsymbol{M}_{\mathbf{n}}\right)\end{array}$ & $\begin{array}{c}\boldsymbol{I}^{*} \\
(\boldsymbol{\%})\end{array}$ & $\begin{array}{c}\boldsymbol{S}_{\mathbf{L}} \\
(\boldsymbol{\%})\end{array}$ \\
2 & 0.833 & 28 & white & 12 & 3 & - & - & - & - \\
3 & 0.192 & 28 & white & 12 & 0 & - & - & - & - \\
\hline
\end{tabular}

${ }^{a}$ The polymerization of [EtVCP]/[DBCC]/[1] (1000/10/1) was performed in EtOAc. 


\section{Post-Polymerization Modification of High Linear $(l)$ Polymer Chain}

\subsection{General Experimental Procedure}

Poly(EtVCP) with high linear repeat units was synthesized and purified according to General Procedure B. Combined 8 runs of 1.0 mmol-scale polymerization gave $1.48 \mathrm{~g}$ polymer ( $87 \%$ yield, $\left.M_{\mathrm{n}}=21.1 \mathrm{kDa}, \nexists=1.19, S_{\mathrm{L}}=95 \%\right)$.

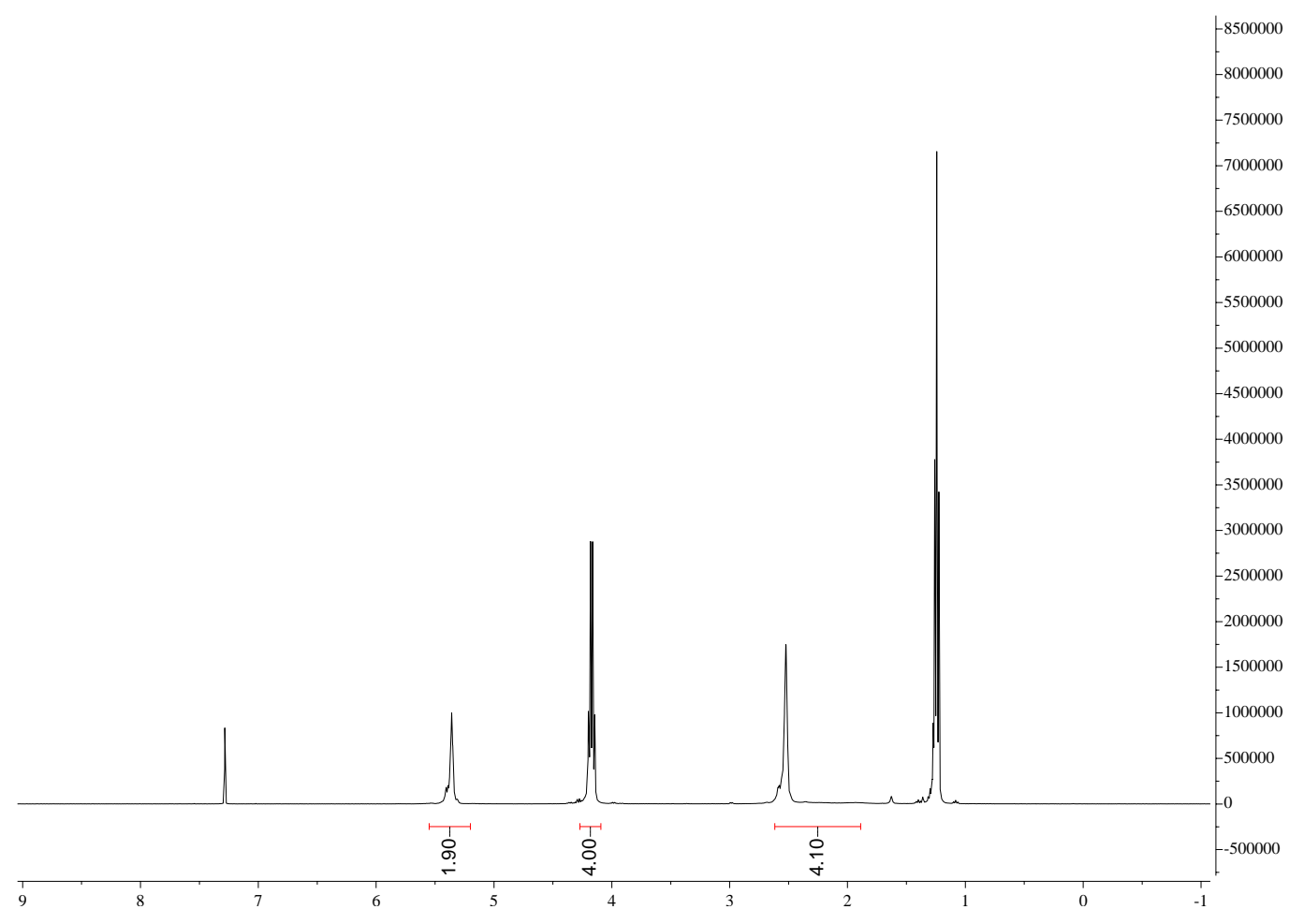

Figure S39. ${ }^{1} \mathrm{H}-\mathrm{NMR}$ Spectrum of poly $(\mathrm{EtVCP})\left(M_{\mathrm{n}}=21.1 \mathrm{kDa}, \oslash=1.19, \mathrm{~S}_{\mathrm{L}}=95 \%\right)$

General Procedure D. In the $\mathrm{N}_{2}$-filled glovebox, poly(EtVCP) (211mg), photocatalyst $2(0.434 \mathrm{mg})$ and $\mathrm{x}(\mathrm{x}=1.0$ or 5.0$) \mathrm{mL}$ of anhydrous EtOAc were sequentially added to an oven-dried $20 \mathrm{~mL}$ scintillation vial (with irradiation of white LED while stirring in the $\mathrm{N}_{2}$-filled glovebox; the temperature was about $28^{\circ} \mathrm{C}$ with a cooling fan, and was about $60{ }^{\circ} \mathrm{C}$ without a cooling fan) or an oven-dried $25 \mathrm{~mL}$ sealed tube with a PTFE screw cap (in a $60{ }^{\circ} \mathrm{C}$ preheated oil bath with $34 \mathrm{~W}$ Kessil blue LED). See Figure S27 for the setup. After $12 \mathrm{~h}$, a $0.10 \mathrm{~mL}$ aliquot was taken and quenched by injecting into a vial containing $\sim 0.70 \mathrm{~mL} \mathrm{CDCl}_{3}$ with $250 \mathrm{ppm}$ butylated hydroxytoluene (BHT). This aliquot was analyzed via ${ }^{1} \mathrm{H}$ NMR to determine the $S_{\mathrm{L}}$, then dried under vacuum for direct analysis by GPC equipped with multi-angle light scattering for $M_{\mathrm{n}}$ and $\oslash$. 


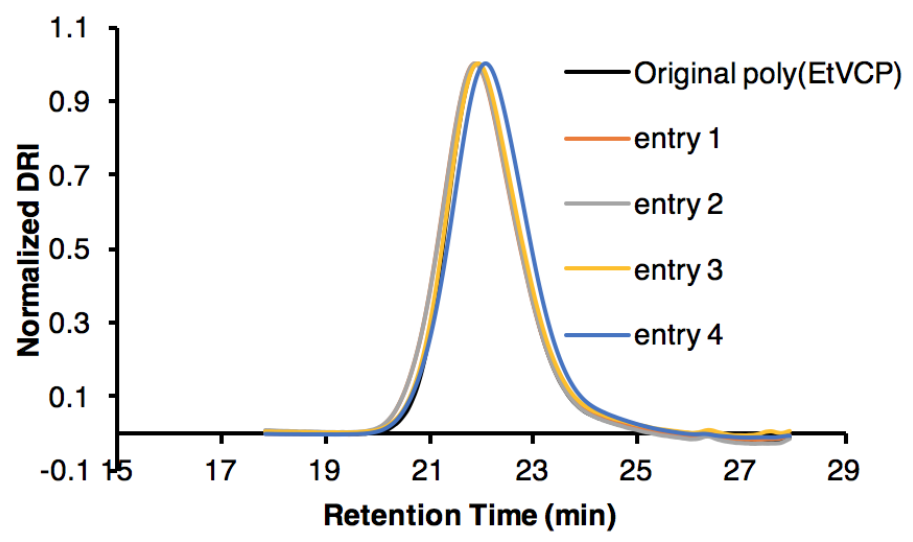

Figure S40. Overlay of GPC traces corresponding to Table 3. 


\subsection{Comparison of Poly(EtVCP) from Free Radical Polymerization, Photoredox}

\section{Polymerization and Polymer-Chain Modification}

Free radical polymerization. In a $\mathrm{N}_{2}$-filled glovebox, EtVCP $(637 \mathrm{mg}, 3.0 \mathrm{mmol}$, 1.0 equiv), benzoyl peroxide (BPO, $21.8 \mathrm{mg}, 0.09 \mathrm{mmol}, 0.03$ equiv) were sequentially added into an oven-dried $25 \mathrm{~mL}$ tube (with PTFE screw cap) equipped with a magnetic stir bar. The tube was then tightly capped and moved out of glovebox. The tube was placed into $80{ }^{\circ} \mathrm{C}$ preheated oil bath and vigorously stirred for $24 \mathrm{~h}$. After cooling to room temperature, $20.0 \mathrm{~mL}$ THF was added to dissolve the resulted polymer. Insoluble polymer was filtered off and the filtrate was concentrated in vacuum. The residue was re-dissolved in $3.0 \mathrm{~mL}$ of EtOAc, then the resulted solution was slowly added into $50.0 \mathrm{~mL}$ of hexane while stirring at $-78^{\circ} \mathrm{C}$. The precipitated polymer was collected, washed with cold hexane $(10.0 \mathrm{~mL} \times 2)$ and dried overnight under vacuum at $50{ }^{\circ} \mathrm{C}$ to a constant weight. $312 \mathrm{mg}$, $49 \%$ yield. $M_{\mathrm{n}}=25.1 \mathrm{kDa}, Ð=3.8, S_{\mathrm{L}}=30 \%$.

Photoredox polymerization. To an oven-dried $20 \mathrm{~mL}$ scintillation vial charged with PC 2 (0.434 mg, $0.001 \mathrm{mmol}, 0.0010$ equiv), EtVCP (212.2 mg, $1.0 \mathrm{mmol}, 1.0$ equiv), 5.0 $\mathrm{mL}$ of anhydrous EtOAc, and $100 \mathrm{uL}$ of $0.10 \mathrm{M} \mathrm{DBMM}$ stock solution in EtOAc were sequentially added. The vial was then tightly capped and placed under white LED irradiation while stirring in the glove box for $12 \mathrm{~h}$ (Figure S1). No cooling fan was used that the polymerization temperature was about $60{ }^{\circ} \mathrm{C}$. Combined 8 runs of such polymerization was concentrated to about $5.0 \mathrm{~mL}$, which was then added into $80.0 \mathrm{~mL}$ of hexane while stirring at $-78{ }^{\circ} \mathrm{C}$. The precipitated polymer was collected by vacuum filtration, washed with cold hexane $(10.0 \mathrm{~mL} \times 2)$ and dried overnight under vacuum at $50{ }^{\circ} \mathrm{C}$ to a constant weight. $1.41 \mathrm{~g}, 83 \%$ yield, $M_{\mathrm{n}}=21.1 \mathrm{kDa}, Ð=1.23, S_{\mathrm{L}}=40 \%$.

Polymer-Chain Modification. See Table 3, entry 4. $M_{\mathrm{n}}=35.2 \mathrm{kDa}, Đ=1.17, S_{\mathrm{L}}=$ $34 \%$. 


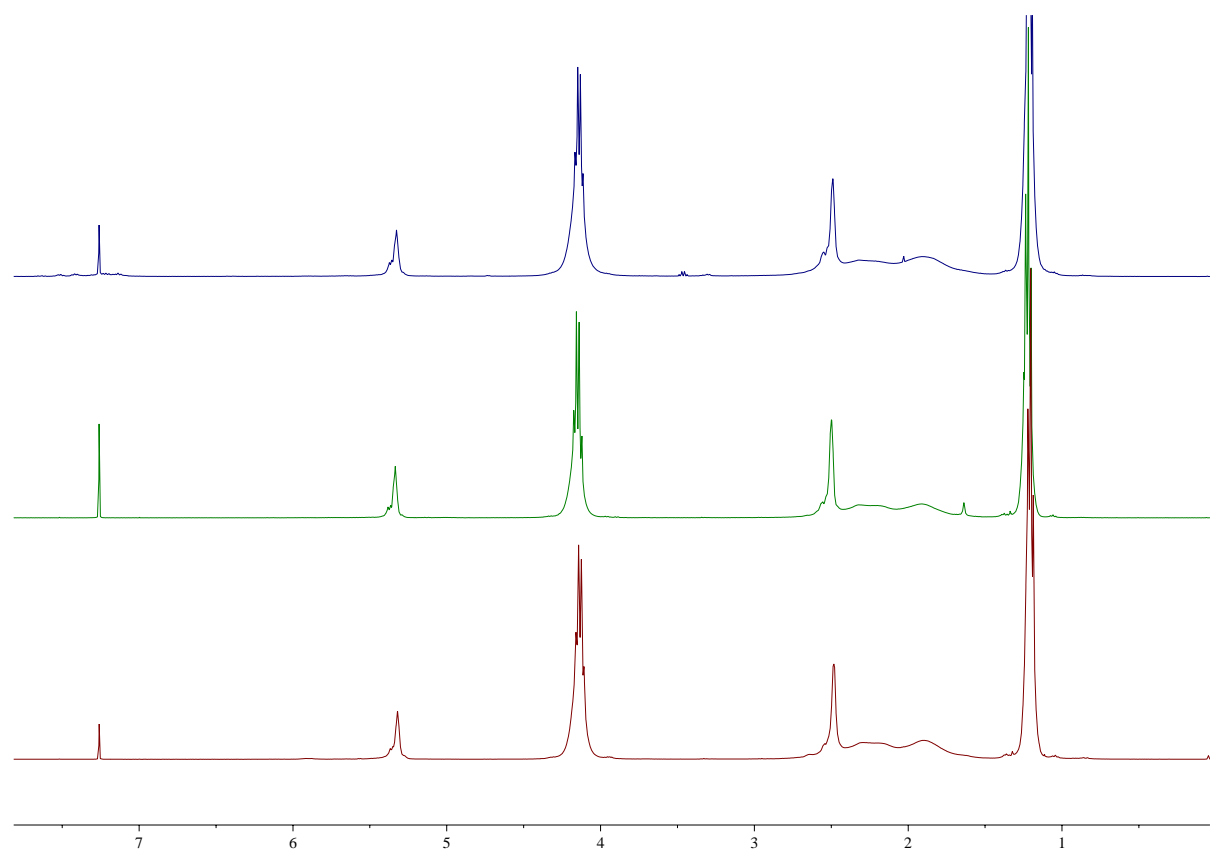

Figure S41. ${ }^{1} \mathrm{H}-\mathrm{NMR}$ spectra of poly(EtVCP) synthesized from free radical polymerization (top), photoredox polymerization in this work (middle), and polymer-chain modification (bottom).

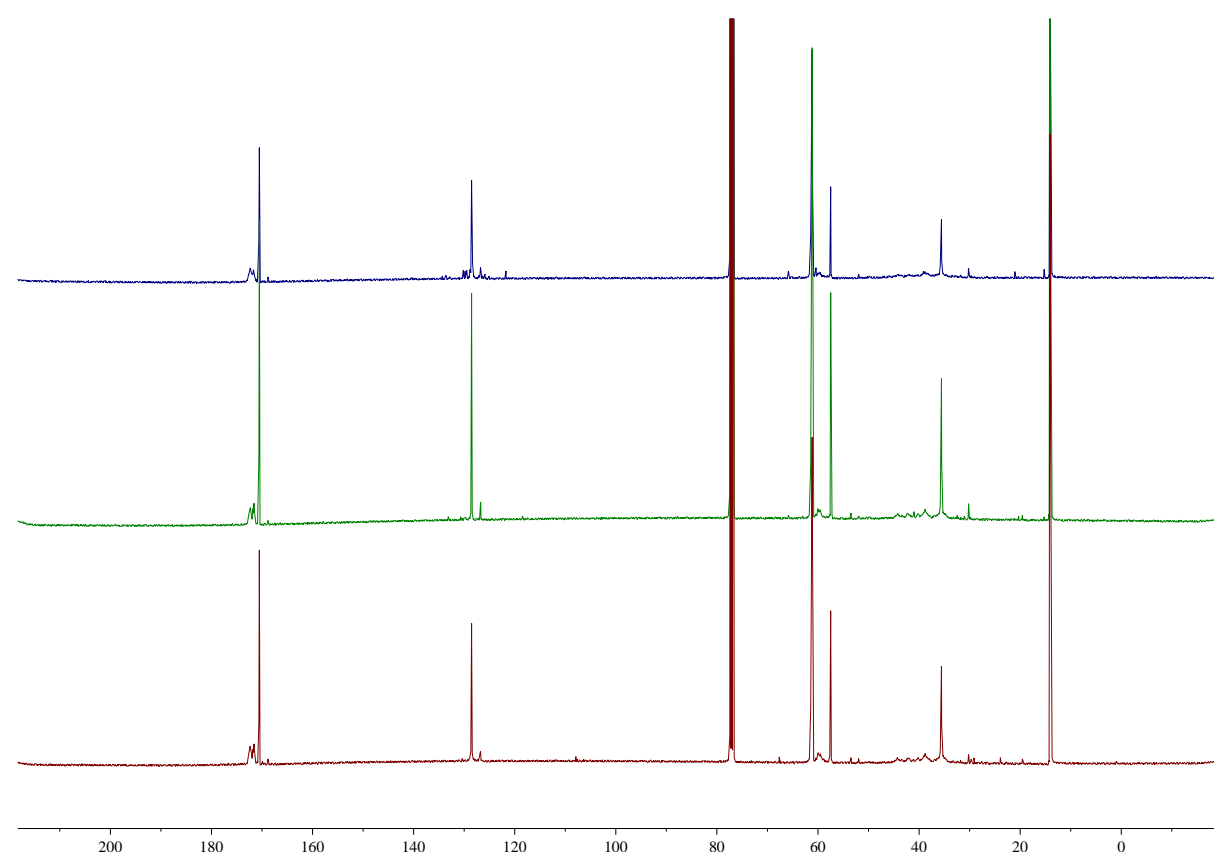

Figure S42. ${ }^{13} \mathrm{C}-\mathrm{NMR}$ spectra of poly(EtVCP) synthesized from free radical polymerization (top), photoredox polymerization in this work (middle), and polymer-chain modification (bottom). 

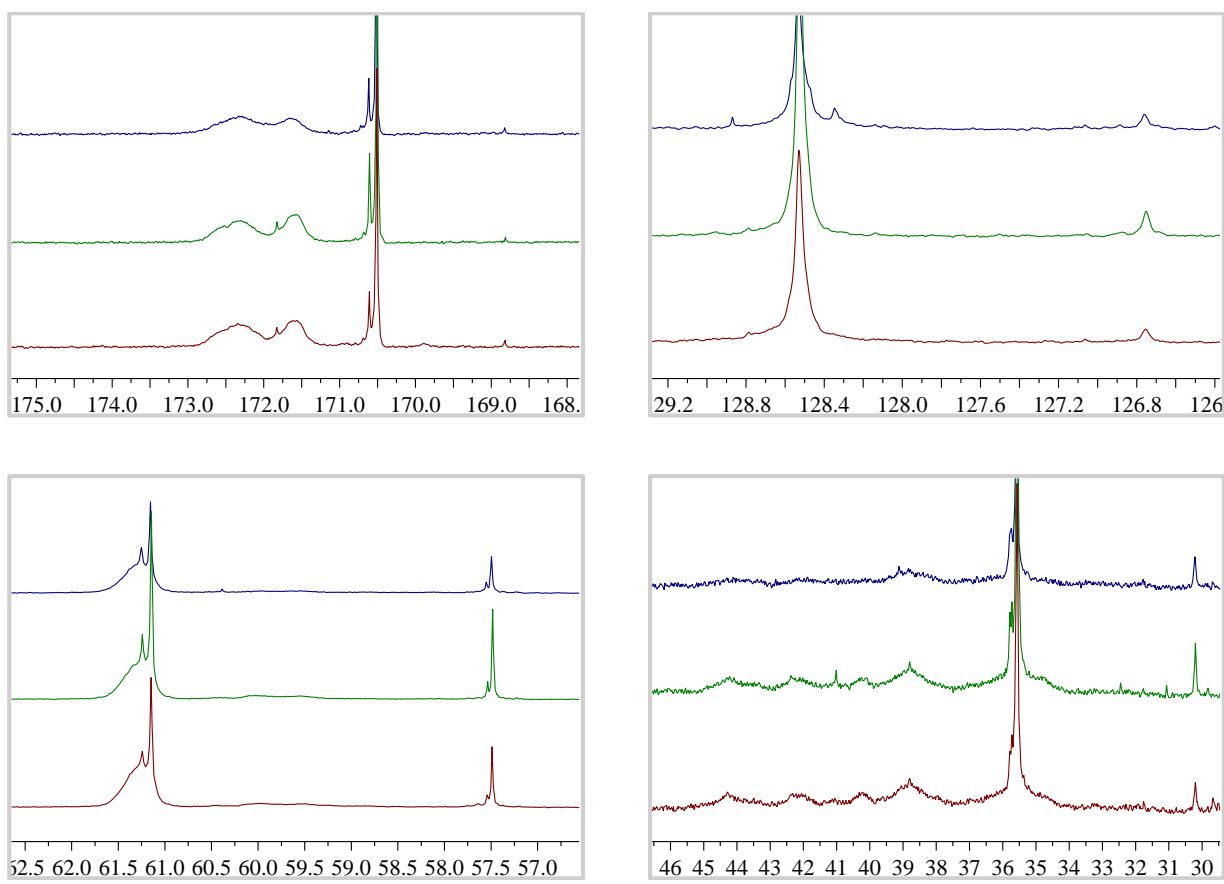

Figure S43. Zoomed ${ }^{13} \mathrm{H}-\mathrm{NMR}$ spectra of poly(EtVCP) synthesized from free radical polymerization (top), photoredox polymerization in this work (middle), and polymer-chain modification (bottom). 


\subsection{Model Reaction Mimicking Polymer-Chain Modification}

\subsubsection{Synthesis of model molecule}
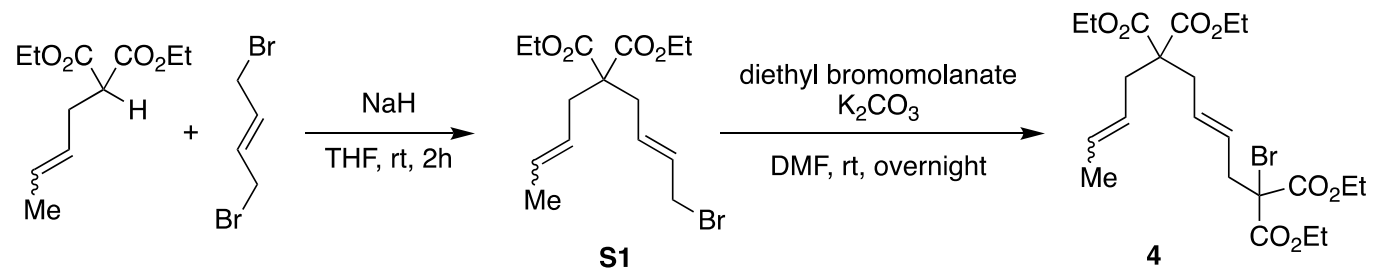

To a suspension of trans-1,4-dibromo-2-butene (1.07 g, $5.0 \mathrm{mmol}, 1.0$ equiv) and $60 \%$ $\mathrm{NaH}$ (200 mg, $5.0 \mathrm{mmol}, 1.0$ equiv) in $20.0 \mathrm{~mL}$ of anhydrous THF, diethyl 2-(but-2-en-1yl)malonate $(E / Z 6: 1)^{6}$ was added dropwise over $10 \mathrm{~min}$. The mixture was then vigorously stirred at room temperature for $2 \mathrm{~h}$. The reaction was carefully quenched by slow addition of sat. $\mathrm{NH}_{4} \mathrm{Cl}$, extracted with ether three times. The combined organic layer was washed with $\mathrm{H}_{2} \mathrm{O}$ and brine, dried over anhydrous $\mathrm{Na}_{2} \mathrm{SO}_{4}$ and concentrated in vacuum. The crude product $\mathbf{S 1}$ was re-dissolved in $15.0 \mathrm{~mL}$ of anhydrous $\mathrm{DMF}$, then $\mathrm{K}_{2} \mathrm{CO}_{3}(691 \mathrm{mg}, 5.0$ mmol, 1.0 equiv) and diethyl bromomalonate $(1.20 \mathrm{~g}, 5.0 \mathrm{mmol}, 1.0$ equiv) were sequentially added. The above mixture was vigorously stirred for $12 \mathrm{~h}$, then quenched by addition of sat. $\mathrm{NH}_{4} \mathrm{Cl}$, extracted with ether three times. The combined organic layer was washed with $\mathrm{H}_{2} \mathrm{O}$ and brine, dried over anhydrous $\mathrm{Na}_{2} \mathrm{SO}_{4}$ and concentrated in vacuuo. The residue was subjected to silica gel flash column chromatography using hexane/EtOAc (20:1 to 10:1) as the eluent to give the final product 4 as a colorless oil. (934 mg, 6:1 inseparable mixture of $E / Z$ isomers, $37 \%$ yield for two steps). ${ }^{1} \mathrm{H} \mathrm{NMR}\left(400 \mathrm{MHz}, \mathrm{CDCl}_{3}\right.$ ) $\delta 5.69-5.36(\mathrm{~m}, 3 \mathrm{H}), 5.22(\mathrm{dddt}, J=15.0,7.5,5.8,1.8 \mathrm{~Hz}, 1 \mathrm{H}), 4.26(\mathrm{q}, J=7.1 \mathrm{~Hz}, 4 \mathrm{H})$, $4.16(\mathrm{q}, J=7.1 \mathrm{~Hz}, 4 \mathrm{H}), 2.97(\mathrm{~d}, J=6.5 \mathrm{~Hz}, 2 \mathrm{H}), 2.64-2.48(\mathrm{~m}, 3 \mathrm{H}), 1.67-1.57(\mathrm{~m}, 3 \mathrm{H})$, $1.28(\mathrm{t}, J=7.1 \mathrm{~Hz}, 6 \mathrm{H}), 1.23(\mathrm{t}, J=7.1 \mathrm{~Hz}, 6 \mathrm{H}) .{ }^{13} \mathrm{C} \mathrm{NMR}\left(100 \mathrm{MHz}, \mathrm{CDCl}_{3}\right) \delta 13 \mathrm{C} \mathrm{NMR}$ (101 MHz, CDCl3) $\delta 170.9$ (minor) 170.8, 166.5, 130.2 (minor), 130.1, 130.0, 127.9 (minor), 127.4, 124.5, 123.5 (minor), 63.1, 62.3, 62.2 (minor), 61.3 (minor), 61.2, 57.5, 57.4 (minor), 41.5 (minor), 41.4, 35.5, 35.4, 29.6 (minor), 18.0, 14.1, 14.0 (minor), 13.9, 13.1 (minor). DART-TOF MS: calcd. for $\left[\mathrm{M}+\mathrm{H}^{+}\right]$505.1437, found 505.1440. 


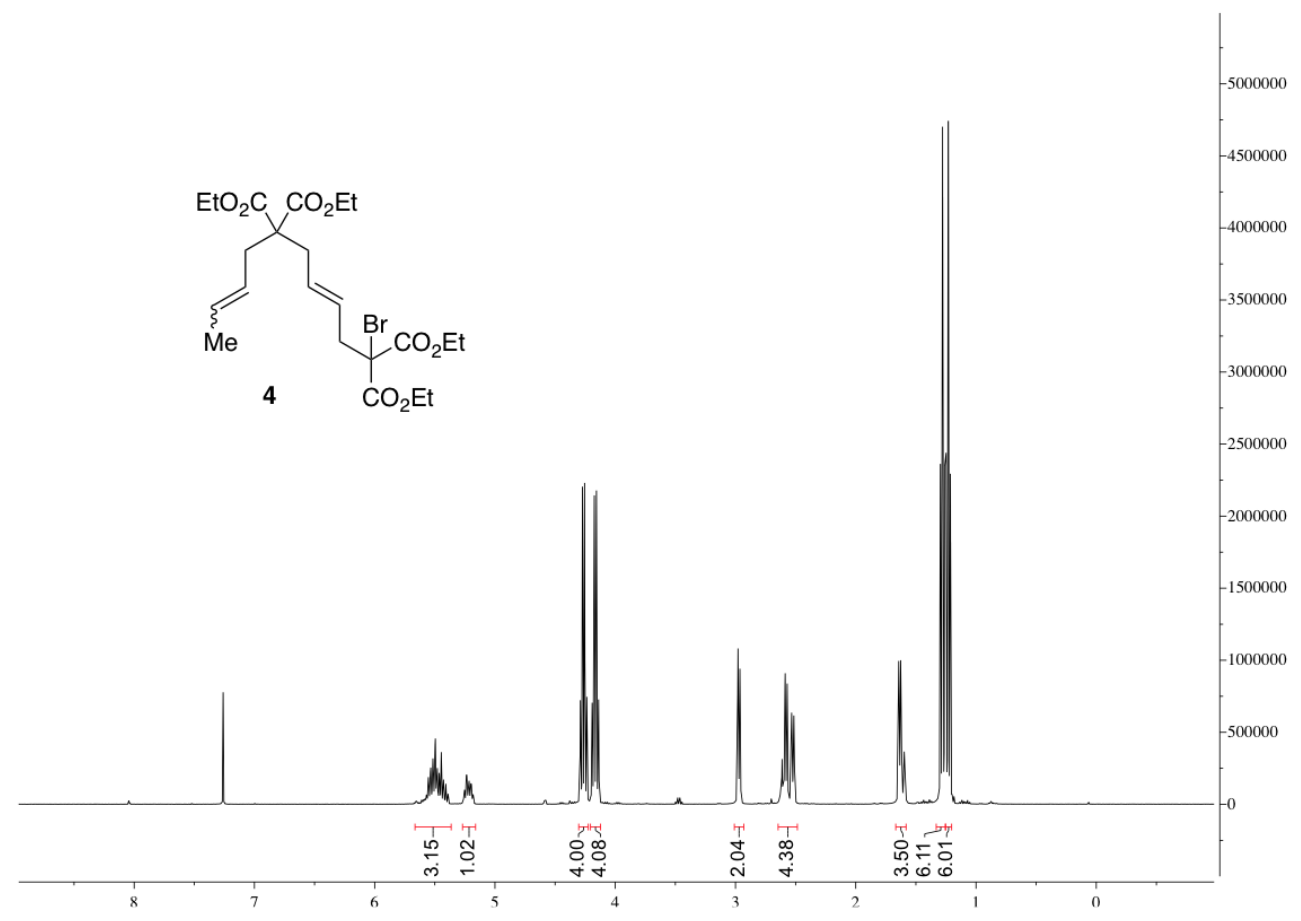

Figure S44. ${ }^{1} \mathrm{H}-\mathrm{NMR}$ spectrum of model molecule 4

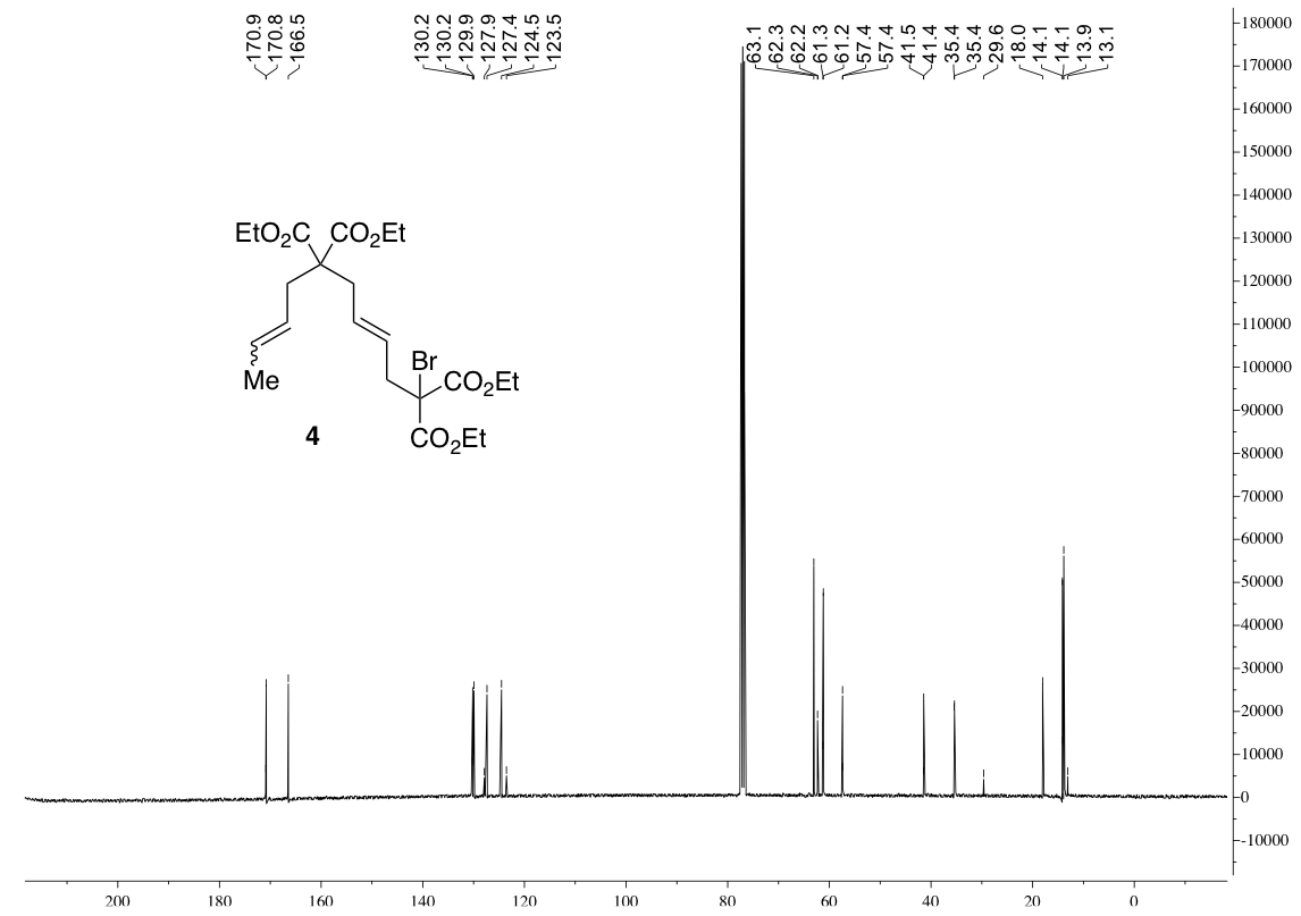

Figure S45. ${ }^{13} \mathrm{C}-\mathrm{NMR}$ spectrum of model molecule 4 


\subsubsection{Results of model reaction}

In the $\mathrm{N}_{2}$-filled glovebox, 4 (101 mg, $0.20 \mathrm{mmol}, 1.0$ equiv), photocatalyst $2(0.87 \mathrm{mg}$, $0.0020 \mathrm{mmol}, 0.010$ equiv), and $1.0 \mathrm{~mL}$ of anhydrous EtOAc were sequentially added to an oven-dried $25 \mathrm{~mL}$ tube (with PTFE screw cap) equipped with a magnet stir bar. The tube was then sealed, moved out of glovebox, and placed into a $60{ }^{\circ} \mathrm{C}$ preheat oil bath with $34 \mathrm{~W}$ Kessil blue LED (see Figure S27 for the reaction setup). After 12h, all volatiles were removed, and the residue was purified by silica gel flash column chromatography (hexane/ EtOAc 20:1 to 10:1). $91.3 \mathrm{mg}$ starting material was recovered (90\% yield), which was eventually found to be a 6:1 mixture of $E / Z$ isomers at $C 8$ and 5.2:1 mixture of $E / Z$ isomers at $\mathrm{C} 3\left(\mathbf{4}^{\prime}\right)$.

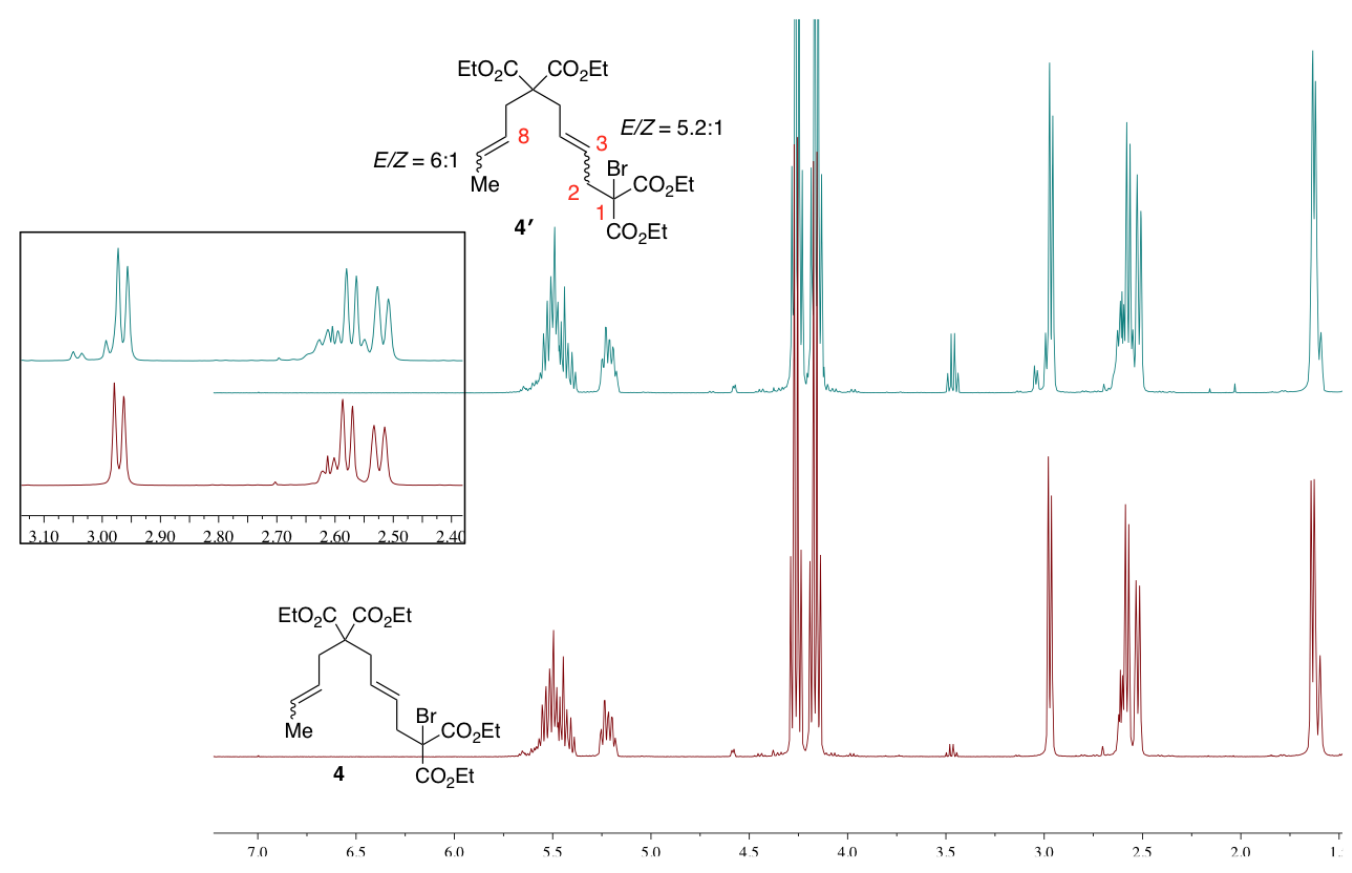

Figure S46. Comparison of ${ }^{1} \mathrm{H}$ NMR of 4 (bottom) and recovered 4' (top) 


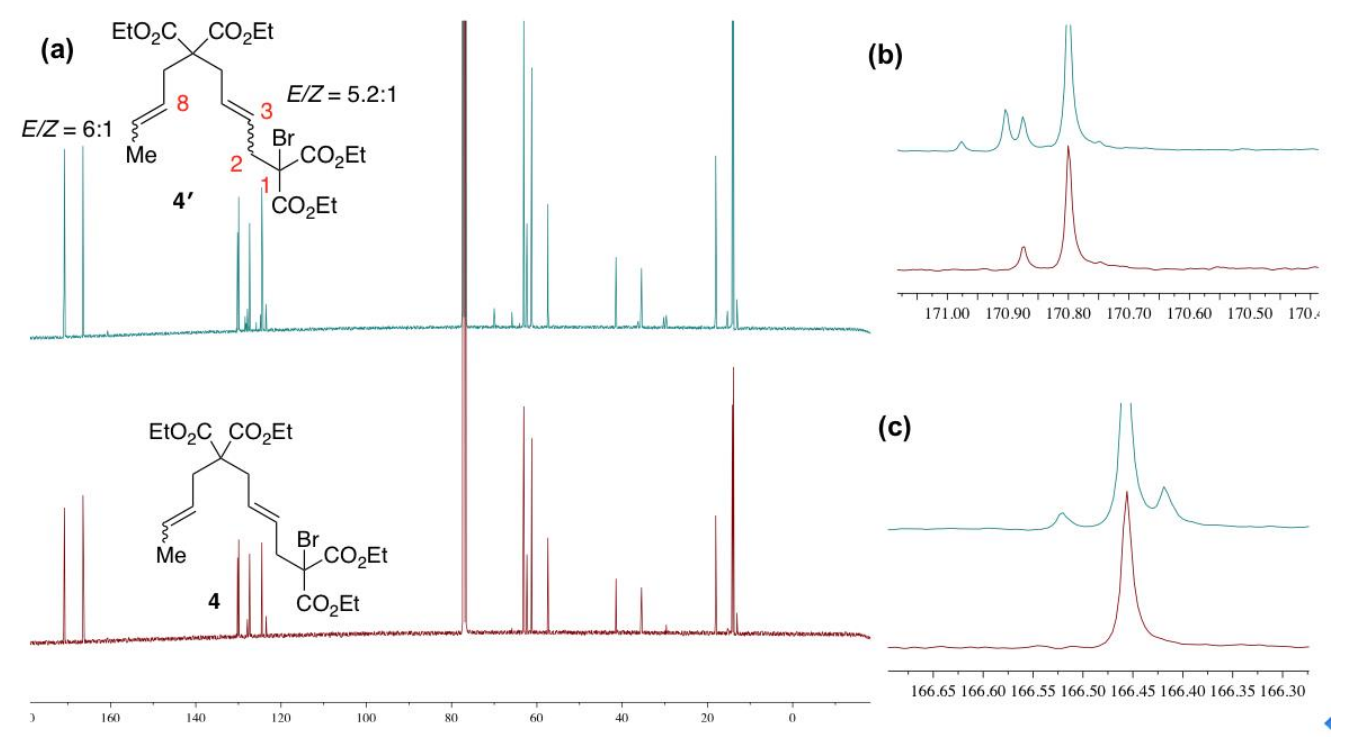

Figure S47. Comparison of ${ }^{13} \mathrm{C}$ NMR of 4 (red) and $\mathbf{4}^{\prime}$ (green). (a) whole ${ }^{13} \mathrm{C}$ NMR spectra; (b) zoomed spectra at $170 \mathrm{ppm}$; (c) zoomed spectra at $166 \mathrm{ppm}$.

Moreover, $5.2 \mathrm{mg}$ products were isolated (5\% yield). The ${ }^{1} \mathrm{H}-\mathrm{NMR}$ spectrum indicated that the cyclization indeed occurred. However, structural analysis based on the ${ }^{1} \mathrm{H}$-NMR spectrum (Figure S48) is difficult because that cyclized products may have several different chemical structures, and each of them are mixtures of up to 8 diastereomers.

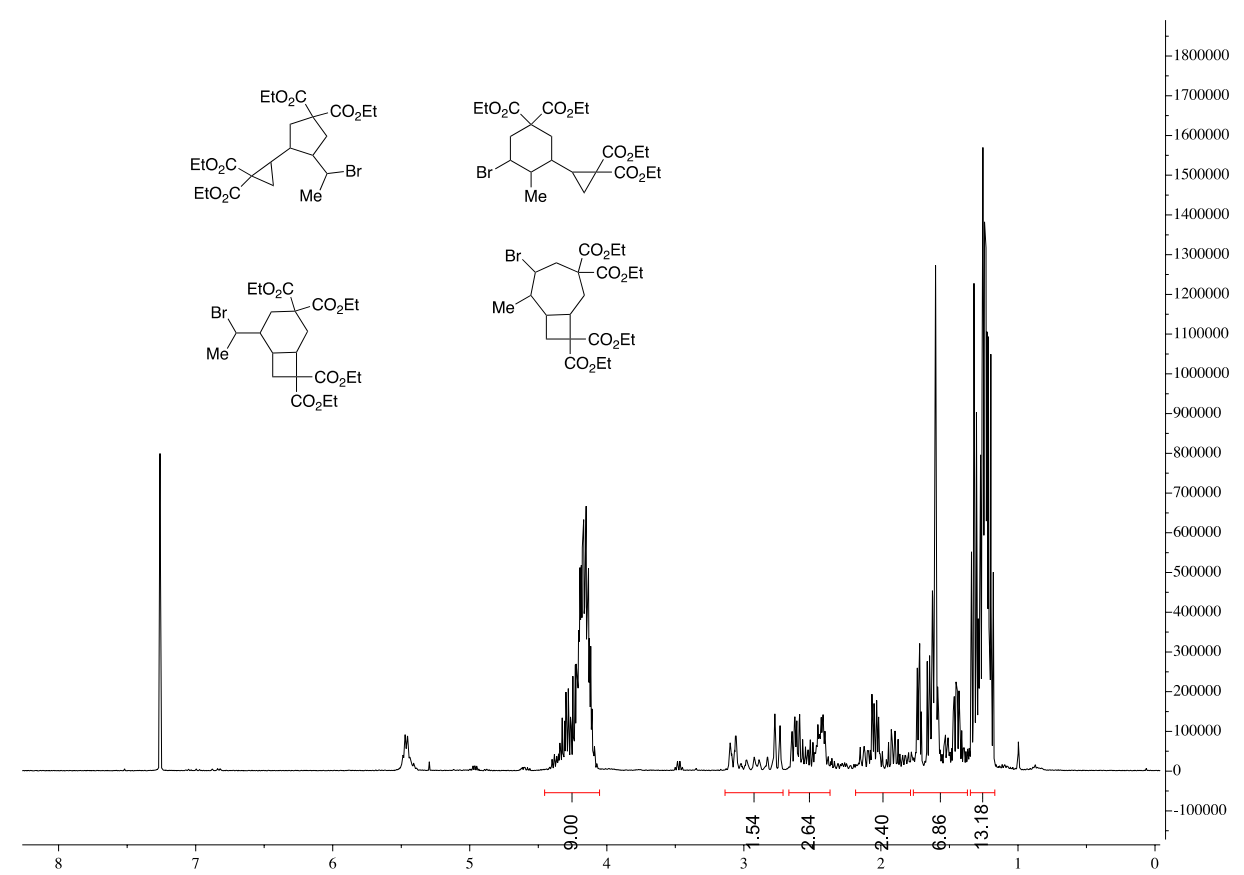

Figure S48. ${ }^{1} \mathrm{H}$ NMR spectrum of cyclized products 


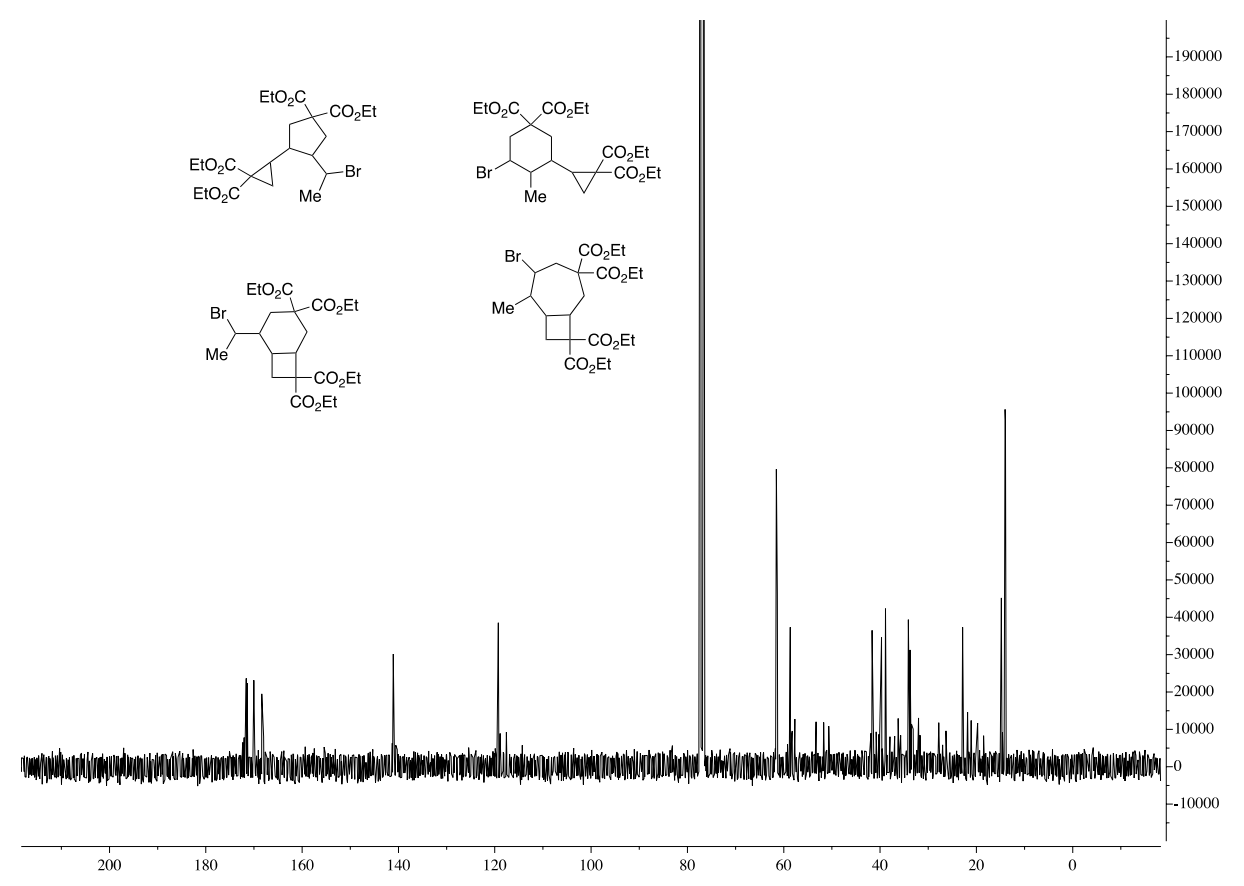

Figure S49. ${ }^{1} \mathrm{H}$ NMR spectrum of cyclized products

ESI-TOF MS analysis of the mixed products confirmed the existence of proposed cyclized products. Besides, two classes of products that respectively lost a $\mathrm{Br}$ atom and a $\mathrm{HBr}$ were also observed. These products are likely formed from disproportionation of the active carbon radicals.

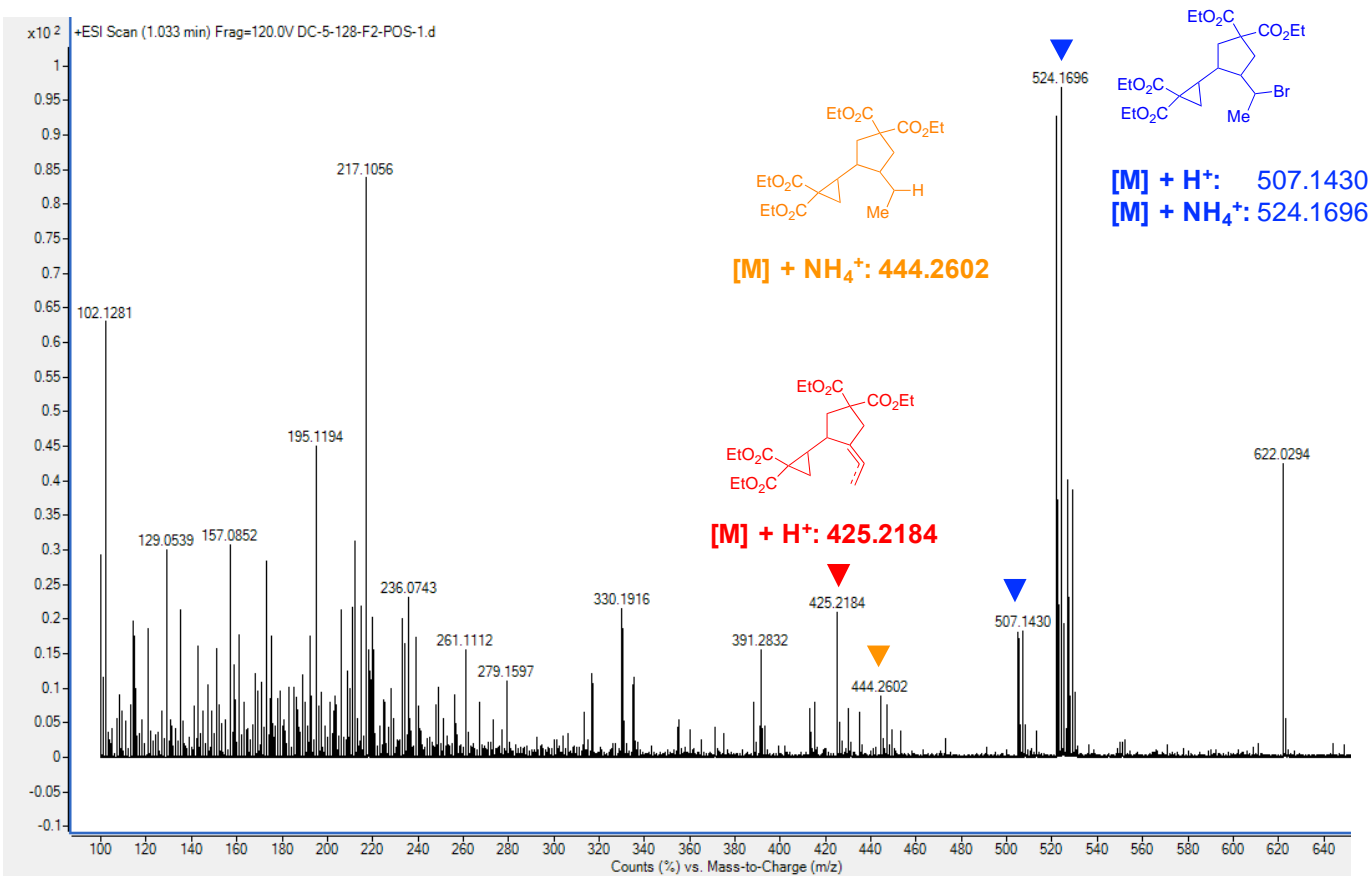

Figure S50. ESI-TOF MS spectrum of the mixed products from model reaction of 4 


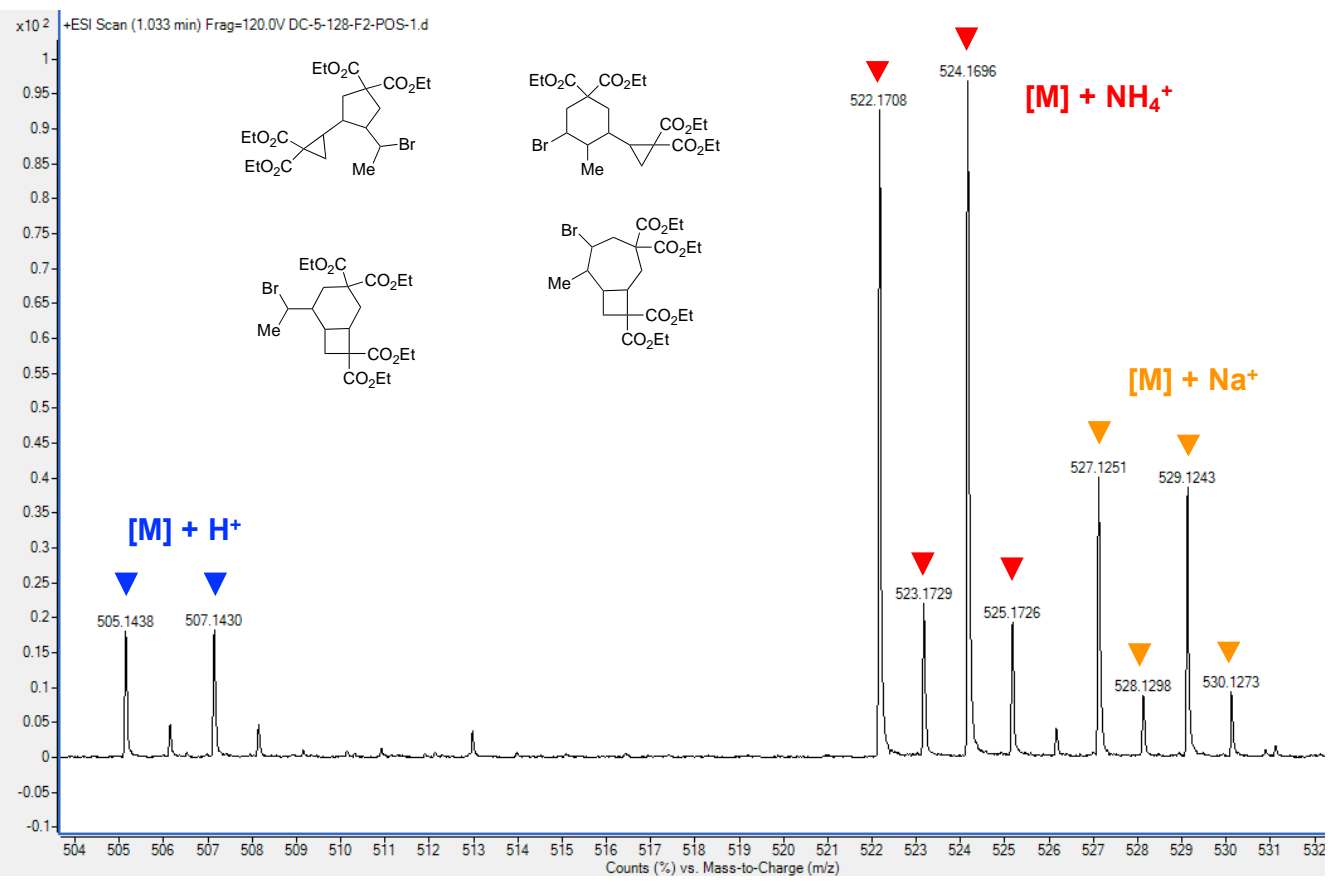

Figure S51. Zoomed ESI-TOF MS spectrum of the cyclized products 


\subsection{Density Functional Theory Calculations}

All calculations were performed using computational chemistry software package Gaussian 09 ver. D01. We acknowledge the use of computational resources provided by the XSEDE - Comet supercomputer (grant number CHE 160041). Geometries of all molecular structures were optimized either at the uM06/6-31+G(d,p)/CPCM-EtOAc or uM06/6-31G(d,p)/CPCM-EtOAc (for some extensive structures) level of theory followed by frequency calculations to obtain zero point energy (ZPE) corrections, thermal corrections, and entropic TS terms using ideal gas approximations; $\quad$ CPCM = conductorlike polarizable continuum model, EtOAc $=$ Ethyl Acetate.

The obtained Gibbs free energy, $\mathrm{G}^{0^{*}}(298 \mathrm{~K}, 1 \mathrm{~atm})$, by default has a standard reference state of $298.15 \mathrm{~K}$ and $1 \mathrm{~atm}$. However, a standard reference state of $298.15 \mathrm{~K}$ and 1 mole/liter $\left[\mathrm{G}^{0}(298 \mathrm{~K}, 1 \mathrm{M})\right]$ is more relevant to our examined systems as the reactions were carried out in the liquid phase. To obtain the Gibbs free energy with relevant standard state reference, $\mathrm{G}^{0}(298 \mathrm{~K}, 1 \mathrm{M})=\mathrm{G}^{0^{*}}(298 \mathrm{~K}, 1 \mathrm{~atm})+\mathrm{RT} \ln (0.08206 \mathrm{~T})$, where $\mathrm{R}$ is the gas constant and $T$ is the temperature. $\Delta \mathrm{G}^{0}(298 \mathrm{~K}, 1 \mathrm{M})=\Delta \mathrm{G}^{0^{*}}(298 \mathrm{~K}, 1 \mathrm{~atm})$ when there is no mole change from the reactant to the product. However, for every net mole change $\Delta \mathrm{G}^{0}(298$ $\mathrm{K}, 1 \mathrm{M})=\Delta \mathrm{G}^{0^{*}}(298 \mathrm{~K}, 1 \mathrm{~atm})-1.89 \mathrm{kcal} / \mathrm{mol}$.

At the converged geometries, single point calculations at uM06/6$311+\mathrm{G}(\mathrm{d}, \mathrm{p}) / \mathrm{CPCM}-\mathrm{EtOAc}$ were performed; the various corrections and entropic TS terms from $\mathrm{uM} 06 / 6-31+\mathrm{G}(\mathrm{d}, \mathrm{p})$ or $\mathrm{uM} 06 / 6-31 \mathrm{G}(\mathrm{d}, \mathrm{p})$ calculations were then applied to the energy obtained with uM06/6-311+G(d,p).

\section{Coordinates of Molecular Structures}

All coordinates are reported as XYZ Cartesian coordinates. Converged geometries were obtained from uM06/6-31+G** level of theory (unless otherwise specified) in CPCM-described solvent EtOAc. Single point energies computed at uM06/6-311+G** level of theory (reported in parentheses) are arranged in the following order: Еок (not ZPE and thermally corrected), $\mathrm{H}(298.15 \mathrm{~K}, 1 \mathrm{~atm}), \mathrm{G}^{0 *}(298.15 \mathrm{~K}, 1 \mathrm{~atm})$, and $\mathrm{G}^{0}(298.15 \mathrm{~K}, 1$ M). They are stated in Hartrees units. All energies reported were calculated using the GAUSSIAN 09 ver. D.01 computational chemistry package. 


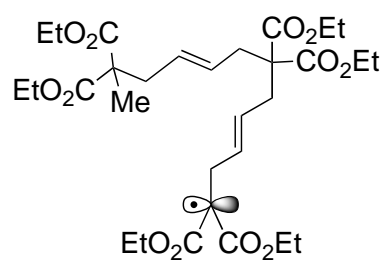

Geometry optimized at uM06/6-31G** level of theory

(neutral radical, -2072.290771, -2071.512503, -2071.644368, -2071.641349)

$\mathrm{C}$

$\mathrm{C}$

$\mathrm{H}$

$\mathrm{H}$

$\mathrm{H}$

$\mathrm{C}$

$\mathrm{H}$

$\mathrm{C}$

C

$\mathrm{O}$

$\mathrm{O}$

$\mathrm{O}$

$\mathrm{O}$

C

$\mathrm{H}$

$\mathrm{H}$

C

$\mathrm{H}$

$\mathrm{H}$

$\mathrm{H}$

C

$\mathrm{H}$

$\mathrm{H}$

C

$\mathrm{H}$

$\mathrm{H}$

$\mathrm{H}$

C

$\mathrm{H}$

$\mathrm{H}$

C

C

$\mathrm{H}$

$\mathrm{H}$

$\mathrm{H}$

C

C

O

$\mathrm{O}$
1.46588

2.91477

0.95547

3.46536

3.35459

0.77634

1.29604

2.77932

2.43429

2.72865

2.81181

2.58160

1.28194

2.27299

1.38596

3.10616

2.04969

1.22312

1.80190

2.94731

0.42722

0.32766

0.91457

$-0.88666$

$-1.33309$

$-1.58668$

$-0.74791$

$-0.68087$

$-1.19296$

$-1.12851$

$-0.98184$

$-0.30657$

0.77681

$-0.50894$

$-0.67103$

$-0.57028$

$-2.49874$

$-0.33147$

$-3.19932$
$-1.01825$

$-0.64850$

$-1.13280$

$-1.27832$

$-0.80773$

$-1.17885$

$-1.04597$

1.20550

1.64879

2.34300

1.74461

0.13381

2.13037

0.39560

1.03768

0.95328

$-0.93348$

$-1.47281$

$-0.78419$

$-1.55711$

2.75334

2.06992

3.67616

3.02729

2.09878

3.48507

3.71326

$-1.50382$

$-0.76393$

$-1.45081$

$-2.89737$

$-3.08446$

$-3.18110$

$-2.22054$

$-3.98232$

$-3.98385$

$-3.00782$

$-3.80650$

$-3.53654$
$-1.93943$

$-1.97374$

$-2.89761$

$-2.68363$

$-0.98024$

$-0.80971$

0.14392

$-3.76044$

$-1.29436$

$-4.17416$

$-0.14611$

$-4.53065$

$-1.74292$

$-5.91412$

$-5.95780$

$-6.35768$

$-6.58140$

$-6.10759$

$-7.63643$

$-6.52497$

$-0.76173$

0.09141

$-0.42265$

$-1.43860$

$-1.81133$

$-0.73272$

$-2.28006$

$-0.74309$

$-0.10999$

$-1.74325$

$-0.14282$

1.21658

1.09539

1.85707

1.72185

$-1.13471$

$-0.03662$

$-2.30593$

$-0.87199$ 


\begin{tabular}{|c|c|c|c|}
\hline $\mathrm{O}$ & -0.53708 & -5.18035 & -0.54199 \\
\hline $\mathrm{O}$ & -2.96528 & -2.40569 & 1.05606 \\
\hline $\mathrm{C}$ & -0.22872 & -6.29892 & -1.39406 \\
\hline $\mathrm{H}$ & 0.74604 & -6.12469 & -1.86443 \\
\hline $\mathrm{H}$ & -0.97738 & -6.34432 & -2.19369 \\
\hline $\mathrm{C}$ & -0.23427 & -7.53231 & -0.53334 \\
\hline $\mathrm{H}$ & -1.21454 & -7.68012 & -0.06936 \\
\hline $\mathrm{H}$ & -0.00458 & -8.41358 & -1.13951 \\
\hline $\mathrm{H}$ & 0.51618 & -7.45693 & 0.25989 \\
\hline $\mathrm{C}$ & -4.39924 & -2.40006 & 1.21251 \\
\hline $\mathrm{H}$ & -4.84363 & -1.91693 & 0.33482 \\
\hline $\mathrm{H}$ & -4.75079 & -3.43791 & 1.23146 \\
\hline $\mathrm{C}$ & -4.70717 & -1.66717 & 2.48870 \\
\hline $\mathrm{H}$ & -4.33904 & -0.63736 & 2.44627 \\
\hline $\mathrm{H}$ & -5.78863 & -1.63857 & 2.65066 \\
\hline $\mathrm{H}$ & -4.24459 & -2.16521 & 3.34651 \\
\hline $\mathrm{C}$ & 3.18510 & 0.83096 & -2.34128 \\
\hline $\mathrm{C}$ & 4.71148 & 1.10421 & -2.22243 \\
\hline $\mathrm{H}$ & 5.02367 & 0.74793 & -1.23325 \\
\hline $\mathrm{H}$ & 5.21678 & 0.48147 & -2.97438 \\
\hline $\mathrm{C}$ & 5.04475 & 2.55184 & -2.37207 \\
\hline $\mathrm{H}$ & 4.97424 & 2.98790 & -3.36911 \\
\hline $\mathrm{C}$ & 5.28225 & 3.34125 & -1.32087 \\
\hline $\mathrm{C}$ & 5.31332 & 4.84592 & -1.38884 \\
\hline $\mathrm{C}$ & 3.88169 & 5.19235 & -1.13249 \\
\hline $\mathrm{H}$ & 5.28395 & 2.91351 & -0.31785 \\
\hline $\mathrm{H}$ & 5.63234 & 5.19821 & -2.37174 \\
\hline $\mathrm{H}$ & 5.95811 & 5.26883 & -0.61380 \\
\hline $\mathrm{C}$ & 2.92535 & 5.28812 & -2.25342 \\
\hline $\mathrm{C}$ & 3.46616 & 5.18484 & 0.28100 \\
\hline $\mathrm{O}$ & 1.71320 & 5.30764 & -2.15820 \\
\hline $\mathrm{O}$ & 4.23422 & 4.87312 & 1.17509 \\
\hline $\mathrm{O}$ & 3.56733 & 5.36796 & -3.42845 \\
\hline $\mathrm{O}$ & 2.20270 & 5.55770 & 0.50024 \\
\hline $\mathrm{C}$ & 2.72782 & 5.43749 & -4.59366 \\
\hline $\mathrm{H}$ & 1.98897 & 4.63294 & -4.53657 \\
\hline $\mathrm{H}$ & 2.19217 & 6.39528 & -4.57914 \\
\hline $\mathrm{C}$ & 3.61860 & 5.29810 & -5.79707 \\
\hline $\mathrm{H}$ & 4.38071 & 6.08381 & -5.82078 \\
\hline $\mathrm{H}$ & 4.11947 & 4.32419 & -5.79038 \\
\hline $\mathrm{H}$ & 3.02376 & 5.37063 & -6.71276 \\
\hline $\mathrm{C}$ & 1.76133 & 5.46530 & 1.86538 \\
\hline $\mathrm{H}$ & 2.41439 & 6.08047 & 2.49560 \\
\hline $\mathrm{H}$ & 1.87186 & 4.42357 & 2.19470 \\
\hline $\mathrm{C}$ & 0.32971 & 5.92471 & 1.90179 \\
\hline $\mathrm{H}$ & -0.05716 & 5.86696 & 2.92342 \\
\hline
\end{tabular}




$\begin{array}{lrll}\mathrm{H} & 0.24231 & 6.96024 & 1.55846 \\ \mathrm{H} & -0.29842 & 5.29637 & 1.26111\end{array}$

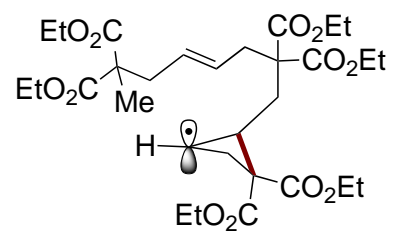

Geometry optimized at uM06/6-31G** level of theory (neutral radical, -2072.27222, -2071.495076, -2071.623833, -2071.620815)

$\begin{array}{lrrr}\mathrm{C} & 1.50982 & -0.77337 & -1.69726 \\ \mathrm{C} & 2.96212 & -0.42024 & -1.70848 \\ \mathrm{H} & 0.99319 & -0.79826 & -2.65875 \\ \mathrm{H} & 3.52558 & -1.09253 & -2.36934 \\ \mathrm{H} & 3.37218 & -0.54468 & -0.69622 \\ \mathrm{C} & 0.82399 & -1.02276 & -0.58133 \\ \mathrm{H} & 1.35053 & -0.97763 & 0.37668 \\ \mathrm{C} & 2.98980 & 1.33647 & -3.60505 \\ \mathrm{C} & 2.39757 & 1.91478 & -1.26642 \\ \mathrm{O} & 2.99804 & 2.46506 & -4.04660 \\ \mathrm{O} & 2.69475 & 2.26916 & -0.14806 \\ \mathrm{O} & 2.74188 & 0.26014 & -4.34957 \\ \mathrm{O} & 1.20770 & 2.12257 & -1.82615 \\ \mathrm{C} & 2.54319 & 0.52606 & -5.75394 \\ \mathrm{H} & 1.74480 & 1.26991 & -5.85873 \\ \mathrm{H} & 3.46611 & 0.97945 & -6.14140 \\ \mathrm{C} & 2.19992 & -0.77346 & -6.42778 \\ \mathrm{H} & 1.29472 & -1.21145 & -5.99495 \\ \mathrm{H} & 2.01951 & -0.59950 & -7.49299 \\ \mathrm{H} & 3.01260 & -1.50225 & -6.33656 \\ \mathrm{C} & 0.18036 & 2.66475 & -0.97599 \\ \mathrm{H} & 0.19020 & 2.11558 & -0.02627 \\ \mathrm{H} & 0.41794 & 3.71243 & -0.75804 \\ \mathrm{C} & -1.12203 & 2.50440 & -1.71008 \\ \mathrm{H} & -1.30361 & 1.44597 & -1.92962 \\ \mathrm{H} & -1.94936 & 2.87876 & -1.10028 \\ \mathrm{H} & -1.11239 & 3.05552 & -2.65549 \\ \mathrm{C} & -0.64003 & -1.32592 & -0.53326 \\ \mathrm{H} & -1.12058 & -0.67505 & 0.21240 \\ \mathrm{H} & -1.10329 & -1.11635 & -1.50584 \\ \mathrm{C} & -0.98007 & -2.78419 & -0.14519 \\ \mathrm{C} & -0.24281 & -3.22120 & 1.12094 \\ \mathrm{H} & 0.82671 & -3.33532 & 0.91687 \\ \mathrm{H} & -0.36547 & -2.46961 & 1.90696 \\ \mathrm{H} & -0.62103 & -4.17635 & 1.49408 \\ \mathrm{C} & -0.67857 & -3.71255 & -1.31979\end{array}$




$\begin{array}{lccc}\mathrm{C} & -2.49361 & -2.83941 & 0.02785 \\ \mathrm{O} & -0.44777 & -3.35730 & -2.45166 \\ \mathrm{O} & -3.26109 & -3.16818 & -0.85038 \\ \mathrm{O} & -0.73512 & -4.99125 & -0.93884 \\ \mathrm{O} & -2.87268 & -2.42472 & 1.23529 \\ \mathrm{C} & -0.54638 & -5.96791 & -1.97968 \\ \mathrm{H} & 0.43664 & -5.80761 & -2.43780 \\ \mathrm{H} & -1.30282 & -5.80043 & -2.75545 \\ \mathrm{C} & -0.66796 & -7.32726 & -1.34777 \\ \mathrm{H} & -1.65506 & -7.45971 & -0.89374 \\ \mathrm{H} & -0.53167 & -8.10515 & -2.10486 \\ \mathrm{H} & 0.09119 & -7.46699 & -0.57172 \\ \mathrm{C} & -4.29523 & -2.36291 & 1.46719 \\ \mathrm{H} & -4.73915 & -1.68630 & 0.72789 \\ \mathrm{H} & -4.71936 & -3.35951 & 1.30018 \\ \mathrm{C} & -4.49777 & -1.88267 & 2.87748 \\ \mathrm{H} & -4.05648 & -0.89126 & 3.02026 \\ \mathrm{H} & -5.56703 & -1.81714 & 3.09898 \\ \mathrm{H} & -4.04063 & -2.57179 & 3.59438 \\ \mathrm{C} & 3.28455 & 1.03304 & -2.14418 \\ \mathrm{C} & 4.76772 & 1.30943 & -1.82809 \\ \mathrm{H} & 4.84362 & 1.29622 & -0.73269 \\ \mathrm{H} & 5.37174 & 0.47279 & -2.19700 \\ \mathrm{C} & 5.34584 & 2.64216 & -2.28819 \\ \mathrm{C} & 6.62225 & 3.09045 & -1.65511 \\ \mathrm{C} & 6.06312 & 2.86182 & -3.68606 \\ \mathrm{H} & 4.57013 & 3.42511 & -2.20548 \\ \mathrm{C} & 7.19038 & 3.61835 & -2.92632 \\ \mathrm{H} & 6.88792 & 3.23986 & -0.61266 \\ \mathrm{H} & 8.20822 & 3.32373 & -3.20966 \\ \mathrm{H} & 7.09994 & 4.70880 & -3.04500 \\ \mathrm{H} & 6.60366 & 1.64132 & -4.40297 \\ \mathrm{C} & 5.27714 & 3.74298 & -4.63701 \\ \mathrm{C} & 7.73034 & 1.56255 & -4.83676 \\ \mathrm{O} & 4.85142 & 4.83144 & -4.32730 \\ \mathrm{O} & 5.14692 & 3.19898 & -5.84948 \\ \mathrm{O} & 5.68151 & 0.67932 & -4.52603 \\ \mathrm{O} & 4.30638 & 3.90885 & -6.77714 \\ \mathrm{H} & 3.28303 & 3.87935 & -6.38138 \\ \mathrm{H} & 4.62519 & 4.95612 & -6.81698 \\ \mathrm{H} & 3.11324 & 3.22271 & -8.11026 \\ \mathrm{H} & 2.17506 & -8.04679 \\ \mathrm{H} & 3.72403 & 3.24721 & -8.46808 \\ \mathrm{H} & -0.49767 & -5.27673 \\ \mathrm{H} & -0.36873 & -6.28789\end{array}$




$\begin{array}{llll}\mathrm{H} & 7.13133 & -0.54362 & -5.35688 \\ \mathrm{C} & 5.46928 & -1.70297 & -4.57931 \\ \mathrm{H} & 5.91930 & -1.82847 & -3.58774 \\ \mathrm{H} & 4.38450 & -1.60739 & -4.45830 \\ \mathrm{H} & 5.67594 & -2.60600 & -5.16247\end{array}$

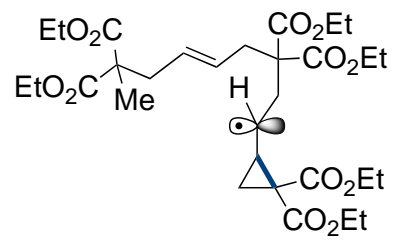

Geometry optimized at uM06/6-31G** level of theory (neutral radical, -2072.285297, -2071.508296, -2071.640011, -2071.636992)

$\begin{array}{lrrr}\mathrm{C} & 1.18105 & -1.22497 & -1.67395 \\ \mathrm{C} & 2.60687 & -0.80020 & -1.81879 \\ \mathrm{H} & 0.58361 & -1.26816 & -2.58642 \\ \mathrm{H} & 3.14405 & -1.43841 & -2.53227 \\ \mathrm{H} & 3.11397 & -0.88878 & -0.84831 \\ \mathrm{C} & 0.59805 & -1.47888 & -0.50187 \\ \mathrm{H} & 1.20054 & -1.41851 & 0.40933 \\ \mathrm{C} & 2.33745 & 0.91997 & -3.71934 \\ \mathrm{C} & 1.92638 & 1.49052 & -1.31229 \\ \mathrm{O} & 2.32451 & 2.01956 & -4.22779 \\ \mathrm{O} & 2.29751 & 1.76757 & -0.19140 \\ \mathrm{O} & 2.04655 & -0.20081 & -4.38030 \\ \mathrm{O} & 0.71510 & 1.74436 & -1.78772 \\ \mathrm{C} & 1.66487 & -0.04677 & -5.76168 \\ \mathrm{H} & 0.80515 & 0.63118 & -5.81115 \\ \mathrm{H} & 2.49193 & 0.42830 & -6.30192 \\ \mathrm{C} & 1.34406 & -1.41811 & -6.28874 \\ \mathrm{H} & 0.52869 & -1.87379 & -5.71730 \\ \mathrm{H} & 1.03490 & -1.35384 & -7.33608 \\ \mathrm{H} & 2.21731 & -2.07515 & -6.22848 \\ \mathrm{C} & -0.20028 & 2.37630 & -0.87045 \\ \mathrm{H} & -0.33631 & 1.70719 & -0.01003 \\ \mathrm{H} & 0.26211 & 3.30782 & -0.52620 \\ \mathrm{C} & -1.47923 & 2.61984 & -1.62089 \\ \mathrm{H} & -1.90312 & 1.68086 & -1.99355 \\ \mathrm{H} & -2.21675 & 3.09171 & -0.96400 \\ \mathrm{H} & -1.29782 & 3.28453 & -2.47132 \\ \mathrm{C} & -0.84995 & -1.82030 & -0.33901 \\ \mathrm{H} & -1.27501 & -1.23909 & 0.48906 \\ \mathrm{H} & -1.40263 & -1.55208 & -1.24799 \\ \mathrm{C} & -1.10049 & -3.31276 & -0.03246 \\ \mathrm{C} & -0.31531 & -3.76703 & 1.20203\end{array}$




\begin{tabular}{|c|c|c|c|}
\hline $\mathrm{H}$ & 0.75849 & -3.76551 & 0.99207 \\
\hline $\mathrm{H}$ & -0.51113 & -3.08513 & 2.03560 \\
\hline $\mathrm{H}$ & -0.59638 & -4.77966 & 1.50436 \\
\hline $\mathrm{C}$ & -0.78180 & -4.13835 & -1.27865 \\
\hline $\mathrm{C}$ & -2.58499 & -3.55184 & 0.22619 \\
\hline $\mathrm{O}$ & -0.93635 & -3.74003 & -2.41064 \\
\hline $\mathrm{O}$ & -3.26545 & -4.35484 & -0.37378 \\
\hline $\mathrm{O}$ & -0.35144 & -5.36305 & -0.97627 \\
\hline $\mathrm{O}$ & -3.03796 & -2.78608 & 1.21817 \\
\hline $\mathrm{C}$ & -0.12571 & -6.24200 & -2.09457 \\
\hline $\mathrm{H}$ & 0.60306 & -5.77584 & -2.76756 \\
\hline $\mathrm{H}$ & -1.06647 & -6.34476 & -2.64818 \\
\hline $\mathrm{C}$ & 0.36123 & -7.55405 & -1.54406 \\
\hline $\mathrm{H}$ & -0.37839 & -7.99176 & -0.86631 \\
\hline $\mathrm{H}$ & 0.53813 & -8.26030 & -2.36058 \\
\hline $\mathrm{H}$ & 1.29892 & -7.42338 & -0.99474 \\
\hline $\mathrm{C}$ & -4.42861 & -2.95256 & 1.56289 \\
\hline $\mathrm{H}$ & -5.03560 & -2.71827 & 0.68080 \\
\hline $\mathrm{H}$ & -4.60263 & -4.00525 & 1.81328 \\
\hline $\mathrm{C}$ & -4.71695 & -2.03267 & 2.71666 \\
\hline $\mathrm{H}$ & -4.52472 & -0.99039 & 2.44348 \\
\hline $\mathrm{H}$ & -5.76677 & -2.12164 & 3.01105 \\
\hline $\mathrm{H}$ & -4.09543 & -2.28416 & 3.58171 \\
\hline $\mathrm{C}$ & 2.76599 & 0.66939 & -2.28276 \\
\hline $\mathrm{C}$ & 4.26429 & 1.07960 & -2.16973 \\
\hline $\mathrm{H}$ & 4.57687 & 0.81202 & -1.15131 \\
\hline $\mathrm{H}$ & 4.82493 & 0.43467 & -2.86149 \\
\hline $\mathrm{C}$ & 4.55800 & 2.51547 & -2.42167 \\
\hline $\mathrm{H}$ & 4.69346 & 2.87638 & -3.43859 \\
\hline $\mathrm{C}$ & 4.54469 & 3.46863 & -1.33206 \\
\hline $\mathrm{C}$ & 4.95332 & 4.88191 & -1.46254 \\
\hline $\mathrm{C}$ & 3.47229 & 4.65529 & -1.28040 \\
\hline $\mathrm{H}$ & 4.62304 & 3.03871 & -0.33371 \\
\hline $\mathrm{H}$ & 5.26269 & 5.23005 & -2.44307 \\
\hline $\mathrm{H}$ & 5.45294 & 5.33567 & -0.61144 \\
\hline $\mathrm{C}$ & 2.54354 & 4.74959 & -2.44446 \\
\hline $\mathrm{C}$ & 2.97918 & 4.86240 & 0.10894 \\
\hline $\mathrm{O}$ & 1.34519 & 4.58148 & -2.39954 \\
\hline $\mathrm{O}$ & 3.69703 & 4.72717 & 1.08117 \\
\hline $\mathrm{O}$ & 3.20672 & 5.01210 & -3.57804 \\
\hline $\mathrm{O}$ & 1.69582 & 5.21335 & 0.19416 \\
\hline $\mathrm{C}$ & 2.42959 & 5.00198 & -4.79006 \\
\hline $\mathrm{H}$ & 1.72946 & 4.16333 & -4.74942 \\
\hline $\mathrm{H}$ & 1.85749 & 5.93699 & -4.83893 \\
\hline $\mathrm{C}$ & 3.39571 & 4.85950 & -5.93421 \\
\hline $\mathrm{H}$ & 4.13997 & 5.66254 & -5.93285 \\
\hline
\end{tabular}




$\begin{array}{lrrr}\mathrm{H} & 3.91675 & 3.89762 & -5.86854 \\ \mathrm{H} & 2.85808 & 4.89202 & -6.88695 \\ \mathrm{C} & 1.16720 & 5.31148 & 1.52801 \\ \mathrm{H} & 1.81319 & 5.96446 & 2.12531 \\ \mathrm{H} & 1.19875 & 4.31109 & 1.98034 \\ \mathrm{C} & -0.23512 & 5.84434 & 1.41567 \\ \mathrm{H} & -0.68258 & 5.93482 & 2.40998 \\ \mathrm{H} & -0.23811 & 6.83338 & 0.94671 \\ \mathrm{H} & -0.86539 & 5.17902 & 0.81566\end{array}$<smiles>CCOC(=O)C1CC(OCC)(C(=O)OCC)CC1C1CC1(OCC)C(=O)OCC</smiles>

Geometry optimized at uM06/6-31G** level of theory

(neutral radical, -2072.306267, -2071.52861, -2071.663093, -2071.660075)

$\begin{array}{lrcc}\mathrm{C} & -0.47802 & 1.18572 & 0.03105 \\ \mathrm{C} & 0.99444 & 0.72010 & -0.10746 \\ \mathrm{C} & 1.77862 & 1.89015 & 0.48867 \\ \mathrm{C} & 1.00800 & 3.16810 & 0.06879 \\ \mathrm{C} & -0.41076 & 2.67387 & -0.33975 \\ \mathrm{H} & -1.09938 & 0.62473 & -0.68797 \\ \mathrm{H} & 1.15898 & -0.19918 & 0.47458 \\ \mathrm{H} & 1.76873 & 1.80046 & 1.58319 \\ \mathrm{H} & 2.82108 & 1.92468 & 0.15696 \\ \mathrm{H} & -1.20055 & 3.25847 & 0.14096 \\ \mathrm{H} & -0.54527 & 2.79757 & -1.42124 \\ \mathrm{C} & 1.06259 & 4.13121 & 1.23975 \\ \mathrm{C} & 1.66302 & 3.86183 & -1.11911 \\ \mathrm{O} & 1.96999 & 4.91439 & 1.41466 \\ \mathrm{O} & 2.60702 & 3.44717 & -1.75288 \\ \mathrm{O} & 0.05936 & 3.94714 & 2.09748 \\ \mathrm{O} & 1.00428 & 4.98550 & -1.41186 \\ \mathrm{C} & 1.50823 & 5.74926 & -2.52479 \\ \mathrm{H} & 1.46717 & 5.12544 & -3.42537 \\ \mathrm{H} & 2.56127 & 5.98696 & -2.33491 \\ \mathrm{C} & 0.65637 & 6.98267 & -2.64392 \\ \mathrm{H} & 0.70708 & 7.58073 & -1.72874 \\ \mathrm{H} & 1.00558 & 7.59949 & -3.47720 \\ \mathrm{H} & -0.39010 & 6.71951 & -2.82754 \\ \mathrm{C} & 0.09964 & 4.71253 & 3.31767 \\ \mathrm{H} & 1.08502 & 4.58579 & 3.78002 \\ \mathrm{H} & -0.01565 & 5.77333 & 3.06683 \\ \mathrm{C} & -1.01431 & 4.20411 & 4.19153 \\ \mathrm{H} & -1.04668 & 4.76941 & 5.12746\end{array}$




\begin{tabular}{|c|c|c|c|}
\hline $\mathrm{H}$ & -1.98286 & 4.31119 & 3.69153 \\
\hline $\mathrm{H}$ & -0.86597 & 3.14611 & 4.43560 \\
\hline $\mathrm{C}$ & 1.34522 & 0.45915 & -1.55180 \\
\hline $\mathrm{C}$ & 2.56882 & -0.38721 & -1.89244 \\
\hline $\mathrm{C}$ & 1.16086 & -0.87863 & -2.15752 \\
\hline $\mathrm{H}$ & 1.22928 & 1.31055 & -2.22051 \\
\hline $\mathrm{H}$ & 0.85624 & -0.94963 & -3.19687 \\
\hline $\mathrm{H}$ & 0.83872 & -1.69253 & -1.50999 \\
\hline $\mathrm{C}$ & 3.42829 & 0.00033 & -3.04272 \\
\hline $\mathrm{C}$ & 3.28070 & -0.98399 & -0.71537 \\
\hline $\mathrm{O}$ & 4.60389 & -0.27559 & -3.14310 \\
\hline $\mathrm{O}$ & 2.97379 & -2.02252 & -0.17228 \\
\hline $\mathrm{O}$ & 4.23777 & -0.16800 & -0.27177 \\
\hline $\mathrm{O}$ & 2.73834 & 0.65880 & -3.98068 \\
\hline $\mathrm{C}$ & 3.48474 & 1.06589 & -5.14128 \\
\hline $\mathrm{H}$ & 4.34876 & 1.65530 & -4.81344 \\
\hline $\mathrm{H}$ & 3.86871 & 0.17012 & -5.64364 \\
\hline $\mathrm{C}$ & 2.55382 & 1.85864 & -6.01673 \\
\hline $\mathrm{H}$ & 2.18762 & 2.74590 & -5.49029 \\
\hline $\mathrm{H}$ & 3.07794 & 2.18710 & -6.91904 \\
\hline $\mathrm{H}$ & 1.69193 & 1.25595 & -6.32019 \\
\hline $\mathrm{C}$ & 4.88577 & -0.56358 & 0.95155 \\
\hline $\mathrm{H}$ & 4.11505 & -0.68817 & 1.72372 \\
\hline $\mathrm{H}$ & 5.36319 & -1.53864 & 0.80078 \\
\hline $\mathrm{C}$ & 5.87377 & 0.51406 & 1.30244 \\
\hline $\mathrm{H}$ & 6.39372 & 0.25804 & 2.23031 \\
\hline $\mathrm{H}$ & 6.62057 & 0.63306 & 0.51134 \\
\hline $\mathrm{H}$ & 5.36728 & 1.47429 & 1.44646 \\
\hline $\mathrm{C}$ & -1.00851 & 0.94201 & 1.39955 \\
\hline $\mathrm{H}$ & -1.06607 & 1.76997 & 2.10646 \\
\hline $\mathrm{C}$ & -1.29547 & -0.44212 & 1.85570 \\
\hline $\mathrm{H}$ & -1.18682 & -1.14213 & 1.01496 \\
\hline $\mathrm{H}$ & -0.56821 & -0.76550 & 2.62327 \\
\hline $\mathrm{C}$ & -2.69422 & -0.63393 & 2.49105 \\
\hline $\mathrm{C}$ & -2.89126 & 0.27701 & 3.69988 \\
\hline $\mathrm{H}$ & -2.91096 & 1.32704 & 3.39003 \\
\hline $\mathrm{H}$ & -3.83596 & 0.04977 & 4.20080 \\
\hline $\mathrm{H}$ & -2.07468 & 0.13498 & 4.41510 \\
\hline $\mathrm{C}$ & -3.85787 & -0.40284 & 1.53382 \\
\hline $\mathrm{C}$ & -2.76877 & -2.09050 & 2.93975 \\
\hline $\mathrm{O}$ & -2.61583 & -2.47476 & 4.07511 \\
\hline $\mathrm{O}$ & -5.01244 & -0.52086 & 1.88290 \\
\hline $\mathrm{O}$ & -2.96231 & -2.89863 & 1.89304 \\
\hline $\mathrm{O}$ & -3.48501 & -0.05919 & 0.30288 \\
\hline $\mathrm{C}$ & -4.55160 & 0.17445 & -0.63807 \\
\hline $\mathrm{H}$ & -5.08963 & -0.76843 & -0.79175 \\
\hline
\end{tabular}




$\begin{array}{lrrr}\mathrm{H} & -5.25706 & 0.88877 & -0.19928 \\ \mathrm{C} & -3.92755 & 0.69167 & -1.90493 \\ \mathrm{H} & -3.40164 & 1.63562 & -1.72282 \\ \mathrm{H} & -3.21269 & -0.03060 & -2.31321 \\ \mathrm{H} & -4.70117 & 0.87073 & -2.65751 \\ \mathrm{C} & -3.00617 & -4.31163 & 2.17741 \\ \mathrm{H} & -2.05336 & -4.60457 & 2.63318 \\ \mathrm{H} & -3.79580 & -4.49331 & 2.91546 \\ \mathrm{C} & -3.26363 & -5.02255 & 0.87766 \\ \mathrm{H} & -3.31084 & -6.10241 & 1.04570 \\ \mathrm{H} & -4.21415 & -4.70126 & 0.44036 \\ \mathrm{H} & -2.46516 & -4.82209 & 0.15646\end{array}$

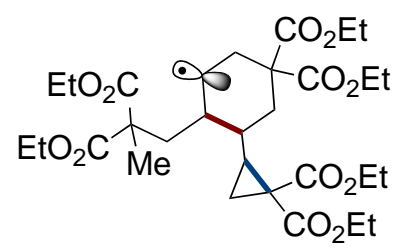

Geometry optimized at uM06/6-31G** level of theory (neutral radical, -2072.316162, -2071.537907, -2071.666586, -2071.663567)

$\begin{array}{lccc}\mathrm{C} & -4.17354 & -0.50881 & 1.18770 \\ \mathrm{C} & -2.70352 & -0.99666 & 1.11221 \\ \mathrm{C} & -1.76886 & 0.18155 & 0.82977 \\ \mathrm{C} & -1.89227 & 1.34666 & 1.81794 \\ \mathrm{C} & -3.37579 & 1.78378 & 1.94237 \\ \mathrm{C} & -4.25449 & 0.61123 & 2.16695 \\ \mathrm{H} & -0.72124 & -0.15096 & 0.79975 \\ \mathrm{H} & -2.45487 & -1.45640 & 2.08059 \\ \mathrm{H} & -4.39245 & -0.09647 & 0.17825 \\ \mathrm{H} & -3.47169 & 2.53220 & 2.73488 \\ \mathrm{H} & -3.63422 & 2.27641 & 0.98829 \\ \mathrm{H} & -4.68044 & 0.43232 & 3.15240 \\ \mathrm{H} & -1.98506 & 0.57653 & -0.17536 \\ \mathrm{C} & -1.08571 & 2.53595 & 1.31075 \\ \mathrm{C} & -1.34487 & 0.93791 & 3.17920 \\ \mathrm{O} & -0.59045 & 2.62972 & 0.21218 \\ \mathrm{O} & -2.00333 & 0.69427 & 4.16383 \\ \mathrm{O} & -0.00732 & 0.87647 & 3.14182 \\ \mathrm{O} & -1.04610 & 3.49859 & 2.23659 \\ \mathrm{C} & -0.32590 & 4.69604 & 1.88354 \\ \mathrm{H} & -0.82431 & 5.16217 & 1.02558 \\ \mathrm{H} & 0.68459 & 4.41474 & 1.56604 \\ \mathrm{C} & -0.31862 & 5.58511 & 3.09614 \\ \mathrm{H} & 0.21710 & 6.51323 & 2.87648 \\ \mathrm{H} & -1.33859 & 5.84060 & 3.39988 \\ \mathrm{H} & 0.17970 & 5.09119 & 3.93659\end{array}$




\begin{tabular}{|c|c|c|c|}
\hline $\mathrm{C}$ & 0.66298 & 0.69313 & 4.40557 \\
\hline $\mathrm{H}$ & 0.38145 & -0.28228 & 4.81921 \\
\hline $\mathrm{H}$ & 0.30265 & 1.46109 & 5.09992 \\
\hline $\mathrm{C}$ & 2.14067 & 0.80225 & 4.14954 \\
\hline $\mathrm{H}$ & 2.39259 & 1.78289 & 3.73382 \\
\hline $\mathrm{H}$ & 2.69100 & 0.67345 & 5.08609 \\
\hline $\mathrm{H}$ & 2.47909 & 0.03433 & 3.44529 \\
\hline $\mathrm{C}$ & -2.53293 & -2.00907 & 0.00229 \\
\hline $\mathrm{C}$ & -1.21675 & -2.77014 & -0.22953 \\
\hline $\mathrm{C}$ & -2.49804 & -3.48185 & 0.13773 \\
\hline $\mathrm{H}$ & -2.95859 & -1.65453 & -0.94466 \\
\hline $\mathrm{H}$ & -2.94939 & -4.08700 & -0.64493 \\
\hline $\mathrm{H}$ & -2.52638 & -3.90383 & 1.13821 \\
\hline $\mathrm{C}$ & -0.10777 & -2.72300 & 0.76604 \\
\hline $\mathrm{C}$ & -0.84196 & -2.74770 & -1.67905 \\
\hline $\mathrm{O}$ & 1.06967 & -2.64156 & 0.49822 \\
\hline $\mathrm{O}$ & -1.32866 & -3.47139 & -2.52205 \\
\hline $\mathrm{O}$ & -0.57183 & -2.80697 & 2.02006 \\
\hline $\mathrm{O}$ & -0.00203 & -1.75111 & -1.94777 \\
\hline $\mathrm{C}$ & 0.39643 & -2.67280 & 3.07248 \\
\hline $\mathrm{H}$ & 1.14918 & -3.46249 & 2.96990 \\
\hline $\mathrm{H}$ & 0.90833 & -1.70813 & 2.94755 \\
\hline $\mathrm{C}$ & -0.35794 & -2.75788 & 4.37178 \\
\hline $\mathrm{H}$ & -1.09540 & -1.94854 & 4.45116 \\
\hline $\mathrm{H}$ & -0.88482 & -3.71365 & 4.45445 \\
\hline $\mathrm{H}$ & 0.33470 & -2.67710 & 5.21585 \\
\hline $\mathrm{C}$ & 0.35525 & -1.57271 & -3.33117 \\
\hline $\mathrm{H}$ & -0.56053 & -1.39856 & -3.90858 \\
\hline $\mathrm{H}$ & 0.80733 & -2.50009 & -3.70158 \\
\hline $\mathrm{C}$ & 1.30170 & -0.40559 & -3.39413 \\
\hline $\mathrm{H}$ & 2.20905 & -0.60867 & -2.81697 \\
\hline $\mathrm{H}$ & 1.58896 & -0.20970 & -4.43134 \\
\hline $\mathrm{H}$ & 0.83104 & 0.49672 & -2.99016 \\
\hline $\mathrm{C}$ & -5.14284 & -1.65154 & 1.49522 \\
\hline $\mathrm{H}$ & -4.74513 & -2.59959 & 1.11950 \\
\hline $\mathrm{H}$ & -5.24514 & -1.77363 & 2.58216 \\
\hline $\mathrm{C}$ & -6.54410 & -1.46209 & 0.89740 \\
\hline $\mathrm{C}$ & -7.30230 & -0.29794 & 1.53544 \\
\hline $\mathrm{H}$ & -7.42617 & -0.47859 & 2.60931 \\
\hline $\mathrm{H}$ & -6.74373 & 0.63562 & 1.40640 \\
\hline $\mathrm{H}$ & -8.28725 & -0.17508 & 1.07713 \\
\hline $\mathrm{C}$ & -6.42411 & -1.23058 & -0.60545 \\
\hline $\mathrm{C}$ & -7.35539 & -2.73460 & 1.12207 \\
\hline $\mathrm{O}$ & -6.82237 & -0.25368 & -1.19555 \\
\hline $\mathrm{O}$ & -7.07974 & -3.60608 & 1.91300 \\
\hline $\mathrm{O}$ & -8.44716 & -2.74067 & 0.35121 \\
\hline
\end{tabular}




$\begin{array}{llll}\mathrm{O} & -5.77927 & -2.24548 & -1.19356 \\ \mathrm{C} & -9.31495 & -3.88439 & 0.48514 \\ \mathrm{H} & -8.73344 & -4.78834 & 0.27012 \\ \mathrm{H} & -9.65120 & -3.94684 & 1.52642 \\ \mathrm{C} & -10.45538 & -3.69643 & -0.47657 \\ \mathrm{H} & -11.13961 & -4.54779 & -0.41578 \\ \mathrm{H} & -11.01773 & -2.78677 & -0.24390 \\ \mathrm{H} & -10.08909 & -3.62329 & -1.50537 \\ \mathrm{C} & -5.58921 & -2.12372 & -2.61787 \\ \mathrm{H} & -6.57290 & -2.01948 & -3.09040 \\ \mathrm{H} & -5.02951 & -1.20047 & -2.81531 \\ \mathrm{C} & -4.85522 & -3.34835 & -3.08884 \\ \mathrm{H} & -3.84684 & -3.40390 & -2.66273 \\ \mathrm{H} & -5.40252 & -4.25699 & -2.81792 \\ \mathrm{H} & -4.75528 & -3.32253 & -4.17813\end{array}$


5.5 Possible Pathways and Cyclic Structures in Polymer-Chain Modification

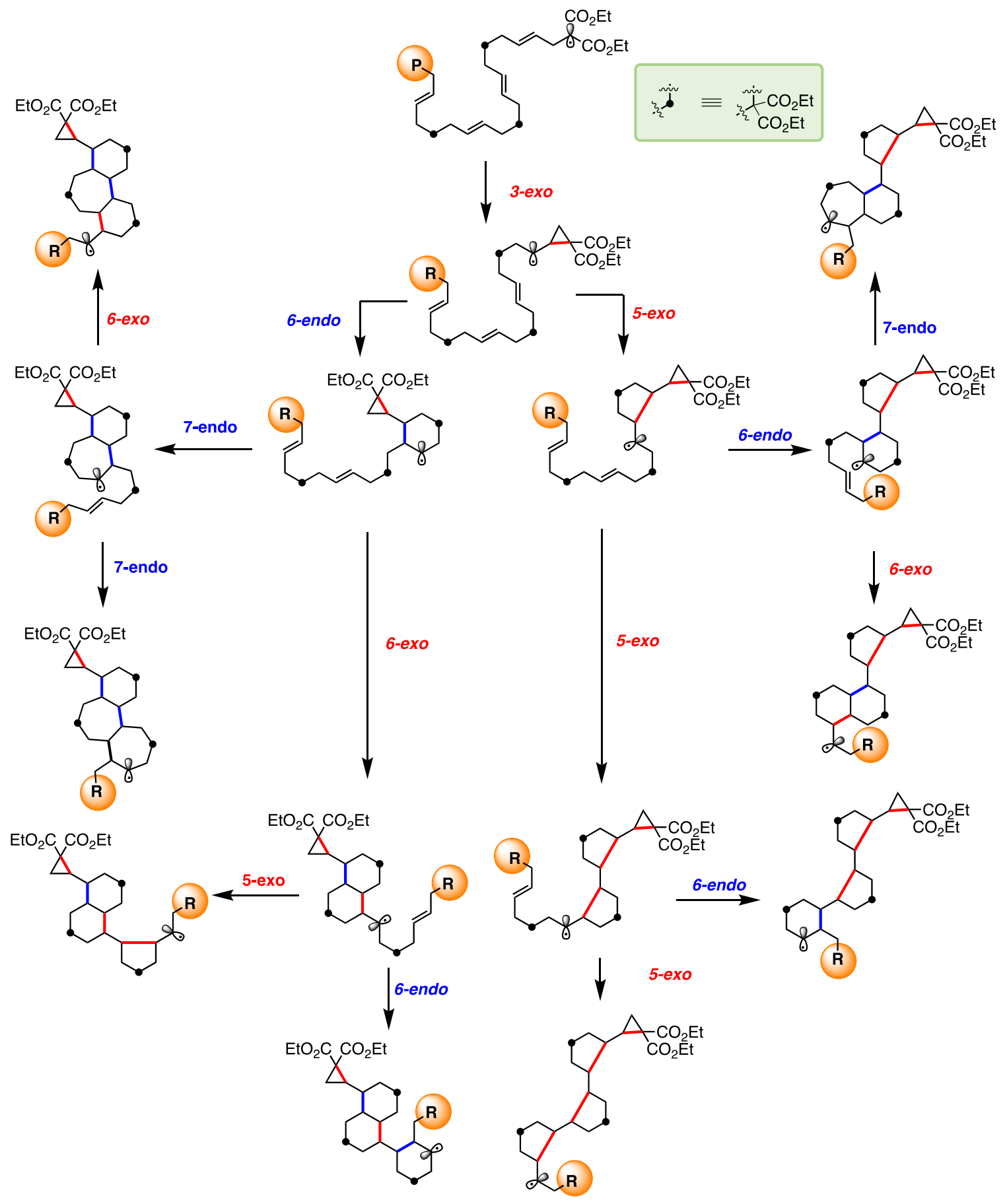

Figure S52. Possible cyclization pathways and cyclic structures 


\section{Synthesis of Poly(EtVCP) with Variable Linear Content}

Poly(EtVCP) I. $M_{\mathrm{n}}=21.1 \mathrm{kDa}, \oslash=1.19, S_{\mathrm{L}}=95 \%$. See section 5.1.

Poly(EtVCP) II. To an oven-dried $20 \mathrm{~mL}$ scintillation vial charged with PC $2(0.434$ $\mathrm{mg}, 0.001 \mathrm{mmol}, 0.0010$ equiv), EtVCP (212.2 $\mathrm{mg}, 1.0 \mathrm{mmol}, 1.0$ equiv), $5.0 \mathrm{~mL}$ of anhydrous EtOAc, and $100 \mathrm{uL}$ of $0.10 \mathrm{M}$ DBMM stock solution in EtOAc were sequentially added. The vial was then tightly capped and placed under white LED irradiation while stirring in the glove box for $12 \mathrm{~h}$ (Figure S1). A cooling fan was used that the polymerization temperature was about $28^{\circ} \mathrm{C}$. Combined 8 runs of such polymerization was concentrated to about $5.0 \mathrm{~mL}$, which was then added into $80.0 \mathrm{~mL}$ of hexane while stirring at $-78{ }^{\circ} \mathrm{C}$. The precipitated polymer was collected by vacuum filtration, washed with cold hexane $(10.0 \mathrm{~mL} \times 2)$ and dried overnight under vacuum at $50{ }^{\circ} \mathrm{C}$ to a constant weight. $1.34 \mathrm{~g}, 79 \%$ yield. $M_{\mathrm{n}}=22.5 \mathrm{kDa}, Ð=1.18, S_{\mathrm{L}}=70 \%$.

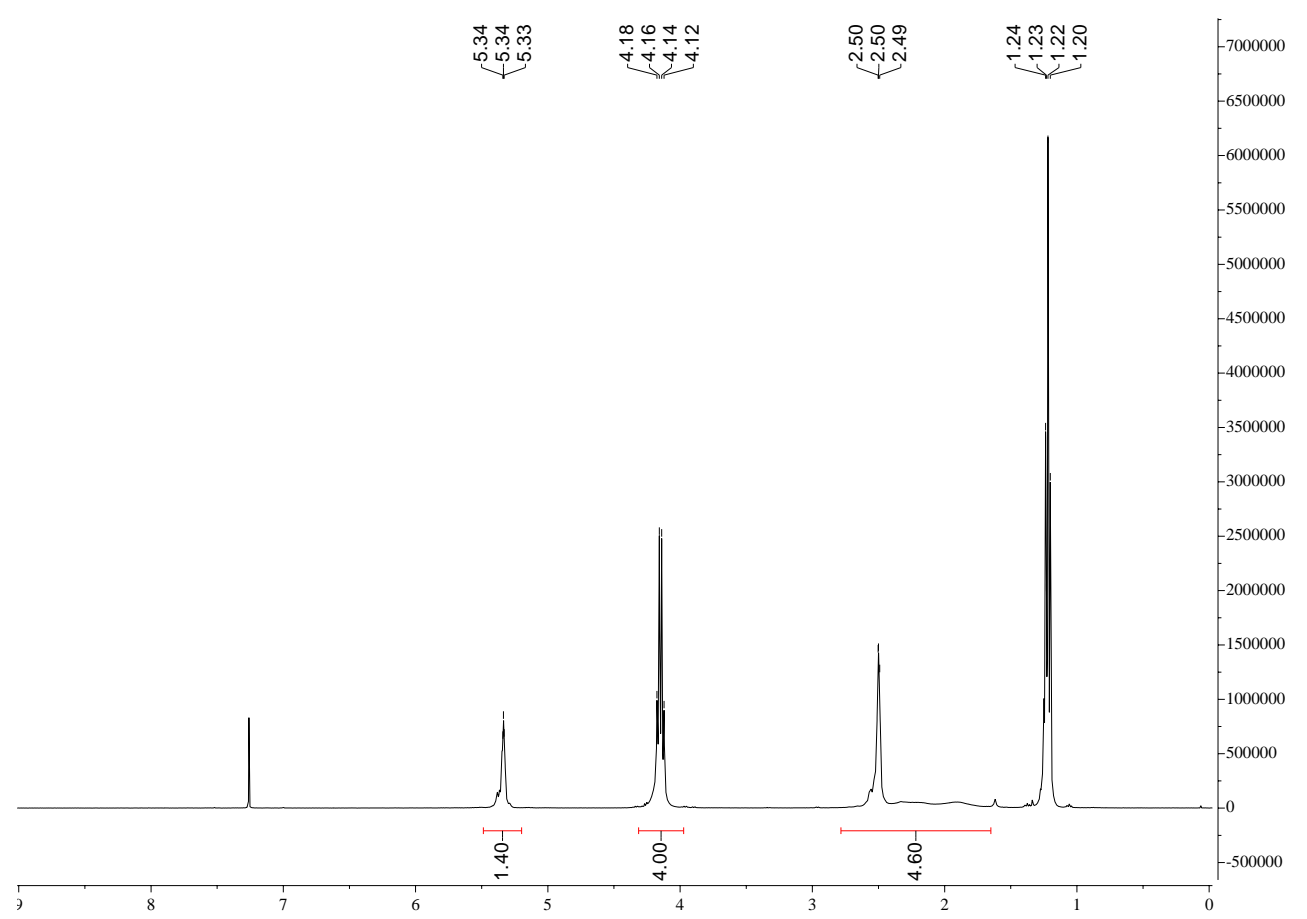

Figure S53. 1H NMR spectrum of poly(EtVCP) II

Poly(EtVCP) III. $M_{\mathrm{n}}=21.1 \mathrm{kDa}, \nexists=1.23, S_{\mathrm{L}}=35 \%$. See section 5.2.

Poly(EtVCP) IV. $M_{\mathrm{n}}=22.9 \mathrm{kDa}, \oslash=1.17, S_{\mathrm{L}}=15 \%$. See section 4.6.1. 


\section{Characterizations of Poly(Vinylcyclopropanes)}

\subsection{GPC Traces, DSC/TGA Curves of Poly(EtVCP)}

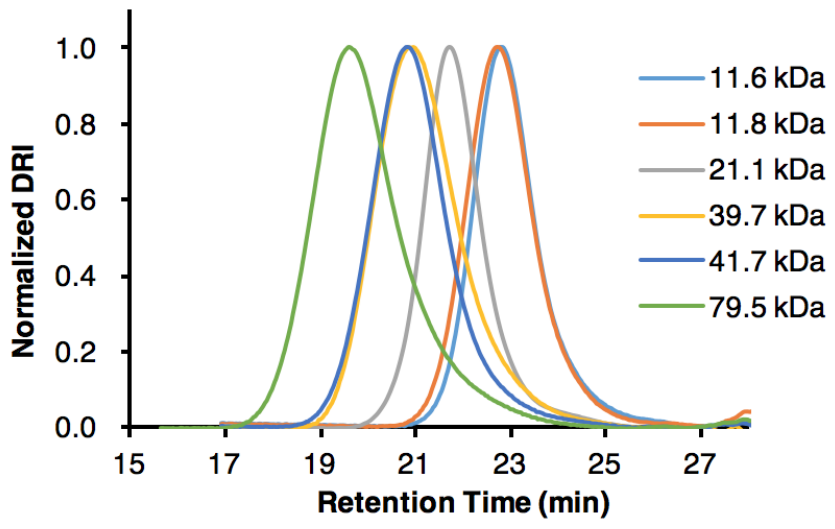

Figure S54. Selected GPC traces of poly(EtVCP) in Table 1.

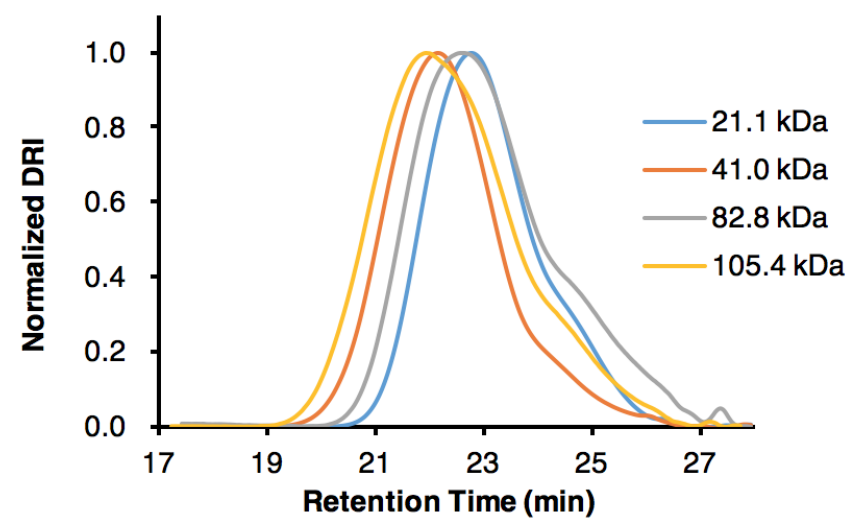

Figure S55. Selected GPC traces of poly(EtVCP) in Table 2.

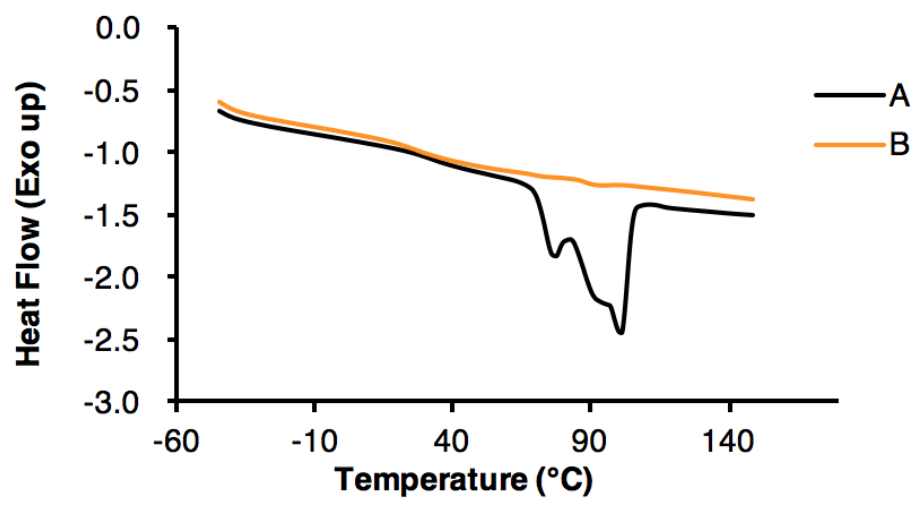

Figure S56. DSC curves of poly(EtVCP) $\left(\mathbf{A}: M_{\mathrm{n}}=21.1 \mathrm{kDa}, Ð=1.15, \mathrm{SL}=97 \% ; \mathbf{B}: M_{\mathrm{n}}\right.$ $=21.1 \mathrm{kDa}, Ð=1.09, \mathrm{SL}=16 \%)$. 


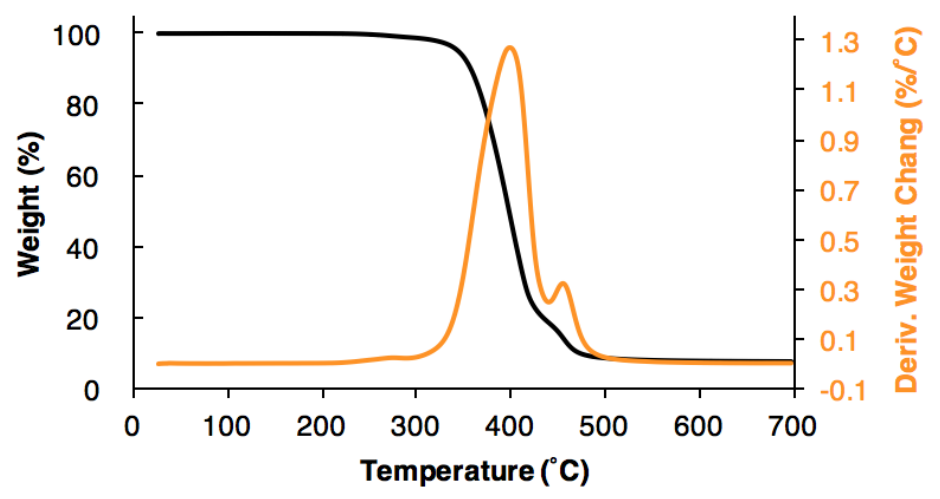

Figure S57. TGA (black) and DTG (oragne) curves of $l$-poly(EtVCP) in Table 1, entry 5. $T_{\mathrm{d}}=357^{\circ} \mathrm{C}, T_{\max 1}=401^{\circ} \mathrm{C}, T_{\max 2}=455^{\circ} \mathrm{C}$.

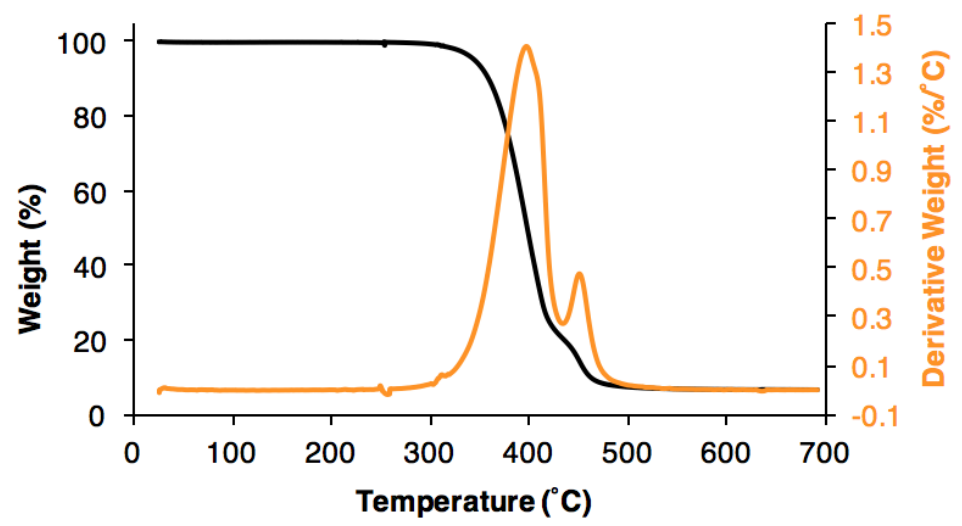

Figure S58. TGA (black) and DTG (orange) curves of $c$-poly(EtVCP) in Table 2, entry 9. $T_{\mathrm{d}}=359^{\circ} \mathrm{C}, T_{\max 1}=398{ }^{\circ} \mathrm{C}, T_{\max 2}=451{ }^{\circ} \mathrm{C}$.

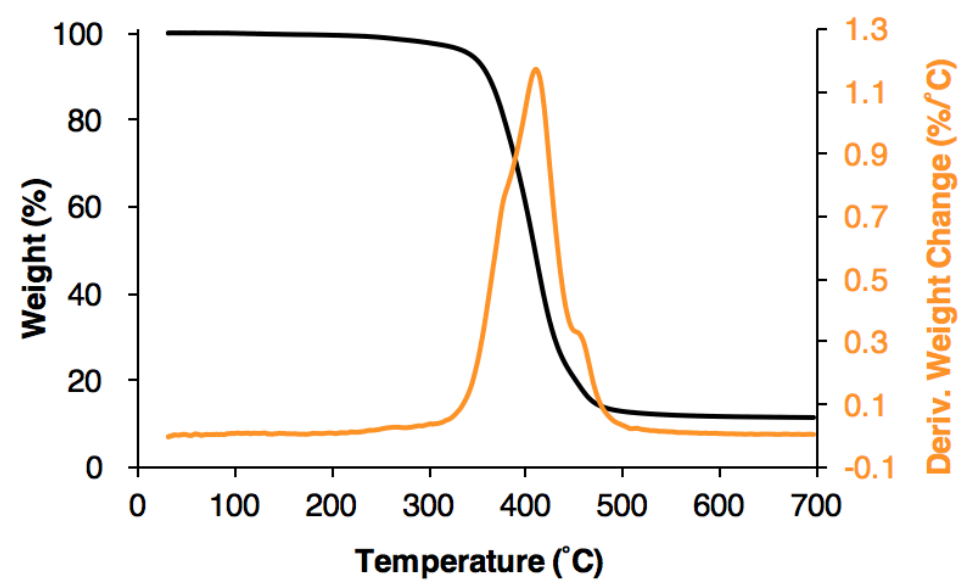

Figure S59. TGA (black) and DTG (orange) curves of poly(EtVCP)- $b$-poly $(\mathrm{PhVCP}) . T_{\mathrm{d}}=$ $360{ }^{\circ} \mathrm{C}, T_{\max }=409{ }^{\circ} \mathrm{C}$. 


\section{2 ${ }^{1} \mathrm{H}-\mathrm{NMR}$ spectra, GPC Traces and DSC/TGA Cures of Poly(PrVCP)}

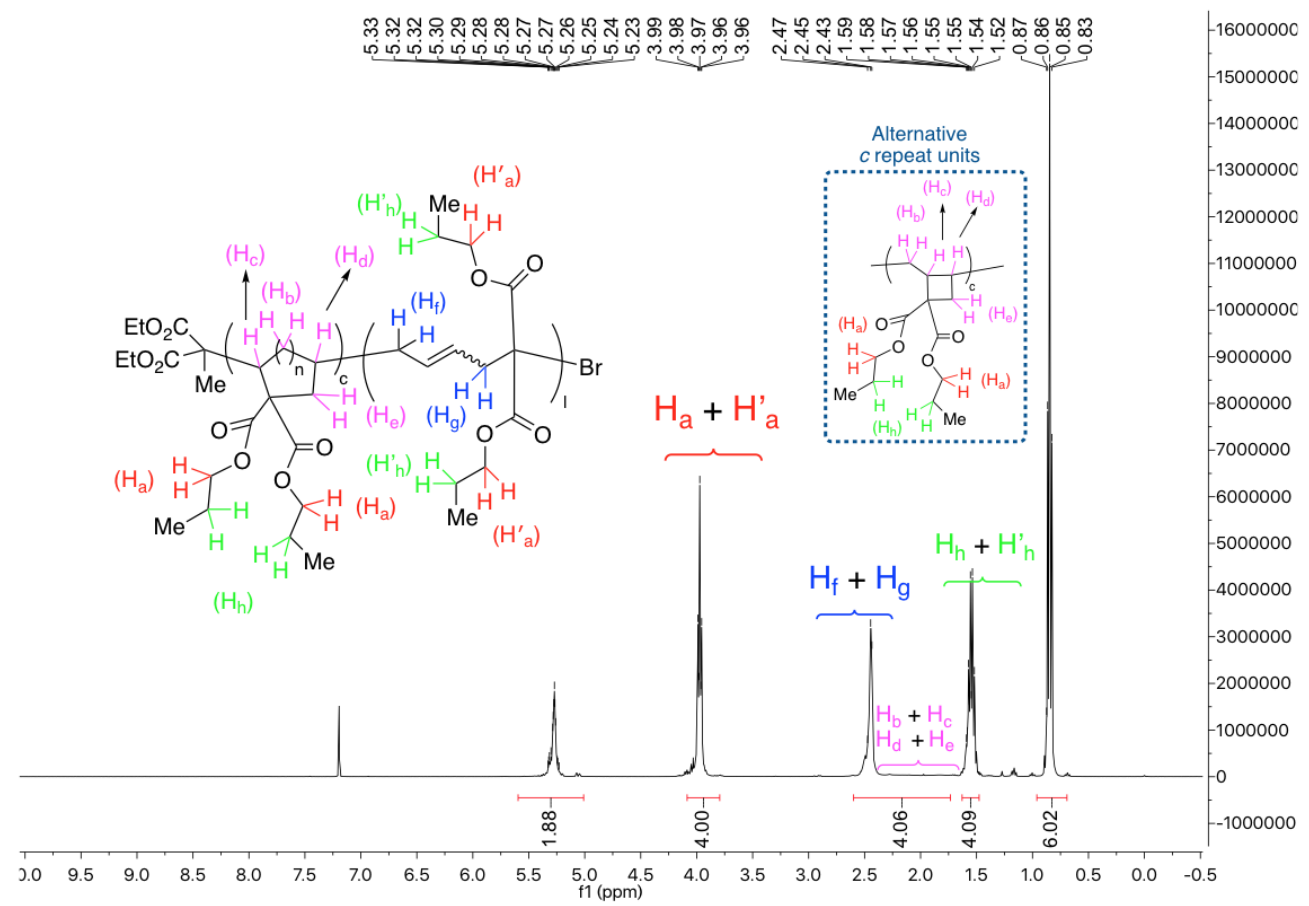

Figure S60. ${ }^{1} \mathrm{H}$ NMR spectrum of $l$-poly(PrVCP) $\left(M_{\mathrm{n}}=25.7 \mathrm{kDa}, Ð=1.12, S_{\mathrm{L}}=97 \%\right)$. ${ }^{1} \mathbf{H}$ NMR (400 MHz, $\left.\mathrm{CDCl}_{3}\right) \delta 5.45-5.17(\mathrm{br}, 1.88 \mathrm{H}), 3.97(\mathrm{t}, J=6.6 \mathrm{~Hz}, 4 \mathrm{H}), 2.70-$ $1.70(\mathrm{br}, 4.06 \mathrm{H}), 1.65-1.45(\mathrm{~m}, 4 \mathrm{H}), 0.85(\mathrm{t}, J=7.4 \mathrm{~Hz}, 6 \mathrm{H})$.

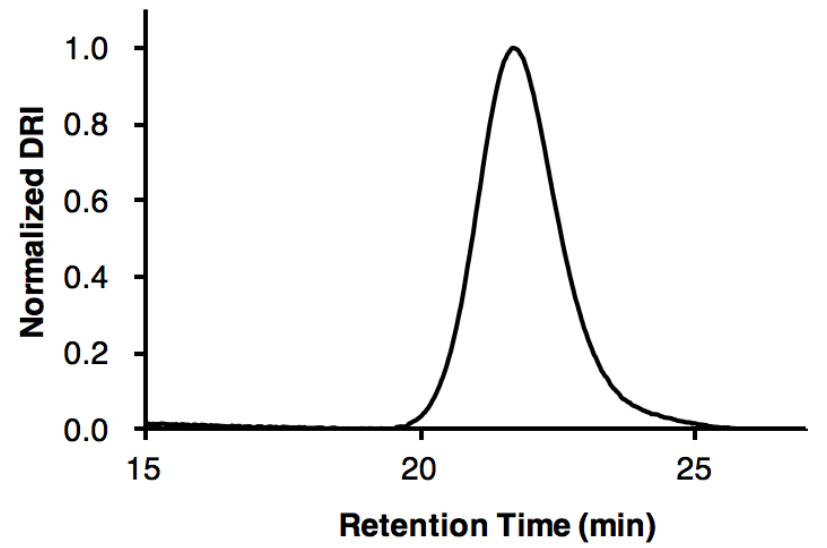

Figure S61. GPC trace of $l$-poly(PrVCP) $\left(M_{\mathrm{n}}=25.7 \mathrm{kDa}, Ð=1.12, S_{\mathrm{L}}=97 \%\right)$ 


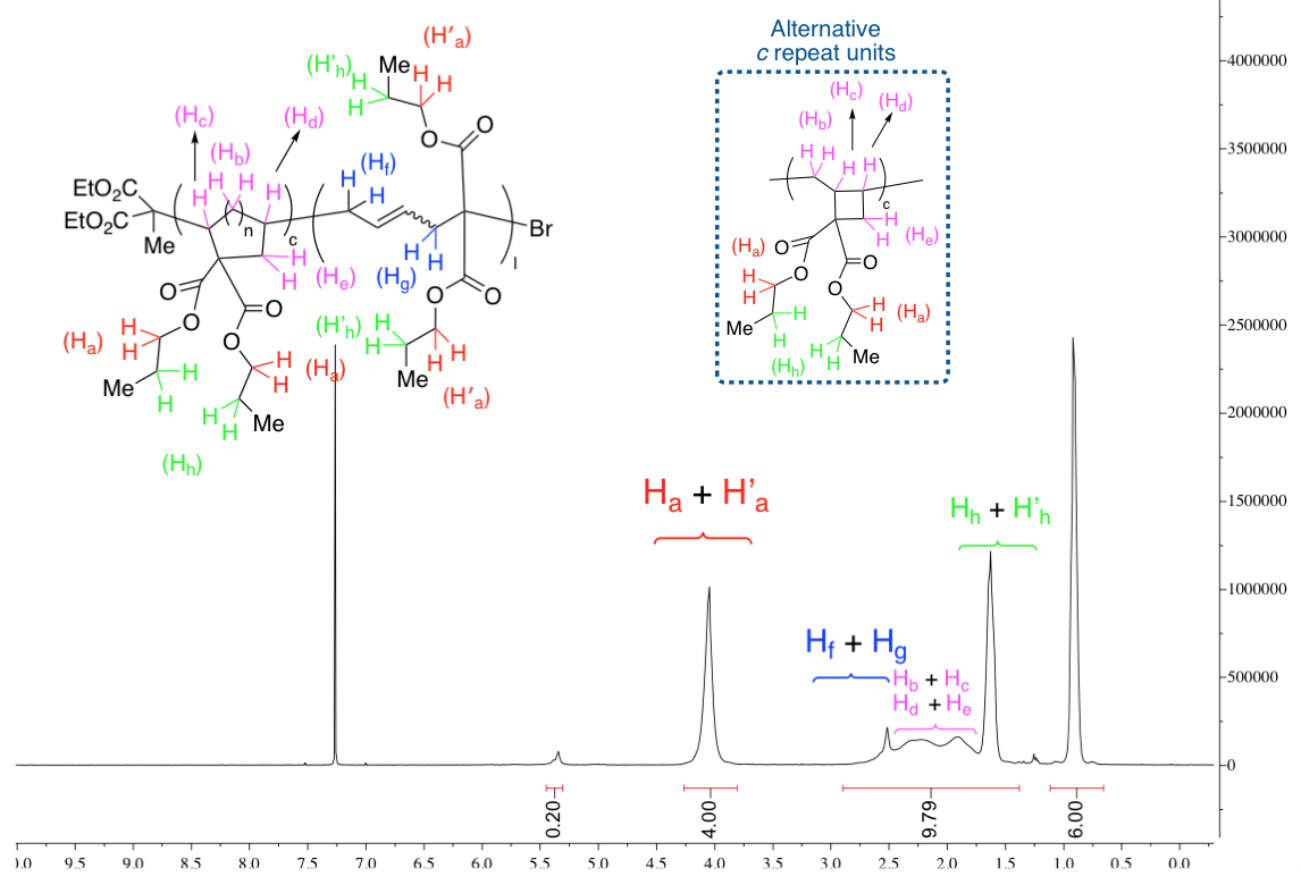

Figure S62. ${ }^{1} \mathrm{H}$ NMR spectrum of $c$-poly $(\operatorname{PrVCP})\left(M_{\mathrm{n}}=29.3 \mathrm{kDa}, Ð=1.11, S_{\mathrm{L}}=10 \%\right)$. ${ }^{1} \mathrm{H}$ NMR (400 MHz, $\left.\mathrm{CDCl}_{3}\right) \delta 5.45$ - 5.17 (br, $0.20 \mathrm{H}$ ), 3.97 (br, 4H), 2.80 - 1.40 (br, 9.79H), $1.20-0.75$ (br, 6H).

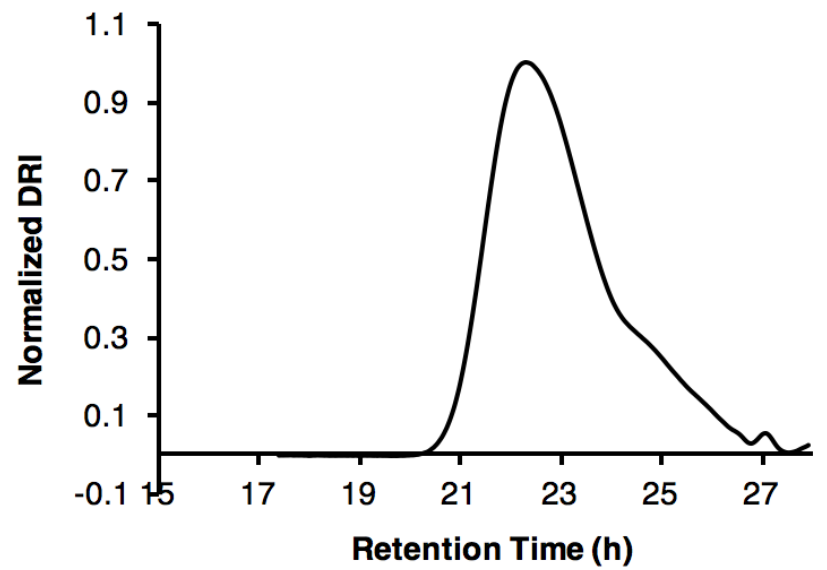

Figure S63. GPC trace of $c$-poly $(\operatorname{PrVCP})\left(M_{\mathrm{n}}=29.3 \mathrm{kDa}, Ð=1.11, S_{\mathrm{L}}=10 \%\right)$ 


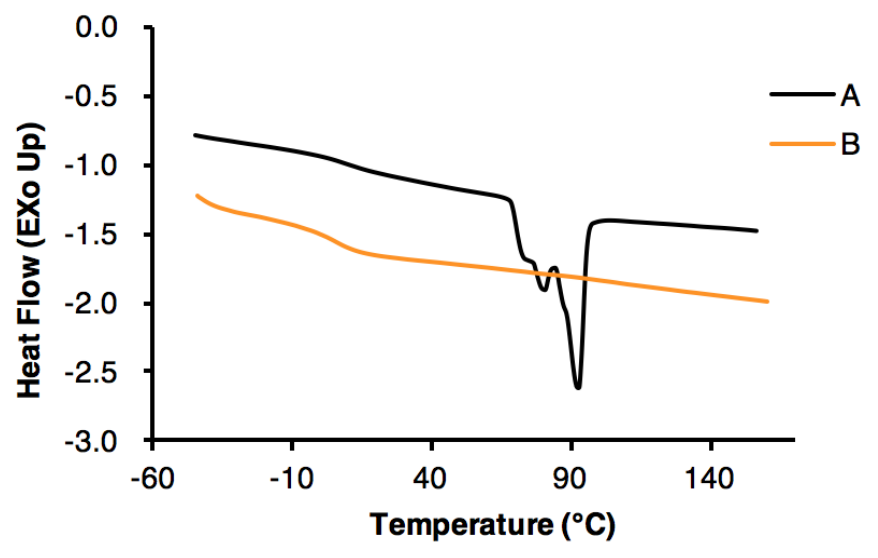

Figure S64. DSC curves of poly(PrVCP) (A: $M_{\mathrm{n}}=25.7 \mathrm{kDa}, \oslash=1.12, S_{\mathrm{L}}=97 \%$; B: $M_{\mathrm{n}}$ $\left.=29.3 \mathrm{kDa}, \oslash=1.11, S_{\mathrm{L}}=10 \%\right)$

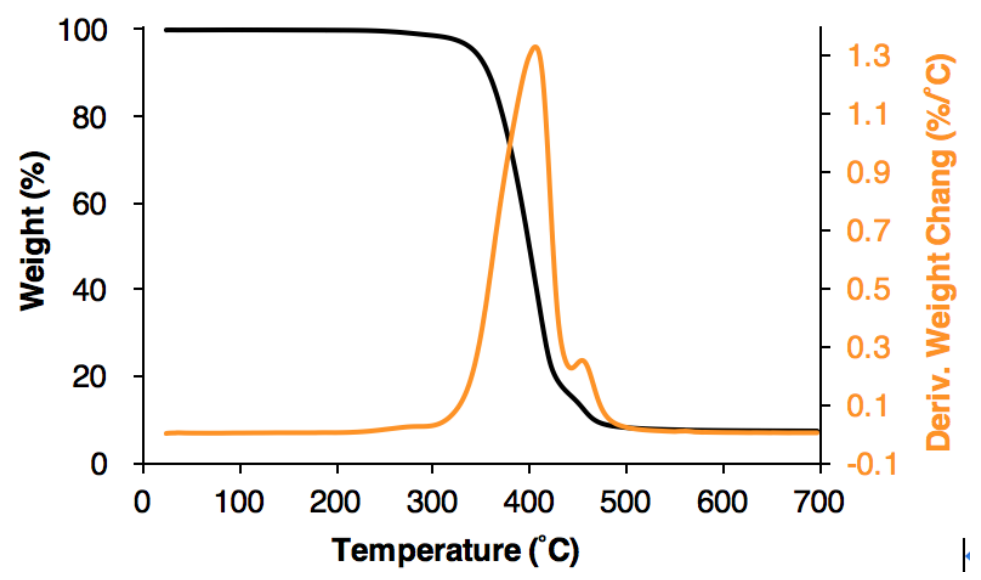

Figure S65. TGA (black) and DTG (orange) curves of $l$-poly $(\operatorname{PrVCP})\left(M_{\mathrm{n}}=25.7 \mathrm{kDa}, \nexists\right.$ $\left.=1.12, S_{\mathrm{L}}=97 \%\right) . T_{\mathrm{d}}=357^{\circ} \mathrm{C}, T_{\max 1}=405^{\circ} \mathrm{C}, T_{\max 2}=455^{\circ} \mathrm{C}$.

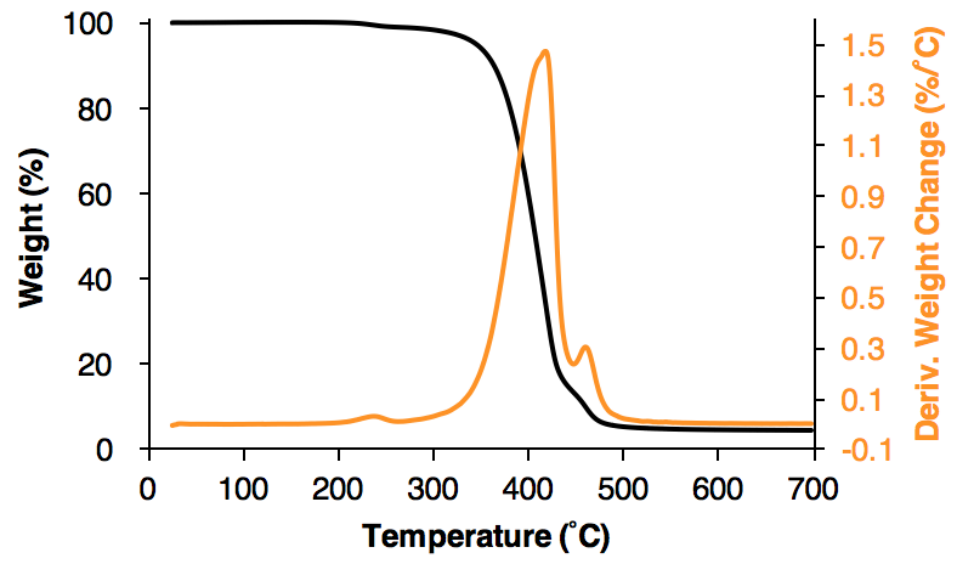

Figure S66. TGA (black) and DTG (orange) curves of $c$-poly $(\operatorname{PrVCP})\left(M_{\mathrm{n}}=29.3 \mathrm{kDa}, \nexists\right.$ $\left.=1.11, S_{\mathrm{L}}=10 \%\right) \cdot T_{\mathrm{d}}=362{ }^{\circ} \mathrm{C}, T_{\max 1}=418{ }^{\circ} \mathrm{C}, T_{\max 2}=459^{\circ} \mathrm{C}$. 


\section{3 ${ }^{1} \mathrm{H}$-NMR Spectra, GPC, DSC, TGA Traces of Poly $(\mathrm{BuVCP})$}

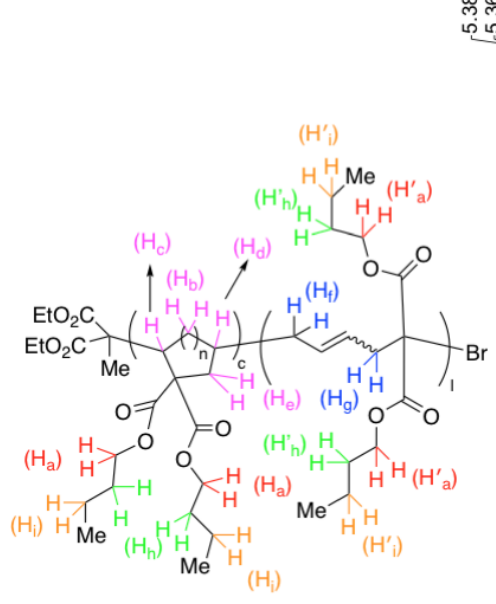

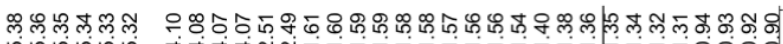
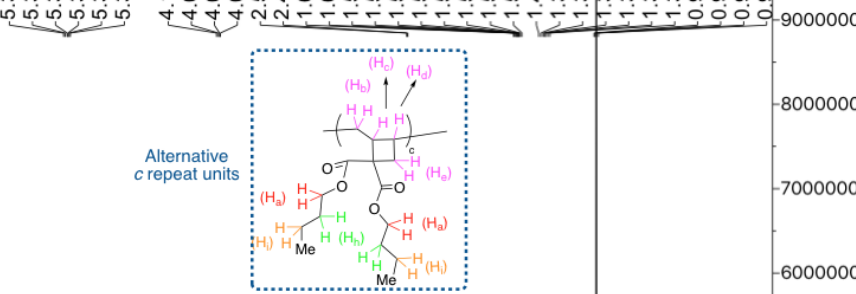

00000

$\mathrm{H}_{\mathrm{a}}+\mathrm{H}_{\mathrm{a}}^{\prime}$
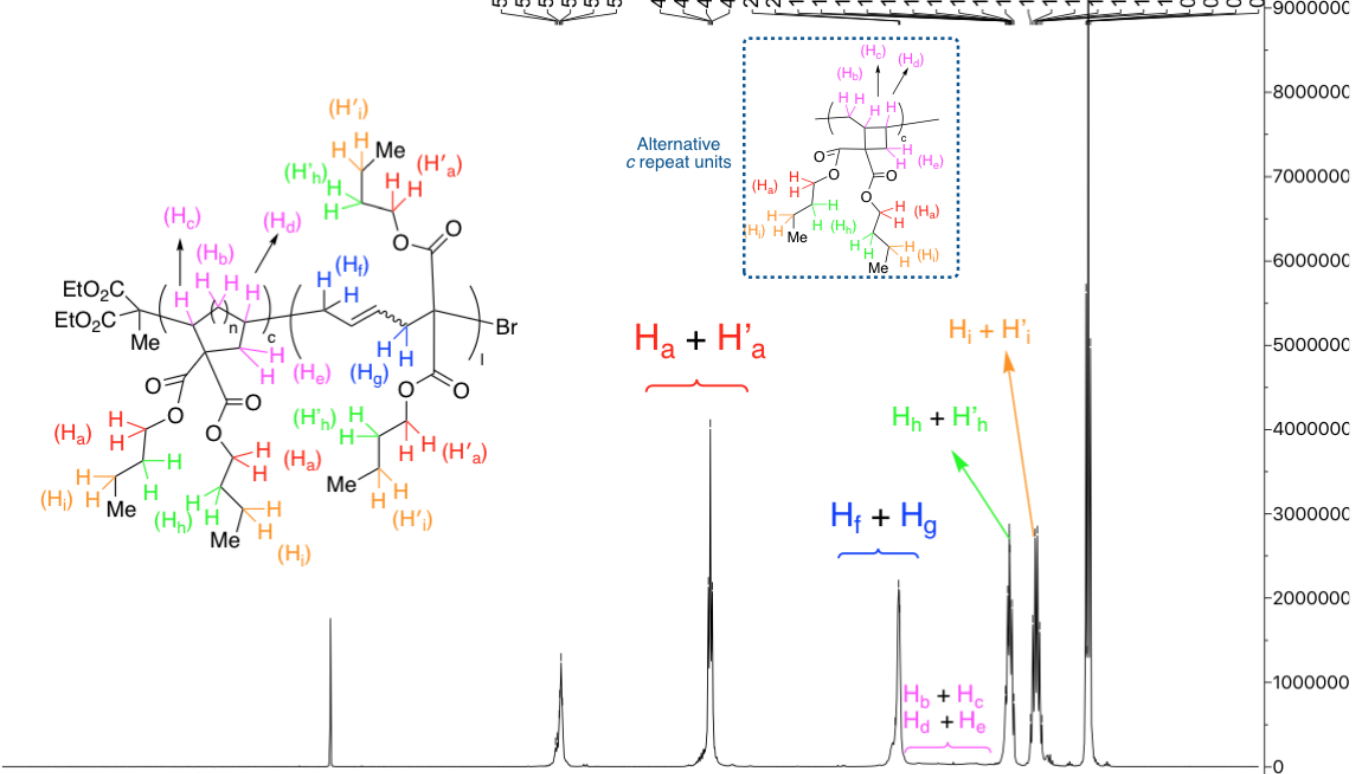

7000000

6000000

5000000

4000000

00000

2000000

1000000

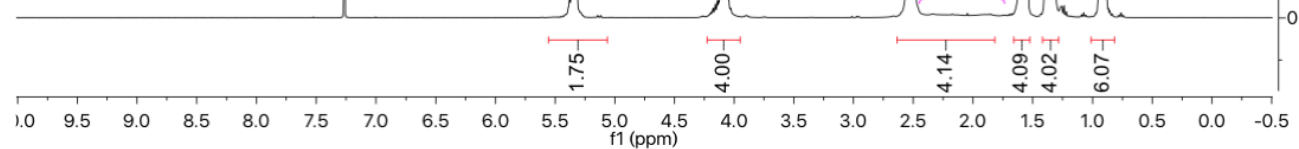

Figure S67. ${ }^{1} \mathrm{H}$ NMR spectrum of $l$-poly $(\mathrm{BuVCP})\left(M_{\mathrm{n}}=27.2 \mathrm{kDa}, Ð=1.15, S_{\mathrm{L}}=93 \%\right)$.

${ }^{1}$ H NMR (400 MHz, $\left.\mathrm{CDCl}_{3}\right) \delta 5.45$ - 5.17 (br, $\left.1.75 \mathrm{H}\right), 4.22-3.98$ (m, 4H), 2.70 - 1.70

(br, 4.06H), $1.65-1.50(\mathrm{~m}, 4 \mathrm{H}), 1.45-1.28(\mathrm{~m}, 4 \mathrm{H}), 0.92(\mathrm{t}, J=7.4 \mathrm{~Hz}, 6 \mathrm{H})$.

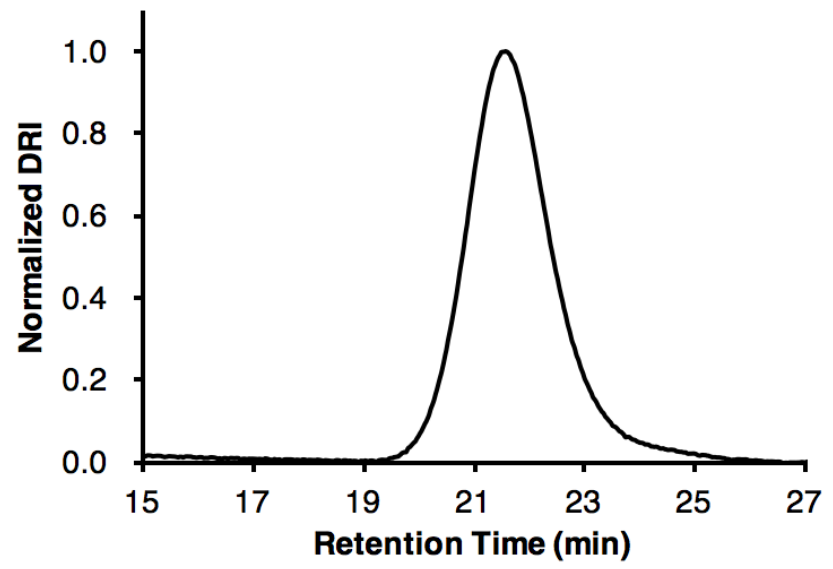

Figure S68. GPC trace of $l$-poly(BuVCP) $\left(M_{\mathrm{n}}=27.2 \mathrm{kDa}, Ð=1.15, S_{\mathrm{L}}=93 \%\right)$ 


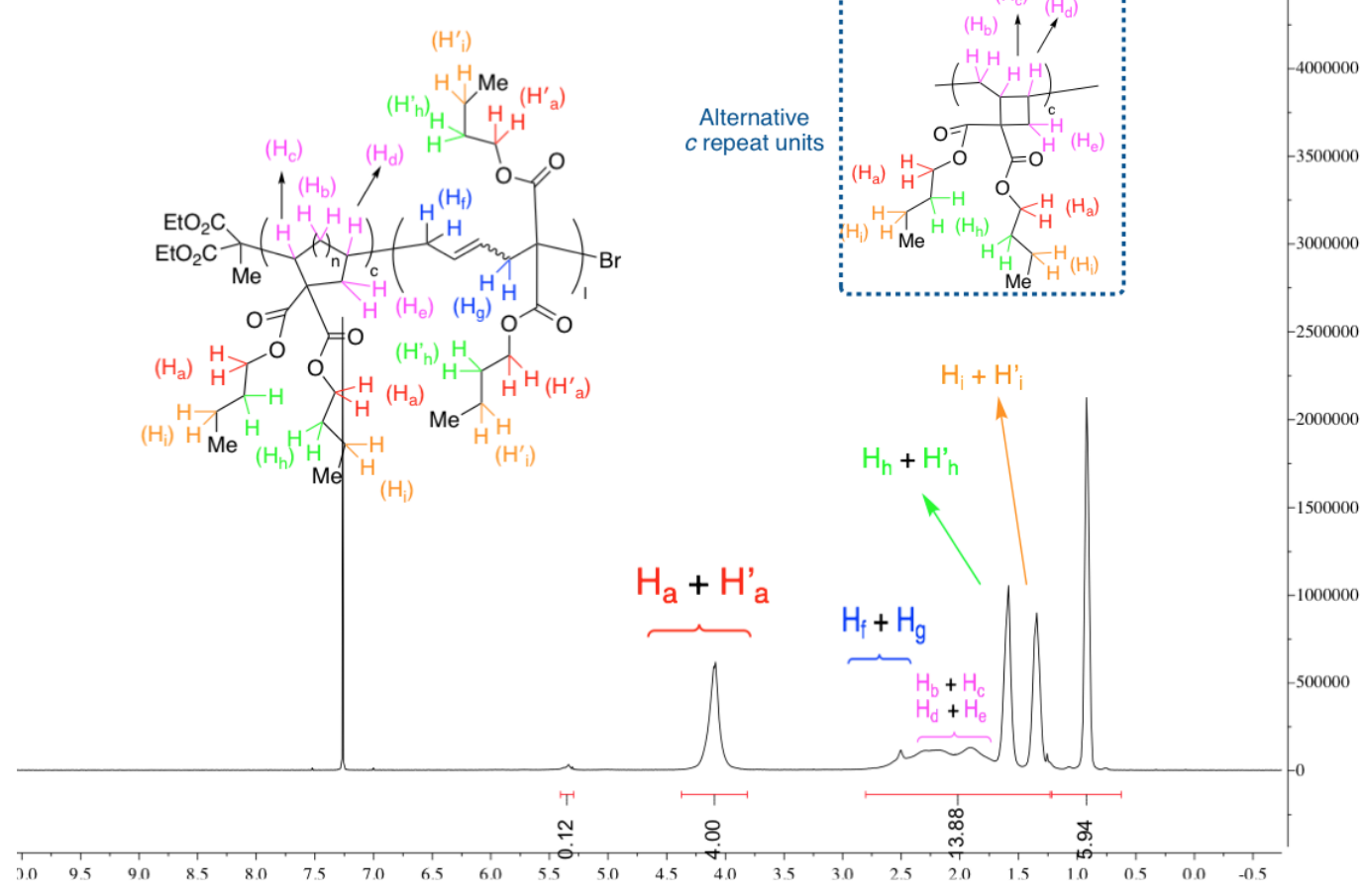

Figure S69. ${ }^{1} \mathrm{H}$ NMR spectrum of $c$-poly $(\mathrm{BuVCP})\left(M_{\mathrm{n}}=31.9 \mathrm{kDa}, Ð=1.10, S_{\mathrm{L}}=6 \%\right)$. ${ }^{1} \mathbf{H}$ NMR (400 MHz, CDCl 3 ) $\delta 5.45$ - $5.30(\mathrm{br}, 0.12 \mathrm{H}), 4.35$ - $3.98(\mathrm{~m}, 4 \mathrm{H}), 2.70-1.70$ (br, 4.06H), $1.65-1.50$ (m, 4H), $1.45-1.28(\mathrm{~m}, 4 \mathrm{H}), 0.92(\mathrm{t}, J=7.4 \mathrm{~Hz}, 6 \mathrm{H})$.

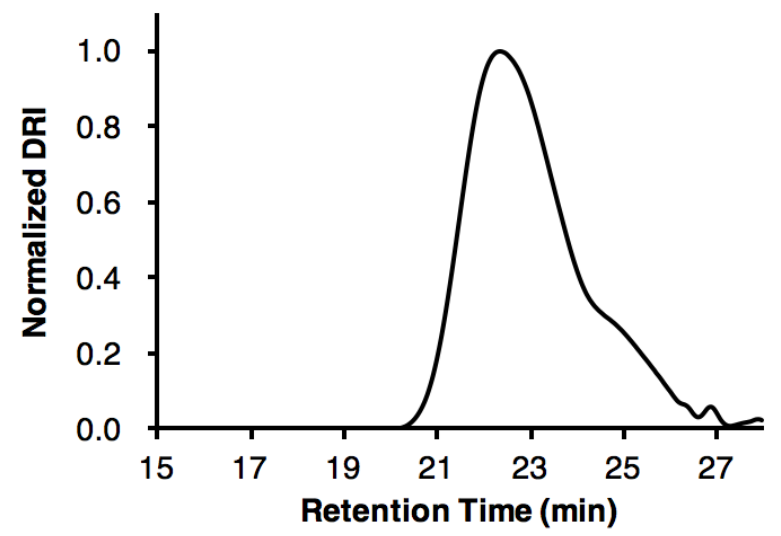

Figure S70. GPC trace of $c$-poly $(\mathrm{BuVCP})\left(M_{\mathrm{n}}=31.9 \mathrm{kDa}, Ð=1.10, S_{\mathrm{L}}=6 \%\right)$ 


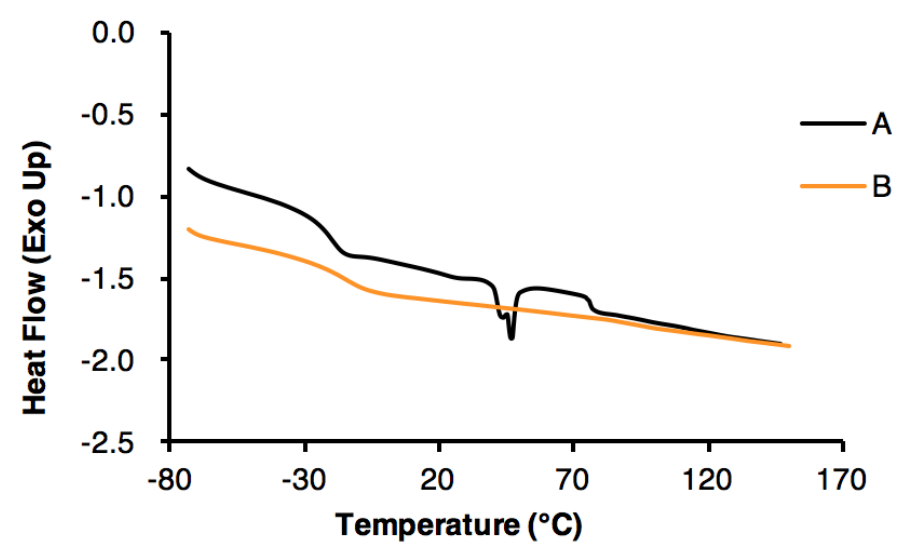

Figure S71. DSC traces of poly(BuVCP) (A: $M_{\mathrm{n}}=27.2 \mathrm{kDa}, \nexists=1.15, S_{\mathrm{L}}=93 \%$; B: $M_{\mathrm{n}}$ $=31.9 \mathrm{kDa}, Ð=1.10, S_{\mathrm{L}}=6 \%$ )

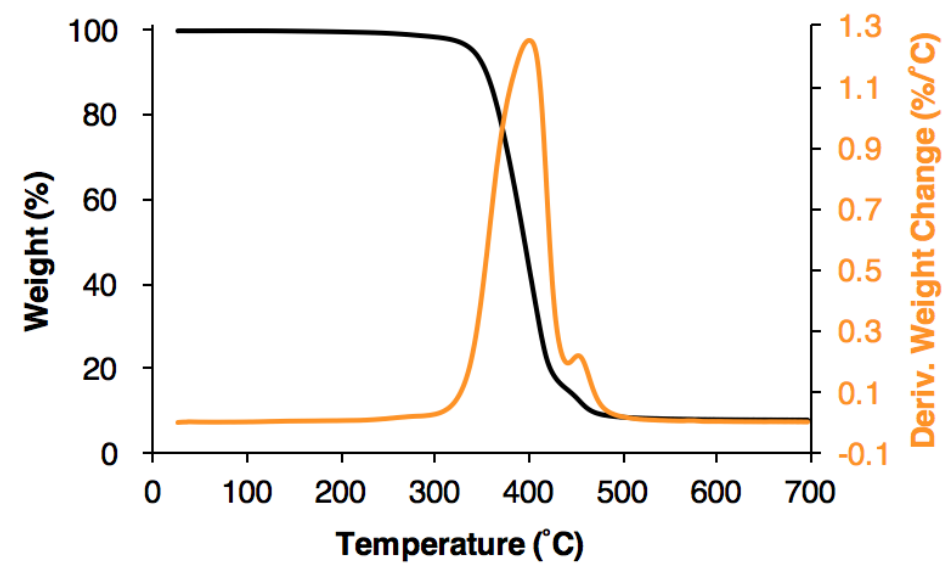

Figure S72. TGA (black) and DTG (orange) curves of $l$-poly $(\mathrm{BuVCP})\left(M_{\mathrm{n}}=27.2 \mathrm{kDa}, \nexists\right.$ $\left.=1.15, S_{\mathrm{L}}=93 \%\right) \cdot T_{\mathrm{d}}=354{ }^{\circ} \mathrm{C}, T_{\max 1}=401{ }^{\circ} \mathrm{C}, T_{\max 2}=452{ }^{\circ} \mathrm{C}$.

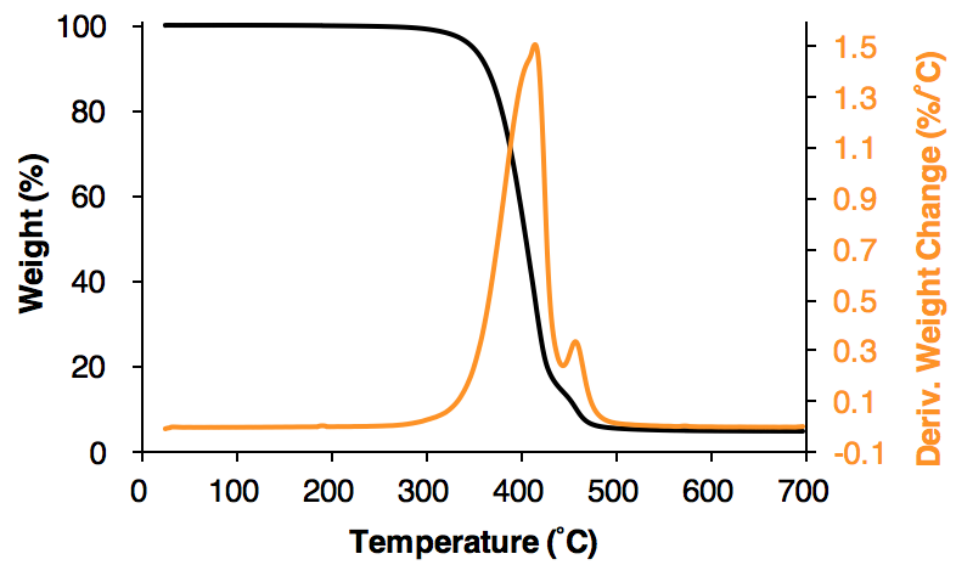

Figure S73. TGA (black) and DTG (orange) curves of $c$-poly $(\mathrm{BuVCP})\left(M_{\mathrm{n}}=31.9 \mathrm{kDa}, \nexists\right.$ $\left.=1.10, S_{\mathrm{L}}=6 \%\right) . T_{\mathrm{d}}=364^{\circ} \mathrm{C}, T_{\max 1}=413{ }^{\circ} \mathrm{C}, T_{\max 2}=458^{\circ} \mathrm{C}$. 


\section{4 ${ }^{1}$ H-NMR Spectra, GPC traces, and DSC/TGA Curves of Poly $\left({ }^{(} \mathrm{BuVCP}\right)$}

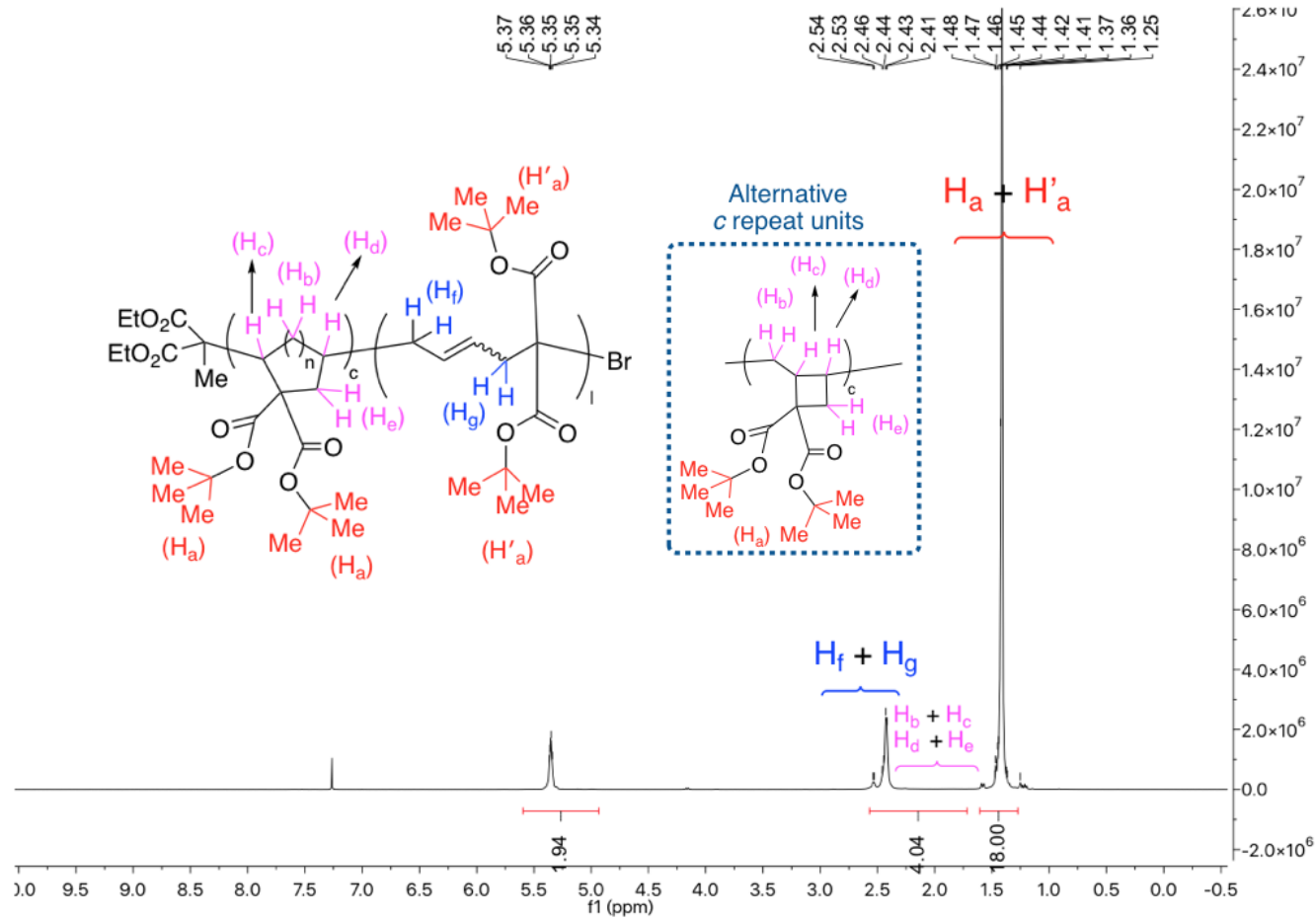

Figure S74. ${ }^{1} \mathrm{H}$ NMR spectrum of $l$-poly $\left({ }^{t} \mathrm{BuVCP}\right)\left(M_{\mathrm{n}}=29.3 \mathrm{kDa}, \nexists=1.19, S_{\mathrm{L}}=98 \%\right)$. ${ }^{1} \mathbf{H}$ NMR (400 MHz, $\left.\mathrm{CDCl}_{3}\right) \delta 5.50-5.05$ (br, $\left.1.94 \mathrm{H}\right), 2.68-1.70(\mathrm{br}, 4.04 \mathrm{H}), 1.65-$ $1.50(\mathrm{~m}, 4 \mathrm{H}), 1.41$ (brs, 18H).

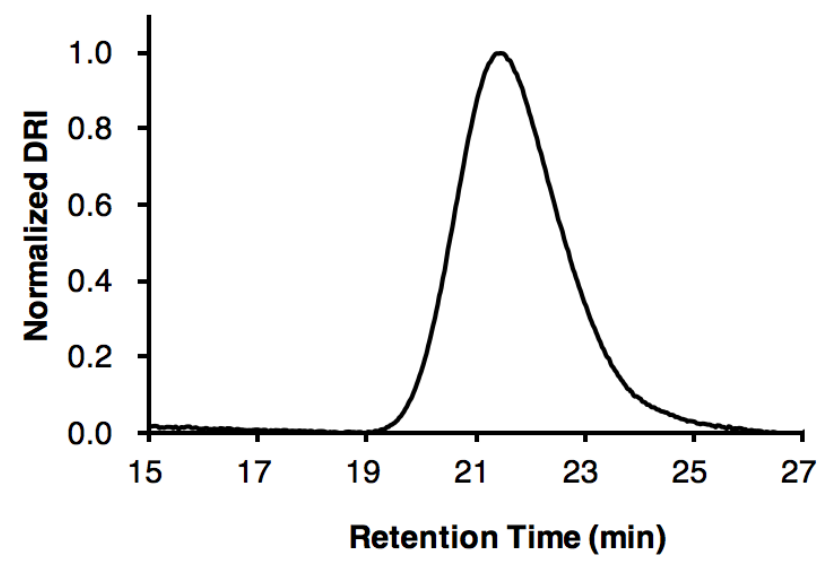

Figure S75. GPC trace of $l$-poly $\left({ }^{t} \mathrm{BuVCP}\right)\left(M_{\mathrm{n}}=29.3 \mathrm{kDa}, \oslash=1.19, S_{\mathrm{L}}=98 \%\right)$ 


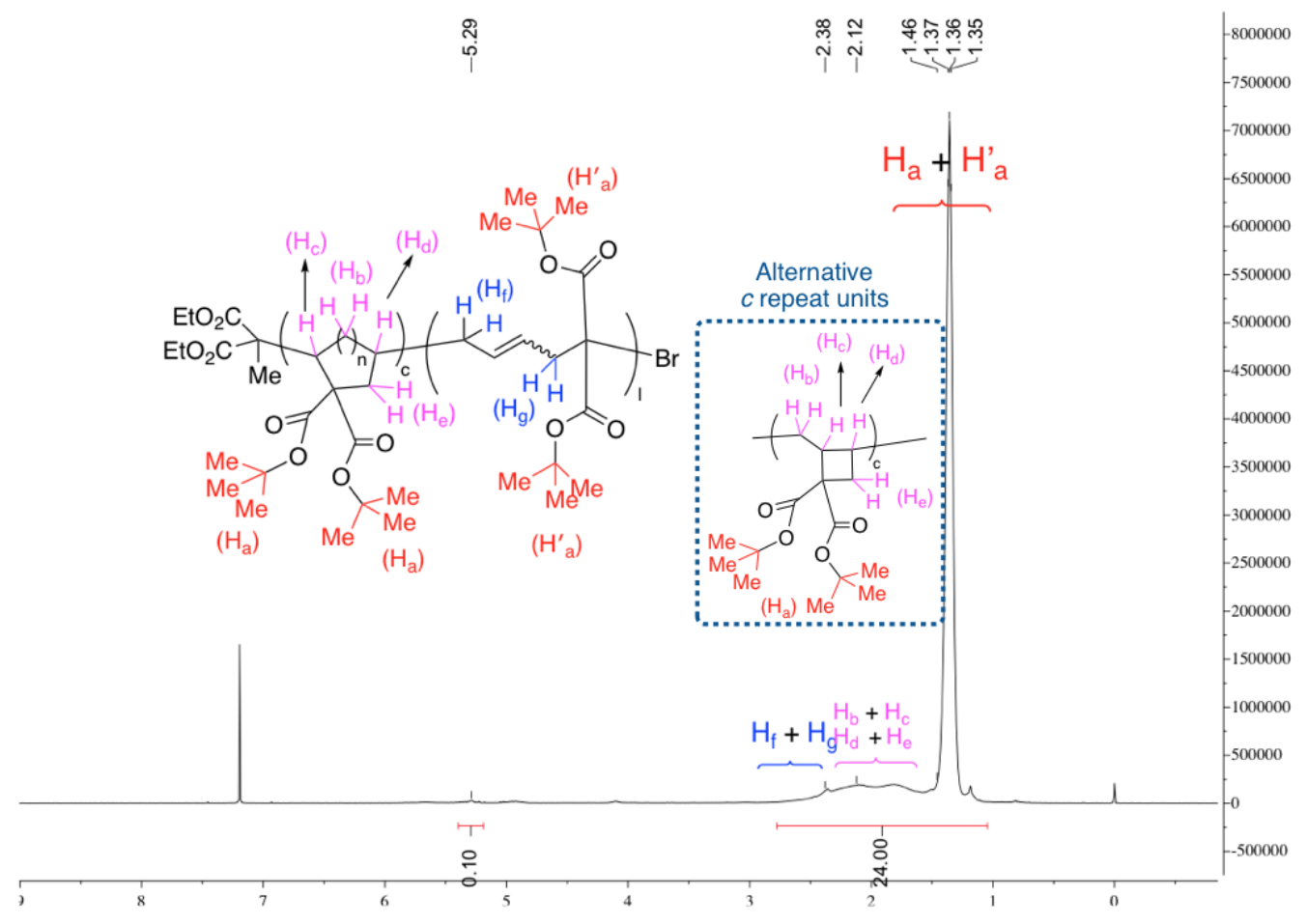

Figure S76. ${ }^{1} \mathrm{H}$ NMR spectrum of $c$-poly $\left({ }^{t} \mathrm{BuVCP}\right)\left(M_{\mathrm{n}}=30.3 \mathrm{kDa}, Ð=1.18, S_{\mathrm{L}}=5 \%\right)$.

${ }^{1} \mathrm{H}$ NMR (400 MHz, CDCl 3$) \delta 5.50-5.05$ (br, $\left.0.10 \mathrm{H}\right), 2.80-0.00$ (br, 24H).

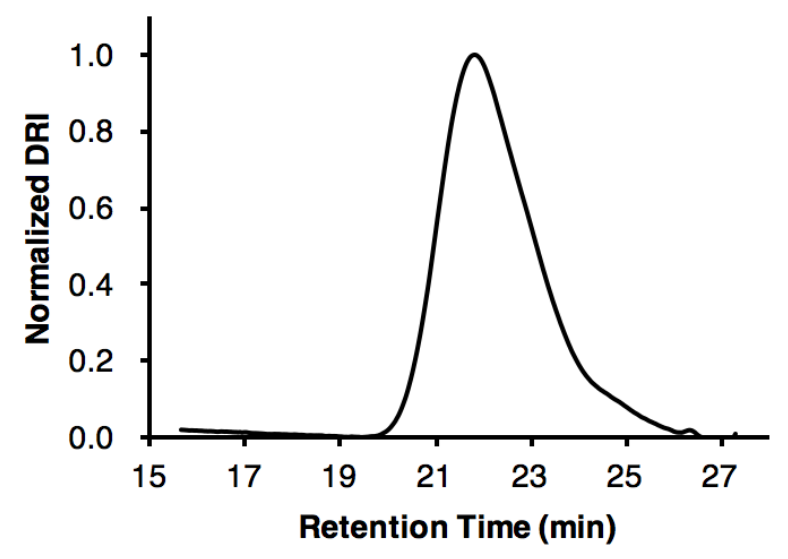

Figure S77. GPC trace of $c$-poly $\left({ }^{t} \mathrm{BuVCP}\right)\left(M_{\mathrm{n}}=30.3 \mathrm{kDa}, Ð=1.18, S_{\mathrm{L}}=5 \%\right)$ 


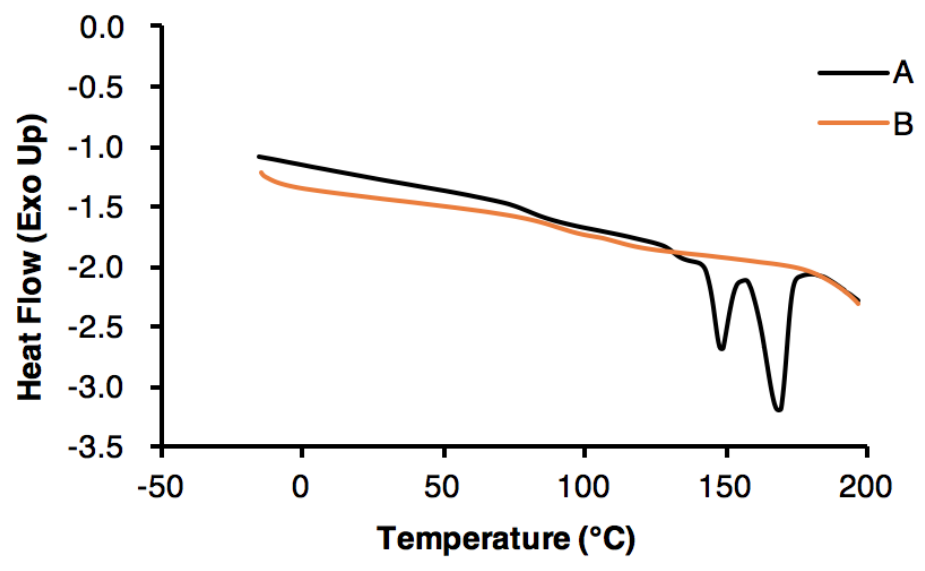

Figure S78. DSC traces of poly $\left({ }^{t} \mathrm{BuVCP}\right)\left(\mathrm{A}: M_{\mathrm{n}}=29.3 \mathrm{kDa}, Ð=1.19, S_{\mathrm{L}}=98 \% ; \mathrm{B}: M_{\mathrm{n}}\right.$ $=30.3 \mathrm{kDa}, Ð=1.18, S_{\mathrm{L}}=5 \%$ )

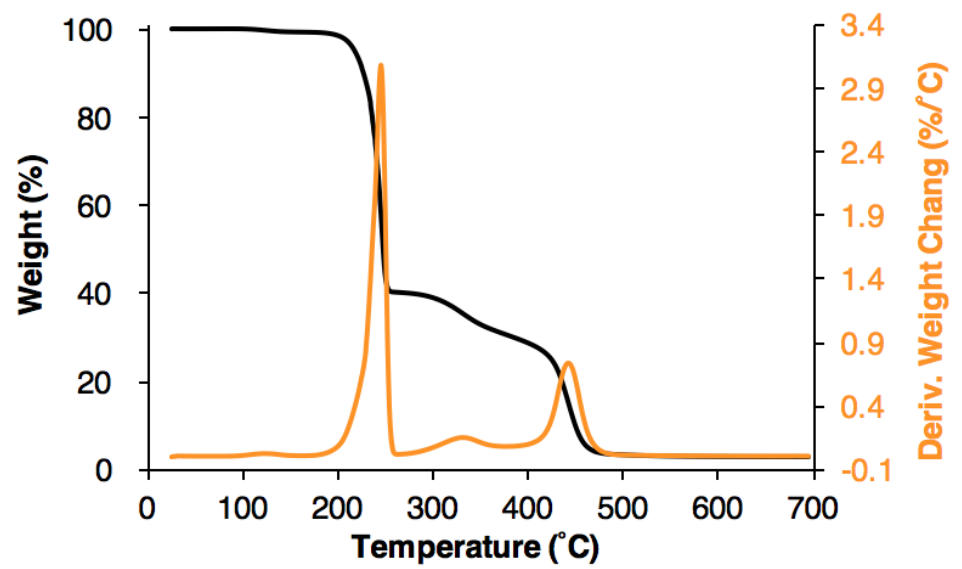

Figure S79. TGA (black) and DTG (orange) curves of $l$-poly $\left({ }^{t} \mathrm{BuVCP}\right)\left(M_{\mathrm{n}}=29.3 \mathrm{kDa}, \nexists\right.$ $\left.=1.19, S_{\mathrm{L}}=98 \%\right) \cdot T_{\mathrm{d}}=227^{\circ} \mathrm{C}, T_{\max 1}=245^{\circ} \mathrm{C}, T_{\max 2}=442^{\circ} \mathrm{C}$.

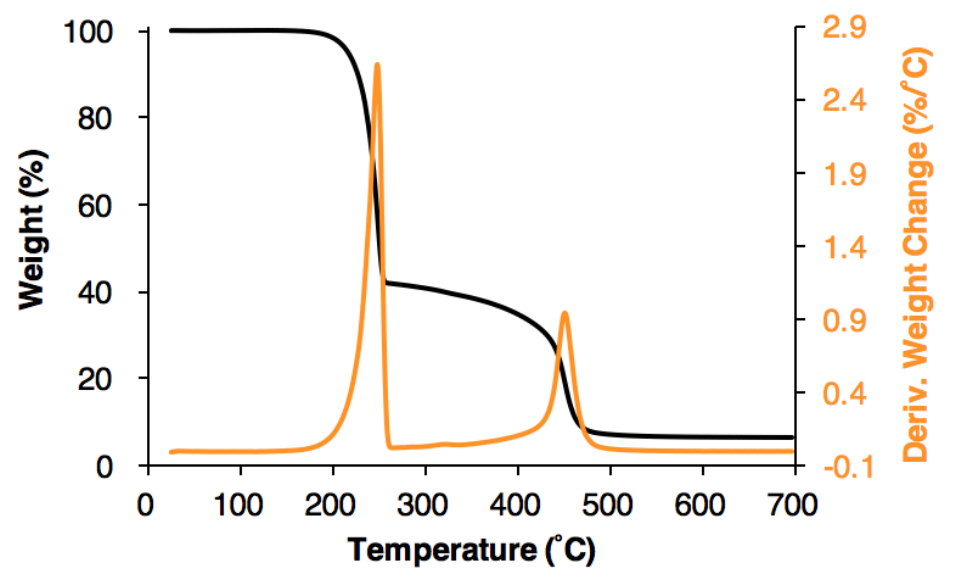

Figure S80. TGA (black) and DTG (orange) curves of $c$-poly $\left({ }^{t} \mathrm{BuVCP}\right)\left(M_{\mathrm{n}}=30.3 \mathrm{kDa}, \nexists\right.$ $\left.=1.18, S_{\mathrm{L}}=5 \%\right) . T_{\mathrm{d}}=226^{\circ} \mathrm{C}, T_{\max 1}=248{ }^{\circ} \mathrm{C}, T_{\max 2}=451^{\circ} \mathrm{C}$. 


\section{5 ${ }^{1}$ H-NMR Spectra, GPC Traces, and DSC/TGA Curves of Poly(BnVCP)}

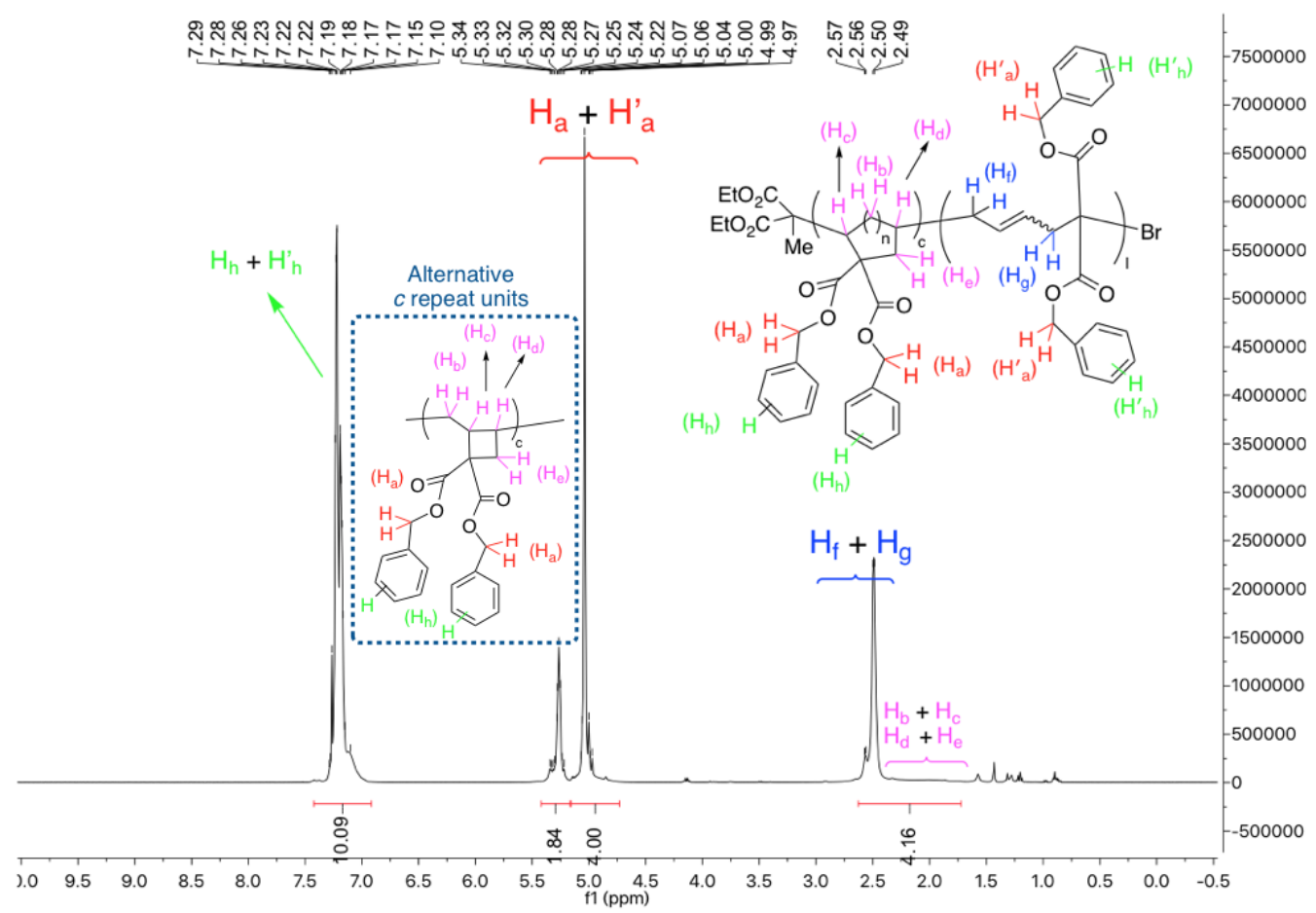

Figure S81. ${ }^{1} \mathrm{H}$ NMR spectrum of $l$-poly $(\mathrm{BnVCP})\left(M_{\mathrm{n}}=32.6 \mathrm{kDa}, Ð=1.16, S_{\mathrm{L}}=92 \%\right)$. ${ }^{1}$ H NMR $\left(400 \mathrm{MHz}, \mathrm{CDCl}_{3}\right) \delta 7.45-6.90$ (m, 10H), $5.44-5.17$ (br, $\left.1.84 \mathrm{H}\right), 5.15$ - 4.80 (br, 4H), $2.70-1.70$ (br, 4.16H).

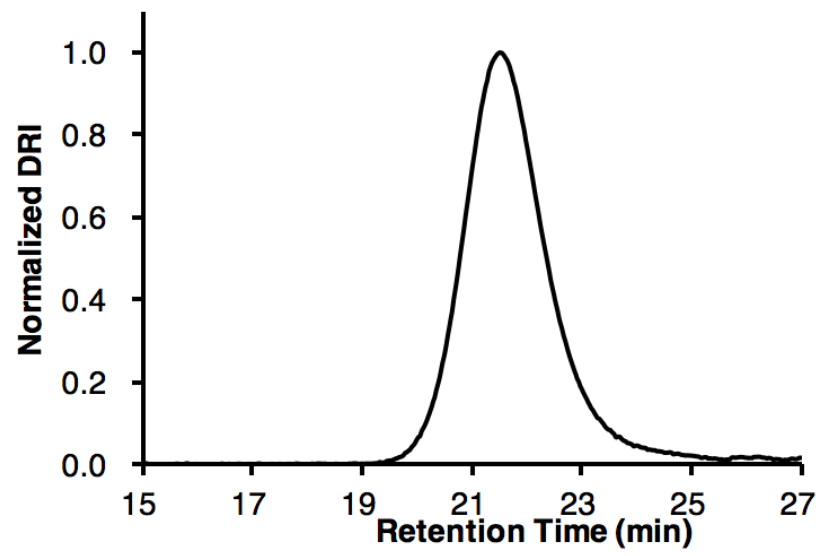

Figure S82. GPC trace of $l$-poly $(\mathrm{BnVCP})\left(M_{\mathrm{n}}=32.6 \mathrm{kDa}, Ð=1.16, S_{\mathrm{L}}=92 \%\right)$ 


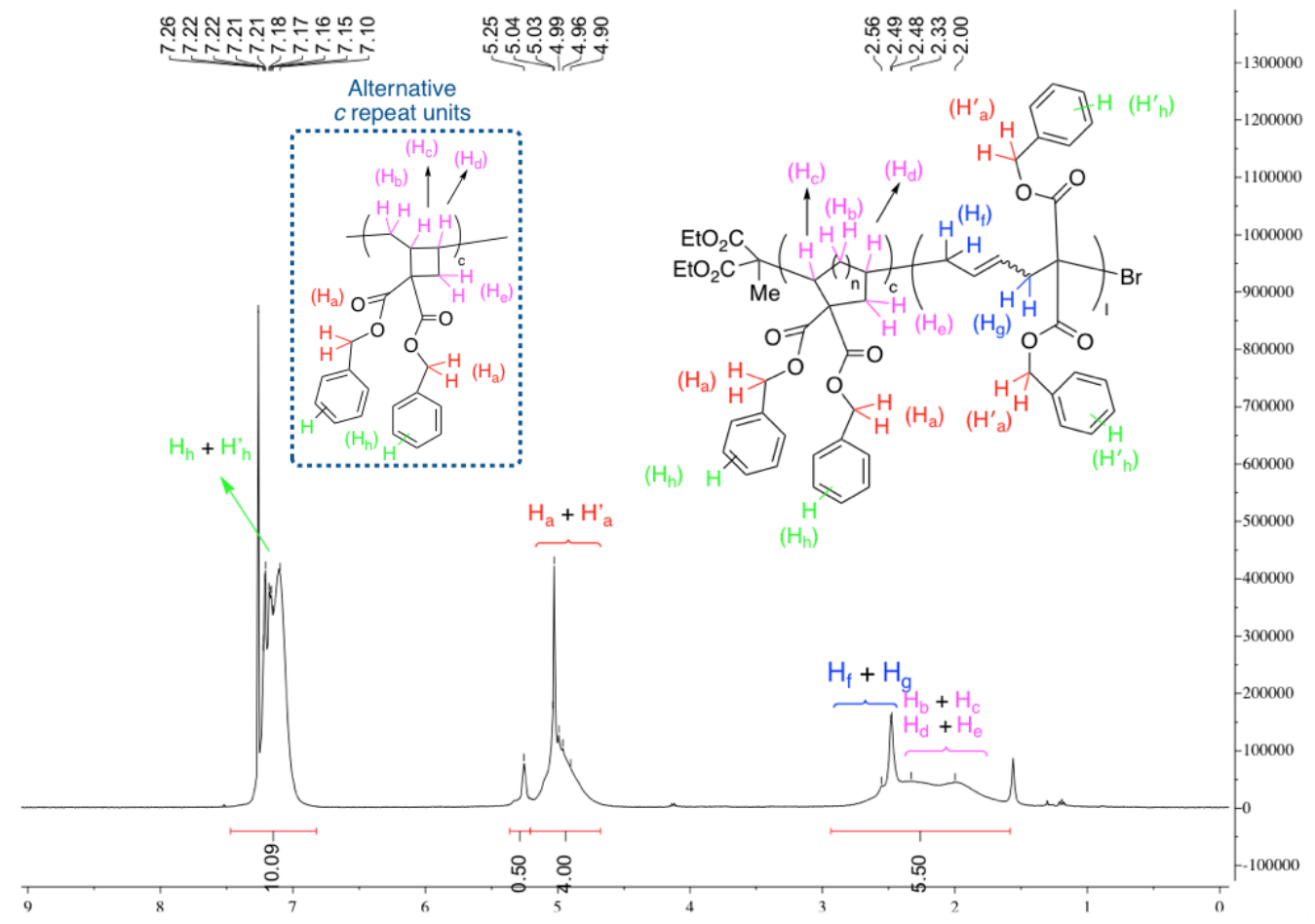

Figure S83. ${ }^{1} \mathrm{H}$ NMR spectrum of $c$-poly $(\mathrm{BnVCP})\left(M_{\mathrm{n}}=28.1 \mathrm{kDa}, Ð=1.18, S_{\mathrm{L}}=25 \%\right)$. ${ }^{1} \mathrm{H}$ NMR (400 MHz, $\left.\mathrm{CDCl}_{3}\right) \delta 7.35$ - 6.85 (m, 10H), 5.35 - 5.20 (br, $0.50 \mathrm{H}$ ), 5.20 - 4.70 (br, $4 \mathrm{H}), 2.80-1.60$ (br, $5.50 \mathrm{H})$.

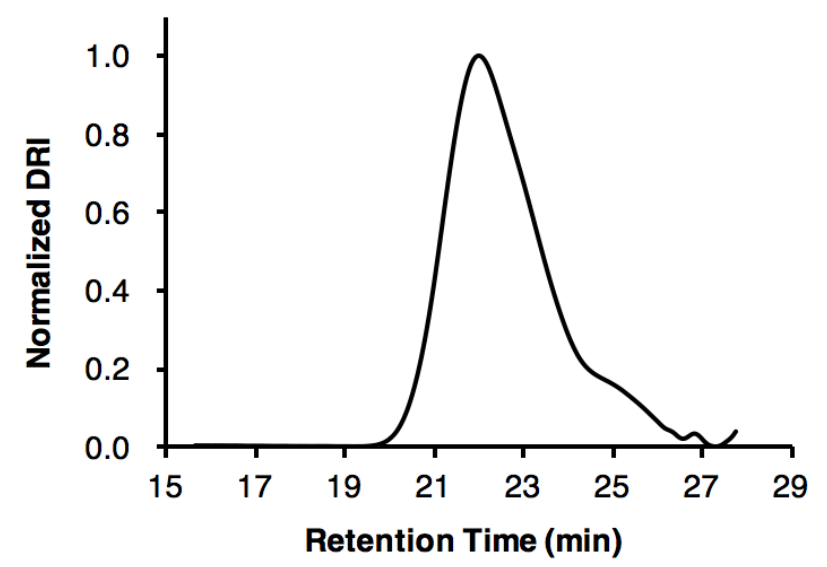

Figure S84. GPC trace of $c$-poly $(\mathrm{BnVCP})\left(M_{\mathrm{n}}=28.1 \mathrm{kDa}, Ð=1.18, S_{\mathrm{L}}=25 \%\right)$ 


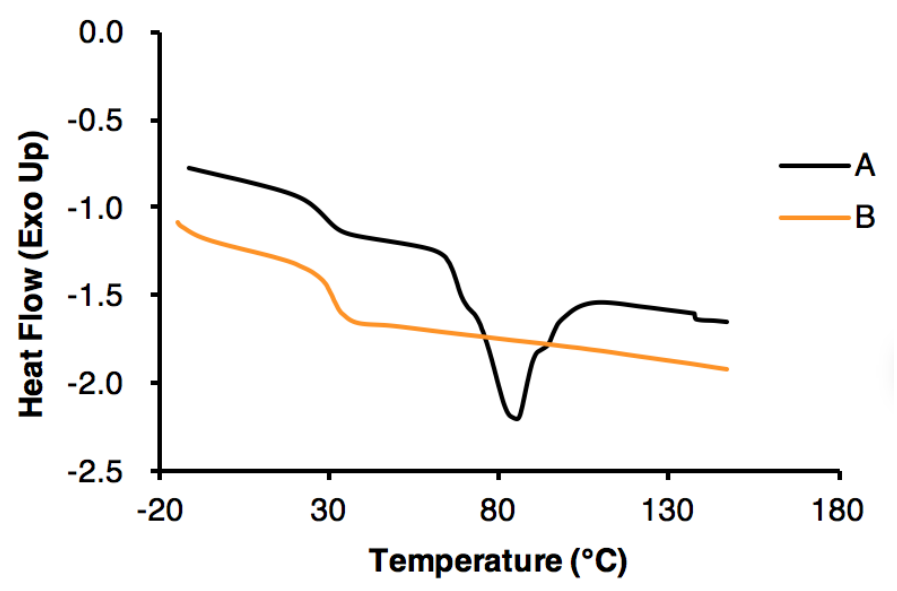

Figure S85. DSC Traces of poly(BnVCP) (A: $M_{\mathrm{n}}=32.6 \mathrm{kDa}, \nexists=1.16, S_{\mathrm{L}}=92 \%$; B: $M_{\mathrm{n}}$ $=28.1 \mathrm{kDa}, Ð=1.18, S_{\mathrm{L}}=30 \%$ )

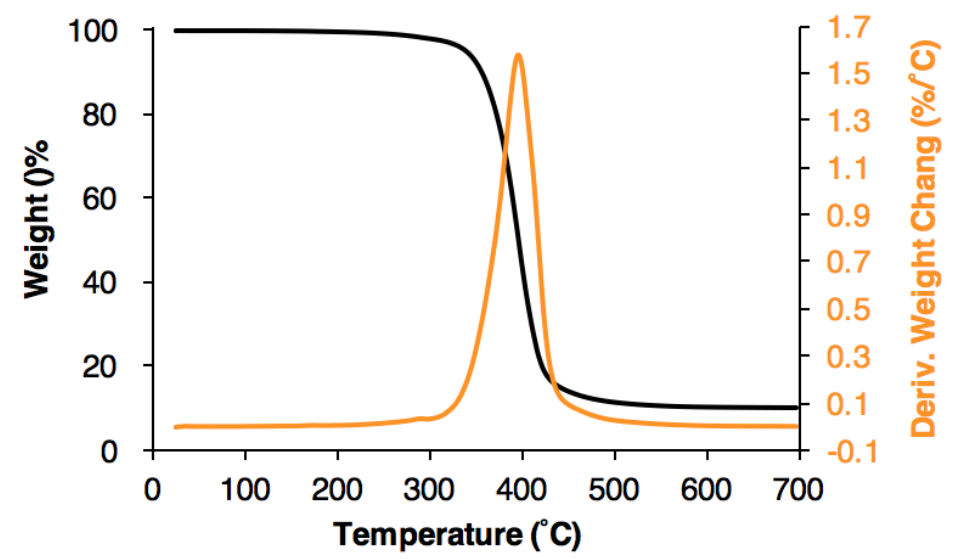

Figure S86. TGA (black) and DTG (orange) curves of $l$-poly $(\mathrm{BnVCP})\left(M_{\mathrm{n}}=32.6 \mathrm{kDa}, \nexists\right.$ $\left.=1.16, S_{\mathrm{L}}=92 \%\right) \cdot T_{\mathrm{d}}=356{ }^{\circ} \mathrm{C}, T_{\max }=396{ }^{\circ} \mathrm{C}$.

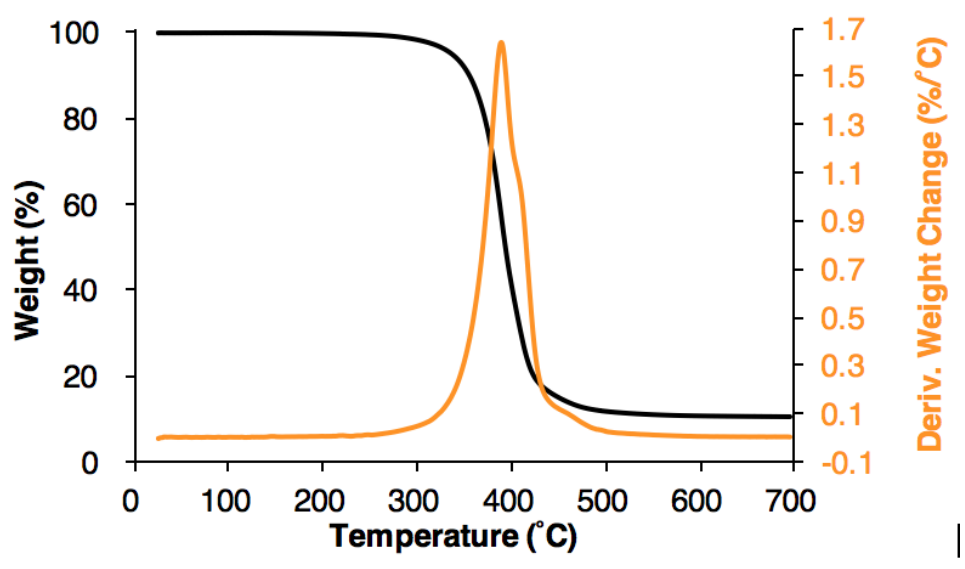

Figure S87. TGA (black) and DTG (orange) curves of $c$-poly $(\mathrm{BnVCP})\left(M_{\mathrm{n}}=28.1 \mathrm{kDa}, \nexists\right.$ $\left.=1.18, S_{\mathrm{L}}=30 \%\right) \cdot T_{\mathrm{d}}=356{ }^{\circ} \mathrm{C}, T_{\max }=389^{\circ} \mathrm{C}$. 


\section{6 ${ }^{1}$ H-NMR Spectra, GPC Traces, and DSC/TGA Curves of Poly(PhVCP)}

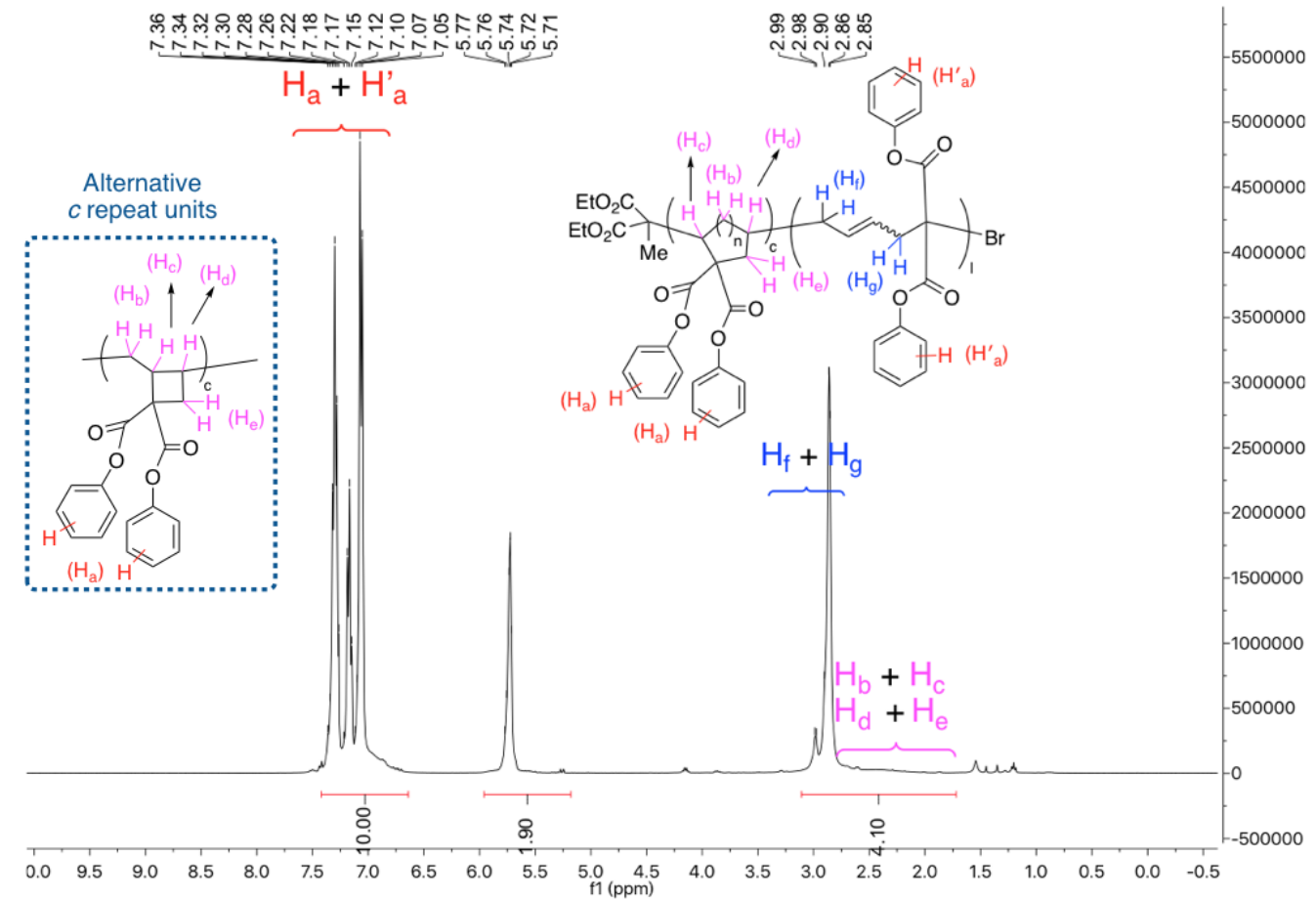

Figure S88. ${ }^{1} \mathrm{H}$ NMR spectrum of $l$-poly $(\mathrm{PhVCP})\left(M_{\mathrm{n}}=30.9 \mathrm{kDa}, Ð=1.24, S_{\mathrm{L}}=95 \%\right)$. ${ }^{1}$ H NMR (400 MHz, $\left.\mathrm{CDCl}_{3}\right) \delta 7.40$ - 6.60 (m, $\left.10 \mathrm{H}\right), 5.95$ - 5.20 (br, $\left.1.90 \mathrm{H}\right), 3.10$ - 1.70 (br, $4.10 \mathrm{H})$.

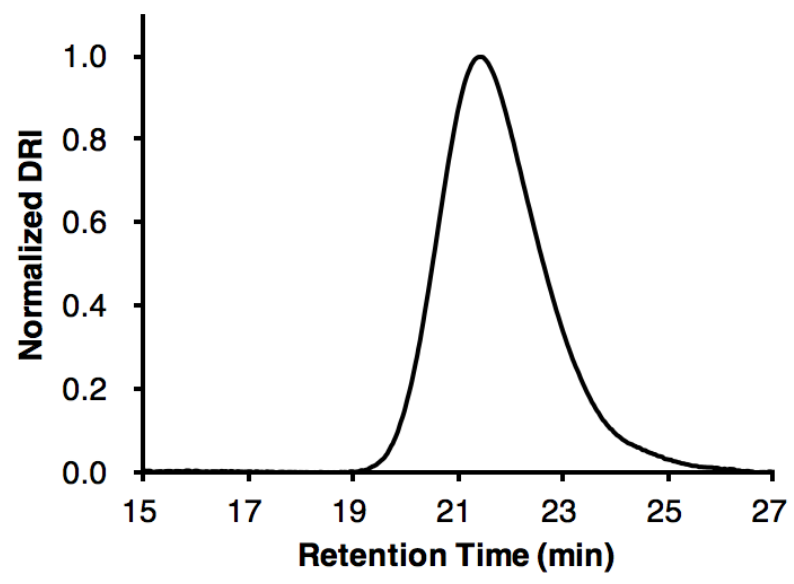

Figure S89. GPC trace of $l$-poly $(\mathrm{PhVCP})\left(M_{\mathrm{n}}=30.9 \mathrm{kDa}, Ð=1.24, S_{\mathrm{L}}=95 \%\right)$ 


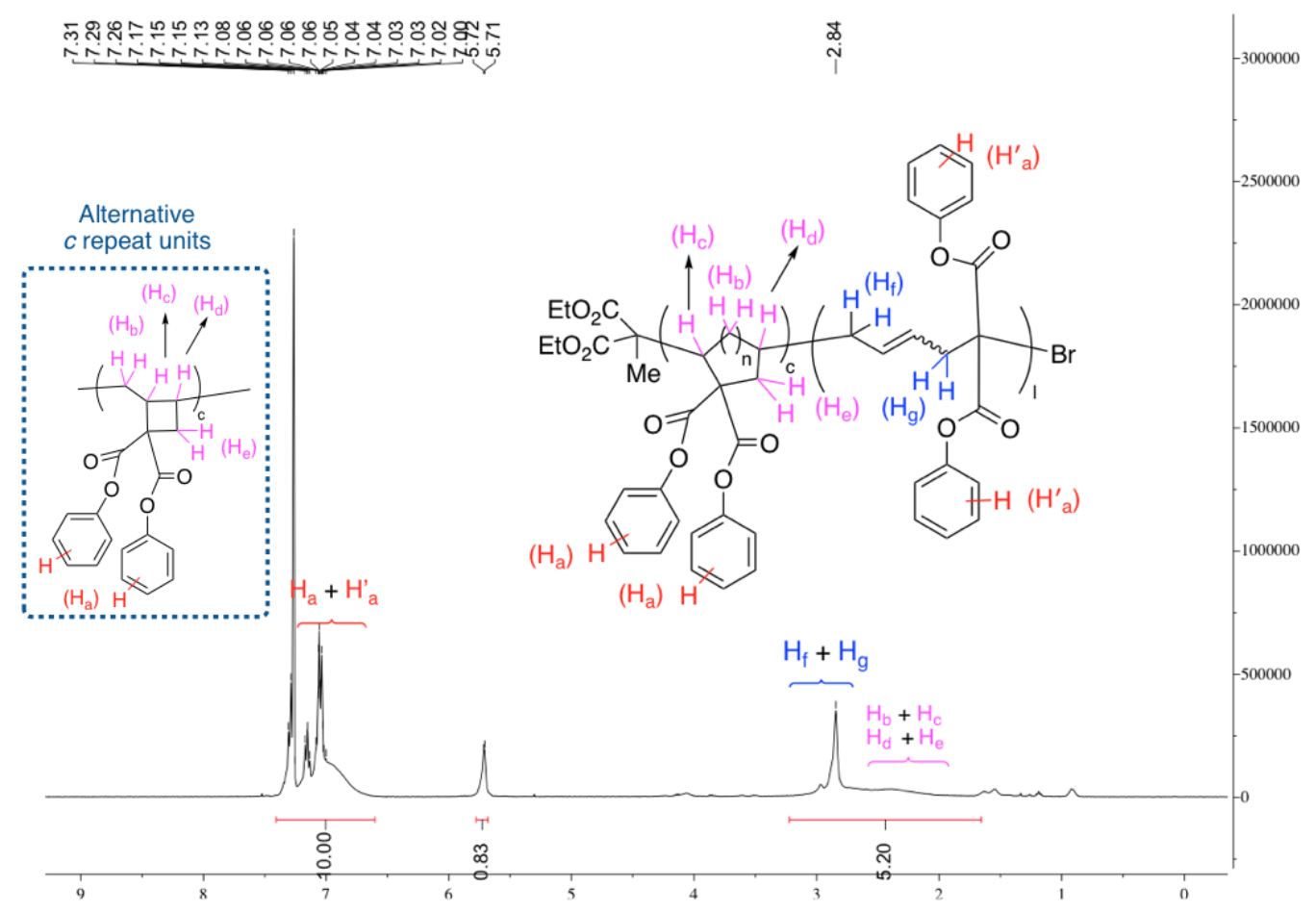

Figure S90. ${ }^{1} \mathrm{H}$ NMR spectrum of $c$-poly $(\mathrm{PhVCP})\left(M_{\mathrm{n}}=46.8 \mathrm{kDa}, Ð=1.06, S_{\mathrm{L}}=40 \%\right)$. ${ }^{1}$ H NMR (400 MHz, $\left.\mathrm{CDCl}_{3}\right) \delta 7.45-6.60$ (m, $10 \mathrm{H}$ ), 5.80 - 5.68 (br, 0.80H), $3.10-1.70$ (br, 5.20H).

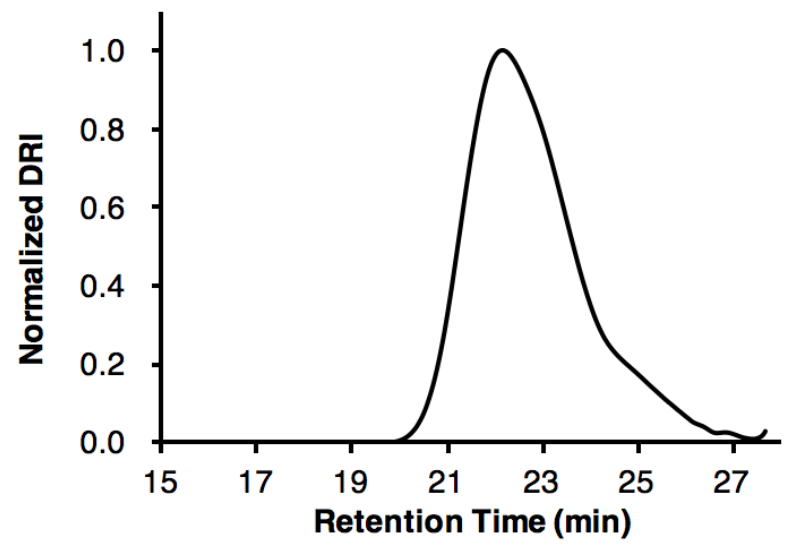

Figure S91. GPC trace of $c$-poly $(\mathrm{PhVCP})\left(M_{\mathrm{n}}=46.8 \mathrm{kDa}, Ð=1.06, S_{\mathrm{L}}=40 \%\right)$ 


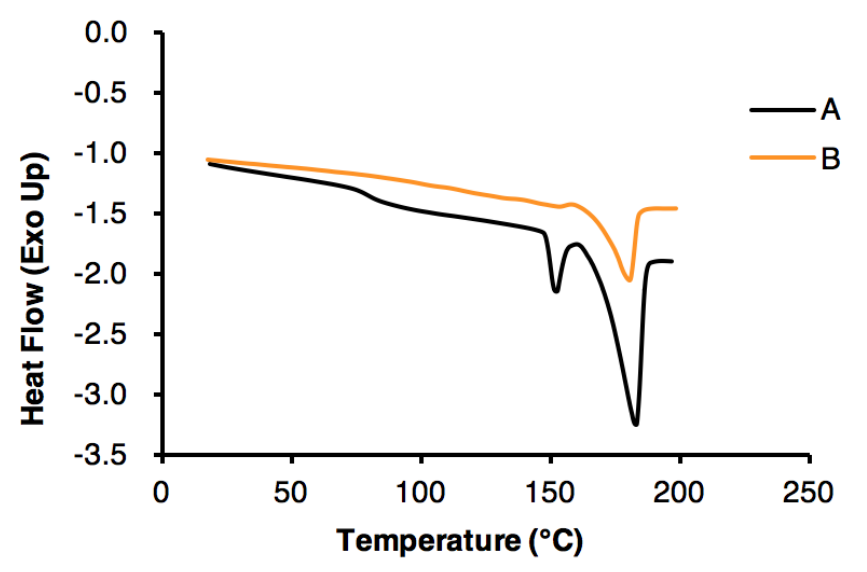

Figure S92. DSC Traces of $c$-poly(PhVCP) (A: $M_{\mathrm{n}}=30.9 \mathrm{kDa}, D=1.24, S_{\mathrm{L}}=95 \%$; B: $M_{\mathrm{n}}$ $\left.=46.8 \mathrm{kDa}, Ð=1.06, S_{\mathrm{L}}=40 \%\right)$

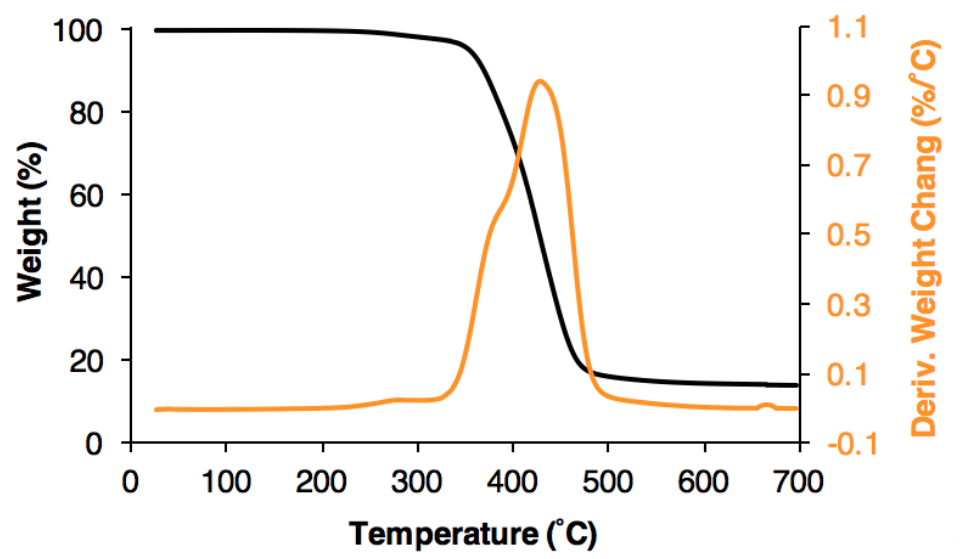

Figure S93. TGA (black) and DTG (orange) curves of $l$-poly $(\mathrm{PhVCP})\left(M_{\mathrm{n}}=30.9 \mathrm{kDa}, \nexists\right.$ $\left.=1.24, S_{\mathrm{L}}=95 \%\right) \cdot T_{\mathrm{d}}=369^{\circ} \mathrm{C}, T_{\max }=438^{\circ} \mathrm{C}$.

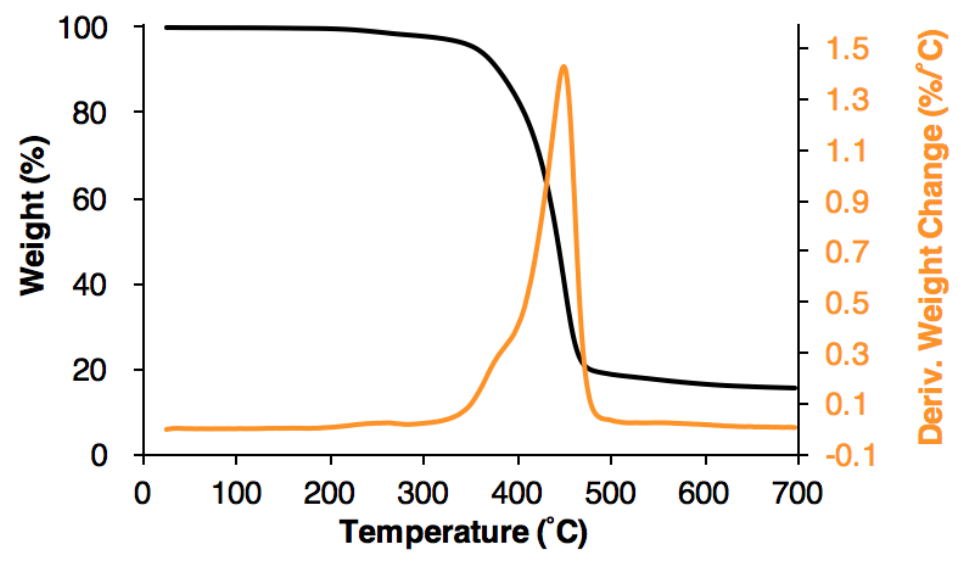

Figure S94. TGA (black) and DTG (orange) curves of poly $(\mathrm{PhVCP})\left(M_{\mathrm{n}}=46.8 \mathrm{kDa}, \nexists=\right.$ $\left.1.06, S_{\mathrm{L}}=40 \%\right) . T_{\mathrm{d}}=380{ }^{\circ} \mathrm{C}, T_{\max }=450^{\circ} \mathrm{C}$. 
7.7 ${ }^{1} \mathrm{H}-\mathrm{NMR}$ Spectra, GPC Traces, and DSC/TGA Curves of Poly(EEVCP)

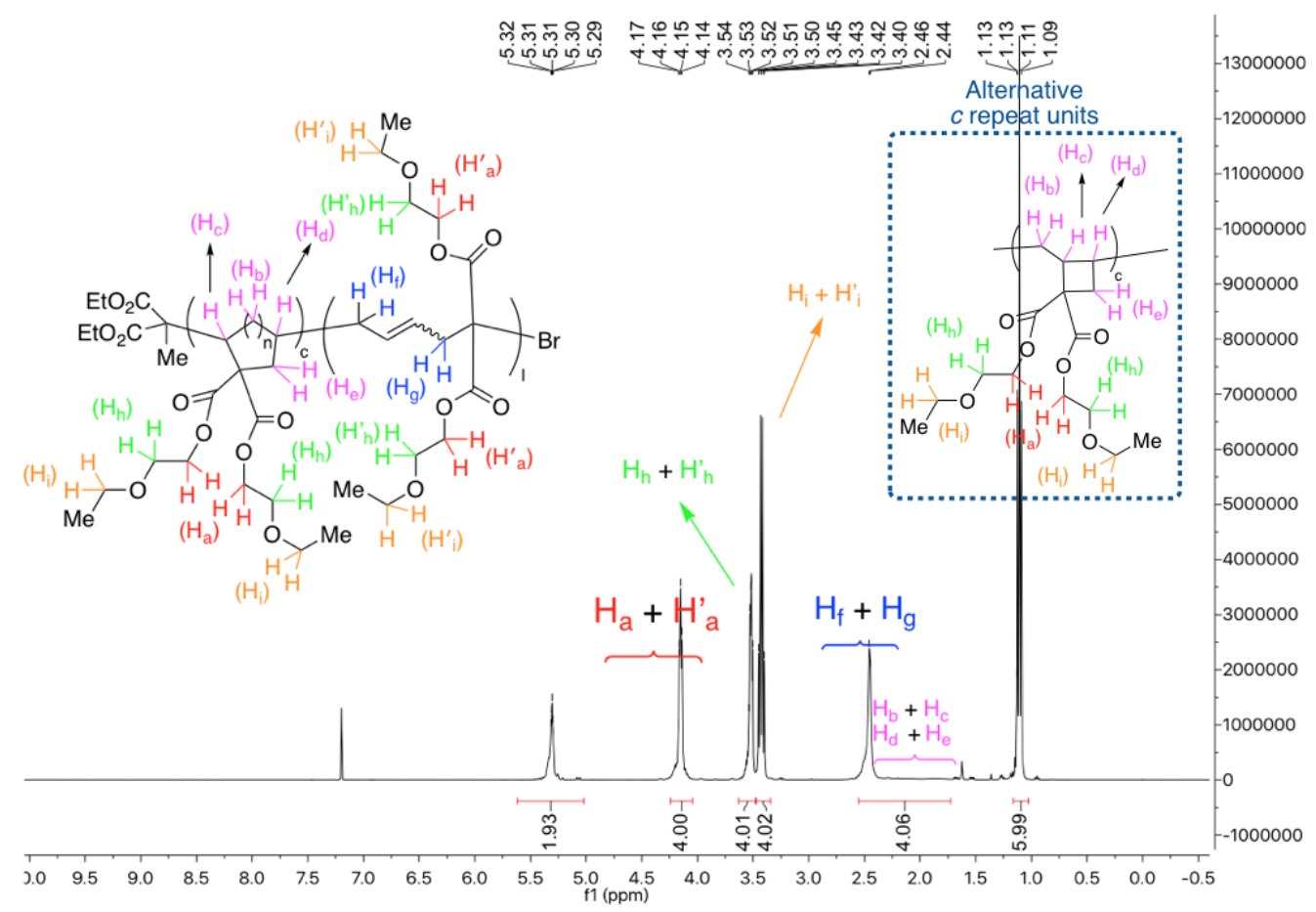

Figure S95. ${ }^{1} \mathrm{H}$ NMR spectrum of $l$-poly(EEVCP) $\left(M_{\mathrm{n}}=29.0 \mathrm{kDa}, D=1.21, S_{\mathrm{L}}=97 \%\right)$. ${ }^{1} \mathbf{H}$ NMR $\left(400 \mathrm{MHz}, \mathrm{CDCl}_{3}\right) \delta 5.55-5.10(\mathrm{br}, 1.93 \mathrm{H}), 4.25-4.05(\mathrm{~m}, 4 \mathrm{H}), 3.63-3.47$ (m, 4H), 3.42 (q, $J=7.0 \mathrm{~Hz}, 4 \mathrm{H}), 2.70-1.70(\mathrm{br}, 4.06 \mathrm{H}), 1.11(\mathrm{t}, J=7.0 \mathrm{~Hz}, 6 \mathrm{H})$.

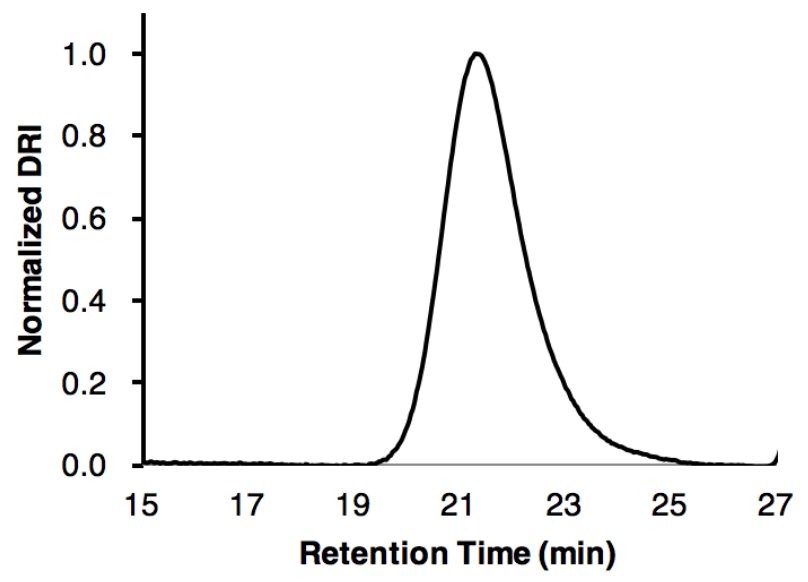

Figure S96. GPC trace of $l$-poly(EEVCP) $\left(M_{\mathrm{n}}=29.0 \mathrm{kDa}, \nexists=1.21, S_{\mathrm{L}}=97 \%\right)$ 


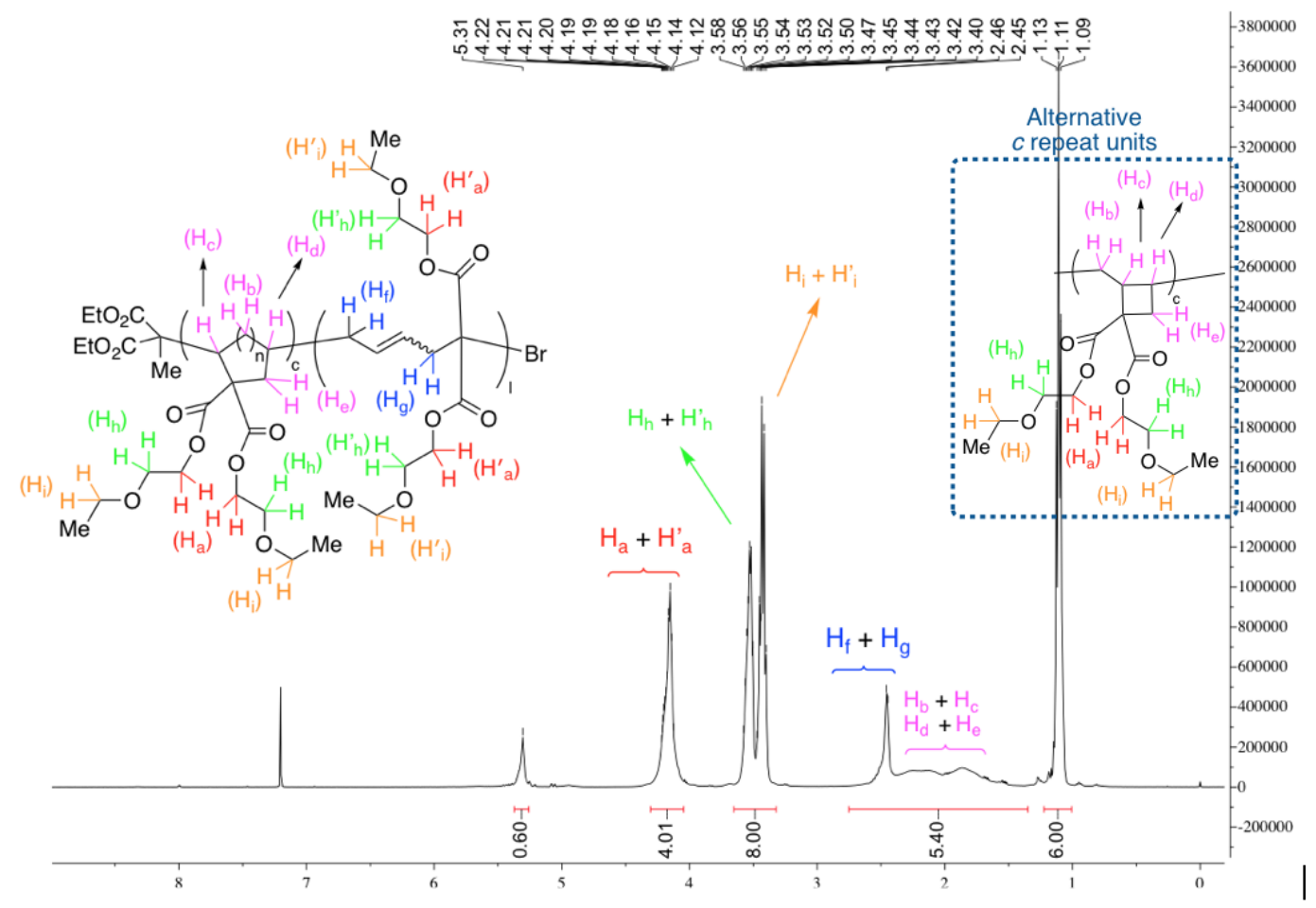

Figure S97. ${ }^{1} \mathrm{H}$ NMR spectrum of $c$-poly $(\mathrm{EEVCP})\left(M_{\mathrm{n}}=35.8 \mathrm{kDa}, Ð=1.03, S_{\mathrm{L}}=30 \%\right)$. ${ }^{1} \mathbf{H}$ NMR (400 MHz, $\left.\mathrm{CDCl}_{3}\right) \delta 5.38-5.25(\mathrm{br}, 0.60 \mathrm{H}), 4.30-4.05(\mathrm{~m}, 4 \mathrm{H}), 3.65-3.36$ (m, 8H), $2.70-1.55$ (br, $5.40 \mathrm{H}), 1.10$ (t, $J=7.0 \mathrm{~Hz}, 6 \mathrm{H})$.

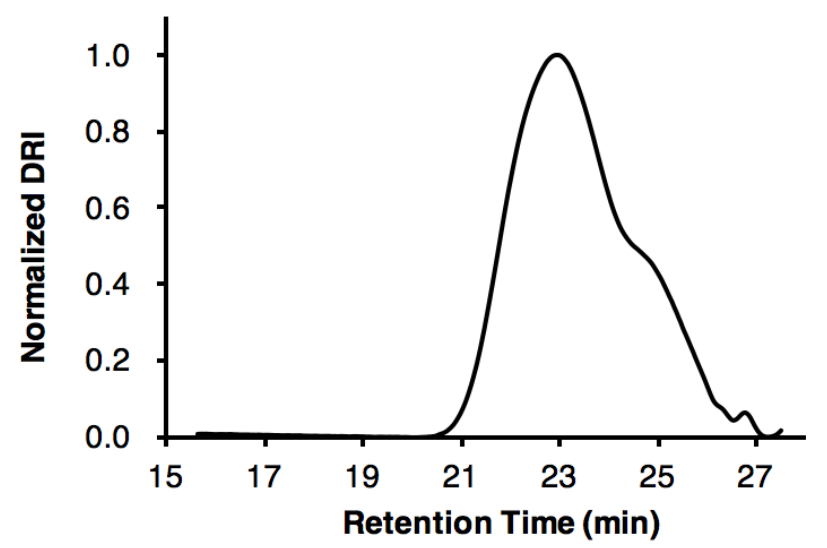

Figure S98. GPC trace of $c$-poly $(\mathrm{EEVCP})\left(M_{\mathrm{n}}=35.8 \mathrm{kDa}, Ð=1.03, S_{\mathrm{L}}=30 \%\right)$ 


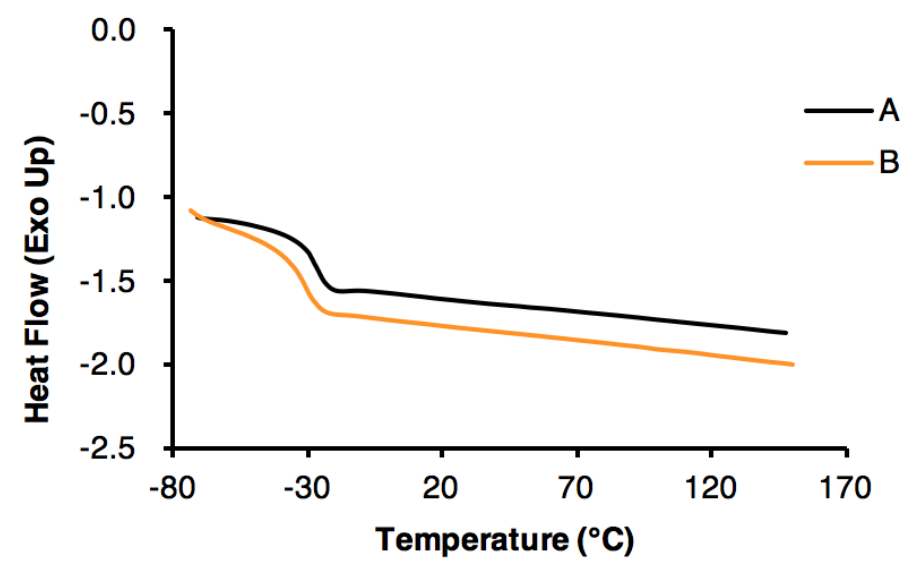

Figure S99. DSC Traces of poly(EEVCP) (A: $M_{\mathrm{n}}=29.0 \mathrm{kDa}, D=1.21, S_{\mathrm{L}}=97 \% ; \mathrm{B}: M_{\mathrm{n}}$ $\left.=35.8 \mathrm{kDa}, \oslash=1.03, S_{\mathrm{L}}=23 \%\right)$

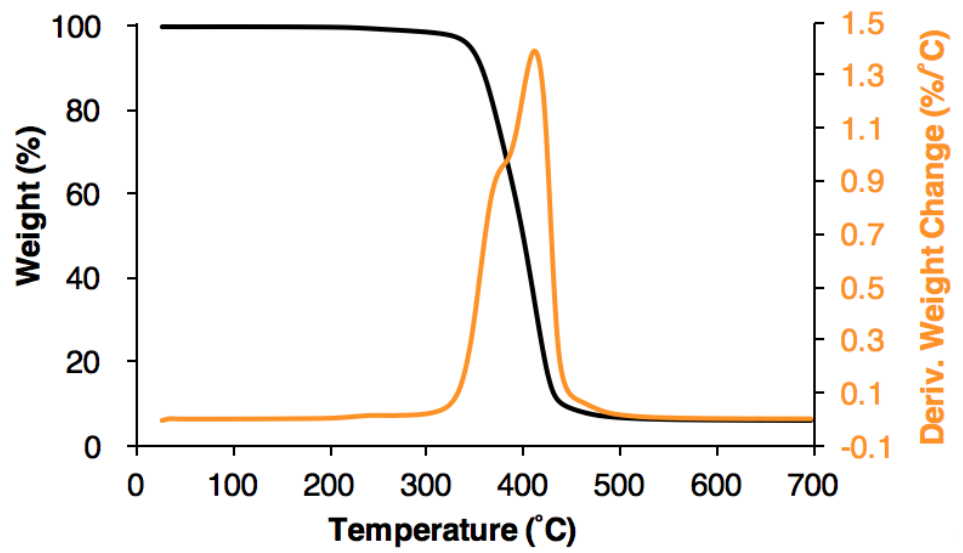

Figure S100. TGA (black) and DTG (orange) curves of $l$-poly $(\mathrm{EEVCP})\left(M_{\mathrm{n}}=29.0 \mathrm{kDa}\right.$, $\left.Ð=1.21, S_{\mathrm{L}}=97 \%\right) \cdot T_{\mathrm{d}}=356^{\circ} \mathrm{C}, T_{\max }=412^{\circ} \mathrm{C}$.

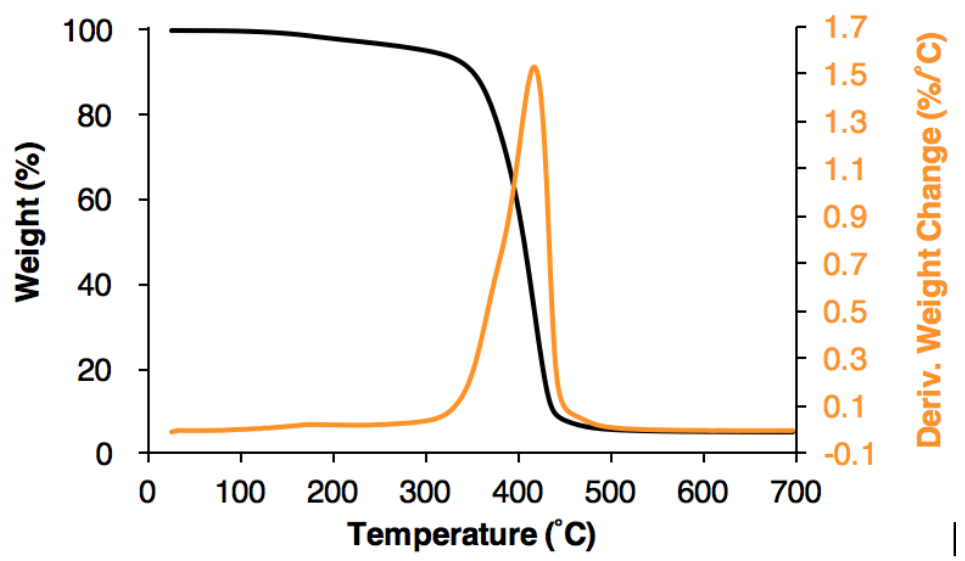

Figure S101. TGA (black) and DTG (orange) curves of poly(EEVCP) $\left(M_{\mathrm{n}}=35.8 \mathrm{kDa}, \oslash\right.$ $\left.=1.03, S_{\mathrm{L}}=23 \%\right) \cdot T_{\mathrm{d}}=351{ }^{\circ} \mathrm{C}, T_{\max }=416^{\circ} \mathrm{C}$. 


\section{8 ${ }^{1}$ H-NMR Spectra, GPC Traces, and DSC/TGA Curves of Poly(CEVCP)}

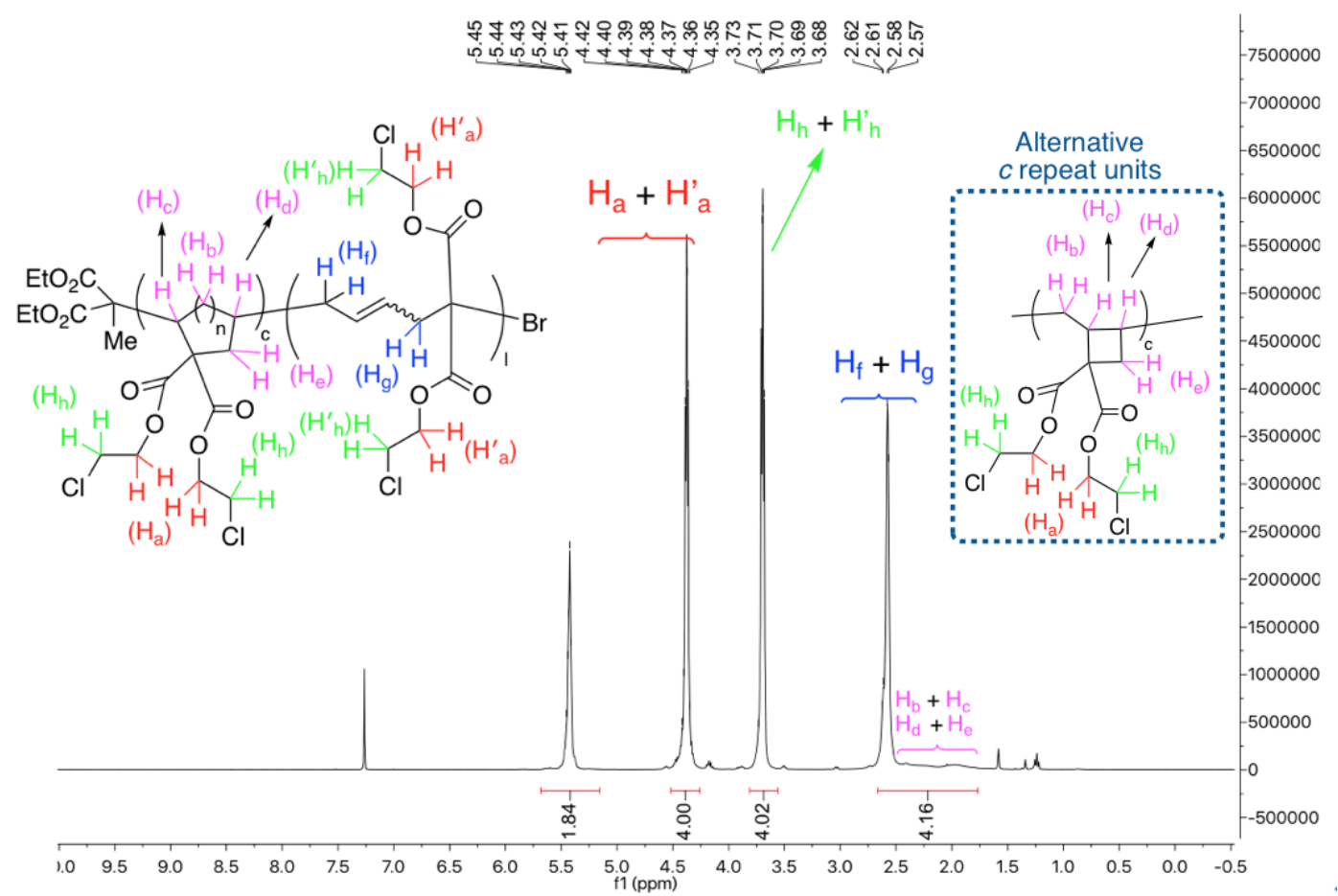

Figure S102. ${ }^{1} \mathrm{H}$ NMR spectrum of $l$-poly $(\mathrm{CEVCP})\left(M_{\mathrm{n}}=26.9 \mathrm{kDa}, \nexists=1.23, S_{\mathrm{L}}=92 \%\right)$. ${ }^{1} \mathbf{H}$ NMR $\left(400 \mathrm{MHz}, \mathrm{CDCl}_{3}\right) \delta 5.66$ - 5.13 (br, $\left.1.84 \mathrm{H}\right), 4.53$ - 4.25 (m, 4H), 3.82 - 3.55 (m, 4H), $2.70-1.70(\mathrm{br}, 4.16 \mathrm{H})$.

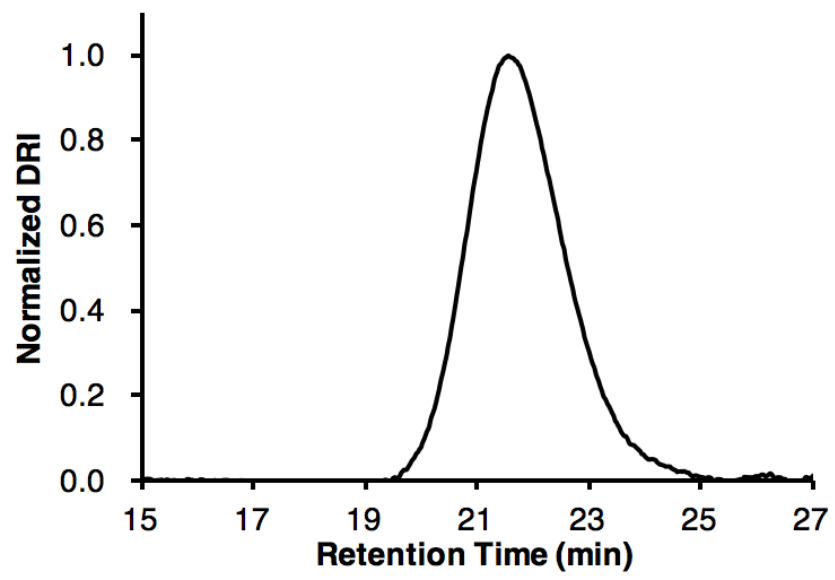

Figure S103. GPC trace of $l$-poly $(\mathrm{CEVCP})\left(M_{\mathrm{n}}=26.9 \mathrm{kDa}, \nexists=1.23, S_{\mathrm{L}}=92 \%\right)$ 


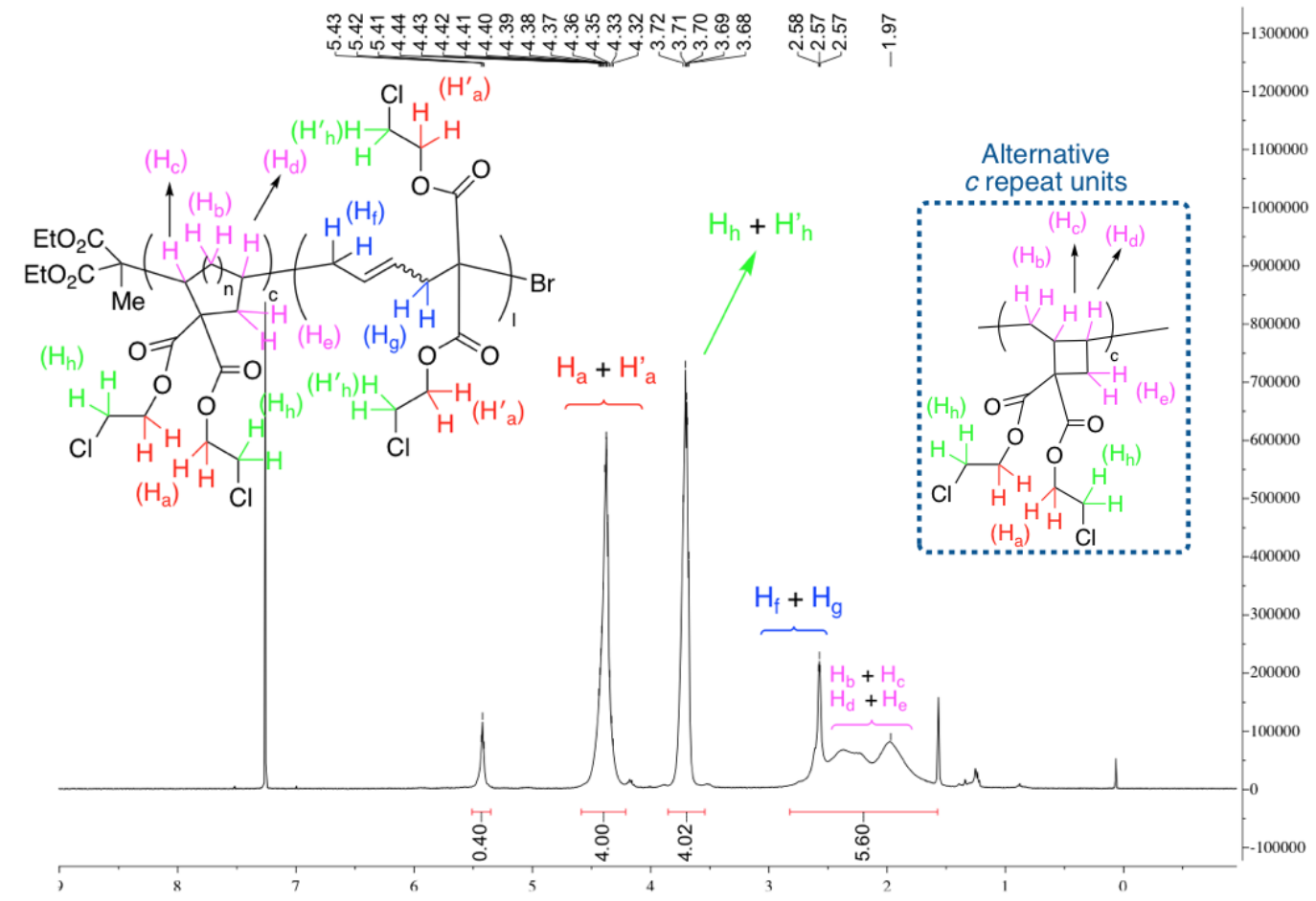

Figure S104. ${ }^{1} \mathrm{H}$ NMR spectrum of $c$-poly $(\mathrm{CEVCP})\left(M_{\mathrm{n}}=29.3 \mathrm{kDa}, Ð=1.13, S_{\mathrm{L}}=20 \%\right)$. ${ }^{1} \mathbf{H}$ NMR (400 MHz, CDCl$) \delta 5.48-5.30(\mathrm{br}, 0.40 \mathrm{H}), 4.55-4.20(\mathrm{~m}, 4 \mathrm{H}), 3.85-3.55$ (m, 4H), $2.70-1.60(\mathrm{br}, 5.60 \mathrm{H})$.

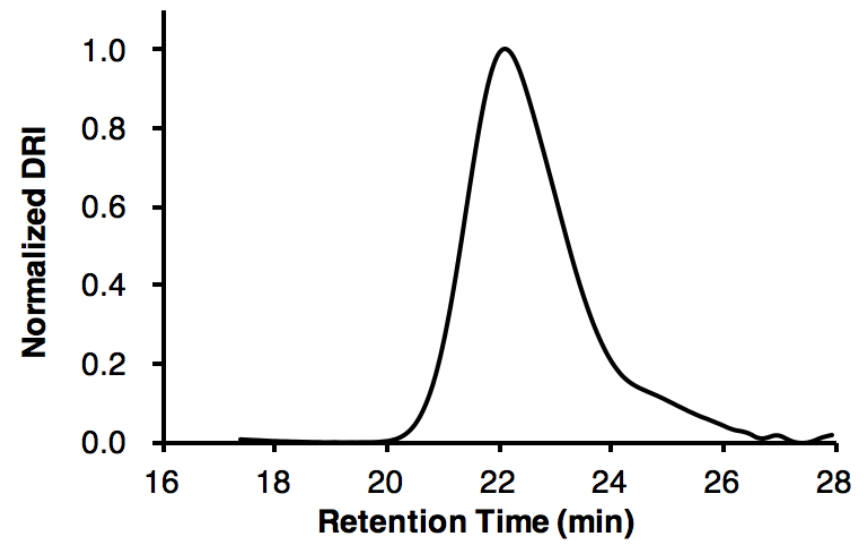

Figure S105. GPC trace of $c$-poly $(\mathrm{CEVCP})\left(M_{\mathrm{n}}=29.3 \mathrm{kDa}, Ð=1.13, S_{\mathrm{L}}=20 \%\right)$ 


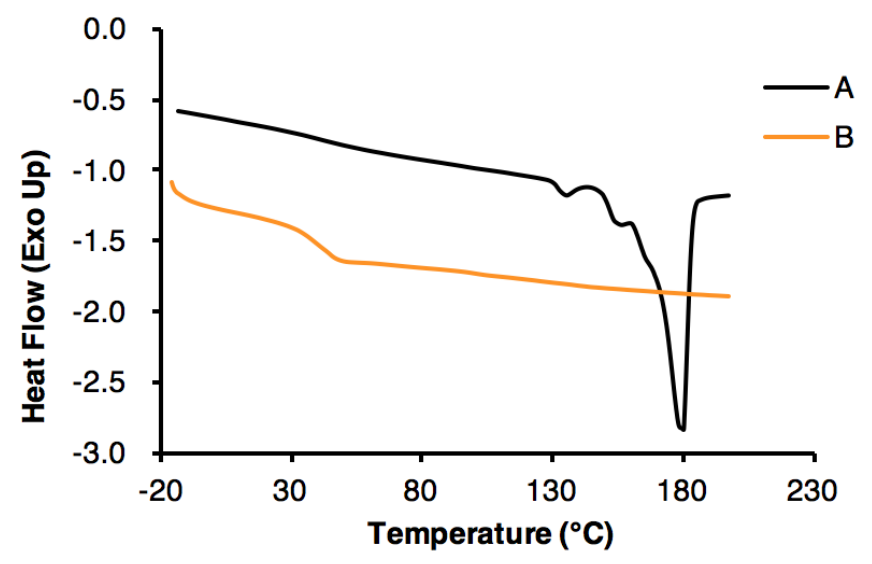

Figure S106. DSC Traces of poly $(\mathrm{CEVCP})\left(\mathrm{A}: M_{\mathrm{n}}=26.9 \mathrm{kDa}, \nexists=1.23, S_{\mathrm{L}}=92 \% ; \mathrm{B}: M_{\mathrm{n}}\right.$ $=29.3 \mathrm{kDa}, \oslash=1.13, S_{\mathrm{L}}=20 \%$ )

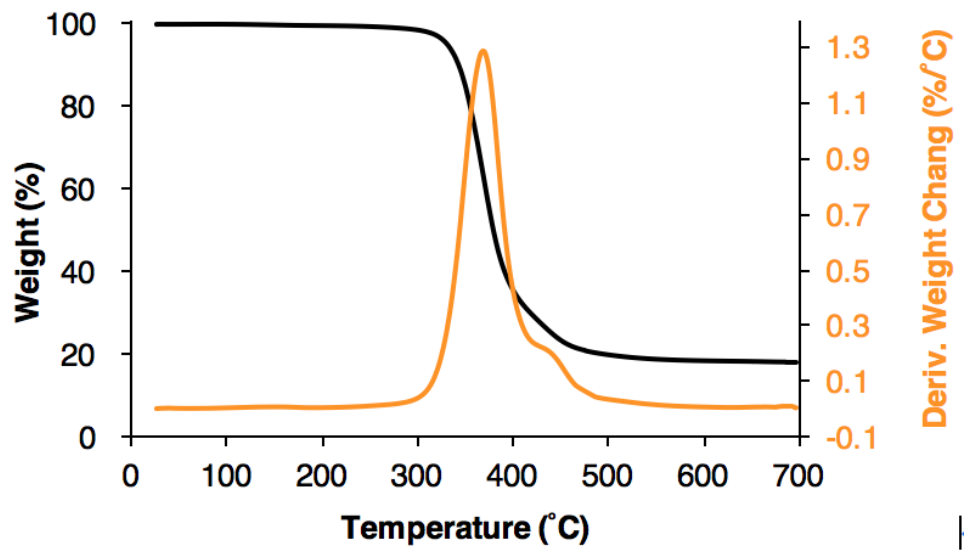

Figure S107. TGA (black) and DTG (orange) curves of $l$-poly $(\mathrm{CEVCP})\left(M_{\mathrm{n}}=26.9 \mathrm{kDa}\right.$, $\left.Ð=1.23, S_{\mathrm{L}}=92 \%\right) \cdot T_{\mathrm{d}}=342^{\circ} \mathrm{C}, T_{\max }=367^{\circ} \mathrm{C}$.

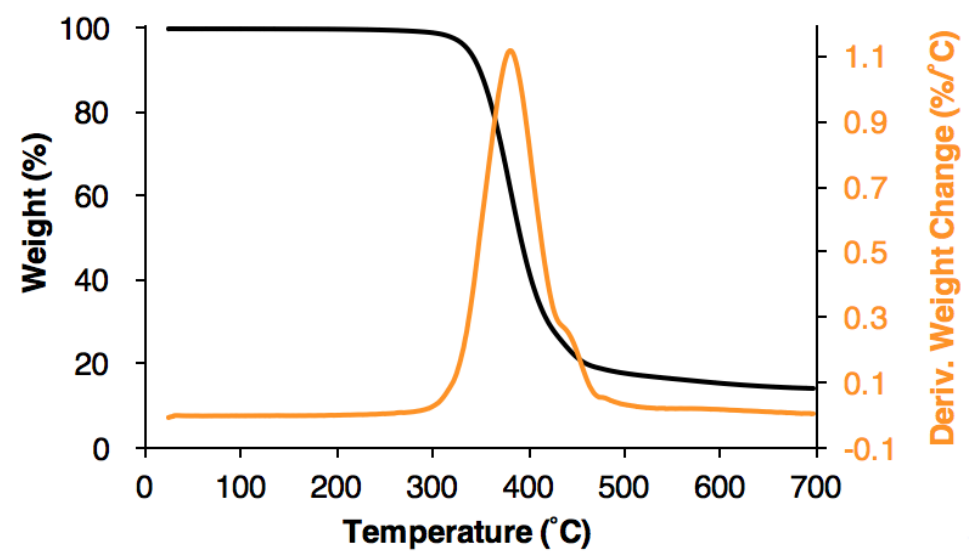

Figure S108. TGA (black) and DTG (orange) curves of $c$-poly $(\mathrm{CEVCP})\left(M_{\mathrm{n}}=29.3 \mathrm{kDa}\right.$, $\left.Ð=1.13, S_{\mathrm{L}}=20 \%\right) \cdot T_{\mathrm{d}}=349^{\circ} \mathrm{C}, T_{\max }=380^{\circ} \mathrm{C}$. 


\section{9 ${ }^{1} \mathrm{H}-\mathrm{NMR}$ spectra, GPC Traces, and DSC/TGA Curves of Poly(LMVCP)}

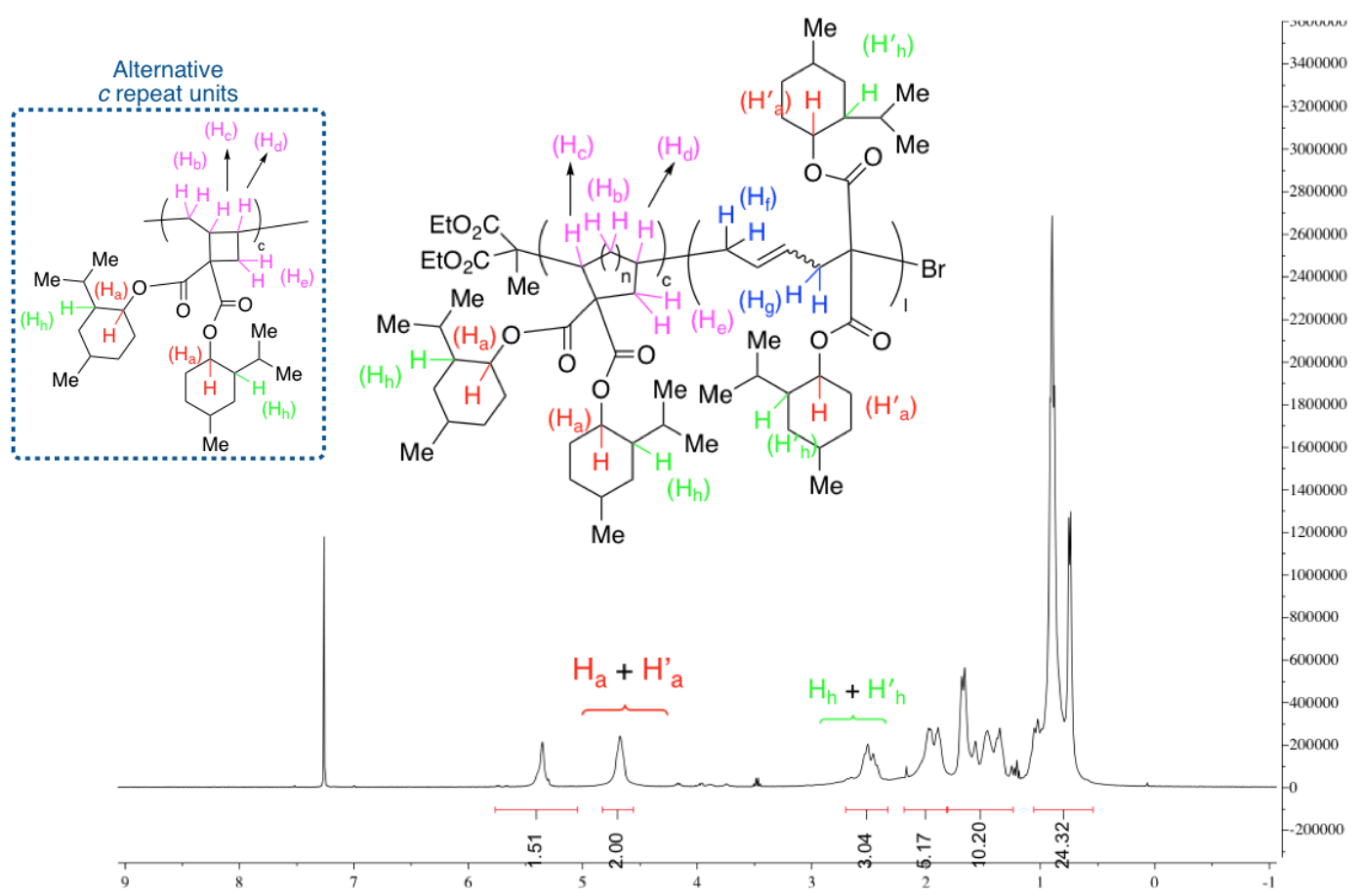

Figure S109. ${ }^{1} \mathrm{H}$ NMR spectrum of $l$-poly $(\mathrm{LMVCP})\left(M_{\mathrm{n}}=42.3 \mathrm{kDa}, \nexists=1.21, S_{\mathrm{L}}=75 \%\right)$.

${ }^{1} \mathbf{H}$ NMR $\left(400 \mathrm{MHz}, \mathrm{CDCl}_{3}\right) \delta 5.50-5.30(\mathrm{br}, 0.01 \mathrm{H}), 5.20-4.00(\mathrm{br}, 2 \mathrm{H}), 3.00-1.75$ (m, 8H), $1.75-1.25$ (br, 8H), $1.25-0.02$ (br, 26H).

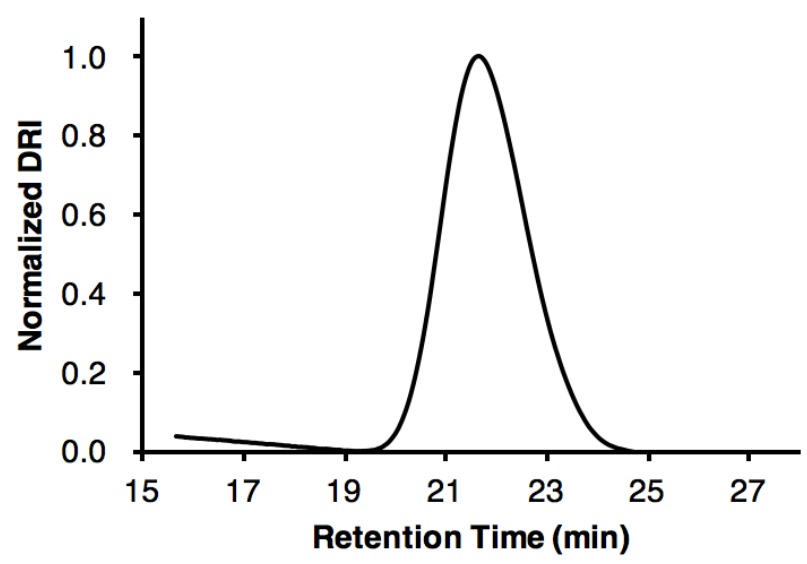

Figure S110. GPC trace of $l$-poly $(\mathrm{LMVCP})\left(M_{\mathrm{n}}=42.3 \mathrm{kDa}, \nexists=1.21, S_{\mathrm{L}}=75 \%\right)$ 


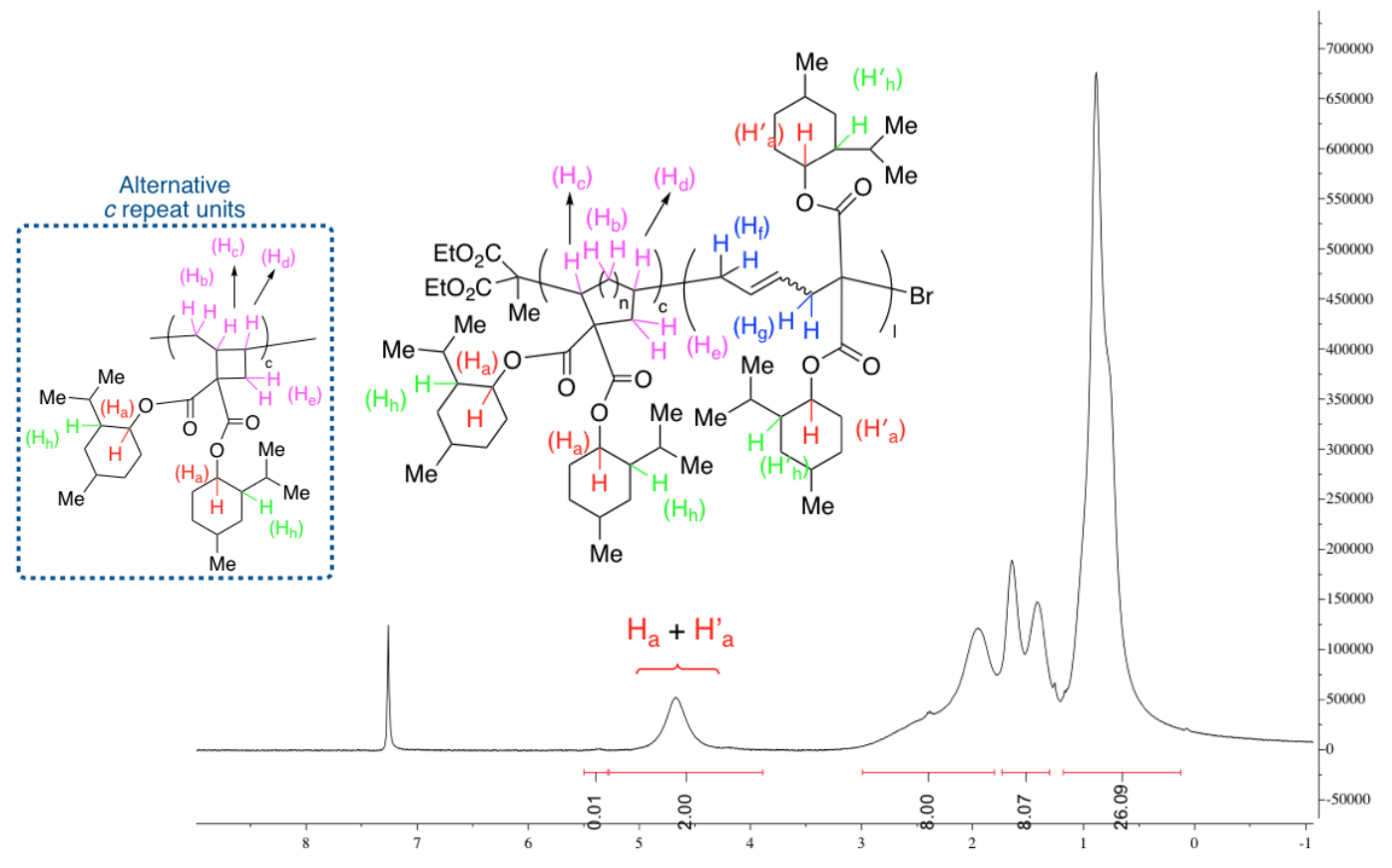

Figure S111. ${ }^{1} \mathrm{H}$ NMR spectrum of $c$-poly(LMVCP) $\left(M_{\mathrm{n}}=52.5 \mathrm{kDa}, Ð=1.20, S_{\mathrm{L}}=1 \%\right)$. ${ }^{1}$ H NMR (400 MHz, $\left.\mathrm{CDCl}_{3}\right) \delta 5.50$ - 5.30 (br, $\left.0.01 \mathrm{H}\right), 5.20-4.00$ (br, 2H), $3.00-1.75$ (m, 8H), $1.75-1.25$ (br, 8H), $1.25-0.02$ (br, 26H).

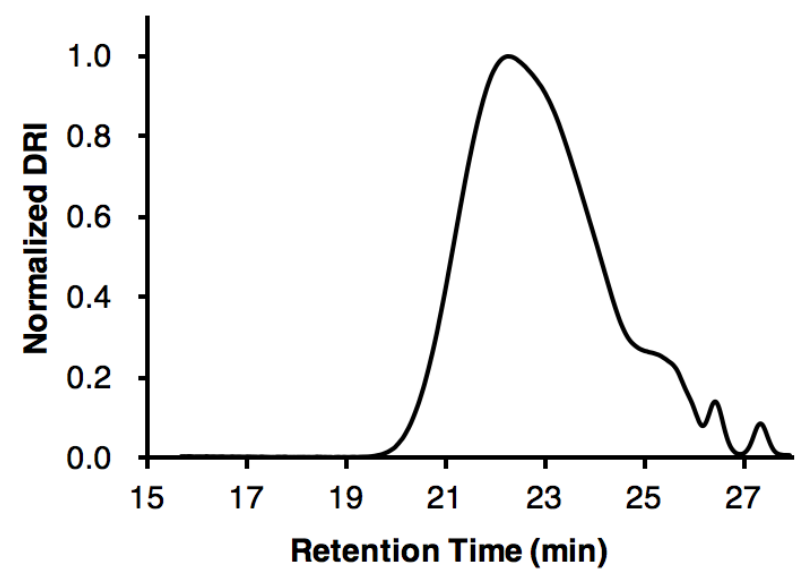

Figure S112. GPC trace of $c$-poly $(\mathrm{LMVCP})\left(M_{\mathrm{n}}=52.5 \mathrm{kDa}, \emptyset=1.20, S_{\mathrm{L}}=1 \%\right)$ 


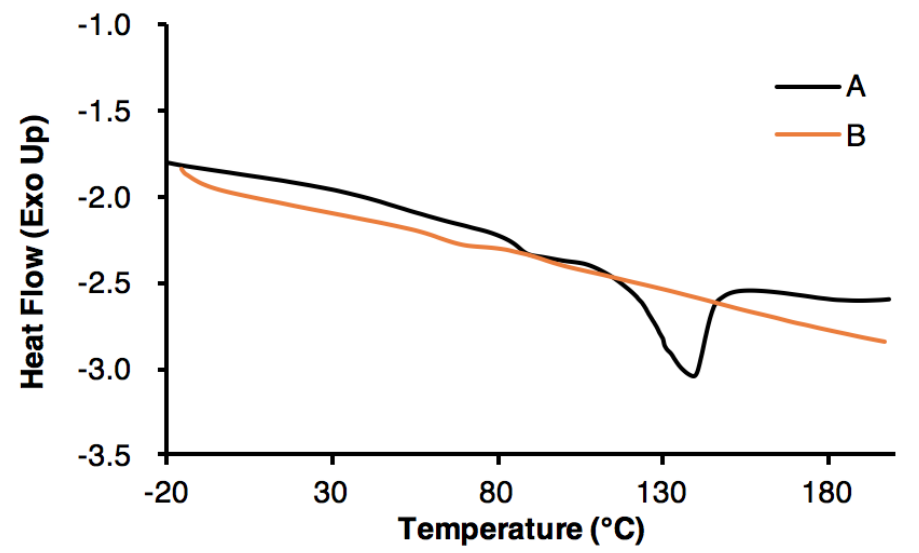

Figure S113. DSC Traces of poly(LMVCP) (A: $M_{\mathrm{n}}=42.3 \mathrm{kDa}, \emptyset=1.21, S_{\mathrm{L}}=75 \%$; B: $\left.M_{\mathrm{n}}=52.5 \mathrm{kDa}, Ð=1.20, S_{\mathrm{L}}=1 \%\right)$

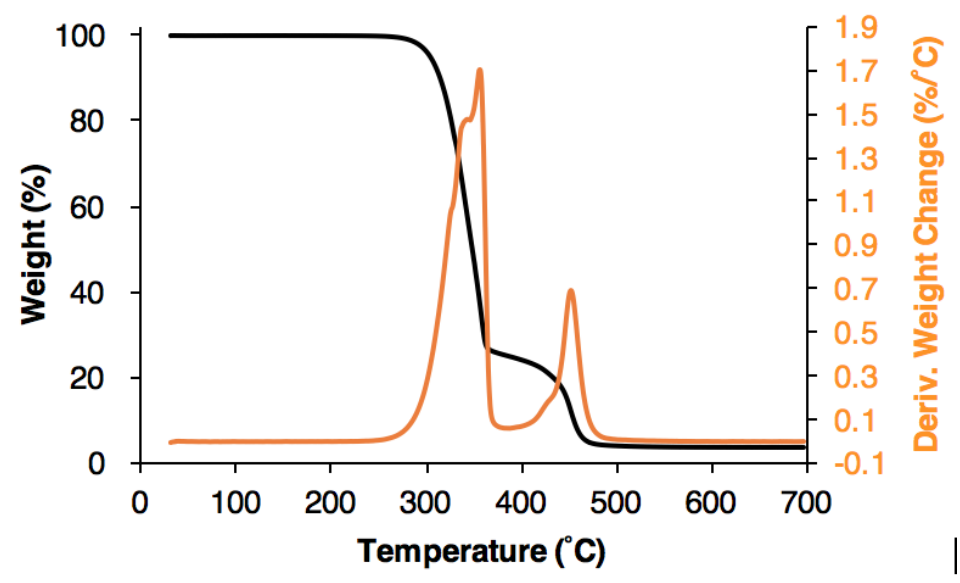

Figure S114. TGA (black) and DTG (orange) curves of poly(LMVCP) $\left(M_{\mathrm{n}}=42.3 \mathrm{kDa}, Ð\right.$ $\left.=1.21, S_{\mathrm{L}}=97 \%\right) . T_{\mathrm{d}}=313{ }^{\circ} \mathrm{C}, T_{\max 1}=361{ }^{\circ} \mathrm{C}, T_{\max 2}=452{ }^{\circ} \mathrm{C}$.

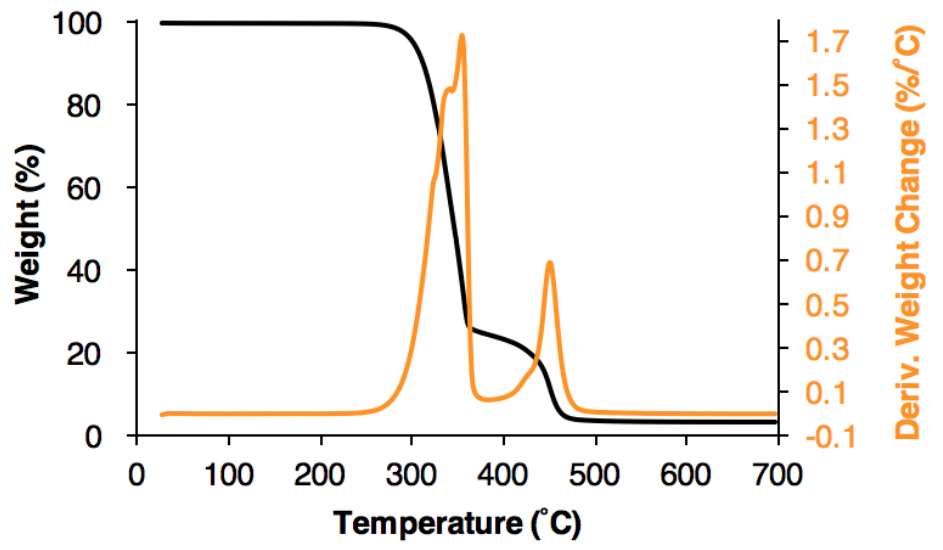

Figure S115. TGA (black) and DTG (orange) curves of poly(LMVCP) $\left(M_{\mathrm{n}}=52.5 \mathrm{kDa}\right.$, $\left.Ð=1.20, S_{\mathrm{L}}=97 \%\right) . T_{\mathrm{d}}=312{ }^{\circ} \mathrm{C}, T_{\max 1}=356{ }^{\circ} \mathrm{C}, T_{\max 2}=451{ }^{\circ} \mathrm{C}$. 


\section{References}

1 Theriot, J. C.; Lim, C.-H.; Yang, H.; Ryan, M. D.; Musgrave, C. B.; Miyake, G. M. Organocatalyzed atom transfer radical polymerization driven by visible light. Science 2016, 352, 1082-1086.

2 Pearson, R. M.; Lim, C.-H.; McCarthy, B. G.; Musgrave, C. B.; Miyake, G. M. Organocatalyzed atom transfer radical polymerization using $\mathrm{N}$-aryl phenoxazines as photoredox catalysts. J. Am. Chem. Soc. 2016, 138, 11399-11407.

3 (a) Hashimoto, T.; Kawamata, Y.; Maruoka, K. An organic thiyl radical catalyst for enantioselective cyclization. Nat. Chem. 2014, 6, 702-705. (b) Leki, R.; Kani, Y.; Tsunoi, S.; Shibata, I. Transition - metal-free coupling reaction of vinylcyclopropanes with aldehydes catalyzed by tin hydride. Chem. Eur. J. 2015, 21, 6295-6300.

4 Pilevar, A.; Hosseini, A.; Šekutor, M.; Hausmann, H.; Becker, J.; Turke, K.; Schreiner, P. R. Tuning the reactivity of peroxo anhydrides for aromatic $\mathrm{C}-\mathrm{H}$ bond oxidation. $J$. Org. Chem. 2018, 83, 10070-10079.

5 Bernhardt, G.; Brunner, H.; Gruber, N.; Lottner, C.; Pushpan, S.; Tsuno, T.; Zabel, M. Carboplatin derivatives with superior antitumor activity compared to the parent compound. Inorg. Chim. Acta. 2004, 357, 4452-4466.

6 Candito, D. A.; Lautens, M. Stereoselective nickel-catalyzed [2+2+2] cycloaddition of enynes and arynes. Synlett 2011, 14, 1987-1992. 